\title{
Sustainable Tourism in New Zealand: The Chinese Visitors' View
}

\author{
by
}

\section{Diana Chan}

\begin{abstract}
A thesis
submitted to the Victoria University of Wellington in fulfilment of the requirements for the degree of Master of Tourism Management
\end{abstract}

Victoria University of Wellington 


\begin{abstract}
This thesis addresses sustainable tourism in New Zealand, in the context of the Chinese inbound visitor market to New Zealand. The purpose of this research is to achieve a better understanding of environmental sustainability in New Zealand's tourism industry, how this impacts on New Zealand's marketing image, and the way the New Zealand tourism industry caters to the Chinese inbound visitor market. To achieve the research aims this study focuses on the following themes: visitor characteristics, trip characteristics, satisfaction, factors that impact on the visitors' decision to visit a destination, sustainable tourism in New Zealand, and New Zealand's marketing image.
\end{abstract}

Using a triangulation research approach the visitors' perspective was obtained through the use of a visitor survey, whereas the suppliers' perspective was gathered via face-to-face interviews. The analytical framework adopted for this study further assisted in the comparison of the two travel structures: tour group and independent travellers, but also the evaluation of the visitors' and suppliers' perspectives. However, one of the key challenges with regards to the size of the visitor sample population during the time of this study was the impact of global issues such as the Sichuan Earthquake, Beijing Olympics, and the global financial crisis; which in essence affected the overall Chinese inbound visitor arrivals to New Zealand.

From the combination of both the quantitative and qualitative data this study indicated that the Chinese visitor market is not as homogeneous as first established by other studies. This research also identified that a number of factors do impact on their decisions to visit a destination, such as safety and security, as well as the destination having a high level of environmental protection. A large proportion of Chinese visitors also perceived New Zealand to be more than just a reasonably sustainable tourism destination. This indicates that New Zealand's 'clean, green' reputation does potentially act as a key pull factor in the Chinese visitors' holidaymaking decisions. However, tour operators believe New Zealand has potential to become a sustainable tourism destination; however, more work is needed to retain the tourism industry's environmental 'sustainability'.

Overall, it was established from the findings that there is a need for alternative tourism products as a means to retain the interest of Chinese visitors to New Zealand. 
It is indicated that current Chinese visitor package tours need to shift focus from being commission-based shopping endeavours to tours that entail aspects that feature the essence of New Zealand and the country's environmental sustainable position. In addition, it is also demonstrated that New Zealand's '100\% PURE' tourism campaign is very standardized, and therefore makes it difficult to attract all of New Zealand's key visitor markets. Hence, to effectively attract the Chinese visitor market, New Zealand should adopt a specific promotional venture that takes advantage of the Chinese visitors concern for status, and their developing use of various information sources, such as the Internet, to push a marketing tagline that appeals explicitly to the Chinese visitor market. 


\section{ACKNOWLEDGEMENTS}

I would like to take this opportunity to extend my heartfelt gratitude and appreciation to those who have assisted me throughout the course of this research. I would especially like to thank my supervisor, Dr. Christian Schott, who has inspired and challenged me throughout this research process. I understand that I haven't always been the easiest person to work with; however, your advice has always directed me to address the central issues of my study.

I am also very thankful for the scholarship provided by the Ministry of Tourism which has given me this great opportunity to undertake my research, and who has also assisted me in attaining various pieces of data and information. I could not have completed this study without the interest and contributions of those who have participated in assisting me to gather information or provided information for this study. Specifically the Chinese visitors, the ADS inbound tour operators, and COVEC. However, I am also extremely grateful to the Auckland International Airport for giving me access to undertake my research on their premises.

I have of course not forgotten my family and friends.

For my fellow Masters students, Ray, Vi, Rudy \& Muganda - It has been awesome getting to know you guys. We've always been there for each other, and I hope we can keep in contact. I wish you all the best for the future!

For my friends and family, you guys really kept me on track, and really made me feel good about this research (even though half of you didn't even know what I was studying). This thesis couldn't have been done without your willingness to help a desperate student, but also as my personal therapists, and in some situations my punching bags!

Mum, dad, Sarah, and my lovely dog Minnie; without your love, support and constant nagging I wouldn't be who I am today, but more specifically where I am today. You guys are my backbone, and I could never thank you enough! 


\section{TABLE OF CONTENTS}

$\begin{array}{ll}\text { Abstract } & \text { ii } \\ \text { Acknowledgements } & \text { iv } \\ \text { Table of Contents } & \mathbf{v} \\ \text { List of Tables } & \text { vii } \\ \text { List of Figures } & \mathbf{x}\end{array}$

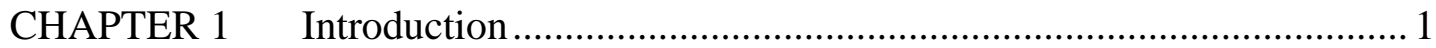

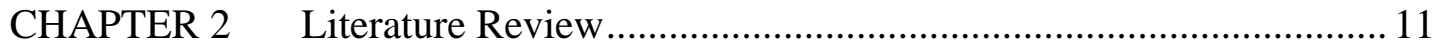

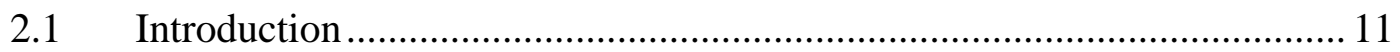

$2.2 \quad$ New Zealand Context............................................................................ 12

2.3 Chinese Outbound Visitor Market ............................................................. 18

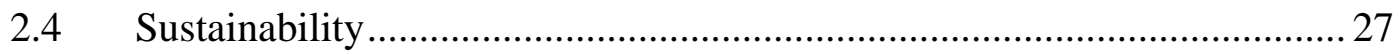

2.4.1 Evolution of Environmental Sustainability \& Tourism ..................... 27

2.4.2 Perceptions of Sustainability.......................................................... 36

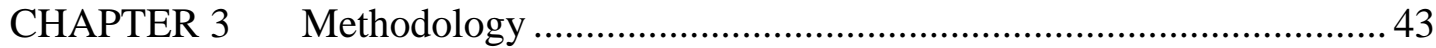

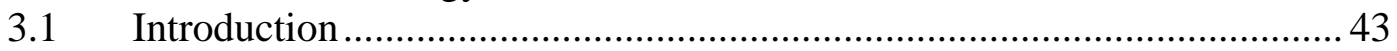

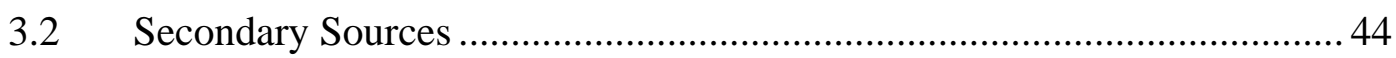

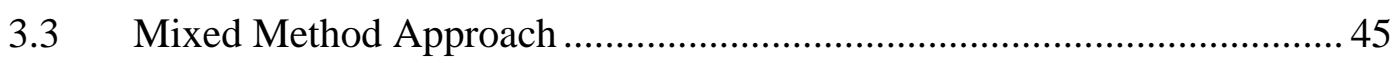

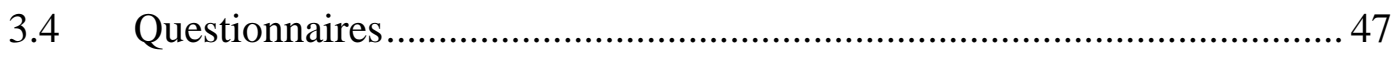

3.4.1 Selection of Sampling Technique ..................................................... 47

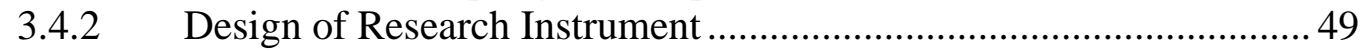

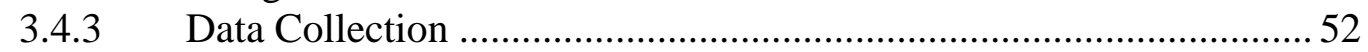

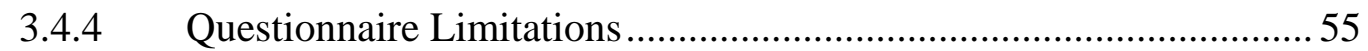

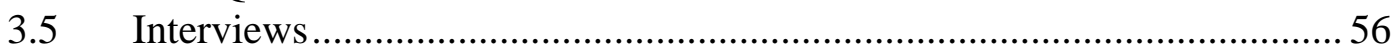

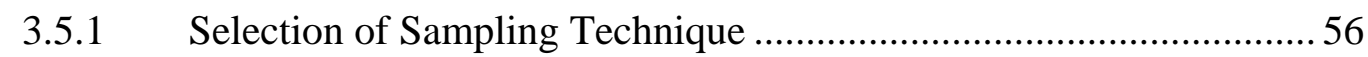

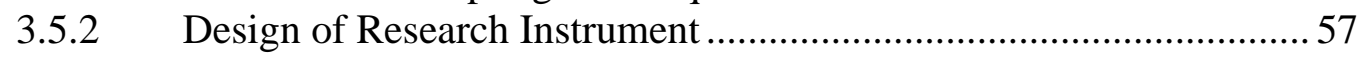

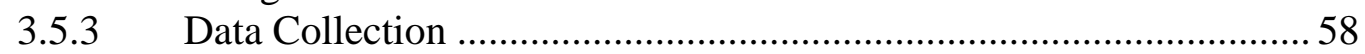

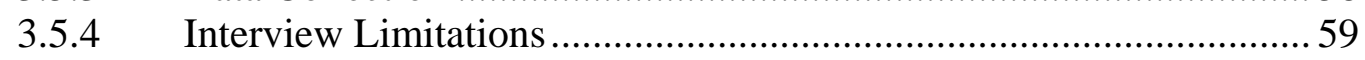

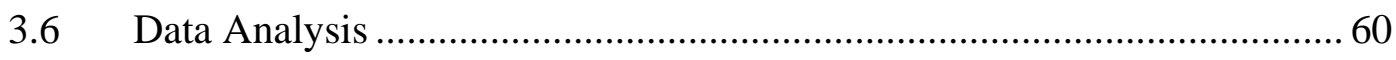

CHAPTER 4 Quantitative Analysis - Chinese Visitors’ Perspective................... 65

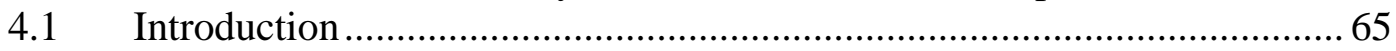

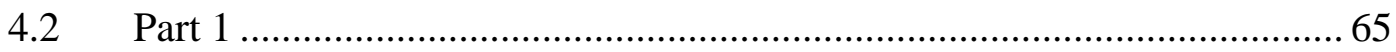

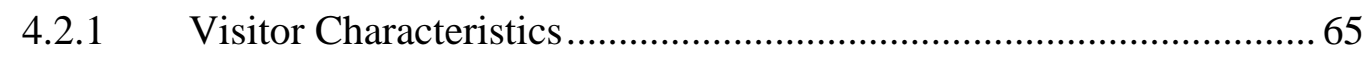

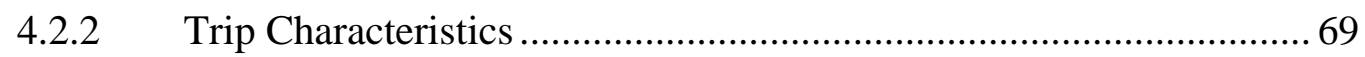

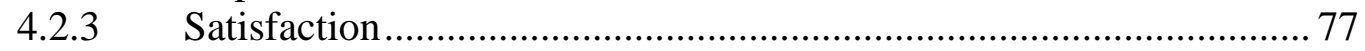

4.2.4 Factors that impact on the Visitors' decision to visit a destination ... 83

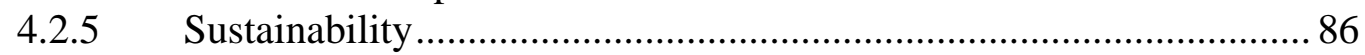

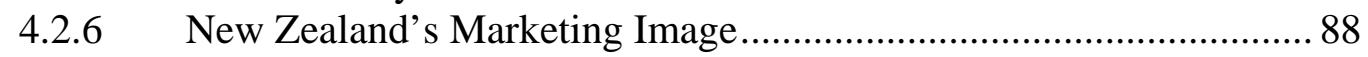

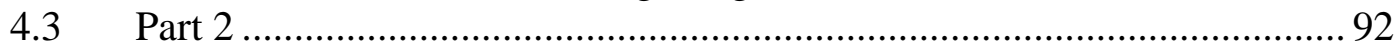

4.3.1 Visitor Characteristics \& Trip Characteristics ................................... 92

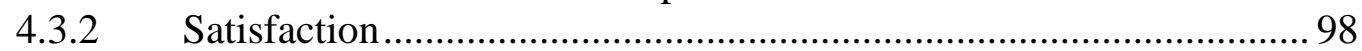


4.3.3 Sustainable Tourism in New Zealand .............................................. 99

4.3.4 New Zealand's Marketing Image.................................................. 103

CHAPTER 5 Qualitative Analysis - ADS Tour Operators’ Perspective........... 105

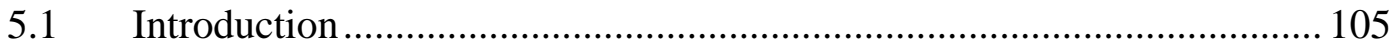

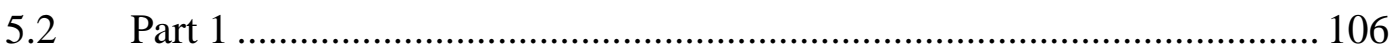

5.2.1 ADS Registered Tour Operator Profile............................................. 106

5.2.2 Chinese Visitor Demographics \& Trip Characteristics..................... 109

5.2.3 Sustainability ........................................................................... 112

5.2.4 Sustainable Tourism Destination .................................................. 122

5.2.5 New Zealand's Marketing Image.................................................... 125

5.2.6 Further Comments made by Tour Operators .................................. 129

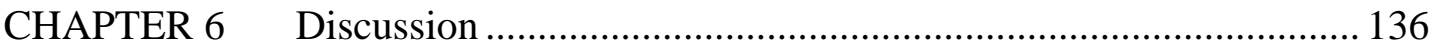

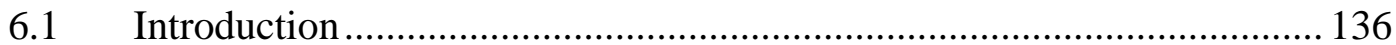

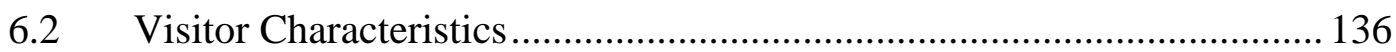

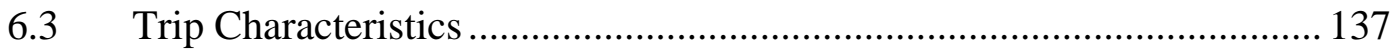

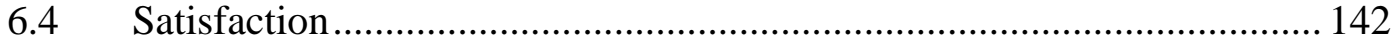

6.5 Factors that impact on the Visitors' decision to visit a destination .......... 145

6.6 Sustainable Tourism in New Zealand ................................................. 147

6.7 New Zealand's Marketing Image .......................................................... 151

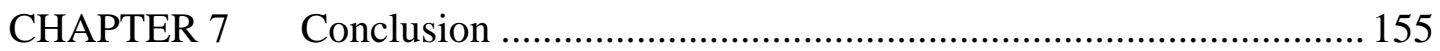

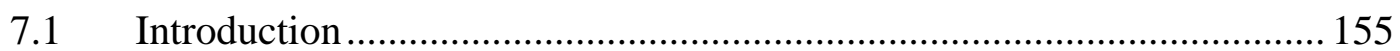

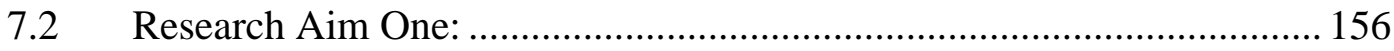

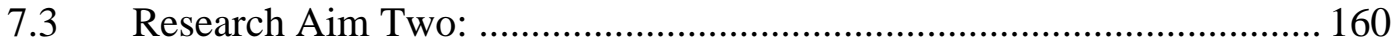

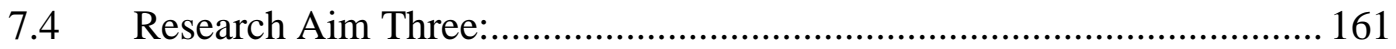

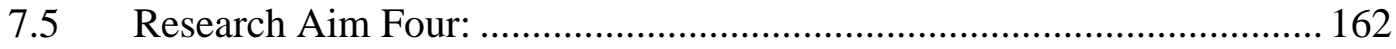

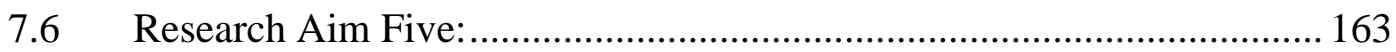

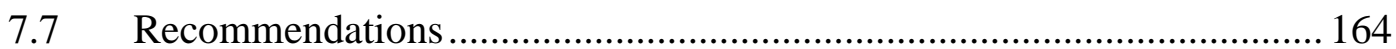

7.7.1 Recommendations for the Private Sector.......................................... 164

7.7.2 Recommendations for the Public Sector ........................................ 167

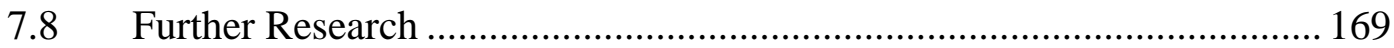

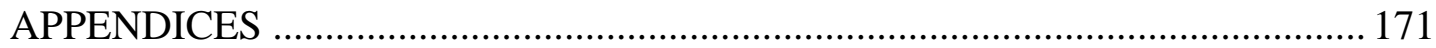

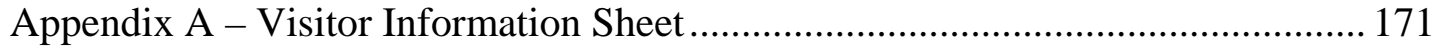

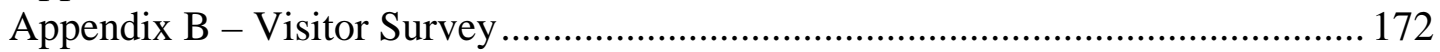

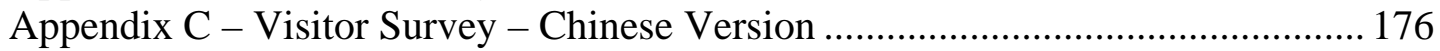

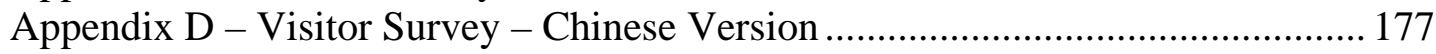

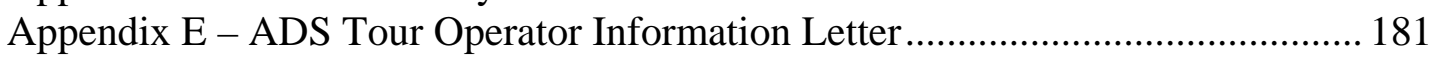

Appendix F - ADS Tour Operator Interview Questions ........................................ 182

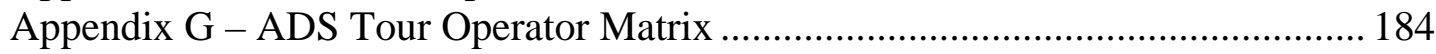

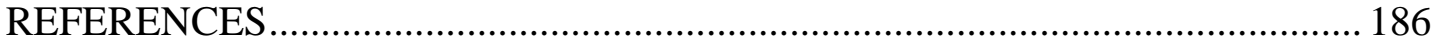




\section{LIST OF TABLES}

Table 2-1: Tourism Milestones 1950's-2008

Table 2-2: Chinese International Visitor Arrivals to New Zealand between YE Nov 2006-YE Nov 2008

Table 2-3: Chinese International Visitor Expenditure in New Zealand between YE Sep 2006-YE Sep 2008

Table 2-4: Ryan \& Mo's (2001) Demographic Profile of Chinese Respondents 24

Table 2-5: Environmental Concerns \& Tourism's Emphasis. 27

Table 2-6: The Conceptual \& Operational Context within which Sustainable Tourism Developed 32

Table 4-1: Visitor Profile 67

Table 4-2: Trip Characteristics 70

Table 4-3: Trip Characteristics - Travelled Internationally/New Zealand. .72

Table 4-4: Trip Characteristics - Visit any countries before arriving or after departing New Zealand 73

Table 4-5: Major Activities Participated in during visit to New Zealand $n=70$ (1) .... 77

Table 4-6: Level of Satisfaction (5-point scale) (\%) $n=68$ 78

Table 4-7: What Respondents Enjoyed the Most about their trip in New Zealand $\mathrm{n}=68$

Table 4-8: What Respondents Enjoyed the Least about their trip in New Zealand $\mathrm{n}=68$

Table 4-9: Factors considered in Respondents decision to visit New Zealand $n=7083$

Table 4-10: Level of Understanding Respondents have of the term 'Sustainability' (5point scale) $(\%) n=52$ 86 
Table 4-11: Do Respondents think New Zealand is a Sustainable Tourism

Destination (5-point scale) (\%) $n=52$

Table 4-12: Did the '100\% PURE NZ' tourism campaign impact on the Respondents

Decision to Visit New Zealand (5-point scale) (\%) $n=30$ .88

Table 4-13: How the Respondents think the '100\% PURE NZ' tourism campaign relates to New Zealand as experienced on the Respondents trip (5-point scale) (\%) $=30$

Table 4-14: Messages that Respondents Associated Most closely with the ' $100 \%$ PURE NZ' tourism campaign (4-point scale) (\%) $n=30$

Table 4-15: Cross tabulation of Travel Structure \& Age Group n=70

Table 4-16: Cross tabulation of Travel Structure \& Length of Stay $n=70$.

Table 4-17: T-test of Travel Structure \& Length of Stay $n=70$

Table 4-18: Cross tabulation of Travel Structure \& New Zealand Islands Visited $\mathrm{n}=70$

Table 4-19: Cross tabulation of Travel Structure \& Main Purpose of Visit to New Zealand $n=70$

Table 4-20: Cross tabulation of Travel Structure \& Major Activities Participated in During Visit to New Zealand $n=70(1)$

Table 4-21: Cross tabulation of Travel Structure \& Sources of Information n=70(1) 98

Table 4-22: Cross tabulation of Travel Structure \& Level of Satisfaction (5-point scale) $n=68$ 99

Table 4-23: T-test of Travel Structure \& Level of Satisfaction $n=68$. 99

Table 4-24: Cross tabulation of Travel Structure \& If the Respondent has heard of the term 'Sustainability' $n=70$ 100 
Table 4-25: Cross tabulation of Travel Structure \& Level of Understanding Respondents have of the term 'Sustainability' $n=52$

Table 4-26: T-test of Travel Structure \& Level of Understanding Respondents have of the term 'Sustainability' $\mathrm{n}=52$

Table 4-27: Cross tabulation of Travel Structure \& Is it Important for Tourists to Understand the term 'Sustainability' $\mathrm{n}=52$

Table 4-28: Cross tabulation of Travel Structure \& Who Respondents believe is the most responsible for dealing with the impacts caused by tourism on the destination $\mathrm{n}=68$

Table 4-29: Cross tabulation of Travel Structure \& Have the Respondents seen the '100\% PURE NZ' tourism campaign $n=68$

Table 4-30: Cross tabulation of Travel Structure \& Did the '100\% PURE NZ' tourism campaign impact on the Respondents decision to visit New Zealand (5-point scale) $\mathrm{n}=68$ 104

Table 4-31: T-test of Travel Structure \& Did the '100\% PURE NZ' tourism campaign impact on the Respondents decision to visit New Zealand $n=68$ 104 


\section{LIST OF FIGURES}

Figure 1-1: Top 5 Visitor Markets to New Zealand between 2003-2007 .................... 5

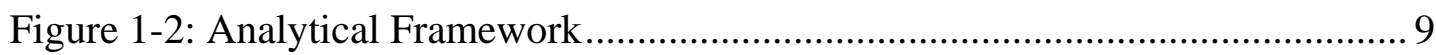

Figure 2-1: Top 5 Visitor Markets to New Zealand between 2003-2007 ................... 14

Figure 2-2: Total International Visitor Arrivals to New Zealand versus Total Chinese

Visitor Arrivals to New Zealand between YE Dec 1999-YE Dec 2008.................... 15

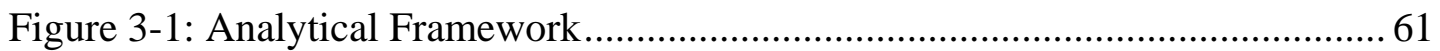

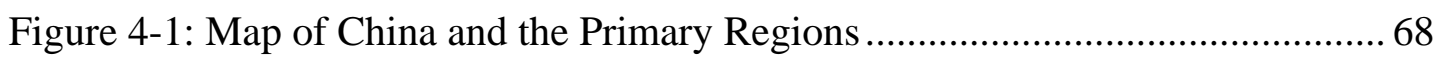

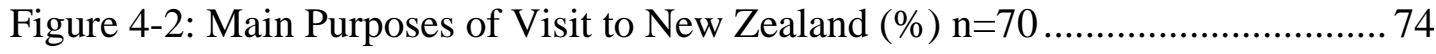

Figure 4-3: Main Sources of Information (\%) n=70 ….......................................... 76

Figure 4-4: Examination of Factors that Impacted on the Respondents Decision to Visit New Zealand $n=70$ 85 


\section{CHAPTER 1 Introduction}

The objective of this thesis is to explore the significant role of sustainability in the New Zealand tourism industry to overseas markets such as the Chinese visitor market to New Zealand. This study is of particular importance for the New Zealand tourism industry to develop a better understanding of the key characteristics and attitudes of an increasingly crucial visitor market to New Zealand (China). This will entail an examination of: sustainable tourism in New Zealand and the Chinese inbound visitor market to New Zealand. As expressed by the World Tourism Organization (UNWTO) sustainable tourism is: 'Tourism that takes full account of its current and future economic, social and environmental impacts, addressing the needs of visitors, the industry, the environment and host communities' (UNWTO, 2004). Although it has been acknowledged that the general understanding of the term 'sustainability' encompasses three components: the environmental, the socio-cultural, and the economic; this research will specifically investigate the environmental element of sustainable tourism in New Zealand. The reason for this specification is due to: firstly the resource constraints of this study, such as time and funding to allow for all three components to be investigated. But secondly, with a reputation of being 'clean and green', it is vital that New Zealand upholds this particular image, which largely involves an array of tourism activities and attractions that integrates various aspects of the natural environment.

As a key element of introducing the subjects of this study, this chapter establishes and illustrates a background of the issues with regards to this study. Firstly, the reasoning of the selection of 'sustainability' as the key focus, and the overall significance and application to the New Zealand tourism industry. Secondly, an overview of the Chinese visitor market, and its particular influence on tourism in New Zealand. Thirdly, the nature of the research problem, and the rationale for this topic; and finally, the presentation of the analytical framework adopted by this study to assist in the analysis and interpretation of the data collected from the visitor and supplier research.

Although the tourism industry is a key economic revenue earner for many countries it is evident that negative impacts also arise with the success of this industry. Since the global upsurge of tourists in the 1950's, increasing numbers of publications have 
developed major concern over the environmental, social, and cultural affects of tourism (Croall, 1995). Several groups have placed a large concern and emphasis on attempting to work to reduce the negative impacts; yet tourism at its worst can produce damaging and destructive results, such as overcrowding, deterioration of the physical environment, conflict with the host community, crime, pollution, and the unacceptable development of land (Croall, 1995). The 1970's and the early 1980's were essentially the era of global re-thinking, and the movement towards the concern for subjects relating to visual pollutions regarding land, air and water; with particular stress on global warming and ozone depletion. This era also generated more awareness of the need for sustainable management and responsive development (Collier, 2006). The concept of responsive development relates directly to the consideration required when developing within the host community, but also the environmental sensitivity and consciousness when developing (Collier, 2006).

The tourism industry in New Zealand has played a major role in the country's economy, and is now the country's largest export sector. The Former Tourism Minister, Damien O’Connor stated that: “Tourism's future depends upon sustainability and delivering greater value from each and every visitor to this country. The industry is one of the most significant contributors to the New Zealand economy” (Beehive, 2008). Hence, emphasis is placed on the need for sustainable tourism in New Zealand and the significant impact it plays on the travel experiences and satisfaction of visitors to the country. At present tourism in New Zealand directly and indirectly contributes \$14.1 billion to the country's total GDP, and maintains 108,100 direct, and 73,100 indirect full-time equivalent jobs (Ministry of Tourism, 2008). In the year ended November 2008 a total of 2,453,555 international visitors arrived into New Zealand, with a total expenditure of $\$ 8.8$ billion (YE March 2007) (Ministry of Tourism, 2008). Therefore, to maintain such levels of visitor arrivals and economic revenue, New Zealand must continue the conserve and preserve resources due to the fact that New Zealand's main attractions have a consistent relationship with the natural environment (Collier, 2006). 
The New Zealand Tourism Strategy 2015 (NZTS 2015) states that a sustainable tourism sector involves:

- New Zealand's customers enjoying their time in the country, and having the desire to travel to the country for the unique and sustainable tourism experiences presented to them.

- Tourism businesses will be financially profitable, able to invest securely in their business, and draw in and preserve their skilled workers.

- The natural environment within New Zealand will be safeguarded and improved, and the environmental footprint of the tourism sector will continue to decrease.

- Tourism stakeholders will work with communities for mutual benefits.

(NZTS 2015, 2008)

Therefore, it is clear that the task of guaranteeing that the growth of the tourism industry in New Zealand is employed to its full potential, and is developed sustainably entails a variety of groups: government departments, ministries and agencies, and regional and local bodies (Collier, 2006). Expressed by the Ministry of Tourism (1992) are the role of the government and the use of tourism growth as a means of enhancing social, environmental, and economic advantages. The concern for environmental conservation and preservation has been widely reviewed by authors in New Zealand, alongside the developing awareness of the impacts of tourism; and in 1997 the Parliamentary Commission for the Environment (PCE) carried out a study on the environmental effects linked to the tourism industry (Page \& Thorn, 2002). The report illustrated three detrimental impacts on the environment as a result of tourism, specifically the loss of some reasonably unspoilt areas of New Zealand's natural environment, the loss of amenity standards from increasing development, and the unwarranted stress on infrastructure (Page \& Thorn, 2002). The PCE formulated a series of recommendations for action to the Minister of Tourism, the New Zealand Tourism Industry Association and the Minister for the Environment, specifically calling for the development of a strategy for sustainable tourism (Page \& Thorn, 2002). Alternatively, in a guide to the Resource Management Act written by the New Zealand Tourism Industry Association (NZTIA), the New Zealand Tourism Board (NZTB), now known as Tourism New Zealand (TNZ), the Ministry for the Environment, conveyed: 
"Typically, environmental resources from the basis of tourist activity. Maintenance of those resources, therefore, is critical to the long-term viability of the New Zealand tourism industry. Sustainable use of resources and the management of the effects of activities, as required by the Resource Management Act 1991 (RMA), offer significant benefits to the industry. If environmental damage is prevented, New Zealand will continue to attract international visitors and a range of opportunities for both international and domestic visitors can be supported”

(Collier, 2006, p.396).

In the guide directed to the Resource Management Act it is also expressed that the tourism industry, and many other industries need to recognize the responsibility for appropriately managing the use of natural and physical resources, which will be the only method that the industry is able to maintain for the long term future (Collier, 2006).

Consequently, the Ministry of Tourism developed the New Zealand Tourism Strategy 2010 and 2015. Mr. O’Connor stated that the primary initiative is to give a certain degree of direction for the public and private sector in implementing the objectives of the New Zealand Tourism Strategy and emphasize the government's commitment to the tourism industry in New Zealand (Beehive, 2008). The supporting two values of the Strategy are: kaitiakitanga (guardianship) and manaakitanga (hospitality) (NZTS 2015, 2008). These values present the basis for the sustainable approach to the development of New Zealand's tourism industry. These two key values are also the foundation for New Zealand's unique approach to sustainability; demonstrating that if the values are delivered, the tourism industry in New Zealand would be able to cater efficiently to their visitors, whilst conserving and managing New Zealand's culture and environment (NZTS 2015, 2008). The Tourism Strategy specifically points out the importance of 'sustainability' in New Zealand's tourism industry, and the nation's exclusive branding. New Zealand's tourism branding focuses particularly on the representation of the natural environment, and with a 'clean, green' marketing image it can be identified that this is what essentially appeals to the country's international visitors; therefore, maintaining this image is vital to attract and retain interest by visitors. Also stated in the Tourism Strategy is the importance in the management of the country's reputation and delivery of tourism products that are sustainable, by doing so it will generate a competitive advantage for New Zealand's tourism industry, but also New Zealand businesses (NZTS 2015, 2008). 
Although tourism in New Zealand has presented a number of opportunities, recent statistics have demonstrated that several of the country's key target markets have stagnated or decreased in visitor arrivals, as seen in figure 1.1.

Figure 1-1: Top 5 Visitor Markets to New Zealand between 2003-2007

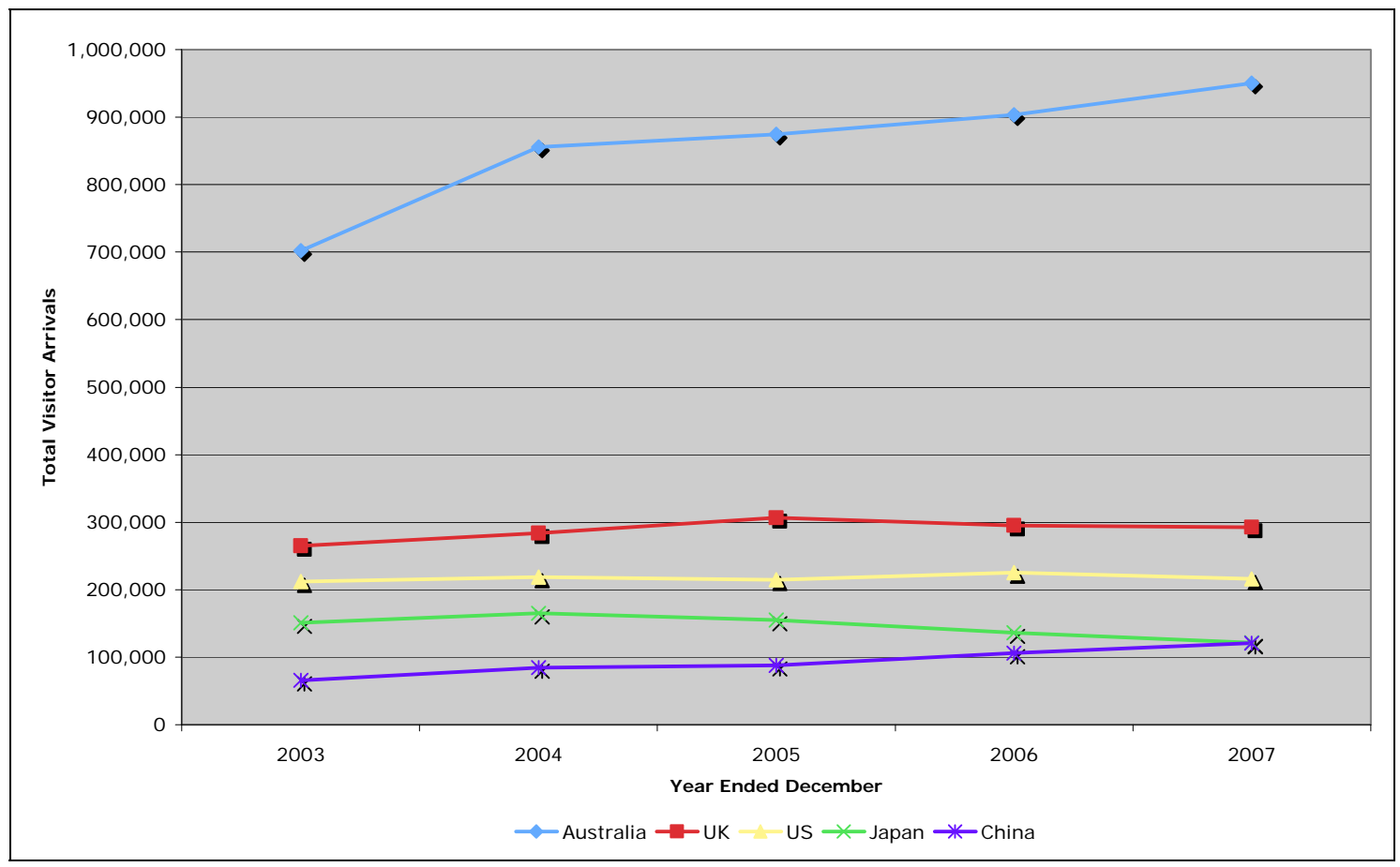

Source: Ministry of Tourism, 2009

Figure 1.1 illustrates Australia as the country's primary inbound visitor market; Asian visitor markets have increasingly become just as vital to the New Zealand's tourism industry. Additionally, with the slight decrease in the number of UK, US, and Japanese visitors to New Zealand, China has begun to draw specific attention in the New Zealand tourism industry. The Chinese visitor market has recently surpassed Japan to become New Zealand's fourth largest inbound visitor market, drawing in a total of 112,398 Chinese visitors in the year ended December 2008; but also bringing in the total expenditure of $\$ 241$ million in the year ended September 2008 (Ministry of Tourism, 2008). However, due to a number of unexpected global issues such as the Sichuan Earthquake, the Beijing Olympics, and the global financial crisis, the total number of Chinese visitors travelling internationally has been affected. George Hickton, Tourism New Zealand chief executive states: "The drop in Chinese arrivals, on top of softening numbers in many major markets, shows the growing importance of Chinese visitors to New Zealand's tourism industry” (TNZ, 2008). From the statement made by Mr. 
Hickton, the 2008-year has demonstrated a number of boundaries to the growth of the Chinese visitor market to New Zealand. Nonetheless, the Chinese visitor market is developing into a consistently opportunist market that has potential to assist in the sustainability of the tourism industry in New Zealand.

In a tracking survey undertaken by TripVision, it was identified that UK travellers indicate that environmental issues and concern have become increasingly important to consumers, with the demand for holidays and tourism products that are associated with being 'responsible' or 'sustainable', which has potential to increase by 5-fold in the next 5 years (Visit Norwich, 2008). This indicates that the increasing demand for sustainable tourism products by UK travellers may have led to a slight decrease in UK visitor arrivals to New Zealand. Even though New Zealand is linked to the 'clean, green' image, due to New Zealand being a long-haul destination the carbon emissions may be what discourages certain visitors from visiting the New Zealand. On the other hand, with the incorporation of both the increasing amount of disposable time and income, and the decreasing legislation associated with Chinese visitor travel, Chinese consumers are now able to travel more freely. As a result, many Chinese consumers demand more unique tourism products and services to broaden their travel experiences. Due to the fact that a primary motivation for Chinese outbound visitors is to expand their travel experiences, the overall distance from China to New Zealand may not be as much of a concern as it is for visitors from origins such as the UK and US. However, it can also be stated that the awareness of environmentally sustainable behaviour by Chinese consumers is limited in contrast to other markets, for example the European market.

On the other hand, the Chinese market still remains quite restricted; and price sensitive, especially if they are first-time travellers (Asia Pacific Foundation of Canada, 2002 in Becken, 2003). Additionally, it has been identified by Tourism New Zealand that the level of satisfaction within the Chinese visitor market to New Zealand is considerably lower than that of other markets (TNZ, 2008). This issue can directly be associated with the large number of commission-based 'shopping tours' that a number of Chinese visitors participate in (TNZ, 2006). These issues require particular attention because the Chinese visitor market has led to many opportunities for the tourism industry in New Zealand, such as the increase in economic revenue; and if New Zealand wishes to retain the Chinese visitor market satisfaction levels need to increase. Moreover, New 
Zealand's rich supply of tourism resources such as the relatively untouched natural environment and unique culture appeals to a variety of visitor markets, but can be identified as a key interest for many Chinese visitors due to the fact that many seek tourism experiences that are associated with status or uniqueness (Ryan \& Mo, 2001).

With regards to 'sustainability' and 'sustainable tourism development', New Zealand stands as a destination that prides itself in being 'clean and green'. Consequently, New Zealand has in general attempted to appeal and attract inbound visitors that appreciate the 'clean and green' aspects of the destination. Due to the Chinese outbound visitor market still being seen as 'young', a large proportion of existing literature has presented the Chinese market as a homogenous group, but as research has now indicated, Chinese visitors are not as homogenous as previously established (Chen, 2002, Zhao, 2006). Nevertheless, with regards to travel experience and environmental concern in comparison to other experienced markets, such as Australia, the UK, and the US, the Chinese visitor market is still undeveloped and under-researched; therefore, it can be conveyed that differing factors may influence the Chinese visitors' holidaymaking decisions. Consequently, it can be established that there may also be differences in the Chinese visitors' behaviours and attitudes towards subjects such as 'sustainability'. Which in turn may result in the need for a change in how the tourism industry caters to Chinese visitors, as well as a potential modification of New Zealand's '100\% PURE' tourism campaign to target the Chinese market more exclusively. This was previously done to target some of New Zealand's larger inbound visitor markets, such as Australia with the additional tagline of 'What's On', in the UK with 'What Do You Say UK?' and the recently devised 'The New Zealand Life Back Promise' for the US (TNZ, 2009).

As a result the following research aims were drawn from the review of previous literature to fill this gap in knowledge, but also from reports made by various tourism stakeholders, such as Tourism New Zealand and the Ministry of Tourism. 
The research statement for this study is:

Sustainable Tourism in New Zealand: The Chinese Visitors' View

To investigate the above research statement, the following research aims were formulated:

1. Enhance existing knowledge of the Chinese visitor market to New Zealand.

2. Establish whether the sustainable development of a destination influences the travel decisions of Chinese visitors and how this impacts on New Zealand's tourism industry.

3. Achieve a better understanding of the Chinese visitor's view and the tour operator's view of sustainable tourism in New Zealand.

4. Identify whether New Zealand's '100\% PURE' tourism campaign is effectively and efficiently attracting Chinese visitors to New Zealand.

5. Establish how the tour operators promote sustainable tourism to their customers.

This thesis is divided into seven chapters; the first chapter focuses on providing a background to the Chinese outbound visitor market, tourism in New Zealand, the Chinese visitor market to New Zealand, and essentially sustainable tourism in New Zealand. This chapter also gives a general interpretation of the research subjects, but also gives rationale to the importance of this study.

Chapter two is divided into three specific sections. The first examines tourism in New Zealand, focusing on the impacts that tourism has had on New Zealand. Secondly, this chapter presents an overview of the Chinese outbound market, with regards to the markets history, and potential for growth. Finally, the last section investigates the evolution of the concept of 'sustainability' and its growth in the tourism industry.

Chapter three draws attention to the research method employed in this study, and the research approaches utilized to investigate the research problem. This chapter also indicates how and why this study was undertaken in such a manner, and the limitations associated with the development and implementation of this study. The methodology chapter also presents the analytical framework (figure 1.2) developed to assist in the analysis and interpretation of data collected. The analytical framework essentially brings together the method employed to analyze the information retrieved from the 
quantitative and qualitative research approaches. The aims indicated at the top of the framework fundamentally guide the structure of this study, specifying the use of the visitors' and suppliers' perspective to examine the key variables/themes shown at the centre of the diagram. The data that was generated by the two research approaches were then analyzed: with the quantitative data being analyzed for descriptive information, and then the content analysis for the qualitative data. Also demonstrated in the framework is the investigation of the Chinese visitors' travel structure, and this was investigated through both the quantitative and qualitative research approaches through inferential analysis.

Figure 1-2: Analytical Framework

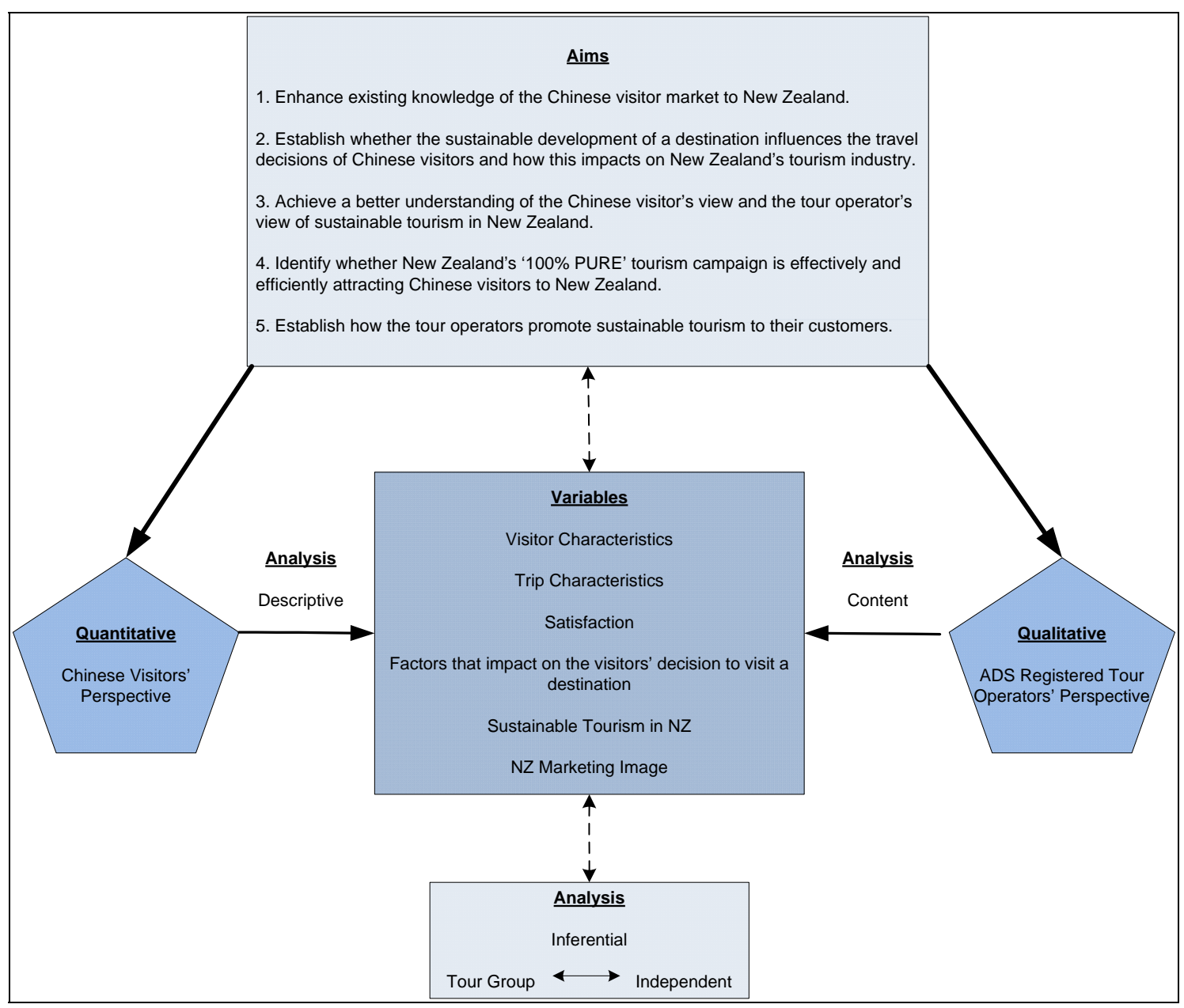

Chapter four will present the quantitative analysis of this study utilizing the visitors' perspective. This chapter will be split into two parts: the first part will examine the different variables: visitor characteristics, trip characteristics, satisfaction, factors impacting on visitors' decision to visit New Zealand, sustainable tourism in New 
Zealand, and the New Zealand marketing image (as indicated in the analytical framework).Whereas, the second part investigates the variables further by inserting an additional variable (travel structure) to examine the similarities and differences between the characteristics and attitudes of tour group and independent travellers.

Chapter five displays the qualitative analysis employing the suppliers’ perspective. In this chapter data collected from the interviews with ADS registered tour operators was examined. The same variables/themes employed in the quantitative analysis were used to keep the overall data analysis and interpretation consistent.

The findings from both chapter four and five were then synthesized in chapter six, which discusses the key findings and implications. This chapter specifically brings together the key themes of both the quantitative and qualitative analysis, so that various assertions could be made about the current and future state of the Chinese visitor market to New Zealand; and the visitor and supplier perspective of sustainable tourism in New Zealand. Hence, the overall findings of this research were reviewed in chapter seven, with a section formulating recommendations for both the public and private sectors of tourism; and lastly a section conveying areas for future research to extend the use of data generated from this study. 


\section{CHAPTER 2 Literature Review}

\subsection{Introduction}

As highlighted in the introduction chapter, this chapter will consist of the literature review. In order to achieve a greater understanding of environmental sustainability in New Zealand's tourism industry this chapter will examine: the New Zealand context, the Chinese visitor market, and sustainability.

The first section of this chapter will discuss the evolution of tourism in New Zealand, the various key visitor markets that have impacted on the development of tourism in New Zealand, and the evolving importance of the Chinese visitor market to New Zealand. Additionally, this section will describe the increasing significance of sustainable tourism as a key aspect of the New Zealand Tourism Strategy 2015.

The second section will address the Chinese outbound market, and the impact of the growing phenomenon of tourism and its influence on the development of the Chinese visitor market. In addition, this section reviews a number of other studies undertaken on the topic of the Chinese outbound market to create an overall comprehension of the existing knowledge of Chinese visitors.

The final section will deal with the key theme of 'sustainability'. It highlights the general understanding of the term 'sustainability', followed by the overall evolution of the concept of sustainability and the developing importance of the environment. This section also expresses the difficulty in developing a consensus over the term, and the complexity in delivering a sustainable tourism industry.

By outlining the three sections it will assist in the understanding of the primary purpose of this study, and by individually addressing the three subject matters an overview of how they complement and overlap each other will become visible, to effectively provide the reader with a clearer understanding of the theory that links to the findings of this study. 


\subsection{New Zealand Context}

The tourism industry has become a significant contributor to both employment and foreign-exchange revenues in the New Zealand economy. For the year ended November 2008 the total international arrivals to New Zealand was 2,453,555 (Ministry of Tourism, 2008). Additionally, in regards to the economic contribution of tourism and the international visitor market to New Zealand, the international visitor tourism expenditure was at $\$ 8.8$ billion (YE March 2007), which is the equivalent to $18.3 \%$ of New Zealand's total export earnings (Ministry of Tourism, 2008). Furthermore, tourism in New Zealand directly and indirectly contributes $\$ 14.1$ billion (or 9.2\%) to the country's total GDP, and maintains 108,100 direct and 73,100 indirect (181,200 total) full-time equivalent jobs (9.7\% of the total workforce in New Zealand) (Ministry of Tourism, 2008). Table 2.1 illustrates the tourism highlights in New Zealand between the 1950's-2008, and helps to develop an understanding of the tourism industry in New Zealand today.

Table 2-1: Tourism Milestones 1950's-2008

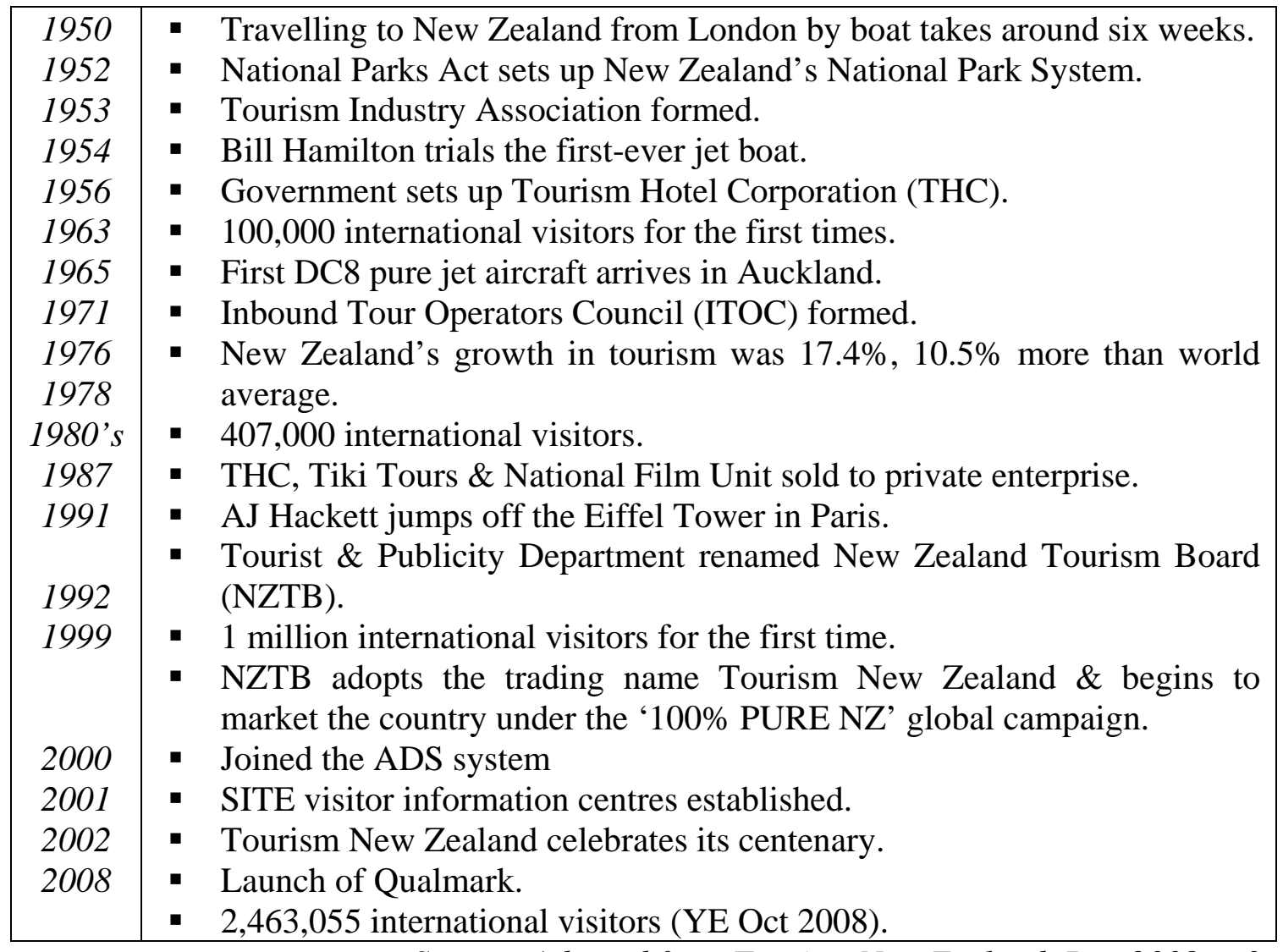
Source: Adapted from Tourism New Zealand, Dec 2008, p.3 
Over the past 50 years the New Zealand tourism sector has developed immensely, from the first visitors in the 1950's travelling to New Zealand from London by boat taking around six weeks, to the growth of tourism in New Zealand reaching 17.4\% which was $10.5 \%$ higher than the world average in 1976 . However, when examining the $20^{\text {th }}$ and $21^{\text {st }}$ centuries a key milestone for tourism in New Zealand was in 1992 when New Zealand received 1 million international visitors for the first time. This then led to the New Zealand Tourism Board (NZTB) adopting the trading name Tourism New Zealand in 1999. Additionally, in 1999 New Zealand signed the Approved Destination Status (ADS) agreement with the Chinese Government which has since then led to the growth of the Chinese visitor market to New Zealand. Furthermore, New Zealand launched Qualmark in 2002; accordingly Tourism New Zealand (TNZ) celebrated their centenary in 2001.

With NZTB adopting the trading name Tourism New Zealand, New Zealand also began to define their target market. It was established that at the principal level, as a destination New Zealand is only able to reach a certain number of visitors, due to four primary reasons: financial constraints, finite resources, proposition match, and the New Zealand Tourism Strategy 2010 (TNZ, 2008). Of all international travellers, New Zealand has a self-defined target market, the 'interactive traveller' (TNZ, 2008). As defined by Tourism New Zealand, the 'interactive traveller' is an international traveller that utilizes a variety of tourism products and services, and seeks experiences that entail connecting and interacting, revealing consideration for natural, social, and cultural environments (TNZ, 2008). 'Interactive travellers' generally carry their own attitudinal and behavioural characteristics, and are consistently associated with three primary markets: Australia, US, and the UK. However, as the Chinese outbound market develops globally, their motives for travel have also evolved, resulting in many Chinese international visitors to fall into the 'interactive traveller' standard, for example their increasing interest in good food, and “eco and nature” highlights (Coventry, 2008).

Figure 2.1 illustrates the growth of New Zealand's five primary markets between 20032007. Australia is clearly identified as the country's primary inbound visitor market; followed by the UK and the US. However, New Zealand has begun to pay more attention to the Chinese visitor market due to it recently surpassing Japan to become New Zealand's fourth largest inbound visitor market (Ministry of Tourism, 2008). To 
New Zealand specifically, the Chinese visitor market has led to many opportunities for the tourism industry. New Zealand's supply of tourism resources such as the natural environment and unique culture appeals to a variety of visitor markets, but can be identified as a key pulling factor for many Chinese visitors because this growing visitor market is one that seeks to expand their travel experiences which are specifically associated with status or uniqueness (Ryan \& Mo, 2001).

Figure 2-1: Top 5 Visitor Markets to New Zealand between 2003-2007

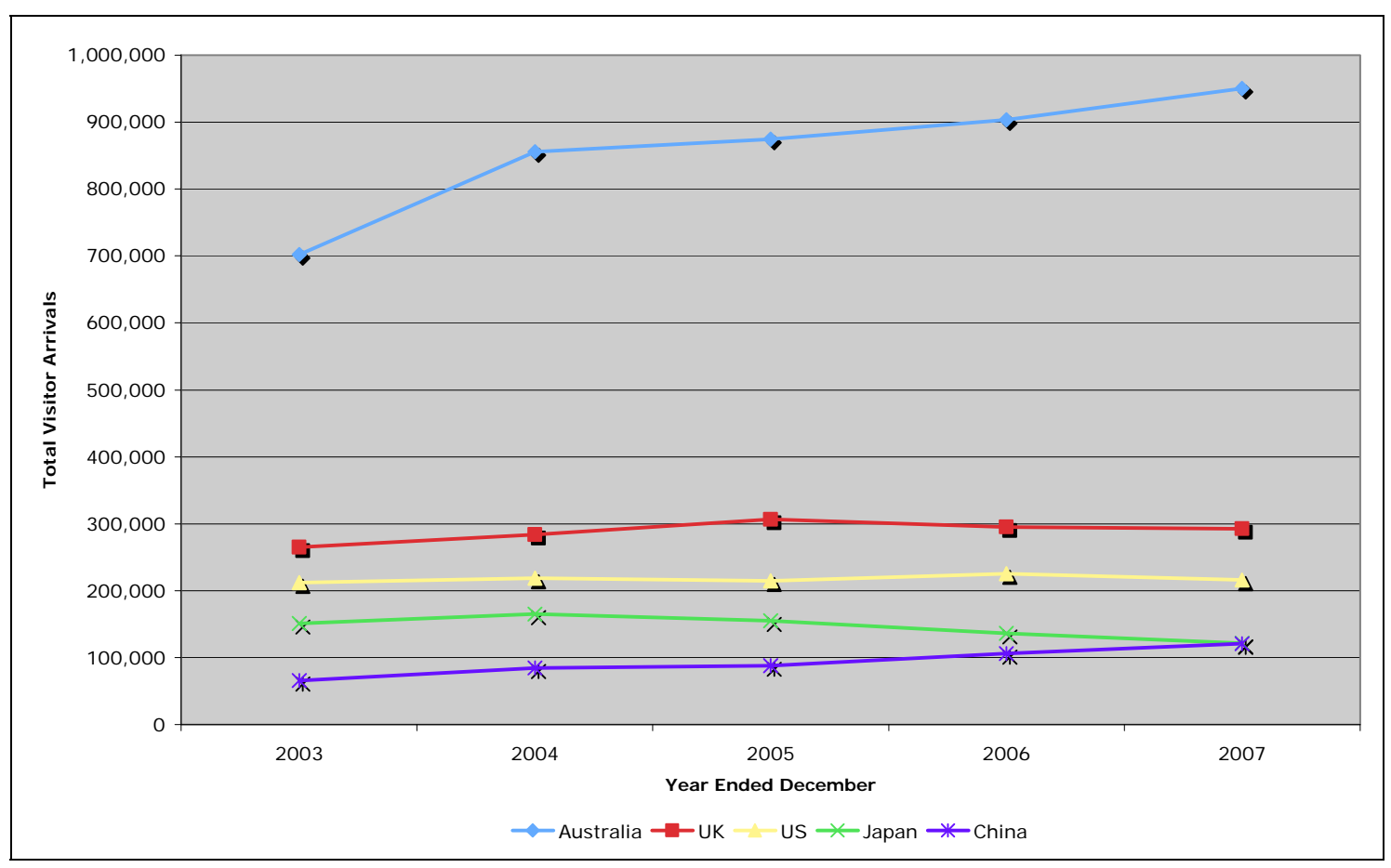

Source: Ministry of Tourism, 2008

Figure 2.2 illustrates a comparison of the total international visitor arrivals and the total Chinese visitor arrivals to New Zealand between year ended December 1999-2008. New Zealand experienced the highest growth rate of Chinese international visitors between 1999 and 2001 (+75.9\%) (Ministry of Tourism, 2008). The tourist numbers from China in 2004 was approximately five times the number of visitors that arrived in New Zealand in 1998 (Ministry of Tourism, 2008), representing the dramatic change in Chinese visitor destination choice, and the possible impact that the signing of the ADS agreement had on the ability for the Chinese population to visit New Zealand more freely since 1999. 


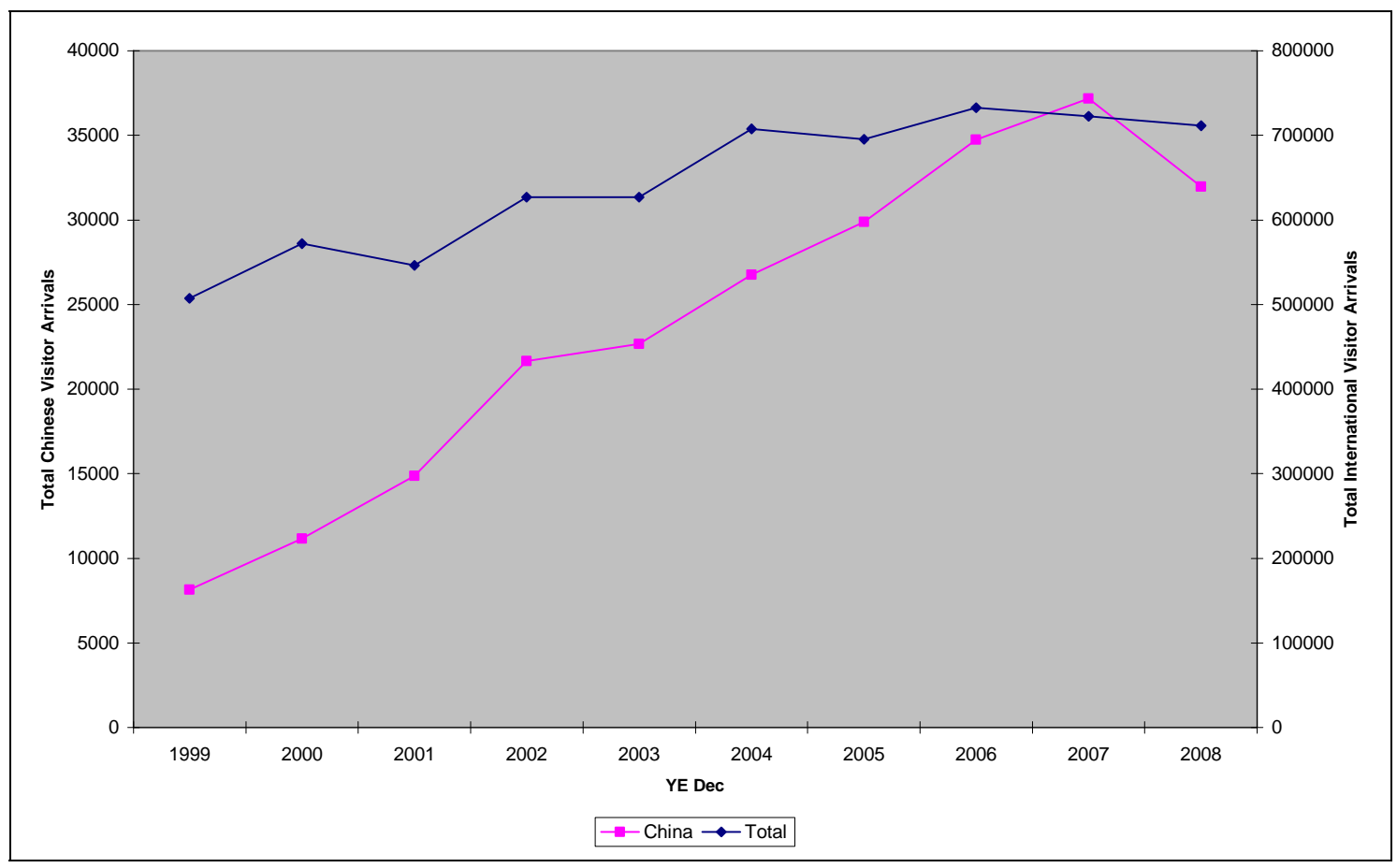

Source: Ministry of Tourism, 2008

The main challenge for the tourism industry in New Zealand is to guarantee the sustainable growth of the industry, and that the primary attraction that brings international visitors to New Zealand is safeguarded (TNZ, 2008). Due to New Zealand's environment being of such importance to New Zealand's tourism industry a number of stakeholders such as the Ministry of Tourism, and the Ministry for the Environment have put efforts into preserving the industry and the various components involved in the industry.

In 1991, the Resource Management Act (RMA) was ratified by the New Zealand Government, this piece of legislation was one of the world's first that overtly looked to exemplify the concept of sustainability in national planning law (Page \& Thorn, 2002). The legislation generated substantial debate and subjective confirmation signifying that the RMA was obstructing the development of tourism; yet, the primary purpose of the legislation was the "promotion of the sustainable management of natural and physical resources” (RMA, 1991 Section 5 in Page \& Thorn, 2002, p.223). Therefore, what was illustrated specifically in the RMA was the focal point on controlling the consequences 
of all development activities, before initiating a method that handles the activities (Page \& Thorn, 2002).

The Ministry for the Environment (2008) specifically stated that New Zealand's natural environment; the host communities, New Zealand's Maori culture, and businesses are all elements of the construction of the tourism industry. The Ministry for the Environment (2008) adds by asserting sustainable tourism in New Zealand involves:

"A healthy and attractive environment is crucial to the success of New Zealand's tourism industry. Tourists are attracted to our unique environment. However, tourism has a direct impact on our environment. For tourism to continue to be successful in New Zealand, tourism businesses need to incorporate sustainable business practices into their operations.”

(Ministry for the Environment, 2008)

To add to the above statement by the Ministry for the Environment (2008), the Former Tourism Minister, Damien O’Connor conveyed that: “Tourism's future depends upon sustainability and delivering greater value from each and every visitor to this country. The industry is one of the most significant contributors to the New Zealand economy" (Beehive, 2008). Therefore, it can be identified that there is a great deal of emphasis on sustainable tourism in New Zealand as a consequence of the significant affect that tourism has on the economy, but also because of the relationship that links New Zealand tourism products to the natural environment.

As a key method employed to assist in the sustainable development of tourism the New Zealand Government has recently reviewed the New Zealand Tourism Strategy 2010 to generate the updated New Zealand Tourism Strategy 2015. The New Zealand Tourism Strategy 2015 focuses on improving the core of tourism, and the overall quality of tourism development in New Zealand. The New Zealand Tourism Strategy 2015 is a joint endeavour between the private sector and Government, with the primary vision being: "In 2015, tourism is valued as the leading contributor to a sustainable New Zealand economy” (Ministry of Tourism, 2008). The Tourism Strategy 2015 is strengthened by two main values, kaitiakitanga (guardianship) and manaakitanga (hospitality), with both values offering the basis for sustainable tourism development (Ministry of Tourism, 2008). 
To guide the vision and values of the New Zealand Tourism Strategy 2015, the Strategy seeks to reach the following four outcomes:

1. New Zealand delivers a world-class visitor experience

2. New Zealand's tourism sector is prosperous and attracts ongoing investment

3. The tourism sector takes a leading role in protecting and enhancing the environment

4. The tourism sector and communities work together for mutual benefit

(Ministry of Tourism, 2008)

The New Zealand Tourism Strategy 2015 distinctively demonstrates the value of 'sustainability' in New Zealand's tourism industry, and the nation's exclusive branding. In essence, New Zealand's tourism branding focuses on the representation of the natural environment; therefore as part of the Tourism Strategy it becomes important to manage the country's reputation as 'clean and green', to deliver tourism products that are sustainable. This thereby creates a certain level of competitive advantage for New Zealand's tourism industry, but also New Zealand businesses (NZTS 2015, 2008). Mr. O’Conner adds by expressing: "the world is placing increased attention on mankind's impact on the environment. Our 100\% Pure brand promise means we have to do all we can to protect our environment. Visitors from our key markets will increasingly seek information to make sure their choices are ethical and sustainable” (Beehive, 2008). From the statement made by Mr. O’Connor it can be acknowledged that with New Zealand's '100\% PURE' branding and image New Zealand needs to be more reliable and noticeable with regards to the steps the tourism industry takes to reduce the environmental impacts and environmental management, to meet the increasing demand by visitors for sustainable products.

Additionally, Eric Park, Senior Operator of the Tourism and Major Events, Sustainable Business Group within the Ministry for the Environment presented a study on sustainable tourism, expressed that a number of visitors to New Zealand have enhanced their environmental sustainable behaviour whilst returning home (Ministry for the Environment, 2008). This change can clearly be observed as an impact of the generation of the New Zealand Tourism Strategy 2015, and the vision for tourism in New Zealand to be a sustainable contributor to the economy in terms of utilizing the country's brand 
positioning (Ministry for the Environment, 2008). Furthermore, Tourism New Zealand has recently added a 'Green’ factor to the Qualmark accreditation system. 'Qualmark Green' assesses the overall environmental performance of tourism businesses, entailing minimum requirements and acknowledging businesses for initiatives in energy, waste, water, conservation, and community (Beehive, 2008). The foundation behind the development of 'Qualmark Green' was to assist in New Zealand's commitment to

preserving New Zealand's tourism resources, satisfying visitor needs, and conserving New Zealand for future generations (Beehive, 2008).

Despite the development of the New Zealand Tourism Strategy 2015 and potentially other sustainable tactics such as Qualmark Green, it has been identified that New Zealand has been slow in producing and implementing sustainable measures and practices (NZ Business, 2008). Sophie Rainford, Green Globe New Zealand's sustainability advisor expresses a similar opinion by stating that: "New Zealand's response to sustainable business practice has been slow considering how long we've been talking about the need for it” (NZ Business, 2008). The Ministry of Tourism has however recently published eight 'best practice' guides aimed at tourism operators, to assist in sustainable tourism operation. However, interestingly none of the guides focus primarily on inbound tour operators, this then links to this study and the examination of the suppliers' perspective of sustainable tourism in New Zealand.

\subsection{Chinese Outbound Visitor Market}

Prior to 2006, the option of destinations for Chinese outbound travellers was not determined by demand, but rather by accessibility (Georg Arlt, 2006). Due to China’s government having control over outbound travel, the Approved Destination Status (ADS) agreements were established to illustrate the official leisure destinations of Chinese travellers (Georg Arlt, 2006). New Zealand was opened to the Chinese outbound market through the ADS in 1997, with the agreements being confirmed in 1999 (Georg Arlt, 2006).

Even though it may seem the Chinese outbound travel market has become less restricted due to the development of the ADS, various tourism stakeholders still hold conflicting 
views regarding whether the Chinese Government will deregulate or further regulate inbound and outbound travel to and from China in the future (Hemstöm et al., 2006). However, it has already been established in literature that outbound business travel from China is less restricted than leisure travel (Hemstöm et al., 2006), which is clearly depicted in various examinations of the Chinese international visitor market undertaken by numerous destination tourism industries (Travel Distribution Summit Asia, 2007; Ooi, 2007). Although the overall outbound market is rather small in comparison to the outbound business travel market, it is predicted to increase in the near future as possibilities of travel become deregulated (Hemstöm et al., 2006).

In correspondence to the World Tourism Organization (WTO), China has developed into the world's fastest-growing source country of domestic and international tourists (China Knowledge Press, 2003). Although a number of organizations, such as the WTO, have stated the importance of the Chinese outbound market, little research has been undertaken on this group (Georg Arlt, 2006). There are three primary causes why the Chinese outbound market has been under-researched and continues as an unfamiliar entity: firstly, broad studies on the fundamentals of outbound tourism have been weak; secondly, the Chinese outbound market has only become of interest to various destinations as the volume of the market has increased; and thirdly, China's outbound and domestic tourism was largely not taken notice of till recently (Georg Arlt, 2006).

There is a misleading conception that the Chinese outbound travel market is well travelled within their own country; however, this is not always the case (Hoffmann, 2005 in Lau \& Tol, 2006). In addition, a vast array of literature has indicated that the Chinese outbound market follow a general trend towards package tours, yet an increasing number of Chinese outbound travellers comprise a sizeable percentage of the overall independent travellers (World Economic Forum, 2003 in Lau \& Tol, 2006). Although China has struggled behind many other countries in regards to industry maturity in relation to both the demand for and the supply of tourism (Lew, 2007), "the World Tourism Organisation estimates that in the year of 2020 China will be ranked as one of the world's top four countries counted on the total number of tourists going abroad” (Hemstöm et al., 2006), providing 100 million outbound travellers internationally (Ooi, 2007). At present, 90\% of the entire Chinese outbound market travels within Asia, with Hong Kong \& Macau making up 70\% of this total (Zhang, 
2006 in Ooi, 2007). Despite the fact that less than 10\% of Chinese outbound travellers visit long haul, high status destinations around the world, these destinations attract a larger proportion of the wealthy Chinese travellers (Ooi, 2007).

While the current percentage of outbound tourists from China is only a small proportion of the nations total population, the percentage of outbound tourists from China is no longer minor in contrast to the outbound markets from other countries, with potential for the Chinese outbound market to grow (Zhao, 2006). Sheldon (1995) conveyed that the potential growth of the Chinese outbound market can be led by the: liberalization of travel restrictions, increasing household incomes, the introduction of holiday pay, and the increasing curiosity of the outside world.

At present, New Zealand has only two direct flights from China, Shanghai and Beijing, on Air New Zealand. However, there are several airlines that supply indirect flights, such as Air New Zealand, Qantas, China Eastern, Korean, Thai and Singapore airlines (Zhao, 2006). In accordance to a study undertaken by the Tourism New Zealand market research department, China has approximately 528 approved outbound agents certified to operate outbound travel to various approved destinations, with an estimated 39 approved outbound agents promoting tours in New Zealand (Zhao, 2006). According to the study, Tourism New Zealand has identified that 28 of the 39 agents are located in Beijing and Guangdong, with the other 30\% distributed throughout Mainland China (Zhao, 2006). In relation to a report produced on by the National Bureau of Statistics in China (2004), results demonstrate that Beijing was positioned as the highest outbound market from China, organizing roughly $30 \%$ of total outbound tours, followed by Guangdong (22\%), Shanghai (11.7\%), Zhejiang (4.3\%), and Jiangsu (4.25\%) (Zhao, 2006, p.6). These statistics thus illustrate that Beijing and Guangdong occupy in excess of 50\% of China's total outbound market to New Zealand (Zhao, 2006).

With New Zealand being one of the first international destinations to receive the ADS, China has become New Zealand's fastest growing international visitor market, with an estimated annual increase of 25\% (Tourism Leading Indicators, 2008). For the year ending November 2008, New Zealand received 112,155 international visitors from China, as seen in table 2.2 (Ministry of Tourism, 2008). However, it can be established that a number of global events that occurred in the 2008-year such as the Sichuan 
Earthquake, the Beijing Olympics, and the global financial crisis, may have affected the number of Chinese outbound visitors travelling internationally. Conversely, as New Zealand's fourth largest inbound visitor market, it is established that by 2013 the number of Chinese visitors is forecast to double and reach 260,000 visitors (Ministry of Tourism, 2008).

Table 2-2: Chinese International Visitor Arrivals to New Zealand between YE Nov 2006-YE Nov 2008

\begin{tabular}{|l|c|c|r|r|r|}
\hline \multicolumn{4}{|c|}{ International Visitor Arrivals } & \multicolumn{1}{c|}{ Growth Rate (\%) } \\
\hline YE November & $\mathbf{2 0 0 6}$ & $\mathbf{2 0 0 7}$ & $\mathbf{2 0 0 8}$ & $\mathbf{0 6 - 0 7}$ & \multicolumn{1}{c|}{$\mathbf{0 7 - 0 8}$} \\
\hline China & 104,699 & 119,880 & 112,155 & 14.5 & -6.4 \\
\hline $\begin{array}{l}\text { Total Visitor } \\
\text { Arrivals to NZ }\end{array}$ & $2,409,582$ & $2,467,461$ & $2,453,555$ & 2.4 & -0.6 \\
\hline
\end{tabular}

Source: Statistics New Zealand, 2008

According to Tourism New Zealand (2008) Chinese inbound visitors to New Zealand on average spend approximately $\$ 3,000$ per visit, these visitors generally stay at primary regions within New Zealand, such as Auckland and Rotorua, staying between 2-4 days; this is identified as the shortest length of stay in New Zealand of any of the destination’s primary visitor markets (Tourism News, 2008). Table 2.3 illustrates the international visitor expenditure, in 2006 it is identified that Chinese expenditure was the highest over the following two years in comparison to the overall visitor expenditure in New Zealand at \$285 million (Ministry of Tourism, 2008). However, the New Zealand tourism stakeholders' opinion of the Chinese market is low yield (comm. Murray \& Osborne, 2003 in Becken, 2003); therefore the Chinese market is not as strongly promoted (comm. Schwass \& Barnes, 2003 in Becken, 2003).

Table 2-3: Chinese International Visitor Expenditure in New Zealand between YE Sep 2006-YE Sep 2008

\begin{tabular}{|l|c|r|r|r|r|}
\hline \multicolumn{2}{|c|}{ International Visitor Expenditure (NZ\$ million) } & \multicolumn{2}{c|}{ Growth Rate (\%) } \\
\hline YE September & $\mathbf{2 0 0 6}$ & $\mathbf{2 0 0 7}$ & $\mathbf{2 0 0 8}$ & $\mathbf{0 6 - 0 7}$ & $\mathbf{0 7 - 0 8}$ \\
\hline China & 285 & 268 & 241 & -5.9 & -10.4 \\
\hline $\begin{array}{l}\text { Total Visitor } \\
\text { Expenditure in } \\
\text { NZ }\end{array}$ & 5,796 & 6,021 & 6,028 & 3.9 & 0.1 \\
\hline
\end{tabular}

Source: International Visitor Survey, 2008 
A number of studies have identified that the majority of Chinese outbound travellers are from high- to middle-income groups, who are generally private enterprise owners, white-collar professionals, and/or representatives from media, sports and entertainment (Becken, 2003). However, travel statistics presented by the World Tourism Organisation (WTO) demonstrate that a large proportion of Chinese outbound travellers now travel for private reasons (57.3\% in 2001), rather than just for business (WTO, 2003 in Becken, 2003). The disposable time and income of the broad Chinese market is quite low; therefore, this market is seen to be more price sensitive, especially if they are first-time travellers (Asia Pacific Foundation of Canada, 2002 in Becken, 2003). Additionally, with limited disposable time many Chinese travellers tend to travel during national holidays such as the 'Spring Festival Week', this is also when it is easier for Chinese travellers to add an additional few weeks of leave.

Previous studies have indicated that the majority of outbound travel from China is through the travel structure of an all-inclusive coach tour; illustrating that the current number of Chinese fully independent travellers (FITs) are still quite low (Wen Pan \& Laws, 2001). According to a report by the Scandinavian Tourist Board (2002), Chinese outbound travellers normally search for experiences that involve scenery, freshness and space, with further features such as safety and cleanliness. In addition, Becken (2003) has stated that a large proportion of Chinese are also fascinated with learning about the 'outside world' and their cultures, especially Western cultures as a means of contrasting to their own lives.

Becken (2003) stated that:

"There is some belief that New Zealand is not sold at its optimum to the Chinese market, because some large companies took possession of a very specific segment (low-quality coach tours), which does not provide customer satisfaction and creates negative word-of-mouth. A similar situation is described for Australia, where Chinese travel agencies negotiate very low prices with Australian suppliers, which results in tours of a poor quality and service. Moreover, little variety is given in current products, limiting potential Chinese tourists’ choices” (p.11).

The Chinese Government still implements strict control over international media, however, a large proportion of Chinese outbound tourists depend on media (e.g. 
newspapers and television) and word-of-mouth from friends and family as a means of gathering information on prospective travel destinations (CTC, 2001, p.19 in Georg Arlt, 2006). The Internet has also become an important tool in the search for information by independent Chinese outbound tourists, specifically as a method to access information, which would generally be difficult to retrieve (Georg Arlt, 2006).

A key strategic goal of the New Zealand tourism industry is to attract a specific type of traveller, the 'interactive traveller', and the existing structure of the Chinese holiday market in one way or another meets these requirements (Becken, 2003). As commented by Becken (2003), there are still a considerable number of Chinese visitors who travel by means of tours only from Auckland to Rotorua and back; however, it is likely that the travel patterns of Chinese visitors to New Zealand will alter and follow those of other markets such as Korean or Japanese visitors.

The WTO (2003) state that there are a number of Chinese FIT (fully independent traveller), who obtain their personalised itineraries from travel agencies in China and then generate their own groups with a selected tour guide (Becken, 2003). Although these travellers are classed as fully independent, they are still travelling as a group, which demonstrates the difficultly to speed up the maturing process from tour group to FIT (fully independent traveller) or SIT (semi-independent traveller).

In a study undertaken by Ryan \& Mo (2001) the authors examined the demographics and perceptions of travel within New Zealand by 400 visitors from the People's Republic of China (PRC). The key purposes for their study was to develop the industry's knowledge of the emerging Chinese visitor market to New Zealand by way of identifying 'the socio-demographics of current Chinese visitors, assess their perceptions of New Zealand as a destination and attempt to define any specific groups that might be of interest' (Ryan \& Mo, 2001).

Table 2.4 demonstrates several key findings from the study by Ryan \& Mo (2001); firstly the majority of the respondents were male (69\%), whereas only $27 \%$ were female. Established from this finding was that it did not illustrate the gender mix of the PRC population, but more of a representation of the cultural tendency in the PRC whereby 
the male take on the task of representing the family group, with males taking on the role of the business traveller (Ryan \& Mo, 2001).

Table 2-4: Ryan \& Mo's (2001) Demographic Profile of Chinese Respondents

\begin{tabular}{|c|c|c|}
\hline Item & $\begin{array}{l}\text { Number } \\
(n=400)\end{array}$ & $\%$ \\
\hline \multicolumn{3}{|l|}{ Gender } \\
\hline Male & 277 & 69.3 \\
\hline Female & 110 & 27.5 \\
\hline Missing data & 12 & 3.2 \\
\hline \multicolumn{3}{|l|}{ Age } \\
\hline Under 14 & 0 & 0 \\
\hline $14-18$ & 4 & 1.0 \\
\hline $19-25$ & 14 & 3.5 \\
\hline $26-34$ & 93 & 23.3 \\
\hline $35-45$ & 136 & 34.0 \\
\hline $46-59$ & 122 & 30.5 \\
\hline 60 and over & 26 & 6.5 \\
\hline Missing data & 5 & 1.3 \\
\hline \multicolumn{3}{|l|}{ Education } \\
\hline Less than junior middle & 21 & 5.3 \\
\hline High School/voc high school & 92 & 23.0 \\
\hline College/university graduate & 250 & 62.5 \\
\hline Postgraduate & 32 & 8.0 \\
\hline Missing data & 4 & 1.2 \\
\hline \multicolumn{3}{|l|}{ Marital Status } \\
\hline Married & 354 & 88.5 \\
\hline Single & 36 & 9.0 \\
\hline Missing data & 10 & 2.5 \\
\hline
\end{tabular}

Source: Ryan \& Mo, 2001, p.16

Table 2.4 also depicts interesting findings in regards to the level of educational qualifications that the Chinese visitors to New Zealand hold, basically the findings were not representative of the broader population of the PRC, due to the Chinese visitors having very high educational qualifications, with $70 \%$ of the visitors having graduate or postgraduate qualifications (Ryan \& Mo, 2001). Hence, expressing that these Chinese visitors to New Zealand have a higher level of discretionary income and come from higher occupational groups in China (Ryan \& Mo, 2001).

This finding was expanded as Ryan \& Mo (2001) examined and analysed the samples via travel patterns, results demonstrated that just over $40 \%$ of the Chinese visitor sample had formerly visited Europe, illustrating a high level of prior overseas travel by the Chinese visitors studied. A quarter of the respondents had stated they had made four or 
more overseas trips prior to their visitation to New Zealand, while 6\% had stated they had made eight or more trips outside of China (Ryan \& Mo, 2001). Ryan \& Mo’s (2001) study also revealed four key factors that demonstrated reasons why Chinese visitors came to New Zealand: social investigative reasons, New Zealand-specific reasons, generalised holiday reasons, and the desire to visit a place that respondents had not previously visited (Ryan \& Mo, 2001).

The factors identified by Ryan \& Mo (2001) are essentially important to this study because it demonstrates that many Chinese visitors are influenced to travel to New Zealand because of a number of environmentally sustainable features, such as it being 'clean and unpolluted'. This study extends the research undertaken by Ryan \& Mo (2001) by investigating Chinese visitor and trip characteristics; however, differs by examining the visitors' attitudes and behaviours towards environmentally sustainable tourism in New Zealand.

Mark Frood, Tourism New Zealand's Regional Manager of North Asia, illustrates the importance of making a 'good solid presence' in the growing Asian market to ensure Chinese visitors understand what New Zealand is about as a tourist destination; however, if this is not accomplished New Zealand's capability to attract Chinese visitors will become more problematical (Tourism News, 2008).

The Chinese economy can be seen as growing at a remarkable rate, with their national GDP reaching 11.5\% in 2007 (Tourism News, 2008). In addition, the disposable incomes of Chinese have been escalating concurrently with the awareness of the outside world by the Chinese (Tourism News, 2008). In spite of this, Chinese visitors to New Zealand have encountered various issues regarding their short lengths of stay, their tendencies of taking group tours, combined with low price, low quality and shoppingfocused visits (Tourism News, 2008). Nonetheless, there are still some Chinese visitors to New Zealand that seek more than just a shopping experience, there is still a large number of Chinese visitors who are interested in different experiences which incorporate nature and culture (Tourism News, 2008). This group of Chinese visitors may still be quite small; however, a larger majority of these visitors are presenting characteristics of fully independent travellers (Tourism News, 2008). 
As a destination, New Zealand has identified how significant it is to increase Chinese visitor numbers and yield (Becken, 2003). However, New Zealand seeks to also make certain that the growth in Chinese visitors concurs with the sustainability objectives established in the New Zealand Tourism Strategy 2015 (NZTS 2015, 2008). A key component of New Zealand's Tourism Strategy 2015 is to aim to effectively employ the use of resources with regards to greenhouse gas emission as a consequence of tourist interactions (NZTS 2015, 2008).

China has become a key part of New Zealand's restoration of its approved travel agent scheme as a means of attempting to improve the low levels of Chinese visitor satisfaction (TNZ, 2005). The satisfaction of Chinese visitors has generated much concern by Tourism New Zealand due to specific findings of research that illustrated $95 \%$ of visitors to New Zealand are satisfied or more than satisfied with their experiences in New Zealand; however, the Chinese market demonstrated lower levels of satisfaction (TNZ, 2005). A potential reason for problems with the level of satisfaction of the Chinese market could be directly related to experiences with low quality tours that consist of little or no tourism activity, falsification of itineraries, over-dependence on commission-based shopping and inexperienced tour guides (TNZ, 2005). In addition, the concentrated price competition between tour operators has largely led to lower quality tours and increased dissatisfaction for Chinese visitors (TNZ, 2005). The new system essentially allows New Zealand-based inbound operators to work under the newly altered China Tour ADS System, given that these operators meet 'fit and proper person' requirements and are able to display conformity with the new Code of Conduct for ADS Tours, issued on 21 September 2007 (TNZ, 2005).

In a further examination of literature, it was acknowledged that even though different value systems and interests are visible between visitors, it can also be identified that there are certain notions that influence how New Zealand is seen as a tourist destination; however, there are a number of understandings that are shared amongst visitors in regards to their views and values concerning the environment they are visiting (Zhao, 2006). Demonstrated in the Tourism Research Summary Report (2006) findings from interviews illustrated that a majority of Chinese tourists established New Zealand's largest competitive advantage was its natural beauty (Zhao, 2006). Additionally, respondents have demonstrated that they frequently deemed New Zealand as a 'clean, 
green, fresh, peaceful' and 'unpolluted, natural, beautiful, landscape', with 'friendly people', living in a 'low populated' country (Zhao, 2006). The findings of this study corroborates New Zealand's 'pure and clean' image that has been identified as a key attraction to various sub-markets from China (Zhao, 2006).

\subsection{Sustainability}

\subsubsection{Evolution of Environmental Sustainability \& Tourism}

Sustainability has developed into a key normative framework for assessing economic, environmental and social policy (Krysiak \& Krysiak, 2006). Tourism activity can essentially be the generator of both positive and negative impacts, as tourism consumers interact directly and indirectly with natural and human environments. In this regard, the tourism industry must understand that management and control is necessary to reduce/limit environmental degradation; thus, expressing the importance of recognizing and practicing 'sustainable development' (Coccossis \& Nijkamp, 1995 in Curtin \& Dusby, 1999).

Before examining 'sustainability', it is essential to explore the history of environmental interest and the tourism industry's response to such issues. Table 2.5 illustrates an outline of the expansion of environmental interest and the broad concentration of the tourism industry by decades (Hudman, 1991).

Table 2-5: Environmental Concerns \& Tourism's Emphasis

\begin{tabular}{|l|l|l|}
\hline \multicolumn{1}{|c|}{ Era } & \multicolumn{1}{|c|}{ Environment } & \multicolumn{1}{c|}{ Tourism } \\
\hline 1950 's & Enjoy \& Use & $\begin{array}{l}\text { Age of exploration \& involvement. } \\
\text { The beginning of mass tourism. }\end{array}$ \\
\hline 1960 's & $\begin{array}{l}\text { Awareness, public involvement \& } \\
\text { protests }\end{array}$ & $\begin{array}{l}\text { Development, great growth. } \\
\text { Elements of environment as } \\
\text { attractions. }\end{array}$ \\
\hline 1970 's & $\begin{array}{l}\text { Institutionalisation, creation of } \\
\text { environmental protection agency in } \\
\text { USA. Concern over visual pollutions, } \\
\text { air \& water. }\end{array}$ & $\begin{array}{l}\text { A decade of growth \& } \\
\text { achievement. Development of } \\
\text { marketing specific to tourism. } \\
\text { Studies on impacts of tourism by } \\
\text { academics. }\end{array}$ \\
\hline 1980 's & $\begin{array}{l}\text { Concern for toxic substances in the } \\
\text { environmental: acid rain, global } \\
\text { warming, and ozone layer. }\end{array}$ & $\begin{array}{l}\text { Expanding world markets \& } \\
\text { technological advancements. }\end{array}$ \\
\hline 1990 's & $\begin{array}{l}\text { Deforestation, climate changes, } \\
\text { desertification, global impacts. }\end{array}$ & Eco-tourism \& sustainability. \\
\hline
\end{tabular}


The 1950's was an era where there was only a small amount of concern over environmental issues (Hudman, 1991). This was also the era when tourism began to boom, where a key focus for travel in the 1950's was to national parks and preservation areas (Hudman, 1991). During the 1950's economic growth was also visible in a majority of the industrialized nations, with the advancements in technology and transportation highlighting the generation of mass tourism (Hudman, 1991). The 1950's were essentially the era that led to the global upsurge of tourists (Hudman, 1991).

In the 1960's society became more aware of various environmental issues with regards to the degradation of flora and fauna, plus impacts considering air and water pollution (Hudman, 1991). In the decade of the 60's, tourism was experiencing prompt growth; with many coastal environments being developed into tourist meccas with inadequate concern by tourists or industry operators of impacts on the environment (Hudman, 1991). Nonetheless, during this time many academics published studies on the issues associated with tourism and the environment, a majority of them focused on specific case studies demonstrating the negative impacts of tourism (Hudman, 1991). The major negative impacts that were being examined by academia during the 60's also contributed to the traditional research into carrying capacity (Saarinen, 2006). However, in excess of the next two decades the method to managing and controlling the degree of negative impacts had developed into an important frame-of-mind; with a specific shift from a period of interest in the late 60's to the awareness that carrying capacity as a potentially challenging theory to put into practice in the early 80's (O’Reilly, 1986; Wall, 1982 in Saarinen, 2006).

The 70's were the decade of environmental concern regarding visual pollutions, specifically air and water, this led to many industrialised societies to generate an increase in interest over the environment and develop laws to assist in protection and conservation. However, this decade also guided the growth and importance of tourism marketing (Hudman, 1991). This era was moreover a time when academics published a large degree of studies on the impacts of tourism (Hudman, 1991). The surfacing of the concept of sustainable development has manifested a union between economic development and environmentalism (Hardy et al., 2002). This union was formally demonstrated at the Stockholm Conference on Humans and the Environment in 1972, the first of a sequence of key United Nations conferences examining numerous global 
environmental concerns (Hardy et al., 2002). The conference endorsed the notion of eco-development at which culture, social and ecological objectives which were incorporated with the notion of development (Sagasti \& Colby, 1993 in Hardy et al., 2002).

In the decade of the 80 's, the focus on visual pollutions was altered to incorporate concern regarding climate change, global warming, ozone changes, the exhaustion of natural resources, and the concern with toxic substances in the environment (Hudman, 1991; Horobin \& Long, 1996). Cooper et al., (1993) claims that there was an amalgamation of both the awareness of the harmful effects of tourism, and the generation of the environmentalist or 'green' conscious mindset in the mid to late 80's (Berry \& Ladkin, 1997). During this period of time, governments and national tourist organizations were acknowledging the issues regarding tourism-generated problems (Hudman, 1991); thus, the concept of 'sustainable development' was utilized. The interest in the impacts of tourism led to a variety of organizations, such as the World Tourism Organization (WTO), to publish articles on carrying capacity, saturation, and the management of tourism impacts (Hudman 1991). It was this acknowledgement from such tourism organizations that has affected the growth rate of tourism (Berry \& Ladkin, 1997). The Brundtland Report covers the concept of 'sustainable development' and put forward an article known as 'Our Common Future', establishing the key message of the need for a long-term identification of how to preserve the environment for future use (Berry \& Ladkin, 1997).

The 1990's were an era that brought about tourism's identification of the industry's role in environmental stability and preservation (Hudman, 1991). Essentially, the term 'sustainable development', and other terms such as 'eco-tourism' began to be used more prevalently as a means of rejuvenating the tourism industry, shifting from mass tourism to alternative tourism, and to reduce the negative impacts of the environment. Clarke (1997) proposed that the progression of the concept of 'sustainable tourism' concerned four approaches, the first pair suggest sustainable tourism as the existing control of a specific scale of tourism, whereas the second pair regard sustainable tourism as an objective to endeavour for (Swarbrooke, 1999; Clarke, 1997). 
The following describe each level of development in chronological order:

- Polar Opposites: This approach regarded sustainable tourism and mass tourism as polar opposites, with sustainable tourism being considered as small-scale tourism (Swarbrooke, 1999; Clarke, 1997).

- A Continuum: By the 1990's, the approach of polar opposites was identified as being inefficient, but rather it was recognized that there were diverse levels of sustainable and mass tourism, with the two points integrating along the spectrum (Swarbrooke, 1999; Clarke, 1997).

- Movement: This approach suggested that mass tourism was no longer regarded as the prime evil in maintaining a sustainable environment, but rather sustainable tourism became a key goal for achievement (Swarbrooke, 1999; Clarke, 1997).

- Convergence: This approach represents the latest comprehension of sustainable tourism as a primary objective that tourism attempts to attain. Convergence essentially appreciates the broader position of sustainable development, focusing on both large- and small-scale interpretations of sustainable tourism (Swarbrooke, 1999; Clarke, 1997).

Hardy et al., (2002) has generated a table (table 2.6) to assist in the chronological comprehension of the context at which sustainable tourism was developed. Table 2.6 illustrates the conceptual and operational context within which sustainable tourism was developed incorporating several vital aspects (Hardy et al., 2002).

Firstly, the development of the context of sustainable tourism through which tourism was acting in response to three central concepts: economic progression, a community foresight, with a conservation goal (Hardy et al., 2002). Yet, sustainable tourism seemed to have given more focus on economic and environmental factors, rather than the impacts on local communities (Hardy et al., 2002); this imbalance was emphasized 
in specific studies undertaken by Butler (1999), Farrell (1999) and Twining-Ward (1999).

Although sustainable tourism is seen as a concept strengthened by the social context (Hardy et al., 2002), it has not been till recently that a noticeable increase in the community and cultural vision foresight was demonstrated in the academic deliberation over the planning for sustainable tourism (Hardy et al., 2002). Academics who have taken a knowledge-based approach to tourism, such as Jafari (1990), Butler (1998) and Bramwell \& Lane (2000), have promoted that there is substantiation that to fully comprehend the concept of 'sustainable tourism', there is a need to consult and integrate the needs of various tourism stakeholders (Hardy et al., 2002). This integration of stakeholder needs should incorporate a depiction of not only the economic and environmental requirements, but also local community and socio-cultural requirements (Hardy et al., 2002).

Lastly, from table 2.6 it can be identified that a large array of theories were generated as proactive methods to respond to existing issues to facilitate variation; whereas, concepts to do specifically with tourism, such as sustainable tourism were reactive techniques to counter the increasing degree of negative affects of tourism (Hardy et al., 2002). 
Table 2-6: The Conceptual \& Operational Context within which Sustainable Tourism Developed

\begin{tabular}{|c|c|c|c|c|c|}
\hline & Economic Vision & $\begin{array}{c}\text { Conservation } \\
\text { Vision } \\
\end{array}$ & $\begin{array}{c}\text { Community } \\
\text { Vision }\end{array}$ & $\begin{array}{l}\text { Academic } \\
\text { Response }\end{array}$ & $\begin{array}{l}\text { Industry } \\
\text { Response }\end{array}$ \\
\hline 1880 & $\begin{array}{c}\text { Industrialisation } \\
\text { \& Economic } \\
\text { Growth }\end{array}$ & $\begin{array}{c}\text { Romantic } \\
\text { Visions } \\
\text { (Hall, 1998) } \\
\end{array}$ & & & $\begin{array}{c}\text { Protection of } \\
\text { Resources (e.g. } \\
\text { National Parks) }\end{array}$ \\
\hline 1940 & \begin{tabular}{l}
\multicolumn{1}{c}{ Development } \\
Stage Paradigm \\
1946: Rostow \\
1947: Marshall \\
Plan \\
\end{tabular} & $\begin{array}{l}\text { 1948: } \\
\text { Formation of } \\
\text { IUCN }\end{array}$ & & & \\
\hline 1950 & $\begin{array}{l}\text { 1951: European } \\
\text { Economic } \\
\text { Recovery } \\
\text { Programme } \\
\text { 1959: Myrdal }\end{array}$ & & & & Mass Tourism \\
\hline 1960 & $\begin{array}{l}\text { 1966: } \\
\text { Environmental } \\
\text { Economics } \\
\text { 1967: Dependency } \\
\text { Paradigm (Frank) } \\
\text { 1969: Hamilton } \\
\text { calls for } \\
\text { development to } \\
\text { conserve resources }\end{array}$ & $\begin{array}{l}\text { 1961: } \\
\text { Formation of } \\
\text { WWF }\end{array}$ & 1964: Christaller & $\begin{array}{l}\text { Advocacy } \\
\text { Approach }\end{array}$ & \\
\hline 1970 & \multicolumn{5}{|c|}{ 1972: Stockholm Conference on Humans and Environments } \\
\hline & $\begin{array}{l}\text { 1978: Ecological } \\
\text { Economics } \\
\text { (Holding) }\end{array}$ & & $\begin{array}{l}\text { 1976: Doxey’s } \\
\text { Irridex } \\
\text { 1979: Dogan's } \\
\text { Five Stages of } \\
\text { Adjustment }\end{array}$ & $\begin{array}{l}\text { 1973: Thurot \& } \\
\text { Cautionary } \\
\text { Platform } \\
\text { 1976: Miossec }\end{array}$ & \\
\hline \multirow[t]{2}{*}{1980} & & $\begin{array}{l}\text { 1980: World } \\
\text { Conservation } \\
\text { Strategy }\end{array}$ & $\begin{array}{l}\text { 1983: Schlenke } \\
\text { \& Stewig }\end{array}$ & \begin{tabular}{l}
\multicolumn{1}{c}{$\begin{array}{c}\text { Adaptancy } \\
\text { Approach }\end{array}$} \\
1980: Butler's Life \\
Cycle Model \\
1982: Dependency \\
Paradigm (Britton)
\end{tabular} & $\begin{array}{l}\text { 1982: WTO/ } \\
\text { UNEP Accord }\end{array}$ \\
\hline & \multicolumn{4}{|c|}{ 1987: Our Common Future } & $\begin{array}{c}\text { Calls for } \\
\text { Alternative } \\
\text { Tourism } \\
\end{array}$ \\
\hline \multirow[t]{3}{*}{1990} & & $\begin{array}{l}\text { 1991: Caring } \\
\text { for the Earth }\end{array}$ & & $\begin{array}{c}\text { Knowledge Based } \\
\text { Platform }\end{array}$ & $\begin{array}{c}\text { Extension } \\
\text { Guides with } \\
\text { Environmental } \\
\text { Focus } \\
\text { Sustainable } \\
\text { Tourism } \\
\text { popularisation }\end{array}$ \\
\hline & \multicolumn{4}{|c|}{ 1992: Rio Earth Summit (UNCED) } & $\begin{array}{c}\text { Agenda } 21 \text { for } \\
\text { tourism }\end{array}$ \\
\hline & & & $\begin{array}{c}\begin{array}{c}\text { Increased focus } \\
\text { on community } \\
\text { role }\end{array} \\
\text { (Simmons, 1994; } \\
\text { Bramwell \& } \\
\text { Lane, 2000) } \\
\end{array}$ & & $\begin{array}{l}\text { Cooperative } \\
\text { research } \\
\text { Centre for } \\
\text { Sustainable } \\
\text { Tourism } \\
\text { (Australia) } \\
\end{array}$ \\
\hline
\end{tabular}

Source: Hardy et al., 2002, p.489-490 
From the 1990's research on the issues regarding the impacts of tourism on the environment were established; however, this generated a new era where a number of conferences and reports were set up to assist in determining how stakeholders would be able to act pro-actively and reactively deal with such concerns. Hence, the early form of 'sustainable tourism' was established as a 'micro solution' struggling with a 'macro problem’ (Clark, 1997 in Welford, Utterhus, \& Eligh, 1999). The remainder of this subsection gives an overview of the various conferences and reports that examine sustainability and/or sustainable tourism.

This growing concern for 'sustainability' and 'sustainable tourism development' partially attributed to the Brundtland Commission Report titled 'Our Common Future' (World Commission for Economic Development (WCED), 1987 in Miller \& TwiningWard, 2005). The Brundtland Commission Report, also known as the Brundtland Report, is a public and international governmental confirmation of the requirement for a needed integration of economic and environmental concerns regarding the sustainable development discussion; yet, the report gives minimum support in relation to operational suggestions (Miller \& Twining-Ward, 2005). Apart from the obvious weaknesses to the report, there were significant statements made that merits specifically highlighting:

"Failure to manage the environment and to sustain development threatens to overwhelm all countries. Environment and development are not separate challenges, they are linked. Development cannot subsist upon a deteriorating environmental resource base; the environment cannot be protected when growth does not account for the costs of environmental destruction”

(WCED, 1987, p.37 in Miller \& Twining-Ward, 2005, p.7). 
The Brundtland Report essentially contended that sustainable development at a local and global level is only attainable through key transformations in how society is planned and controlled (UN Division for Sustainable Development, 2004). The Brundtland Report's definition of 'sustainable development' takes into consideration three key features:

1. The environment and the economy interact and are interrelated;

2. The time-scale under consideration extends into the long-term future;

3. Inter- and intra-generational equity is entailed

(UN Division for Sustainable Development, 2004)

Since the Brundtland Report, the United Nations Conference on Environment and Development (UNCED) was undertaken five years later in Rio de Janeiro, recognized as the 'Rio Earth Summit', marking a key transformation regarding sustainable development with an enhanced partnership between developed and developing nations, with extensive contribution of Non-Governmental Organizations (NGOs) (Miller \& Twining-Ward, 2005). At the Earth Summit in Rio, 1992, it was in effect the first occasion on an international level that the connection between development and conservation was largely acknowledged (Croall, 1995); communicating the interconnected relationship between the two suggestions, rather than a conflicting assumptions (Croall, 1995). The Rio Earth Summit resulted in the generation of five documents, one of which was the global action plan, 'Agenda 21' (UN Division for Sustainable Development, 2004).

Agenda 21 recognizes environmental and developmental concerns that are identified as threats to the planet in the $21^{\text {st }}$ century, setting out strategies and guidelines to embark upon such issues (UN Division for Sustainable Development, 2004). Agenda 21 has demonstrated to be especially significant, with 182 world governments signing Agenda 21 at the 1992 Rio Earth Summit, obligating to a plan of action to reach/achieve sustainable development (UN Division for Sustainable Development, 2004). 
As one of the world's key priorities, Agenda 21 is a blueprint for sustainable development, overlooking a large variety of themes and tackling a broad range of issues brought up by the concept (Roberto \& Salom, 2001). In Agenda 21 there are four primary chapters relevant to tourism:

Section I: Social \& Economic Dimensions

Section II: Conservation \& Management of Resources

Section III: Strengthening the Role of Major Groups

Section IV: Means of Implementation

(UN Division for Sustainable Development, 2004)

The World Conference on Sustainable Tourism, together managed by the World Tourism Organization (WTO) and the UN Educational, Scientific and Cultural Organization (UNESCO), took place in Lanzarote in April 1995. This conference was essentially the utilization of the principles of the Rio Declaration in relation to tourism development as a vital strategic value (Aronsson, 2000). The World Conference on Sustainable Tourism ended in two documents: the Charter for Sustainable Tourism and the Sustainable Tourism Plan of Action (Aronsson, 2000).

The Charter for Sustainable Tourism, that 'sustainable tourist development' is:

"meant any form of development, provision of amenities or tourist activity that emphasises respect for and long-term preservation of natural, cultural and social resources and makes a positive and equitable contribution to the economic development and fulfilment of people living, working or staying in these areas"

(WTO, 1995 in Roberto \& Salom, 2001, p.810)

The Sustainable Tourism Plan of Action makes an attempt to outline and explain what tourism sustainability involves:

"tourism development shall be based on criteria of sustainability, which means that it must be ecologically bearable in the long term, economically viable, as well as ethically and socially equitable for the local communities”

(WTO, 1995 in Aronsson, 2000, p.37) 


\subsubsection{Perceptions of Sustainability}

It has been illustrated that the generation of a comprehensive consensus over the concept of 'sustainability' has proven difficult (Cabezas et al., 2003), and with an estimated 60 definitions of 'sustainability' (Anonymous, 2005), it can be recognised that many academics and practitioners have identified the present increase of human movement and the continued significance of the pressure on the host ecosystems (Cabezas et al., 2003). Due to the fact that a number of analysts stating that there is no precise definition of sustainable tourism, the term is therefore occasionally assumed as an ideology and a standpoint rather than being an exact operational explanation (Clarke, 1997 in Saarinen, 2006).

According to Van der Borg et al. (1996)

"sustainability has become a central issue in much of today's tourism development literature. However the application of the concept of sustainable tourism development has largely been limited to non-urban or rural areas”

(p.308 in Pearce \& Butler, 2002, p.21)

In consideration to the statement made by Van der Borg et al. (1996), both Hunter (1995) and McKercher (1993) argue that the notion of sustainable development entails two primary characteristics: the support on the highlighting of the non-modification and conservation of the environment, whilst the tourism industry endeavours to place itself closer to development (Pearce \& Butler, 2002).

Boyd \& Butler (1996) state that it is noticeable that in the field of tourism the implementation of 'sustainability' can be expressed in a development model where the model acts as a retort to countless issues, for example: to the increasing responsiveness of the environment by society; and to various 'exogenous market pressures' to extend the tourism industry more sustainably (Pearce \& Butler, 2002).

Although the term 'sustainable development' was initially focused on the conservation and preservation of natural resources, the definition of the term is still vague, demonstrating clear difficulty in the translation and meaning of the concept (Horobin \& Long, 1996). 'Sustainable development can be interpreted differently to different 
people’ (Horobin \& Long, 1996); and therefore can incorporate not just environmental concerns but also economic and socio-cultural concerns.

As a deliberation of the United Nation's World Commission on the Environment \& Development (WCED) definition of sustainable development, Repetto (1986, p.15) has broadened the interest of the concept in this fashion:

"Sustainable development is a development strategy that manages all
assets, natural resources, and human resources, as well as financial and
physical assets, for increasing long-term wealth and well-being. Sustainable
development, as a goal rejects policies and practices that support current
living standards by depleting the productive base, including natural
resources, and that leaves future generations with poorer prospects and
greater risks than our own."

(Pearce et al., 1990, p.4 in Tosun, 2001, p.290)

In the assessment of the perspective that Repetto (1986) described of sustainable development, it was established that a number of arguments appear (Tosun, 2001). Firstly, the notion of sustainable development is principally deemed as a long-term strategy as a means to preserve and conserve the environment (Tosun, 2001). Secondly, sustainable development aims to recommend an inter- and intra- generational impartial concentration of interests (Tosun, 2001). Lastly, the concept of sustainable development is recognized as a universal recommendation which can be applied to all countries without the need to take into account the degree of development, socio-cultural and political circumstances (Tosun, 2001).

The concept of 'sustainable tourism' is still a recently explored and developed term that was generated from the common fascination with 'sustainable development' (Bramwell \& Lane, 1993; Hunter, 1995 in Horobin \& Long, 1996), and the mounting acknowledgment that tourism can present negative impacts. Essentially, the implementation of the term 'sustainable tourism' is still under development due to the uncertainty and interpretation of the concept; however, putting 'sustainable tourism' into practice continues to be dependent on the compliance and capability of individuals in the tourism industry to generate and action guidelines (Horobin \& Long, 1996). 
Sustainable tourism is generally thought to stress the environmental, social and economic components of the tourism system (Swarbrooke, 1999); leading to a definition that sustainable tourism is:

"tourism which is economically viable but does not destroy the resources on which the future of tourism will depend, notably the physical environment and the social fabric of the host community"

(Swarbrooke, 1999, p.13)

Butler (1993) expands on the above interpretation by expressing that based on literature; 'sustainable tourism' is generally intended by the following:

"tourism which is developed and maintained in an area (community, environment) in such a manner and at such a scale that it remains viable over an infinite period and does not degrade or alter the environment (human and physical) in which it exists to such a degree that it prohibits the successful development and well being of other activities and processes"

(Butler, 1993, p.29 in Butler, 1999, p.12)

Croall (1995) states that sustainable tourism will only have a minimal negative affect if all stakeholders partake in the overcoming of obstacles; however, a few of the main obstacles can be associated with mass tourism, and the traditional attitudes linked with the mass holiday market. These can also involve the strictly business-related aims of tour operators, and the issue of many other stakeholders to look past short-term visions (Croall, 1995). In general, there has been a large degree of complexity in influencing tourism businesses that tourism can be both environmentally viable and profitable simultaneously; there has also been an unwillingness by governments to constructively support their contentions on sustainability and sustainable tourism development when little or inadequate funding is made available to tourism businesses (Croall, 1995).

The tourism industry is essentially constructed from an extensive array of sectors and services, generating a wide range of interests and conflicts between stakeholders (Carey et al., 1997). Krippendorf (1987) states that: “everybody wants more business, a larger share of the market. They will move heaven and earth and use well contrived methods to reach their goal” (Carey et al., 1997, p.426). With regards to the statement made by Krippendorf (1987) it must be understood that the tour operators' main priority is to keep their businesses in operation; therefore, are not predominantly concerned in the long-term development of the overall tourism industry (Carey et al., 1997). Hence, 
alternative forms of tourism are crucial to reach a certain level of sustainable tourism development (Carey et al., 1997).

In the past, tour operators have been seen as a major contributor to the magnitude of harm triggered by mass tourism (Croall, 1995). Yet, many tour operators reject this suggestion based on the pretext that a large proportion of holidaymakers refuse to change their own travel habits and patterns, due to their need and want to escape from their daily lives (Croall, 1995). Hence, if holidaymakers conveyed their interest in search for more sustainable forms of tourism then tour operators would be more likely to change their tourism products and/or services to meet their modified needs or wants (Croall, 1995).

The production of mass low-quality tourism was generally developed from the 'getrich-quick' attitude of tour operators (Croall, 1995); and the unrestrained overdevelopment of environments for tourism. In 1992, an environmental organization, ARK, organized a campaign to attempt to alter tourists' views of environmental responsibility (Croall, 1995). During this campaign, the organization endeavoured to appeal to a number of tour operators to partake in the proceedings by putting out the initiative of incorporating information in their brochures regarding local culture; however, many of the tour operators refused to do so because they believed that it would in essence be scandalous or badgering to the tourists (Croall, 1995).

Although it may seem that it has been difficult to persuade tour operators to alter their methods of operation to act or deliver products more sustainably, it has also been problematic in attempts to alter the attitude of tourists. Sustainable tourism fundamentally signifies the encouragement of people to function in a particular way to generate a certain degree of sympathy with or awareness of the host community, or concentration on the degradation of the environment or excess-use of local resources (Croall, 1995).

Potentially tourists refuse to change their travel decisions because a key motivation is to essentially indulge in the act of relaxation; and in many circumstances this comes at the cost of the environment and possibly the traditions and culture of the host community. However, as exposure and knowledge of sustainable undertakings and procedures 
deepen, people in general have expanded their acceptance of the term and its related considerations. To investigate this further, a study conducted for the Department for Environment Food and Rural Affairs (DEFRA), in the UK, by the University of Surrey was set out to expand the understanding of the public's response to sustainable leisure and tourism (Miller et al., 2007). Participants were examined in relation to three specific areas: environmental issues in leisure and tourism choices, leisure behaviour goals, and tourism behaviour goals (Miller et al., 2007). With regards to the findings of DEFRA's study, participants did not consider the environment when making leisure and tourism choices (Miller et al., 2007).

The DEFRA study identified five primary reasons why participants did not take into account the environment when making leisure and tourism choices (Miller et al., 2007).

1. Leisure and tourism were not considered as environmental behaviours, due to the behaviours of the participants being apprehensive with satisfying the participants’ own needs or family needs (Miller et al., 2007).

2. The environmental impacts caused by leisure and tourism was not fully comprehended, with participants concentrating more on tangible effects, such as litter and pollution (Miller et al., 2007).

3. A number of participants were not apprehensive on the subject of the impacts of leisure and tourism, specifically the less tangible impacts, such as global warming (Miller et al., 2007).

4. A number of participants saw no reason to alter their leisure or tourism behaviour except when other people or countries decrease their environmental impacts (Miller et al., 2007).

5. Overall participants opposed to modifying their leisure and tourism choices for the benefit of the environment (Miller et al., 2007).

With regards to the results concerning the participants' leisure behavioural goals, findings demonstrated the reasonable willingness of participants to undertake more of their leisure activities closer to home, with the acceptance of more or improved local facilities (Miller et al., 2007). Other participants were open to or enthusiastic about utilizing public transportation when embarking on leisure activities (Miller et al., 2007). However, when examining the participants' particular tourism behavioural goals, 
participants expressed their defiance to shorter breaks rather than key holidays; yet, were willing to take into account undertaking more UK holidays (Miller et al., 2007). As demonstrated on both the leisure and tourism behaviour goals, there was confirmation illustrating the compliance of participants to carry on with their existing array of activities; however, with a higher level of thought for the environment (Miller et al., 2007).

Governments are also another key group in the raising of sustainable tourism, even though they have frequently been quite slow in regards to understanding or implementing the notion itself (Croall, 1995). Only since the early 1990's has the interest over environmental issues generated a larger proportion of awareness, at which the environmental situation has started to attain a critical level in specific regions of the world, calling for the need for grave undertaking (Croall, 1995). A report published in 1991 by the UK government's task force 'Maintaining the Balance', was seen to be a crucial step to assist in the examination of sustainable tourism (Croall, 1995). The main objective of the task force was:

\begin{abstract}
"to examine the scale and nature of the problems caused by visitor numbers at tourist sites and areas, and to examine the environmental and other benefits which tourism brings to such areas"
\end{abstract}

(Croall, 1995, p.26)

At the $7^{\text {th }}$ Annual Conference of the German Council for Sustainable Development in Berlin, 2007, Helen Clark (Former Prime Minister of New Zealand) expressed New Zealand benefiting from a reputation as a destination with a 'pristine environment' (Scoop International News, 2007). In Clark's speech it was also clear that she believed that as a country in the $21^{\text {st }}$ century, New Zealand needs to be sustainable as a means of dealing with long-term issues that may impact on the nations' primary business sectors and markets; therefore Clark expressed that "sustainability and prosperity will go handin-hand” (Scoop International News, 2007).

Further on in the Former Prime Minister's speech on sustainable development she articulates sustainability as a crucial subject in the $21^{\text {st }}$ century, and that over time New Zealand's search to become more sustainable will develop into an essential feature of “New Zealand's unique national identity” (Scoop International News, 2007). The 
Former Prime Minister expands on the issue by stating that each nation constructs their own understanding of the concept of sustainability through their own value systems; hence developing into a focal point for stakeholders and decision makers at various levels in society, may it be local or national governments, to organisations, businesses, and homes to understand such an issue (Scoop International News, 2007).

To conclude, it can be established that approaches to achieving sustainable tourism is to tackle and prevent issues generated by forms of tourism that have caused negative impacts on the environment and society. With regards to achieving a certain level of sustainability, the tourism industry is required to excel in 'greening' tourism products and services (Godfrey, 1998). The concept of sustainable tourism can be associated with the development of new products, or the targeting of new market segments; therefore as argued by Hunter \& Green (1995) it is viable to establish sustainable tourism as also recognizing the possibility responsible policies and practices (Budeanu, 2005). Sustainable tourism in New Zealand is established as a key objective in the New Zealand Tourism Strategy 2015, and to deepen the understanding of environmentally sustainable tourism in New Zealand, this study examines the Chinese visitor market and their attitudes towards sustainability. 


\section{CHAPTER 3 Methodology}

\subsection{Introduction}

In order to reach the aims of this study, it was important to select and implement a suitable research method to present an extensive assessment of the appropriate themes. It is identified by a number of researchers such as Decrop (1999) and Pearce \& Butler (1993), that the implementation of more than one source of data improves the ability to investigate the research problem through the decrease of personal and methodological predispositions to essentially increase a study's generalisability (Chen, 2002). Therefore, this study employs the use of a two-type triangulation approach on both data and method as a means of developing avenues to enhance and provide more suitable information. The two research approaches employed in this study were a quantitative approach to assess the Chinese visitors' interpretation of the research problem, and a qualitative approach to gain the understanding of the ADS inbound tour operators perception.

To provide an in-depth interpretation of the aims, certain variables were identified to ensure that all data was utilized effectively to reach the goals of this study, these variables included: visitor characteristics, trip characteristics, satisfaction, factors that impact on the visitors' decision to visit a destination, sustainable tourism in New Zealand, and New Zealand's marketing image. These variables were essentially developed from the examination of previous literature, and the needs for further research as expressed by Tourism New Zealand and the Ministry of Tourism.

This chapter therefore gives an outline of the importance of the use of secondary sources in the development of an overview of the research themes, followed by the description of the sampling method (questionnaires and interviews), data collection, research design, and limitations associated with the development and implementation of this study. An analytical framework was then developed to assist in the flow of data retrieved, but also as a means of structuring the data presented through the visitors' and suppliers’ perspective. 


\subsection{Secondary Sources}

To begin this study, secondary sources were employed as a means of developing and understanding the major foci: the Chinese visitor market, 'sustainability', and tourism in New Zealand. The secondary data was essentially utilized to assist in generating a new area of research, with the main advantages being: the ability for the researcher to save finance and time, but also to employ the secondary data for comparative analysis with primary data collected.

The Ministry of Tourism was contacted for support in providing data and information regarding the Chinese international visitor market. This data included information on the subject of the Chinese visitor demographics and characteristics such as age, gender, educations, and occupation; but also information regarding Chinese visitor trip characteristics obtained from New Zealand's International Visitor Survey (IVS). Data available from the IVS offered the research with direction and statistical locale for existing data to be utilized for a broad comparative analysis with data collected from this study. The Ministry of Tourism also assisted in approaching and contacting the Auckland International Airport to ask for permission for this research to be undertaken on their property, and as the medium of communication with COVEC, the Ministry of Tourism’s official research company.

This study also employed other statistical data and information concerning the outbound Chinese visitor market, and the New Zealand tourism industry. Apart from the Ministry of Tourism website (i.e. www.tourism.govt.nz), the Tourism New Zealand website also aided the understanding of the primary characteristics of the Chinese visitor market to New Zealand, as well as to identify the ADS (Approved Destination Status) tour operators in New Zealand, and the procedures involved in becoming an ADS registered tour operator (i.e. www.tourismnewzealand.com). Apart from utilizing websites to gather statistical data and information, articles and reports on the Chinese visitor market to other destinations were also employed in this study, for example Hanqin \& Lam (1999) in a Hong Kong context, Hemstöm, Luu \& Unenge (2006) in a Swedish context, and Ooi (2007) examining Chinese visitors to Denmark. Moreover, tourism research specifically focused on the Chinese inbound market to New Zealand was used to assess 
existing knowledge of this market, for example studies undertaken by Ryan \& Mo (2001), Chen (2002), and Zhao (2006). Yet, publications such as 'The Tourist Review', 'Tourism News', and 'China Hospitality News' also contributed to the deepened comprehension of the Chinese visitor market in New Zealand.

These secondary sources attempt to assist the researcher in examing certain aspects of the primary aims of this study. However, utilizing secondary sources was not sufficient enough to thoroughly investigate the principal aims of this study, therefore the following section illustrates the research techniques employed in this study.

\subsection{Mixed Method Approach}

This study employed a mixed method approach, using both quantitative and qualitative methods. The mixed method approach permits specific linkages to be identified between the quantitative and qualitative methods, and with this approach the researcher is better prepared to reach a more informed conclusion in regards to findings (Denscombe, 2007).

Combinations of various research methods are employed for a number of reasons when undertaking research. A primary purpose for researchers to use a mixed method approach can particularly be related to the complexity of the research problem at hand. Due to such complexity, the researcher may believe that one research method or approach is unable to systematically tackle the primary research problem (Richards \& Morse, 2007). Essentially, the core method of research in a mixed method approach is supported by the secondary method through supplementing the existing data gathered. Additionally, with a combined research strategy the overall research is less prone to compromise the validity of data (Richards \& Morse, 2007).

Essentially, this study employs the use of two research methods to examine two different respondent groups. The quantitative method is to examine the Chinese international visitor market to New Zealand, whereas the qualitative method is to study New Zealand tour operators that market New Zealand to the Chinese visitor market. 
Due to the fact that there would only be a limited amount of time available to undertake the research and to collect the data, it was difficult to gain a large sample population from either the quantitative or qualitative techniques; therefore by utilizing both methods the researcher is able to counter the issues with the size of the sample populations by gaining views from both the visitor an supplier.

Quantitative research is valuable for this research in a number of ways. Firstly, quantitative data allows for a range of statistical techniques to be employed to examine mathematical and probability principles; giving further credibility to the data and findings received (Denscombe, 2007). Secondly, quantitative research allows the researcher to arrive at other purposeful conclusions, with the ability to identify matters of causality (Veal, 1997). Thirdly, this method of research can remove or decrease the researcher's bias in regards to judgement (Veal, 1997). Fourthly, quantitative data provides the researcher with the capability to adapt to larger sample populations, escalating the generalizability of findings and distinctiveness of minor variations (Veal, 1997).

Quantitative research also has a variety of weaknesses. The first of these weaknesses involves the limited in-depth detail of information in regards to the context that is provided to the researcher. This research method is also restricted concerning the ability to manage the research environment, which would therefore make it complex to establish whether respondents were answering questions truthfully (Veal, 1997). Additionally, there are greater possibilities that quantitative data can be misinterpreted, with potential problems with data analysis (Veal, 1997).

Qualitative research is also beneficial in this study because the data that is received will be 'grounded', and will maintain the respondent's original point-of-view. Qualitative research also allows for richer and more detailed data, justifying various alternative explanations to a variety of conclusions (Denscombe, 2007). Qualitative data is primarily founded on the quality of information, essentially leading to more meaningful data, which would direct the researcher to the identification of relationships and patterns. Various methods of qualitative research also assist in obtaining a holistic view of the issue being studied, through generating the ability to gather respondent insights to refine drawbacks. 
Limitations also arise with the use of qualitative research. Qualitative research can occasionally lead away from the primary aims of the research when the researcher probes respondents for answers, there may also be a lack of consistency and reliability of data when utilizing various probing methods. With qualitative research the data may vary due to the differing levels of experience respondents may have; and with some respondents having higher levels of experience this could then limit the targetability of information (Veal, 1997). Due to the fact that the quantitative findings are unable to be generalised to the broader population, qualitative research was employed to examine relationships and complexities in this study.

In essence, the use of a mixed method approach was the best choice for this study and was strongly driven by a number of reasons; firstly, because of the size of the sample population, with the quantitative research having a larger sample than the qualitative research, and secondly because of the time and financial constraints that may impact on the validity and reliability of data collected.

\subsection{Questionnaires}

\subsubsection{Selection of Sampling Technique}

Questionnaires were employed as the quantitative method of data collection. This method is helpful when a large population is being studied; this is also an appropriate research method to examine Chinese respondents' mindsets regarding sustainable tourism, due to the ability for the researcher to receive standardized data from the same set of questions. Additionally, by employing the use of questionnaires it also allows questions to be translated into Chinese, this ensures the respondents ability to participate in the survey and comprehend questions being asked.

For the reason that the Chinese visitor market to New Zealand is still a developing visitor market to the country, little is known about their preferences and behaviours. Therefore, there are a number of limitations that arise regarding accessibility to Chinese visitors in New Zealand, for example identifying where to find the visitors, and where it would be most convenient to get the visitors to complete the questionnaires. To gain a more thorough understanding and representation of the Chinese visitors' perception of 
New Zealand, it is required for the researcher to examine or take into consideration visitor perspectives before and after the visit to New Zealand. However, this will require collecting data from the visitors' country of origin and carrying out surveys on the day the visitor is to leave or when they return to their origin. Therefore, due to resource constraints such as time and finance, this ideal data collection method was adjusted to allow the data to be collected within New Zealand. An exit survey at Auckland International Airport was thus employed to allow for questions to be asked concerning the visitors' complete trip to New Zealand, as the survey will be conducted at the end of their visit.

Questionnaires essentially rely on written information that is immediately collected from the responses given by respondents. Questionnaires can gather two types of information - 'facts' and 'opinions' (Denscombe, 2007). The 'factual information' that is gathered from the questionnaire will fundamentally expose basic information about the respondents, such as demographic characteristics. Whereas, questionnaires can also allow the researcher to examine the 'opinions' of the respondents disclosing information regarding their attitudes, insights, beliefs, preferences, reactions, and values (Denscombe, 2007).

In regards to the selection process for participants of the questionnaires, a probability sampling approach was used, as there was some idea of the likelihood that the selected participant group was representative of a sample of the larger population being studied (Denscombe, 2007). Fundamentally, in all types of research, the selection of the population sample is extremely important. This is due to the fact that the sample being a representation of the larger population examined, and to ensure findings gathered are a precise indication of the whole (Bouma, 1993). When selecting a sample, a key objective to keep in mind is "the manner in which the sample is drawn determines to what extent we can generalise from the findings” (Bouma, 1993, p.114). Basically, the only way that the data collected from a sample can be reliable in relation to the larger population is when the sample studied is revealed to represent the larger population (Bouma, 1993). Therefore, if the sample is unrepresentative of the whole, the findings of the study will be limited and erroneous. 
A stratified sampling approach was employed as the selection process for participants of the questionnaires. This sampling approach was implemented because it holds to the fundamental principle of randomness, within a specific boundary (Denscombe, 2007). This sampling approach is a combination of random selection, and deciding on participants based on certain identity or purpose characteristics (Denscombe, 2007). There are a number of conditions that can be employed to 'stratify' a population, which is specifically used to segregate a larger classification into a more defined and manageable group (Bouma, 1993). Examples of such criteria are: age; stage in the life cycle; gender; occupation; ethnicity; and more (Bouma, 1993, p.125). In regards to this study, the visitor's country of origin was used to stratify the larger population. When employing the stratified sampling method, every first Chinese international visitor was intercepted to undertake the questionnaire due to the time restrictions to undertake such a study, and the limited ability to reach this specific market.

Alternative methods to the implementation of the questionnaires were also considered, such as observation research and focus groups. However, these methods were ruled-out due to the fact that observational research being an attempt to identify rationale of tourist behaviours and preferences. Additionally, through observation the researcher is unable to positively identify who out of the observed population are the sample population, i.e. Chinese international visitor. Furthermore, with regards to focus groups there are concerns with finding available Chinese respondents who have time while on holiday in New Zealand to participate in the focus group, and with focus groups the researcher is unable to question the respondents about their entire trip in New Zealand because they may not have yet completed their visit.

\subsubsection{Design of Research Instrument}

The questionnaires were conducted as an on-site survey. This on-site user survey can either be completed by the interviewer or by the respondent (Veal, 1997). For this study a respondent-completion questionnaire was preferred for practical reasons, due mostly to the language barrier between the potential respondents and researcher. There are some advantages that arise with the use of respondent-completion questionnaires; firstly, the level of anonymity respondents can receive when being questioned on sensitive issues (Williams, 2003). However, these questionnaires also allow for less complex/short questionnaires to be analysed at a faster rate; additionally, respondent- 
completed questionnaires can reduce the danger of researcher and/or environmental bias (Williams, 2003). Alternatively, questionnaires are a useful tool when investigating a population that is from a differing nationality that may speak another language. Due to the fact that questionnaires are generally an amalgamation of both open-ended and close-ended questions, it is usually less problematic to translate from one language to another, potentially reducing language issues.

Respondent-completed questionnaires can also bring forth certain limitations. Although this form of questionnaire may seem to be cheaper and quicker to administer, the simplicity of the questionnaire, due to design may cause crucial answers to be misinterpreted by the respondent (Veal, 1997). In that regard, inadequate responses and a low degree of completion may occur; and with poor responses the study is then limited in reliability and validity (Veal, 1997). A low standard of completion of the questionnaires will also mean that there could be a bias in the data collected, which would be unrepresentative or less representative of the larger population being studied (Veal, 1997). However, within this study this was overcome by employing a mixed method approach, and taking into account the views of both the visitors and suppliers.

In terms of the design of the respondent-completion questionnaire, closed, open and likert scale questions were employed in the questionnaire distributed to the Chinese visitors. Respondents were asked closed-questions to determine their responses with regards to predesigned answers that the researcher organised to obtain certain attitudes (Williams, 2003). On the other hand, open-ended questions required respondents to answer in their own words their opinions and views of the question. In some circumstances respondents may not be as forthcoming in volunteering to answer openended questions because of a variety of reasons. Most of which involve: the questions taking longer to answer due to the fact that they require the respondent to reflect on past experiences, respondents may need to think systematically about their attitudes, or because respondents may not be as informed about the subject to answer such questions (Williams, 2003).

Whereas, likert scales require respondents to decide on their level of agreement with a certain statement; in general a five-point scale is used to denote a particular value to the response. However, for this specific study a number of different scales were employed 
to ensure that the scale utilized was suitable for the question being investigated. Essentially, likert scale measurements primarily measure activity at the ordinal level due to the responses being represented in ranking alone (Veal, 1997). Nonetheless, these types of questions are straightforward to conduct, and are easily comprehendible, with a higher likelihood of generating more reliable information. There are also key limitations with this form of questioning, there would firstly be an issue with the reproducibility of the study, and secondly, the validity of the information may be hindered by the quick interpretation of the questions by respondents (Veal, 1997).

Overall, the visitor survey examined the visitor demographics, trip characteristics, visitor satisfaction, interpretations and attitudes towards sustainable tourism in New Zealand, and New Zealand's marketing image. However, due to the language barrier that exists between the market being examined and the researcher, the questionnaires developed in English were translated into Mandarin, to ensure respondents were able to answer questions appropriately, and to their full potential. The responses received were then translated back into English to identify the key interrelationships and findings from the questionnaires.

The design of the questionnaire incorporated several segments: the first section of the visitor survey focused on the visitor demographics, trip characteristics, and satisfaction. By examining these key areas the researcher was able to tackle a major aim of this study, which was to essentially enhance existing knowledge of the Chinese visitor market to New Zealand. This section was potentially considered one of the primary segments due to the findings being employed for comparative analysis with previous research that also investigated the Chinese outbound market.

The second section examined 'sustainability', with a number of questions being utilized to address the aim of establishing whether the sustainable development of a destination influences the travel decisions of Chinese visitors and how this impacts on New Zealand's tourism industry. Moreover, this section seeks to generate a more comprehensive understanding of the Chinese visitor's view of 'sustainability'.

Lastly, the final section deals with the assessment of New Zealand's marketing image. Due to the fact that New Zealand's ' $100 \%$ PURE NZ' tourism campaign is the 
country's main promotional representations. This section will attempt to establish whether there is a need for a change in how the tourism industry caters to Chinese visitors, but also identify how effective the campaign is in reaching and attracting Chinese visitors. Finally this section will assess whether the Chinese visitor market believes sustainable tourism in New Zealand is promoted appropriately and successfully.

However, while conducting the questionnaire survey there may potentially be issues regarding the reluctance of Chinese visitors to provide truthful responses, due to the fact that criticism is seen as impolite in the Asian culture (Laabs, 1994). Yet, others may believe that being honest about their opinions and experiences in New Zealand is a good thing, for future improvements within the New Zealand tourism industry, even if they are negative aspects. Additionally, the possibility of Chinese visitors declining to participate in the study could potentially still be quite high due to the fact that many may believe that this research is inappropriate and inconsequential to them because they are only visitors to the destination, they will most likely not repeat visit, with results of this study not impacting on their daily lives (Chen, 2002).

Therefore, to counteract this issue, the researcher utilized souvenirs as a method of attracting the visitors to participate in the visitor survey. Conversely, due to the similar ethnic background of the researcher, this possibility influenced the respondents to partake in the study, but also obtain the trust of the visitors to ensure them that the data they provide will be handled with care, as a 'face' giving process for the visitors. As a key cultural influence on the Chinese visitor's participation in this study may be related to the 'face-giving' factor. 'Face' as conveyed by Ho (1976) is the respectability and/or consideration that a person can retain from others, this can also be associated with social networks and the extent to which the person is viewed by others (Hwang, 1987). This was therefore an important aspect that the researcher had to take into consideration when implementing both the questionnaires and interviews. It was essential that the researcher gave that 'face' or respectability to the respondents as a means of drawing participation, but also honesty when answering the survey questions.

\subsubsection{Data Collection}

In an attempt to stay consistent with the International Visitor Survey (IVS) the method of data collection employed for this study was an exit survey at New Zealand's primary 
international airports: Auckland, Wellington and Christchurch. However, Wellington and Christchurch were eventually excluded as sites for data collection due to the limited number of Chinese visitors exiting from this gateway. Due to the fact that permission was necessary to undertake the data collection process, there were also a number of criteria that permitted the research to be carried out at Auckland International Airport. The criteria set by Auckland International Airport entailed a COVEC escort to be with the researcher at all time while undertaking the research at the airport, the distribution of the questionnaires could only be done at the departure gates, and not outside or around the waiting lounges, and lastly the research can only be implemented for a 7-day period. As a result of the time and location constraints presented by the criteria set, the situation potentially restricted the number of Chinese international visitors to be survey, but also the development of a larger sample population. Nevertheless, a 70\% response rate was attained, and collecting data at Auckland International Airport allows for a combination of both tour group and independent visitors to be questioned for this investigation. Additionally, there is a higher density of Chinese international visitors at airports compared to other sites in New Zealand; furthermore implementing an exit survey at Auckland International Airport allows for questions to be asked regarding the entire visitor's trip to New Zealand as the survey will be completed at the end of their visit.

An alternative method of site selection was considered prior to the use of the three primary international airports, and this was to distribute the questionnaires at four major tourist destinations within New Zealand: Auckland, Wellington, Christchurch, and Queenstown. The main reason why these sites were to be chosen was due to the identification of Chinese tourist flows, and the illustration in the Tourism Leading Indicators Monitor (April 2008) that the primary Regional Tourism Organization (RTO) areas visited by Chinese holiday visitors includes are: Auckland (by $98 \%$ of Chinese holiday visitors), Rotorua (89\%), Waikato (26\%), Canterbury (14\%), Queenstown (12\%), and Fiordland (7\%) (Ministry of Tourism, 2008). Therefore, for the purpose of this study, Auckland and Rotorua was to be chosen due to these two regions receiving the majority of Chinese visitors in the North Island, with Queenstown and Christchurch chosen for the two regions representing the South Island. However, the reasons why this method was dismissed was due firstly to specifically identify a site in each location that would be non-bias environmentally, but also allow for a fair representation of the sample population. Secondly, by undertaking the study in four different locations within 
New Zealand would have meant the data collection process would have been lengthier. Thirdly, by intercepting the Chinese tourists while they are still travelling within New Zealand would mean that the researcher might re-encounter them at another research site whilst they were still travelling, but also by intercepting the visitors they may have less time to complete the questionnaires properly, and they would not have completed the trip at that stage.

Nevertheless, the location for the data collection in this study was in the waiting area at the departure gates. At the selected gates the researcher approached every person within the area to determine whether they are visitors from Mainland China (excluding those from Macau and Hong Kong), and invited the Chinese visitors to participate in the study. The selected gates consisted of departing flights that fly directly and indirectly to Mainland China through transit points. A flight schedule was employed to assist in the selection of the appropriate direct and indirect flights, which were assumed to carry a large proportion of Chinese visitors. The study was coordinated with COVEC (the research company employed to undertake the IVS) to ensure that the researcher abided by the criteria set out by Auckland International Airport. A primary reason to undertake the research at the departure gates was to reduce interference with particular activities that occur within the airport, such as duty free shopping, customs, and/or immigration procedures.

Although the survey was respondent-completed (see Appendix B and for the Chinese version see Appendix D), the researcher was available to assist the respondents if any questions occurred. Additionally, each respondent was given an information sheet (see Appendix A and for the Chinese version see Appendix C) about the research to explain what the research was about and what the information would be used for to reduce conflict and confusion. Completed questionnaires were then handed back to the researcher. However, as a result of the limited access to the major international airports in New Zealand to specifically examine Chinese visitors and to gain a more comprehensive understanding of the Chinese visitor market and 'sustainability' it was necessary to undertake face-to-face interviews with New Zealand tour operators, which will be discussed later in this chapter. 


\subsubsection{Questionnaire Limitations}

With regards to the implementation of the visitor survey at Auckland International Airport, it was identified early on in the study that the primary exit points from New Zealand was an excellent site to undertake this study on the Chinese visitor market. However, there were a number of limitations connected to gaining access and implementing the visitor survey. With regards to accessibility to Auckland International Airport, there were several issues that delayed the progress of this research, the main issue being gaining access to the data collection site. Due to the fact that the Ministry of Tourism acted as the medium of communication with the Auckland International Airport and COVEC, much was dependent on the Ministry to express the significance of this study to influence stakeholders to support the research. Nonetheless, the communications between the various stakeholders to finalize the arrangements of the study was relatively time-consuming therefore delaying the implementation of the research.

Conversely, there were also a number of limitations that occurred during the process of data collection. As expressed earlier in this chapter, the primary criteria that was stated by Auckland International Airport was that the researcher was required to be escorted by a COVEC member at all times. This was a more significant limiting factor than anticipated because the researcher was therefore unable to undertake the research on certain days and shifts due to the unavailability of COVEC escort (s). In addition, the researcher was unable to target certain flights because in some instances the COVEC interviewers were targeting different flights, so the researcher was unable to leave to target alternative flights. On the other hand, when a flight did arise that the researcher sought to target, both COVEC and the researcher attempted to reach the same sample population, which essentially reduced the total number of respondents obtained for this study. The reason why the total number of respondents obtained was reduced related to the problem when COVEC employees had interviewed a specific visitor, that participant was not asked to partake in this study, so as not to inconvenience the respondent. As such, the bulk of the completed questionnaires for this study were undertaken on the days that the researcher was personally escorted to flights that specifically went to Beijing or Shanghai, and were not being targeted by COVEC interviewers. 
In addition to the above criteria set out by the Auckland International Airport, the researcher was only given a 2 week period to complete the questionnaires; however, due to the above limitation it became difficult to reach the intended 200 completed questionnaires. However, more specifically in regards to the implementation of the visitor survey, not all Chinese visitors were keen on participating in the study. The reasons why some visitors refused participation in this study involved: privacy reasons, the visitor may not have trusted the researcher with their information, the visitor may not have felt the research was significant enough to participate in, and/or the visitor may have felt the questionnaire would take too long to complete prior to their departure. Nonetheless, many respondents decided to participate in the survey when they realized that a certain degree of 'face' and cultural respect was given to participants, through the presentation of a small souvenir.

\subsection{Interviews}

\subsubsection{Selection of Sampling Technique}

Interviews were employed as the secondary form of data collection and was a key research method in this study to gather 'factual information' with regards to the suppliers' point of view. However, the interviews were also employed to explore more multifaceted and delicate relationships and occurrences (Denscombe, 2007). Interviews enable the researcher to get respondents to expand and explain further their 'opinions', giving an additional insightful understanding of data, with the ability to arrange alternative explanations to conclusions (Denscombe, 2007). Nonetheless, the form of interview utilized and the methods in which the interviews are implemented will essentially depend on the research question and methodology (Richards \& Morse, 2007).

A non-probability sampling approach was implemented in the selection of participants for the interviews, because this study attempts to develop an understanding of certain concepts and circumstantial factors such as 'sustainability' and the Chinese visitor market. The face-to-face interview technique was employed to investigate inbound tour operators. Interviewees were selected from a list of ADS registered New Zealand tour operators found on the Tourism New Zealand website (www.tourismnewzealand.com). The ADS, also known as 'The Tourism New Zealand China Group Tour Approved 
Destination Status System', involves the approval of New Zealand based inbound tour operators which operate within the China ADS system and monitoring their conduct, performance and quality standards (TNZ, 2008). Furthermore, no specific sampling method was employed, due to the limited number of ADS inbound tour operators that promote and market their products to visitors from China.

\subsubsection{Design of Research Instrument}

In reality interviews have shifting forms of structure, yet all respondents generally get a set subject with the researcher having a potential list of questions that would likely be investigated during the interview. In this study semi-structured interviews were carried out to examine the key issues. Like structured interviews, semi-structured interviews allow the researcher to associate the responses from the questionnaire with answers to structured questions asked in the interviews. For the semi-structured interviews the researcher developed open-ended questions prior to the interviews, arranged in a fairly orderly manner. Generally, the interviewees were asked the same questions by the researcher, however, the order of the questions maybe different and the probes may vary from planned and unplanned. Semi-structured interviews was more appropriate because the researcher had some sense of knowledge of the topic being investigated, therefore offering the researcher more systematisation and ease of question delivery with preplanned questions (Richards \& Morse, 2007). Additionally, in semi-structured interviews the interviewer is able to be more accommodating in regards to the order of questions being asked; additionally, semi-structured interviews permits interviewees to speak more liberally about broader issues introduced by the researcher (Denscombe, 2007).

The development of the interview schedule for this study was generated from a number of components; the main two aspects include previous literature, and the questionnaires that were distributed to the Chinese visitors. The primary motivation for utilizing past literature in developing the interview schedule related directly to: identifying the research gaps and cultivating questions to tackle the disparities. Whereas, the questions in the questionnaires, and the responses given by the respondents of the questionnaires were also employed to generate the interview schedule because the researcher was able to establish areas that needed to be examined further but from the suppliers' perspective. By gaining the suppliers perspective the researcher is able to undertake a comparative 
analysis between the visitors perspective, but also to produce a more in-depth understanding of both the Chinese visitor market and 'sustainability' (see Appendix F). The primary aims of the interviews were to: develop existing knowledge of the Chinese visitor market to New Zealand, to attain an improved understanding of the tour operators' view of 'sustainability', to establish if the tour operators believe New Zealand is a sustainable tourist destination, and to ascertain how the tour operators promote sustainable tourism in New Zealand to their customers.

Although the interviews were estimated to take approximately 30 minutes, the actual duration of the interviews differed between interviewees, this was due to the interviewees having different views and perceptions, but also if an interviewee developed an interesting point the researcher may have employed an unplanned probing question. Therefore, interviews took between 20-40 minutes to complete, differing between interviewees. With the study attempting to comprehend various concepts and circumstances connected to 'sustainability', the face-to-face interview method was seen as most suitable to extend insight and awareness.

Unstructured interviews were also considered as a substitute for the semi-structured interviews, however, was not implemented because this method would be difficult for the researcher to obtain a complete understanding of the subject without having a list of planned questions that would assist in interpreting the aims of the study. Telephone and email interviewing was considered as alternative forms of qualitative data collection methods; however, there are particular disadvantages that occur with these interviewing methods. For example, with telephone interviewing there is generally a lesser response rate than many other forms of interviewing such as face-to-face, therefore in many circumstances telephone interviews need to be much shorter (Williams, 2003). This form of interviewing can mean that respondents are able to terminate the interview when they wish, and without notification or justification, by hanging up the telephone (Williams, 2003).

\subsubsection{Data Collection}

At the time of sampling and data collection only nineteen inbound tour operators were registered on the ADS list, eighteen of the tour operators were located in Auckland, with the only one tour operator located in Christchurch therefore was excluded from the 
study, but this tour operator was also excluded because of resource constraints such as time and finance.

From the eighteen ADS registered tour operators located in Auckland all were firstly contacted via a postal letter informing the managers of the organizations about this study, the importance of the study, what the interviews will entail, and what the data or information will be used for (see Appendix E). After the letters were sent, telephone calls and emails were employed to confirm whether the tour operators would participate in the interviews. All were contacted, with nine tour operators accepting to participate, six declining, and three non-responses to the request for participation; therefore receiving a $36.8 \%$ response rate. Two of the tour operators that had agreed to participate in the interview, however did not turn up to the interview appointment, therefore resulting in only seven completed interviews.

It is understood that the interview data may have been more meaningful if the sample population was larger, however, due to the fact that only ADS tour operators were employed as the sample population there would unquestionably be some who would decline participation. ADS registered tour operators were the only operators examined because this group clearly target and cater to the Chinese visitor market, but also because these tour operators are part of the ADS programme, essentially meaning the operators will all abide by similar rules and regulations in the operation of their tours for the Chinese visitor market.

\subsubsection{Interview Limitations}

Although the interviews contributed greatly to the information gathered in the questionnaires, there were a number of limitations that occurred during the implementation of the interviews. The primary issues that arose was the fact that this study did not implement the use of any form of sampling technique, due to the fact that there was only nineteen ADS registered inbound tour operators. Moreover, it was difficult to influence the ADS registered tour operators to participate in the interviews, the researcher could have considered undertaking the study on non-ADS registered tour operators; however, this would have impacted on the consistency in the actual tour operators interviewed. There was also a problem in proving the importance of this research and attaining value from the ADS tour operators that this study would assist 
their understanding of the Chinese visitor market and the New Zealand tourism industry. However, with regards to the difficulty in the implementation of the interviews, there were concerns and struggles with asking all the interview questions during the interviews because some interviewees did not understand or have not heard of vital areas of the study, for example 'sustainability', 'sustainable tourist destinations', and the 'New Zealand Tourism Strategy 2015'.

Conversely, there were problems with communicating and potentially transcribing the tour operator interviews due to language barriers, which also impacted on the understanding of some interview questions by tour operators. Although the inbound tour operators interviewed were all based in New Zealand not all spoke and understood English at the same level. This was understandable due to the fact that the majority of the operators specifically target the Chinese visitor market; hence, communication in their clients' mother tongue is essential. Yet, this generated a number of communication issues between the interviewee and the researcher, because the researcher was unable to communicate with the interviewee in Mandarin.

\subsection{Data Analysis}

The data analysis process of this research was fundamentally guided by an analytical framework (figure 3.1), which displays the researcher's structure for contextualizing and analysing the data collected in this study. Essentially, the analytical framework assists both the researcher and the reader in identifying specific components of the data, in particular which features of the data the researcher should place more attention to with regards to analysis. The analytical framework demonstrates the examination of both the perspectives of the Chinese visitor to New Zealand, and the ADS registered tour operators in New Zealand. This particular integrative approach arguably gives a general level of knowledge of both the consumers and suppliers of tourism in New Zealand, conveying an extensive picture of the relationships that occur within the tourism industry in New Zealand. 


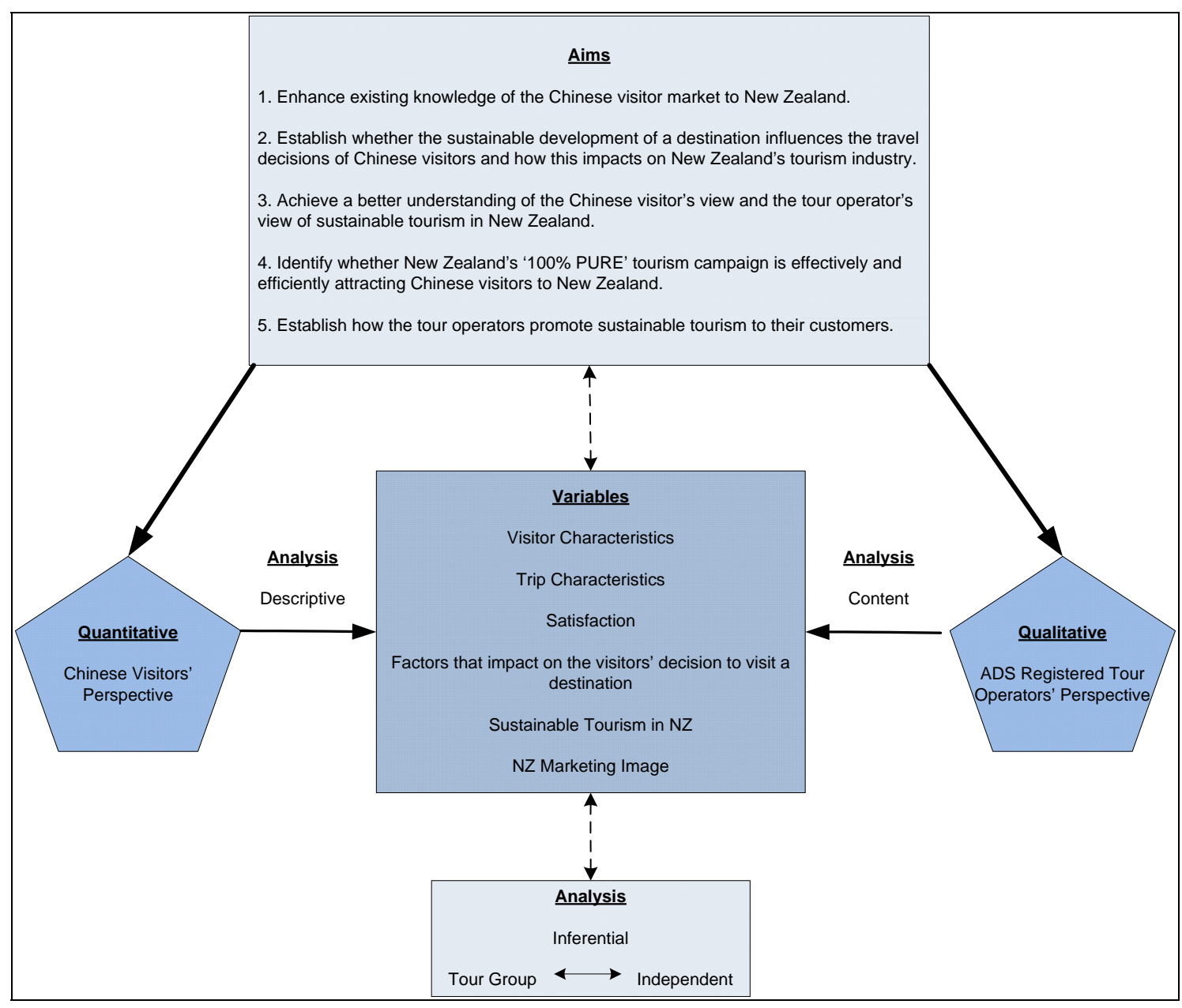

With regard to the analysis of the quantitative data, responses were coded to aid the overall numerical understanding of the data collected; however, open-ended responses were kept in the original form. Due to the fact that the majority of the Chinese respondents answered in Chinese, open-ended responses were translated back into English to allow the researcher to analyse data further. As a result of the constant need for translation, it is established that there may have been certain pieces of information that would have been 'lost in translation', thus reducing the reliability and validity of data. Hence, increasing the importance of employing the use of both quantitative and qualitative research techniques.

The analysis of the quantitative data extracted from the Chinese visitor questionnaires the visitor perspective was divided into two parts. The first part involved the general interest in descriptive statistics and acquiring how common a particular occurrence may take place (frequencies), the mean array of data collected, but also the degree of 
inconsistencies within the data (for example, central tendencies and differences between variables) (Cavana, Delahaye, \& Sekaran, 2001).

The second part of the quantitative analysis examined the inferential statistics. Inferential statistics assist the researcher in identifying how variables are associated with one another, and establish whether differences appeared between differing groups, i.e. tour group visitors and independent travellers (Cavana, Delahaye, \& Sekaran, 2001). It is conveyed in the International Visitor Survey (IVS) that there are several types of travellers that visit New Zealand; therefore the variable 'travel structure' was employed in the cross-tabulations of this study. The travel structures that were expressed in the IVS are: tour group, package traveller, fully independent traveller (FIT), and semiindependent traveller (SIT). Due to the fact that there are so many categories, this study examined the similarities and differences between two specific travel structures that encompass the characteristics of the broader categories, these were the total package traveller (classified as a traveller that has both the characteristics to be determined as a tour group and package traveller), and the total independent traveller (classified as a traveller that has both characteristics to be determined as a FIT and SIT) (TNZ, 2008). For the purpose of this study, the total package traveller was referred to as 'tour group visitors' and total independent travellers were referred to as 'independent travellers'. Travel structure was also employed as a variable in this study due to the interest in the diverse forms of travel, i.e. tour group and fully independent travellers (FITs). The reason for the interest can be related to the lack of literature on the Chinese visitor market and the types of travel style they employ, this variable will also expand knowledge on the homogeneity of the Chinese visitor market to New Zealand. But more particularly implementing the use of travel structure will benefit this study by permitting detailed information to be established about the Chinese outbound market not yet recognized in literature.

The statistical analysis program SPSS was employed to investigate both descriptive and inferential statistics, to essentially examine the primary objective of this study, which is to generate a greater understanding of the Chinese visitor market to New Zealand and to extend existing knowledge of 'sustainability'. With regards to the development of inferential statistics, chi-square and t-tests were employed to examine the extent to which there were significant statistical differences between Chinese tour group visitors 
and independent travellers. The chi-square tests were utilized to assess the differences with variables, but more specifically to determine whether a relationship exists between two cross-tabulated variables is significant. With chi-square there are a number of criteria involved, for example, no more than $20 \%$ of the cells are able to have an expected frequency of less than 5 , and if this criterion is infringed the chi-square test will give deceptive results. Therefore, when this situation does occur the significance level expressed for the Likelihood Ratio is utilized instead of the Pearson chi-square (Cavana, Delahaye, \& Sekaran, 2001). Whereas, t-tests were undertaken to investigate the means and standard deviations between two groups with regards to changing variables to establish if a significant relationship exists between the variables (Cavana, Delahaye, \& Sekaran, 2001). With regards to both the chi-square and t-tests the most frequent significant level $(\alpha)$ of 5 percent was employed ( $\alpha=0.05$ ) (Cavana, Delahaye, \& Sekaran, 2001). The significance level and the confidence level are interrelated concepts, i.e. with the significance level of 5 percent $(\alpha=0.05)$ the confidence level equals 95 percent (Cavana, Delahaye, \& Sekaran, 2001).

In essence, the researcher endeavours to identify relationships between data, let it be within the quantitative data, qualitative data, or between both the quantitative and qualitative data. Firstly, the visitor characteristics, trip characteristics, and satisfaction were examined from the quantitative data to essentially extend the existing knowledge of the Chinese visitor market to New Zealand. Visitor characteristics and trip characteristics were basically observed to gain a descriptive profile of the Chinese visitors to New Zealand. The descriptive data collected on the Chinese visitors to New Zealand, such as visitor demographic profile, and trip characteristics allows the data to be used for basic comparative analysis with other studies and between different groups. By comparing primary and secondary data similarities and differences can be established acknowledging statements made regarding whether the market has changed concerning development and maturity. As part of developing descriptive analysis on the Chinese visitor market to New Zealand the level of visitor satisfaction was also investigated. The reason why the visitor satisfaction was studied is due to assist in identifying whether the New Zealand tourism industry is offering Chinese visitors tourism products that are meeting their needs and wants. 
In regards to satisfying the other aims of this study various components were examined, such as the factors impacting on the visitors' decision to visit New Zealand, sustainability, sustainable tourism in New Zealand, and New Zealand's marketing image. Fundamentally, by investigating the factors impacting on the visitors' decision to visit New Zealand the study is able to establish if the findings correspond with the aim to ascertain if the sustainable development of a destination affects the Chinese visitors' travel decisions. In a separate section of this study the concept of 'sustainability' was observed in association with opinions concerning sustainable tourism in New Zealand. In this section of the study the analysis of the questionnaires endeavour to investigate the views of 'sustainability' by the Chinese visitors; in addition, this analysis will also assist in identifying whether the visitors believe New Zealand to be a sustainable tourism destination. In the last segment of the questionnaire analysis New Zealand's marketing image was studied to establish if the Chinese visitors thought 'sustainability' in New Zealand is promoted appropriately.

For the analysis of the qualitative section of this study, the semi-structured interviews that were implemented to investigate ADS registered tour operators was effectively employed to refine the significance of questions concerning the Chinese visitor market, and in particular clarifying attitudes towards sustainable tourism in New Zealand. After the completion of the interviews the transcribing of the tape recordings took place, due to the fact that communications with interviewees were still fresh in the mind of the researcher. Notes that were taken by the researcher during the interviews were also used in the content analysis of the interviews to help ascertain explicit themes linking to the aims of this research. Themes were then examined from the transcribed interviews, and were then discussed to identify any specific trends. 


\section{CHAPTER 4 Quantitative Analysis - Chinese Visitors' Perspective}

\subsection{Introduction}

The quantitative analysis chapter is a segment that examines the questionnaires completed by Chinese visitors to New Zealand. The questionnaire was generated to gain a visitors' perspective on sustainable tourism in New Zealand, and to extend the existing knowledge of the Chinese visitor market to New Zealand. Due to the growing importance of the Chinese visitor market to New Zealand, it is necessary to examine further the various factors that may impact on the visitors' preferences and travel behaviours. This chapter was divided into two parts; the first part entailed the overview of the frequencies linked to the variables demonstrating the general demographics, trip features, and travel preferences and behaviours of the Chinese visitors. Whereas, the second part examined the questionnaire data further by undertaking statistical testing such as, chi-square, and t-tests, on travel structure: tour group and independent travellers. Distinguishing and evaluating the similarities and differences between Chinese tour group and independent travellers allows a more comprehensive interpretation of whether the Chinese market is as homogenous as previously suggested. The main purpose of this chapter is to broaden the understanding of the Chinese visitor market, the visitors' view with regards to sustainable tourism in New Zealand, the impact of environmental sustainability on the visitors' decision to visit a destination, and in essence the effectiveness of the New Zealand tourism campaign.

\subsection{Part 1}

\subsubsection{Visitor Characteristics}

In total 100 Chinese international visitors exiting New Zealand from Auckland International Airport were intercepted in this study, with only 70 visitors accepting to participate in this research, it resulted in a 70\% response rate. Out of the 70 Mainland Chinese international visitors studied there was almost a 50:50 split between the two genders, with $51.4 \%$ females, and $48.6 \%$ males (table 4.1 ). According to a study 
undertaken by the Swedish Tourist Authority (2004), it was identified that there are a larger proportion of male travellers from China travelling internationally than there are female; however, this study found that there were slightly more female Chinese visitors than male, this could be due to a number of reasons such as the changes in the role of gender within China itself, the increase in leisure travel within the general Chinese population, or possibly the response rate of this study. The majority of the respondents were in the age groups of $30-49$ (47.1\%), with $31.4 \%$ of the sample population $18-29$ years, and 21.5\% over 50 years old (table 4.1). The International Visitor Survey (IVS) statistics indicate that the median age of Chinese visitors to New Zealand is 44.5 years old, which shows close resemblance to the results of this study that specifies the majority of respondents being between 30-49 years (47.1\%) (Ministry of Tourism, 2008).

With regard to the occupation of the Chinese visitors, it was identified that the larger proportion of the respondents work in a skilled profession (34.4\%), followed by those working in a professional job (17.2\%), students (10\%), self-employed (9.9\%), and then those working in an administrative position (7.1\%) (table 4.1). Of the respondents that work within a skilled profession, $18.6 \%$ of the total respondents work as teachers, comprising the largest percentage of total responses. However, it was also established that respondents who work within the professions of telecommunications (7.1\%), and property development (7.1\%) were seen as a predominant career for the respondents examined. In terms of occupation, prior research has suggested that a key number of Chinese outbound travellers are from high- to middle-income groups, who are by and large entrepreneurs, white-collar professionals, and/or representatives from media, sports and entertainment (Becken, 2003). This was also clearly identified in this study, as a considerable number of Chinese respondents stated they were either in managerial, administrative or qualified employment positions. 
Table 4-1: Visitor Profile

\begin{tabular}{|c|c|}
\hline Characteristic & Chinese International Visitor (\%) \\
\hline $\begin{array}{l}\text { Gender: } \\
\text { Male } \\
\text { Female }\end{array}$ & $\begin{array}{r}\mathbf{n}=\mathbf{7 0} \\
48.6 \% \\
51.4 \%\end{array}$ \\
\hline $\begin{array}{l}\text { Age Group: } \\
\text { 18-29 years } \\
30-49 \text { years } \\
50-69 \text { years }\end{array}$ & $\begin{array}{r}\mathbf{n}=70 \\
31.4 \% \\
47.1 \% \\
21.4 \%\end{array}$ \\
\hline $\begin{array}{l}\text { Occupation: } \\
\text { Skilled } \\
\text { Professional } \\
\text { Student } \\
\text { Self-employed } \\
\text { Administrative } \\
\text { Managerial } \\
\text { Service } \\
\text { Clerical } \\
\text { Semi-skilled } \\
\text { Not Specified } \\
\text { Retired }\end{array}$ & $\begin{array}{r}\mathbf{n}=70 \\
34.4 \% \\
17.2 \% \\
10 \% \\
9.9 \% \\
7.1 \% \\
5.7 \% \\
5.7 \% \\
2.8 \% \\
2.8 \% \\
2.9 \% \\
1.4 \%\end{array}$ \\
\hline $\begin{array}{l}\text { Place of Residence in Mainland China: } \\
\text { North China } \\
\text { South Central China } \\
\text { East China } \\
\text { Northwest China } \\
\text { Southwest China } \\
\text { Northeast China }\end{array}$ & $\begin{array}{r}\mathbf{n}=70 \\
9.9 \% \\
22.9 \% \\
67.1 \% \\
0 \% \\
0 \% \\
0 \%\end{array}$ \\
\hline
\end{tabular}

By examining the visitor characteristics of the Chinese respondents it was established that the most common places of residence of the respondents were within the Eastern region of China (67.1\%), along side those from the Southern region (22.9\%), and then the respondents from the Northern region (table 4.1). From the results it was identified that there were no Chinese visitors that travelled to New Zealand from the Northwest, Southwest, or Northeast regions of China. From the total respondent population the largest proportion stated that their main place of residence was Shanghai (48.6\%); whilst, Hu Bei (10\%), and Beijing (7.1\%) follow. It is acknowledged that the above cities and/or provinces are from differing regions within China (as illustrated in figure 4.1), i.e. Shanghai is within the Eastern region, Hu Bei is within the Southern region and Beijing within the Northern region of China. Therefore, possibly demonstrating the 
fact that the Chinese visitor market to New Zealand does not appear to only come from one region within China, but visitors come from a variety of cities and/or provinces.

Figure 4-1: Map of China and the Primary Regions

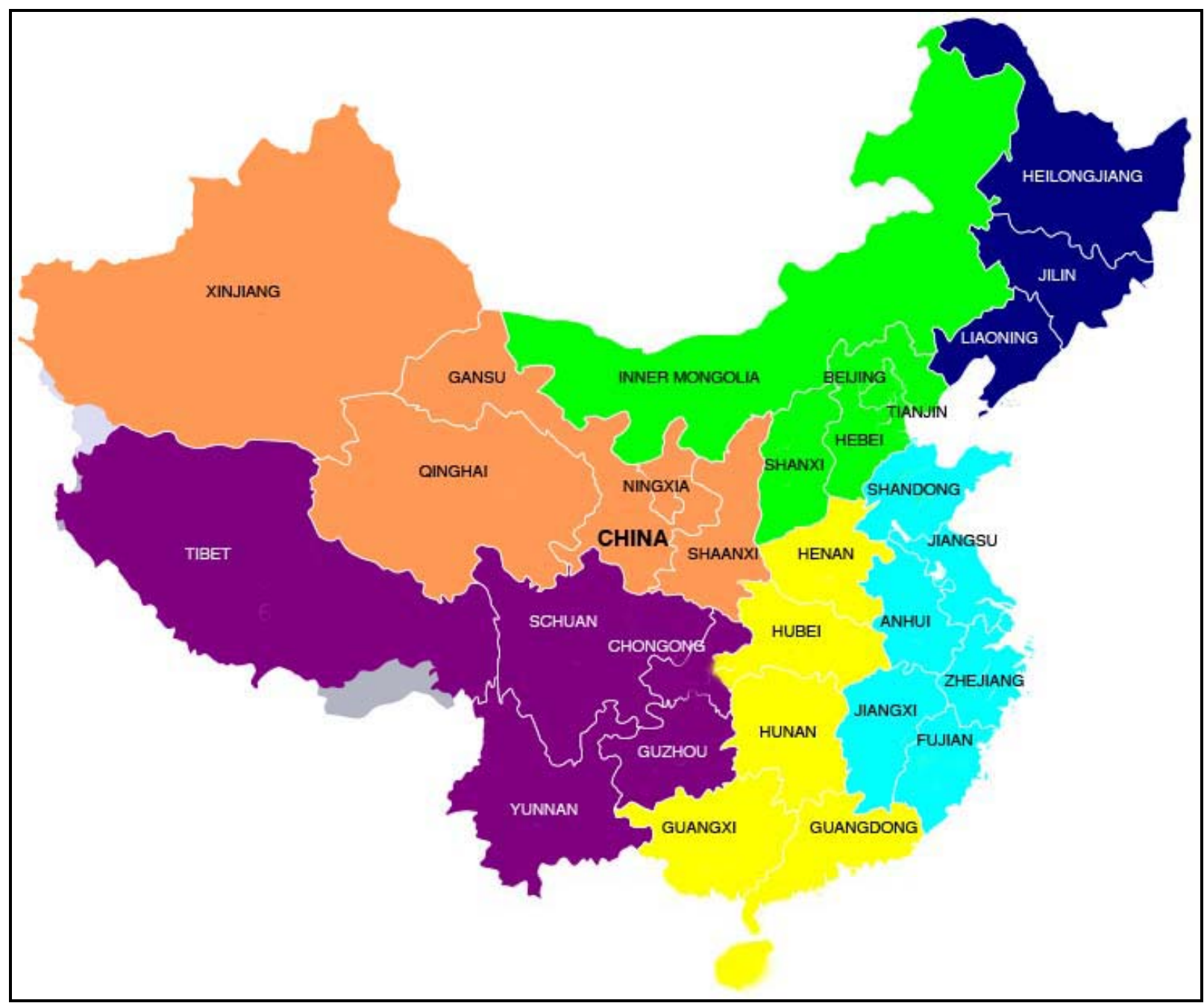

Key

Source: Wikipedia, 2008

Orange $=$ Northwest

Purple $=$ Southwest

Yellow $=$ South Central

Cyan $=$ East

Green $=$ North

Blue $=$ Northeast

Direct flights from Auckland to Shanghai, launched by Air New Zealand in 2006, could play a role in the majority of respondents reporting they were from Shanghai. Air New Zealand also launched direct flights from Auckland to Beijing early July 2008; in spite of this, during the period that this study was undertaken the numbers of visitors from Beijing were low compared to those coming from Shanghai. However, as previous 
studies have demonstrated cities within China such as Guangzhou, Beijing and Shanghai have the highest percentages of outbound travel from China (Zhao, 2006), and exhibit a wider spread proportion of mature, middle class Chinese who are experienced travellers who have travelled internationally two to three times, who travel independently or with their families (Tourism Business, 2007). With regard to the above statement, the average earnings of employed persons by regions within China demonstrate that both Beijing (39684yuan) and Shanghai (37585yuan) have the highest average income within China, thus illustrating people within these regions should have a higher level of disposable income (National Bureau of Statistics of China, 2008). However, this was not clearly identified in the number of visitors that travelled to New Zealand from Beijing during the period of this research, this could have been due to the time that this research was being undertaken, because of the Sichuan earthquake that occurred May in 2008, the Beijing Olympics; but more specifically because less Auckland to Beijing flights were able to be targeted during the data collection period (as expressed in methodology).

\subsubsection{Trip Characteristics}

As illustrated in table 4.2, responses from this study indicated that the length of stay in New Zealand was between one night and 60 nights. The most common lengths of stay was 5 nights (18.6\%), followed by 6 nights (12.9\%), and 3 nights (10\%), with the mean length of stay of 12.63 nights, and a median of 6 nights. There was also one respondent that stated he/she only stayed in New Zealand for one night (1.4\%); however, 3 respondents stated they visited New Zealand for 60 nights (4.3\%). According to statistics presented by Tourism New Zealand, Chinese visitors to New Zealand stay between 2-4 days (TNZ, 2008), with the median length of stay for Chinese holiday visitors to New Zealand of 3 days (YE March 2008), which is identified as the shortest length of stay of any of New Zealand's target visitor markets (Tourism News, 2008). Conversely, this study found that the largest proportion of respondents stayed in New Zealand for 4-7 nights (47.1\%). 
Table 4-2: Trip Characteristics

\begin{tabular}{|l|r|}
\hline \multicolumn{1}{|c|}{ Characteristic } & Chinese International Visitor (\%) \\
\hline Length of Stay: & $\mathbf{n = 7 0}$ \\
\hline 1-3 nights & $14.3 \%$ \\
$4-7$ nights & $47.1 \%$ \\
8-14 nights & $15.7 \%$ \\
15-22 nights & $2.9 \%$ \\
$23-30$ nights & $4.3 \%$ \\
31 nights or more & $15.7 \%$ \\
\hline New Zealand Island Visited: & $\mathbf{n = 6 8}$ \\
North Island only & $48.5 \%$ \\
South Island only & $4.4 \%$ \\
Both North \& South Island & $47.1 \%$ \\
\hline Travel Structure: & \\
With a tour group & $\mathbf{n = 7 0}$ \\
Independently & $54.3 \%$ \\
& $45.7 \%$ \\
\hline
\end{tabular}

In the evaluation of the New Zealand Islands that respondents visited, from the 68 responses $47.1 \%$ reported that they travelled to both the North and South Islands during their travels in New Zealand, with $48.5 \%$ of the visitors travelling only to the North Island, and $4.4 \%$ of visitors travelling only to the South Island. A possible reason why more respondents travelled only to the North Island rather than the South Island could be due to the fact that the visitor survey was only conducted at Auckland International Airport, and the visitors that may have only visited the South Island were overlooked if they exited from Christchurch International Airport. Alternatively, a greater number of Chinese visitors travelled to the North Island rather than the South Island because the North Island potentially has a larger variety of predominant activities and/or attractions within a smaller spatial spread, for example Auckland, Rotorua, and Taupo. Signifying that with a smaller spatial spread and considering the principal length of stay for Chinese visitors to New Zealand of 1 to 5 nights; visitors are able to undertake a larger array of activities and stopover at more attractions. The median length of stay for Chinese holiday visitors as expressed by the Ministry of Tourism (YE March 2008) was 3 days; however, this demonstrated a divergence in the results depicted in this study, as the median length of stay was 6 nights, which is clearly higher then that illustrated by the Ministry of Tourism, this will be examined further in the discussion section of this study. 
From the results of the study, and as illustrated in table 4.2, it was identified that there were a larger percentage of respondents travelling around New Zealand with a tour group (54.3\%); than there were independent Chinese travellers (45.7\%). This is not unexpected, due to the fact that it has been documented that most of the current outbound travel from China travel with tour groups or all-inclusive coach tours, demonstrating the limited number of fully independent travellers (FITs) (Wen Pan \& Laws, 2001). Then again, this study illustrates that there is not a large difference in the number of tour group travellers and FITs as may have previously been recognized, demonstrating the maturing of the Chinese outbound visitor market. With consideration to the maturing of the Chinese visitor market, this can be established by the close correspondence between the number of tour group travellers and FIT, indicating the increasing number of FIT; but also the developing travel experience of the Chinese visitors, and the increased accessibility to destinations, such as New Zealand.

When asked if the respondents had travelled internationally in the last 5 years (excluding Macau and Hong Kong), 67.1\% of the 70 respondents expressed they had (table 4.3). From the 47 respondents who had, 87.2\% travelled internationally between 1-3 times. The mode number of trips taken internationally by the respondents was 2 trips (40.4\%), with the mean number of trips taken at 2.51 trips. Additionally, when examining the travel behaviours of the Chinese outbound market, it was recognized that in 2001 over 12 million Chinese visitors travelled internationally; however, these trips were mainly made to Hong Kong, Macau, Thailand, Japan, Russia, United States, Korea and Singapore (WTO, 2003 cited in Becken, 2003, p.1). Hence, demonstrating that the Chinese outbound market has become an increasingly well-travelled visitor market.

From the respondents questioned, 87.1\% demonstrated that they have not previously visited New Zealand (table 4.3). However, from the $12.9 \%$ that had the majority reported having visited either once or twice (55.6\%). Out of the nine respondents expressing they have previously visited New Zealand, only one respondent stated they have previously visited a total of 25 times (11.1\%), which was the largest number of trips previously made by respondents to New Zealand. With a mean number of previous trips made to New Zealand at 5.33. 
Table 4-3: Trip Characteristics - Travelled Internationally/New Zealand

\begin{tabular}{|c|c|}
\hline Characteristic & Chinese International Visitor (\%) \\
\hline $\begin{array}{l}\text { Have respondents travelled internationally in the last } 5 \\
\text { years? }\end{array}$ & $\mathbf{n}=\mathbf{7 0}$ \\
\hline Yes & $67.1 \%$ \\
\hline No & $32.9 \%$ \\
\hline Number of international trips taken in the last 5 years: & $\mathrm{n}=\mathbf{4 7}$ \\
\hline 1 trip & $31.9 \%$ \\
\hline 2 trips & $40.4 \%$ \\
\hline 3 trips & $14.9 \%$ \\
\hline 4 trips & $2.1 \%$ \\
\hline 5 trips & $4.3 \%$ \\
\hline 10 trips & $6.4 \%$ \\
\hline Have respondents previously visited New Zealand? & $\mathbf{n}=\mathbf{7 0}$ \\
\hline Yes & $12.9 \%$ \\
\hline No & $87.1 \%$ \\
\hline Number of times previously visited New Zealand: & $\mathbf{n}=\mathbf{9}$ \\
\hline 1 trip & $33.3 \%$ \\
\hline 2 trips & $22.2 \%$ \\
\hline 4 trips & $11.1 \%$ \\
\hline 5 trips & $11.1 \%$ \\
\hline 7 trips & $11.1 \%$ \\
\hline 25 trips & $11.1 \%$ \\
\hline
\end{tabular}

In the questionnaire, respondents were asked to state whether they visited another country before arriving into New Zealand, and whether they were going to visit another country after departing New Zealand. By asking respondents these questions, the researcher is able to identify if there is a possibility that the Chinese visitors that come to New Zealand are on a tour linked with a trip to other destinations. The results from the sample population illustrated that $44.3 \%$ of the 70 respondents had visited another country before arriving in New Zealand (table 4.4). From these respondents that stated they had visited another country before arriving in New Zealand, 84.4\% had reported that they had visited Australia, followed by the United States of America (6.2\%). Of the 70 respondents, $87.1 \%$ expressed that they would not be visiting another country after they depart New Zealand; of the remaining nine respondents, five visitors were going to visit Australia, followed by two visitors reporting they will travel to Hong Kong, and one travelling to India; however, one respondent stated that he/she would be visiting both Europe and Russia. A possible reason for the respondents stating that they had travelled to Australia prior to arriving in New Zealand could be due to the visitors being part of a tour that included the visitation of both Australia and New Zealand on the 
same trip, and this could also be a reason for those who stated that they will be visiting Australia after they depart New Zealand. On the other hand, the high percentage of those that travelled to Australia before arriving into New Zealand could be a result of New Zealand only having two direct routes, Shanghai-Auckland and Beijing-Auckland, which indicates that various visitors from China would have been required to travel to Australia prior to arriving into New Zealand, or have to transfer from another destination such as Hong Kong or Singapore. Ryan \& Mo (2001) also indicate in their study that many Chinese visitors have visited New Zealand as part of a package with a tour to Australia; yet, the researchers also suggested that it could be an indication of the circumstances regarding airfares and flight schedules.

Table 4-4: Trip Characteristics - Visit any countries before arriving or after departing New Zealand

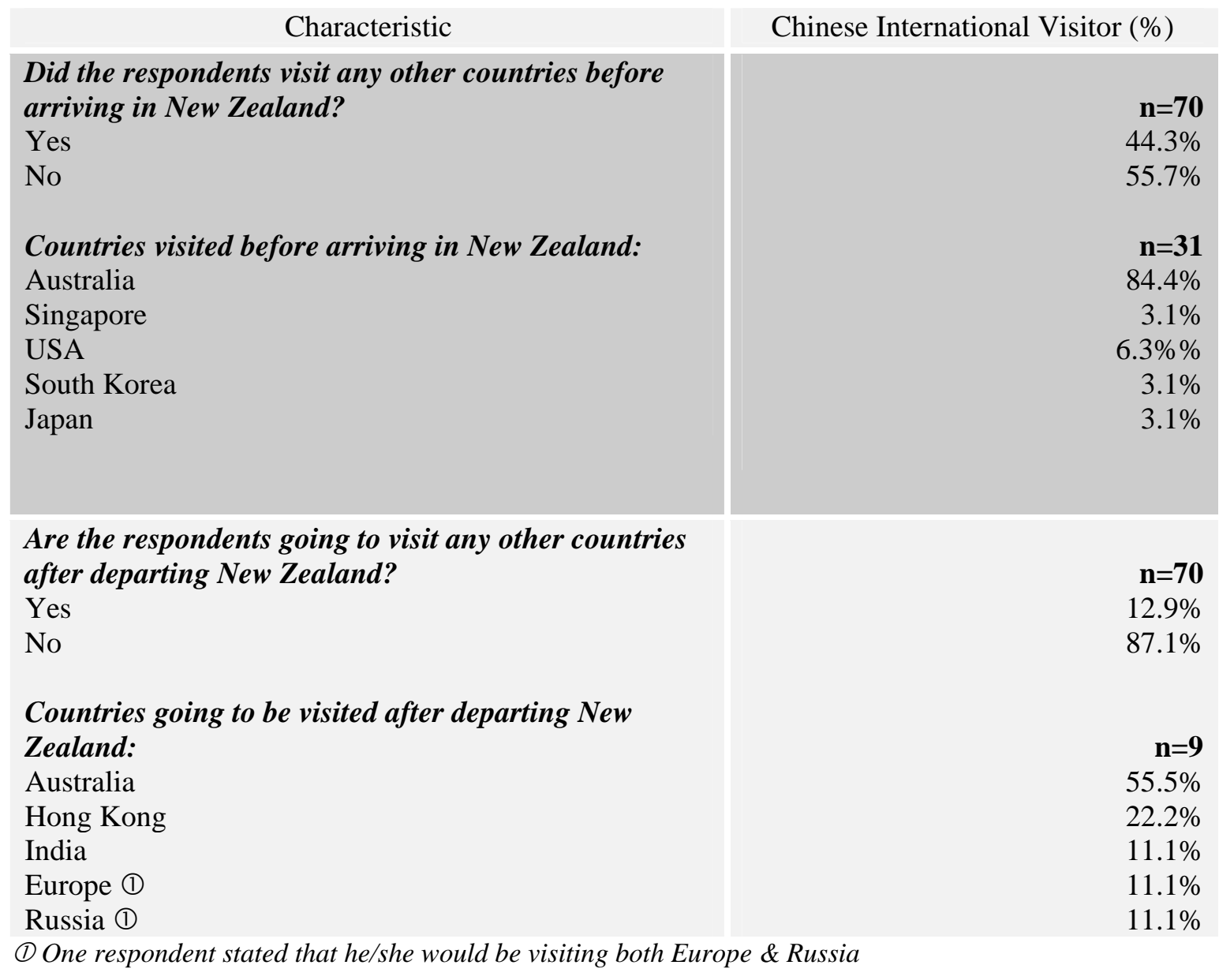




\subsubsection{Main Purpose of Visit to New Zealand}

As demonstrate in figure 4.2, the main purpose of the majority of respondents' visit to New Zealand was for a holiday/vacation (48.6\%); however, 22.9\% of the respondents stated that they were in New Zealand to visit friends and family. Out of the 70 respondents $14.3 \%$ expressed that they were visiting New Zealand for business and 8.6\% were in New Zealand for a conference/convention. With regards to the responses stating that the respondent's main purpose of visit to New Zealand was to visit friends and family, all 16 of these respondents travelled independently around New Zealand. This finding was also visible when examining those who travelled to New Zealand for educational purposes. Due to the fact that these visitors were in New Zealand for a reason other than holidaying being part of a tour group would have been less functional or accommodating to their purpose of visitation. However, concerning the respondents that were visiting New Zealand for a holiday/vacation $82.4 \%$ were part of a tour group. Another key finding ascertained in the responses was that although previous studies have shown that a large percentage of Chinese outbound travellers travel for business reasons, for example Zhang (2006) stated that the numbers of Chinese visitors that participate in tour groups travelling for leisure purposes are in comparison smaller than the Chinese visitors travelling for business purposes.

Figure 4-2: Main Purposes of Visit to New Zealand (\%) n=70

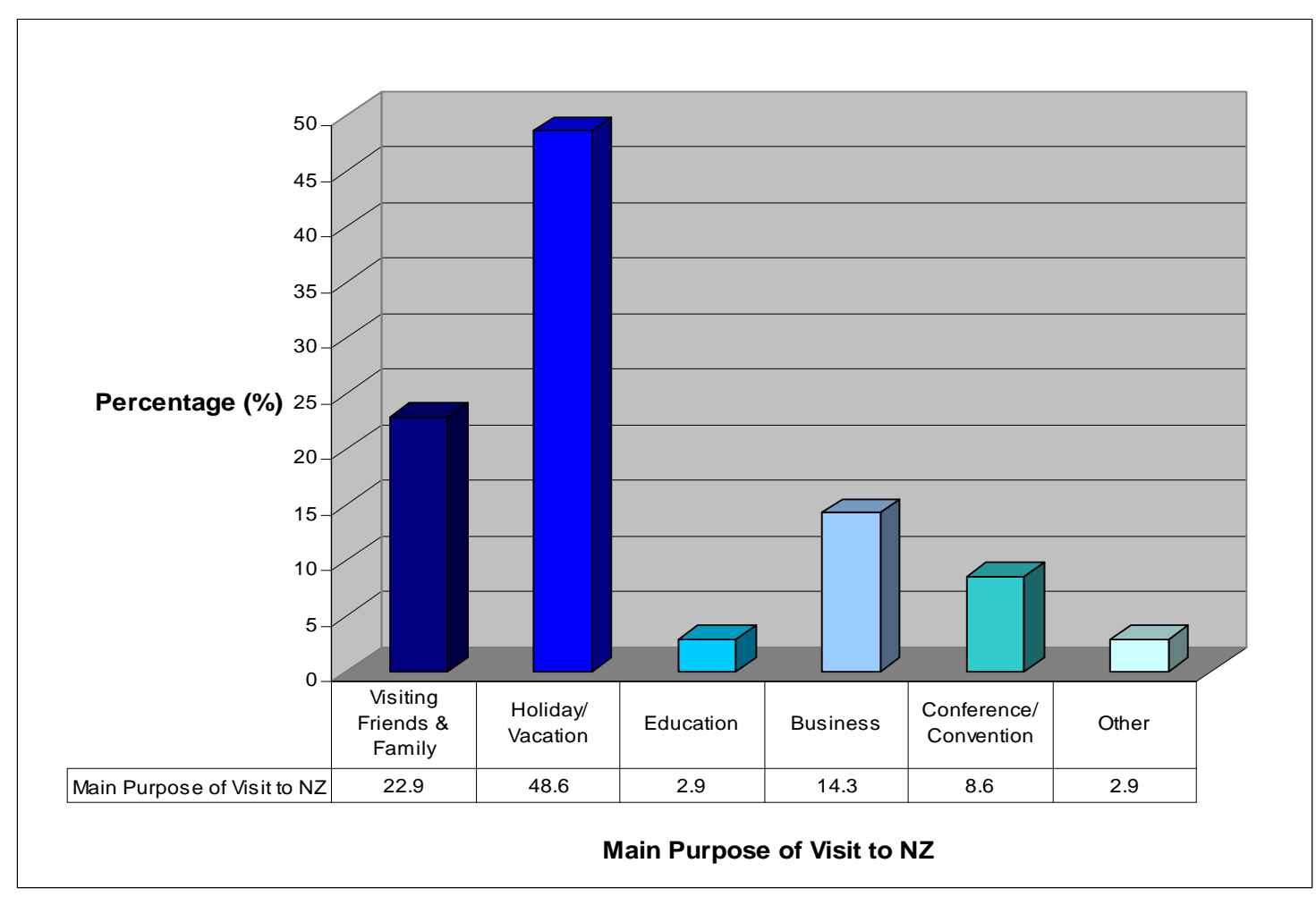


However, from the findings in this study the number of Chinese visitors visiting New Zealand for leisure purposes is significantly higher than those travelling for business intensions. The proportion of Chinese holidaymakers is beginning to increase and exceed those just travelling to destinations, such as New Zealand, for business purposes.

\subsubsection{Main Source of Information}

As a potential method to comprehend the Chinese visitors, their main sources of information employed to learn about New Zealand prior to arrival was examined. Out of the 70 respondents, the bulk of responses indicated that they gathered their information from friends and family (26.9\%), as demonstrated in figure 4.3. Yet, other sources of information such as the organization the respondent works for or work colleagues (23.1\%), travel agents (15.4\%), Internet website/s in Chinese (10.6\%), and/or guidebooks (9.6\%) were also important in obtaining information about New Zealand. However, when investigating the other categories that weren't expressed as being as highly significant, these included Internet website/s in English (6.7\%), newspaper/magazine (3.8\%), with television/radio was the source of information that was employed the least by respondents at 1\%. According to Tourism New Zealand the two most-used sources of information by Chinese visitors planning a trip to New Zealand are travel agents in their origin and travel guides/books (TNZ, 2008); however, results from this study indicates that the Internet has also become of almost equal importance in regards to attaining information concerning their travel plans.

When examining the sources of information employed by the respondents it was clear that across all the ages the same trend appears, illustrating friends and family as the main source of information, followed by the organization the respondent works for or work colleagues, and their travel agents. However, as defined by Tourism New Zealand, the main target market of New Zealand, 'interactive travellers', tend to be high users of technology (such as the Internet), and from the responses given there are increasingly more Chinese visitors that are beginning to utilize Internet websites in English or Chinese to obtain information about New Zealand before their visit; in fact the number of respondents that employed the use of the Internet over exceeded those who used the traditional destination guidebooks and travel agents. This will be examined further in the discussion chapter of this thesis. 


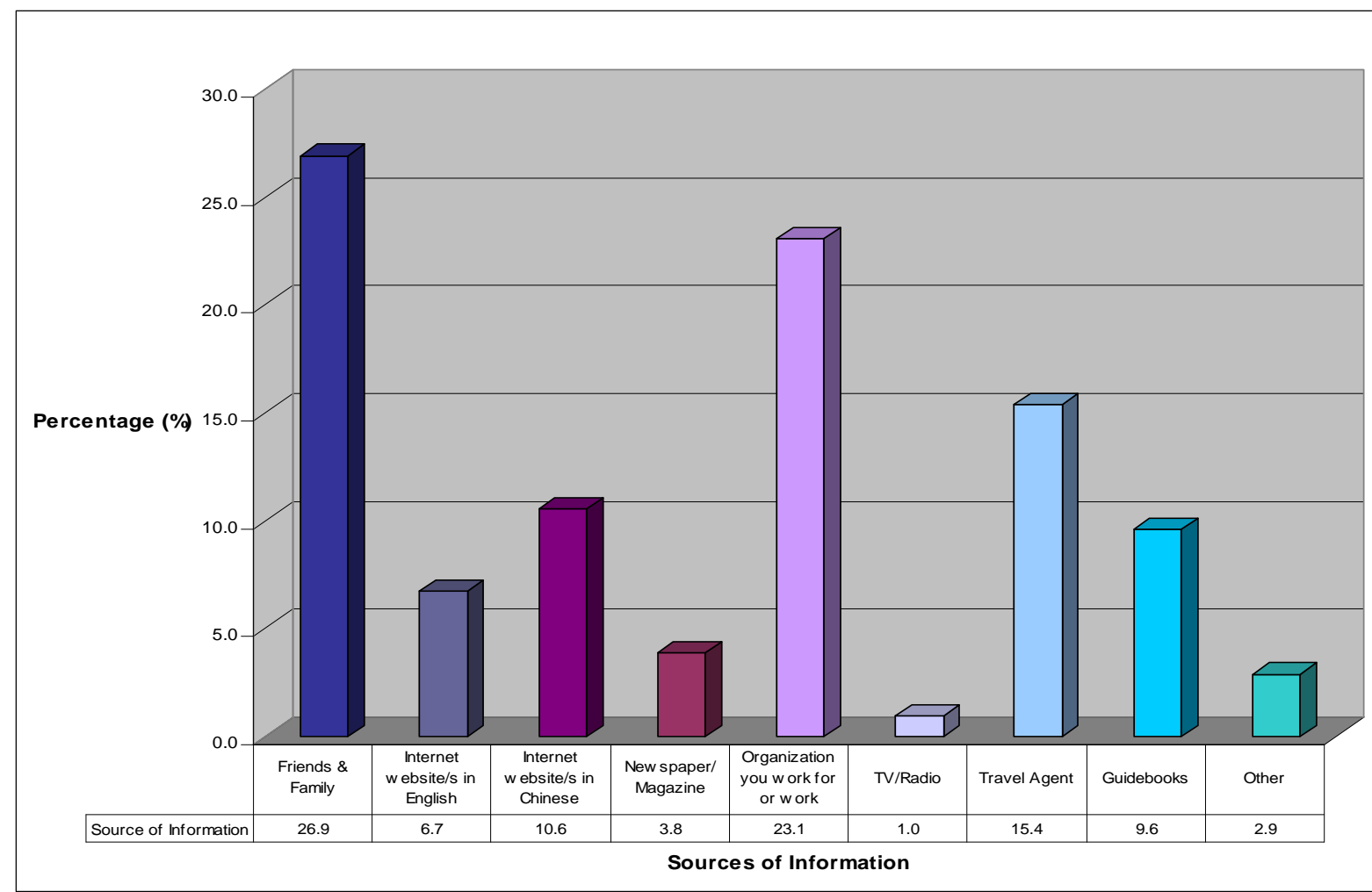

\subsubsection{Major Activities participated in during visit to New Zealand}

When the Chinese visitors were asked the major activities they participated in whilst visiting New Zealand the majority of respondents stated they participated in sightseeing (77.1\%), marginally followed by shopping (72.9\%) (table 4.5). Respondents also confirmed they visited a historical site (61.4\%), saw a Maori cultural performance (57.1\%), and/or visited a botanical garden (54.3\%). It has been documented by organizations such as the Asia Pacific Foundation of Canada (2002) that Chinese put a large degree of importance on status, through the form of travel that they take, through to the destinations that they choose to visit, this fundamentally leads to the various activities and attractions that they choose to partake in. The majority of Chinese visitors visit the major attractions within the destination, which was clearly identified in this study as the larger proportion of the population participated in activities that were iconic to New Zealand itself, or to the specific location within New Zealand that the Chinese visitor was visiting, for example sightseeing, the Maori cultural performance, museums/galleries, botanical gardens and hot pools/geothermal sites. 
Table 4-5: Major Activities Participated in during visit to New Zealand $\mathbf{n = 7 0}$ (1)

\begin{tabular}{|l|r|}
\hline \multicolumn{1}{|c}{ Major Activities } & Percentage of Cases (\%) \\
\hline Sightseeing & $77.1 \%$ \\
\hline Shopping & $72.9 \%$ \\
\hline Visited a Historical Site & $61.4 \%$ \\
\hline Maori Cultural Performance & $57.1 \%$ \\
\hline Visited a Botanical Garden & $54.3 \%$ \\
\hline Visited a Museum/Gallery & $48.6 \%$ \\
\hline Visited a Casino & $45.7 \%$ \\
\hline Visited a Beach & $42.9 \%$ \\
\hline Visited a Farm & $38.6 \%$ \\
\hline Visited hot Pools/Geothermal Sites & $35.7 \%$ \\
\hline Visited Friends \& Family & $27.1 \%$ \\
\hline Zoo/Wildlife/Marine Park & $17.1 \%$ \\
\hline Bungy Jumping & $5.7 \%$ \\
\hline Rafting/Kayaking/Jet Boating & $5.7 \%$ \\
\hline Tramping & $5.7 \%$ \\
\hline Visited a Vineyard & $5.7 \%$ \\
\hline Fishing & $4.3 \%$ \\
\hline Mountain/Rock Climbing/Caving & $4.3 \%$ \\
\hline Snow Boarding/Skiing & $4.3 \%$ \\
\hline Whale/Dolphin Watching & $4.3 \%$ \\
\hline Golf & $1.4 \%$ \\
\hline Other & $1.4 \%$ \\
\hline Total & $621.4 \%$ \\
\hline (1) Multiple Response Question & \\
\hline
\end{tabular}

\subsubsection{Satisfaction}

The level of satisfaction of the Chinese respondents was considered in the questionnaire as a means of interpreting the visitors' experience in New Zealand. This question was particularly important for the tourism industry in New Zealand due to the recent negative publicity regarding the lower than average level of satisfaction of Chinese visitors to New Zealand. Additionally, Chinese visitors have gained poor levels of satisfaction from their experience in New Zealand, due to possible reasons concerning the tendency for Chinese visitors to go on shopping tours. The reasons for the tendency of Chinese visitors potentially going on shopping tours entail: bringing back souvenirs for friends and family after a holiday as part of the Chinese culture, shopping can be a means of memorabilia for the Chinese visitors of their journey, or shopping as a form of experiencing the destination. 
Table 4-6: Level of Satisfaction (5-point scale) (\%) n=68

\begin{tabular}{|c|c|c|c|c|c|}
\hline $\begin{array}{c}\text { Very } \\
\text { Dissatisfied } \\
1\end{array}$ & 2 & $\begin{array}{c}\text { Moderately } \\
\text { Satisfied } \\
3\end{array}$ & 4 & $\begin{array}{c}\text { Very } \\
\text { Satisfied } \\
5\end{array}$ & Total \\
\hline $0 \%$ & $1.5 \%$ & $48.5 \%$ & $26.5 \%$ & $23.5 \%$ & $100 \%$ \\
\hline
\end{tabular}

When studying the level of satisfaction of the respondents, as illustrated in table 4.6, it was clear that on a 5-point scale, $23.5 \%$ demonstrated they were 'very satisfied', with no responses expressing the respondents were 'very dissatisfied' with their travel experience in New Zealand. There was a 50:50 split between responses conveying respondents were above moderately satisfied, and those that stated they were only 'moderately satisfied' or lower. Although it was identified that there was a high percentage of Chinese visitors that were 'moderately satisfied' or above 'moderately satisfied' with their visit to New Zealand, there was still $1.5 \%$ of the responses that rated their level of satisfaction at ' 2 '. However, $48.5 \%$ of the 68 responses illustrated that they were 'moderately satisfied' with their visit to New Zealand. As demonstrated in a document by The Ministry of Economic Development (updated February 2006), Tourism New Zealand showed that 95\% of visitors to New Zealand were 'satisfied' or more than 'satisfied' with their experience in New Zealand; yet, the Chinese visitor market demonstrated a lower level of satisfaction. This was clearly illustrated in this study with only $50 \%$ of the Chinese respondents expressing their level of satisfaction were above 'moderately satisfied'. When examining the overall picture of the respondents' level of satisfaction, the mode was at 3.00 ('moderately satisfied'), with the mean at $3.72(\mathrm{SD}=0.844)$ and the median at 3.50 .

Within the questionnaire distributed to the Chinese sample population, an open-ended question was asked regarding what respondents enjoyed the most about their trip to New Zealand. This was an added question to further extend the interpretation of the respondents' level of satisfaction with their trip to New Zealand. Table 4.7 displayed several trends identified from the responses; these were also reflected in more recent research on the Chinese market, such as the respondents' concern for whether the destination was safe and secure, and if the destination had a good natural environment. These trends were clearly identified in an article by Coventry (2008), the article specifically states that developments in the Chinese outbound market demonstrates 
safety as a significant stimulus in their decisions to visit a destination. The article by Coventry (2008) also illustrated that 'eco and natural' highlights were established as the fourth most important component, with an increasing significance of the environment in the Chinese visitors' holiday decisions.

Table 4-7: What Respondents Enjoyed the Most about their trip in New Zealand n=68

\begin{tabular}{|l|r|}
\hline \multicolumn{1}{|c|}{ Responses } & Percentage of Responses (\%) \\
\hline Good Environment & $19.4 \%$ \\
\hline Friendly Locals & $12.5 \%$ \\
\hline Beautiful Scenery & $10.0 \%$ \\
\hline Clean/Fresh Air & $7.5 \%$ \\
\hline Good public transportation & $5.6 \%$ \\
\hline Other & $5.4 \%$ \\
\hline Good food & $5.0 \%$ \\
\hline Good \& Unique customer service & $5.0 \%$ \\
\hline Safe and secure destination & $4.4 \%$ \\
\hline Unique culture & $3.8 \%$ \\
\hline Good Accommodation & $3.8 \%$ \\
\hline Good Hygiene & $3.1 \%$ \\
\hline Clean 'Green’ Image & $3.1 \%$ \\
\hline Good conservation/Good at keeping the & \\
\hline environment/Good recycling schemes & $2.5 \%$ \\
\hline NZ is quiet/Little amounts of people & $1.9 \%$ \\
\hline Nice weather & $1.9 \%$ \\
\hline Good sightseeing/Unique Tourist Sites & $1.9 \%$ \\
\hline Good lifestyle & $1.3 \%$ \\
\hline Good Agriculture & $1.3 \%$ \\
\hline Development \& Co-ordination of NZ Society & $1.3 \%$ \\
\hline Total Responses & $\mathbf{1 0 0 \%}$ \\
\hline
\end{tabular}

With regard to this study, the destination having a 'good environment' was clearly the most enjoyable aspect of the respondents' trip in New Zealand (19.4\%); this could potentially be a 'good environment' for tourists, or having a 'good natural environment'. However, there were also other examples given by respondents that reflected a similar trend involving the importance of environmental components during their visit to New Zealand, for example beautiful scenery (10\%), clean/fresh air (7.5\%), clean 'Green' image (3.1\%), and New Zealand's good conservation/keeping of the environment (2.5\%). Tourism New Zealand also identified that Chinese visitors believe that New Zealand delivers well with regards to natural landscapes and clean environment, averaging a score of over 8.6 points out of 10 for satisfaction (2008). Nonetheless, 
enjoying the safety and security during the respondents New Zealand trip was also identified in the responses $(4.4 \%)$.

Apart from the trends associated with the factors that may have been important in making their decision to visit New Zealand, there were clearly visible trends appearing concerning cultural aspects. These areas particularly focused on responses expressing the respondents enjoying the friendliness of locals (12.5\%), the good and unique customer service (5\%), the unique culture (3.8\%), New Zealand being quiet or not having a crowded environment (1.9\%), the lifestyle (1.3\%), and the development and co-ordination within New Zealand society (1.3\%).

The responses regarding what respondents enjoyed the most about their trip in New Zealand also included an identification of the most enjoyed aspects of the tourism industry, for example good public transportation (5.6\%), good food (5\%), good accommodation (3.8\%), good sightseeing and unique tourist sites (1.9\%). There were also other responses that did not follow any particular trend and stood on their own as an independent response, for example the most enjoyable aspect of the respondent's trip as reported by the Chinese visitors to New Zealand was the good hygiene (3.1\%), nice weather $(1.9 \%)$, good agriculture $(1.3 \%)$, with all the other independent responses totalling $5.4 \%$.

Other authors and tourism organizations have also undertaken research to understand the Chinese outbound visitor market further, such as the Scandinavian Tourist Board (2002) and the Asia Pacific Foundation of Canada (2002) which have stated that Chinese holidaymakers seek the experience of 'outstanding scenery, freshness and space', with features such as safety and cleanliness as destination features that are also pursued by the Chinese travellers (Becken, 2003). This study also identified the fact that the Chinese visitors expressed a high level of enjoyment from specific destination characteristics that are clearly stimulated by the imagery of New Zealand and the awareness of the country being 'green', unpolluted, and being secure. Ryan \& Mo (2001) add to this by establishing the fact that positive imagery plays an impact on the decisions of Chinese visitors to New Zealand and this imagery therefore affects the realization linked to these specific aspects prior to visitation. 
According to the least enjoyed aspects of the respondents trip to New Zealand, as demonstrated in table 4.8, it was identified that respondents demonstrated various trends with regards to their responses, specifically concerning the impact of the high cost of several components of the visitors trip, safety and security, and essentially cultural and language barriers.

Table 4-8: What Respondents Enjoyed the Least about their trip in New Zealand n=68

\section{Responses}

High prices/Shopping too expensive/High price
for scenic spots
Bad Food
Bad public transportation
Bad weather
Language Barrier/Issues with communication
Bad shopping/No night-time shopping
Bad Accommodation
Hard to locate places/Bad road signage
Too quiet/Limited number of people
Undeveloped Chinese environment
Bad public facilities
Bad security
Bad medical \& hospital services
Duration of flight from China/No direct flights to
NZ
Not use to the lifestyle
Too many casinos
When visiting sites, we didn’t stay long enough
Lack of industrial \& economic environment
Bad sightseeing
No duty tax refunds
Total

Total

\section{Percentage of Responses (\%)}

$17.3 \%$

$13.3 \%$

$13.3 \%$

$11.2 \%$

$9.2 \%$

$8.7 \%$

$3.1 \%$

$3.1 \%$

$3.1 \%$

$3.1 \%$

$2.0 \%$

$2.0 \%$

$2.0 \%$

$2.0 \%$

$1.0 \%$

$1.0 \%$

$1.0 \%$

$1.0 \%$

$1.0 \%$

$1.0 \%$

$100 \%$

From the 68 responses regarding the least enjoyed components of the respondents trip to New Zealand, the majority of the responses expressed facets concerning the cost of the visit as the least enjoyed aspect of their visit, for example high prices/expensive shopping/high price of some scenic spots (17.3\%). In further analysis of the aspects that were least enjoyed by the Chinese visitors was the issues that arose with communication and language (9.2\%); also expressed by the respondents was the concern with the duration of the flight from China to New Zealand, and the problem regarding there not being direct flight from the origin to the destination (2.0\%). Conversely, $4.4 \%$ of the 
responses demonstrated that they believed New Zealand had poor security, which potentially led to the decreased enjoyment of their trip in New Zealand.

The cultural element was also expressed in the responses, mainly involving the quietness of New Zealand as a result of there being limited numbers of people in New Zealand (3.1\%), and the underdeveloped Chinese environment (3.1\%). With regard to the responses reporting that the respondents least enjoyed the underdeveloped Chinese environment, it can be identified that the Chinese visitors are seemingly interested in other cultures; however, they still pride themselves in their heritage, and feel more comfortable in their own cultural surroundings. Furthermore, responses illustrated that respondents thought they least enjoyed the lifestyle in New Zealand because they haven't adapted to the New Zealand environment (1\%), and lack of industrial and economic environment (1\%) impacting negatively on one respondent's enjoyment in New Zealand. Responses also demonstrated that respondents enjoyed a number of other tourism industry components the least during their visit to New Zealand, for example responses illustrated public transportation was bad (13.3\%), and bad food (13.3\%).

With regards to food, it was indicated by Tourism New Zealand that Chinese visitors demonstrated that their level of satisfaction with the availability of good food was comparatively lower than other visitor markets (2008). Besides the issues with the food, respondents expressed that the shopping in New Zealand was bad, with one response depicting there was no night-time shopping (8.7\%); with $3.1 \%$ of the responses portraying accommodation as the least pleasing aspect of the visitors trip to New Zealand. By identifying these particular issues that the Chinese visitors enjoyed the least about New Zealand's tourism industry will essentially point out where improvements are needed to potentially enhance the sustainability of New Zealand as a tourist destination, but also as a means of developing the Chinese visitor market into a sustainable medium for the tourism industry.

The Chinese respondents also showed little enjoyment in regards to certain public facilities 2\%; additionally, there were two other areas that were related to bad public facilities in New Zealand, involving the difficulty to locate places/bad road signage (2\%) and the bad medical/hospital service (2\%). Although a number of responses that expressed that there were certain aspects of New Zealand's public facilities that they 
believed was poor, it is important for these issues to be addressed, principally the problem regarding the difficulty in locating certain places, and the poor road signage.

\subsubsection{Factors that impact on the Visitors' decision to visit a destination}

In the questionnaire there was a question that examined a number of factors that Chinese visitor's may have considered in their decision to visit New Zealand. This question was asked on a 5-point scale ranging from whether the respondents believed the factors were 'unimportant' (1) to 'very important' (5). The factors that were being investigated involved: the duration of flight from China, the overall cost of the visit, if the destination was safe, if the destination was an English-speaking country, and whether a high level of environmental protection impacts on the respondents' decision to visit New Zealand. This question was essentially asked to establish which factors were more important in the eyes of the respondents, but also if a destination's level of environmental protection is a significant influence when Chinese visitors choose their holiday destinations.

Table 4-9: Factors considered in Respondents decision to visit New Zealand $\mathbf{n}=70$

\begin{tabular}{|c|c|c|c|c|c|c|}
\hline Factors & $\begin{array}{l}\text { Unimportant } \\
1\end{array}$ & $\begin{array}{c}\text { Of Little } \\
\text { Importance } \\
2\end{array}$ & $\begin{array}{c}\text { Moderately } \\
\text { Important } \\
3\end{array}$ & $\begin{array}{c}\text { Important } \\
4\end{array}$ & $\begin{array}{c}\text { Very } \\
\text { Important } \\
5\end{array}$ & Total \\
\hline $\begin{array}{l}\text { Duration of } \\
\text { flight from } \\
\text { China }\end{array}$ & $32.9 \%$ & $34.3 \%$ & $15.7 \%$ & $7.1 \%$ & $10 \%$ & $100 \%$ \\
\hline $\begin{array}{l}\text { Overall cost of } \\
\text { the visit }\end{array}$ & $10 \%$ & $30 \%$ & $17.1 \%$ & $25.7 \%$ & $17.1 \%$ & $100 \%$ \\
\hline $\begin{array}{l}\text { Safe } \\
\text { destination }\end{array}$ & $5.7 \%$ & $8.6 \%$ & $7.1 \%$ & $40 \%$ & $38.6 \%$ & $100 \%$ \\
\hline $\begin{array}{l}\text { English- } \\
\text { speaking } \\
\text { country }\end{array}$ & $12.9 \%$ & $28.6 \%$ & $24.3 \%$ & $21.4 \%$ & $12.9 \%$ & $100 \%$ \\
\hline $\begin{array}{l}\text { High level of } \\
\text { environmental } \\
\text { protection }\end{array}$ & $14.3 \%$ & $4.3 \%$ & $21.4 \%$ & $24.3 \%$ & $35.7 \%$ & $100 \%$ \\
\hline
\end{tabular}

In terms of examining whether the duration of flight from China to New Zealand was an important factor in the decision for the respondents to visit the destination (table 4.9), only $10 \%$ of the respondents believed that this factor was 'very important', with the majority of respondents expressing that this factor was 'moderately important' or below 
(82.9\%), with $32.9 \%$ of respondents stating that this factor was 'unimportant' in their decision to visit New Zealand.

Out of the 70 responses given in relation to the importance of the overall cost of the visit in the respondents' decision to visit New Zealand (table 4.9), 17.1\% of the respondents expressed that this factor was 'very important', with $30 \%$ of the responses articulated that the respondents believed that the overall cost of the visit was 'of little importance; however, this was closely followed by the respondents who believed that the overall cost of the visit as 'important' in their decisions to visit New Zealand (25.7\%).

When investigating the safety of the destination on a scale of importance in the respondent's decision to visit New Zealand (table 4.9), 38.6\% of the respondents believed that this factor was 'very important'. The safety within the destination was the factor that had the highest proportion of responses that stated the factor as 'very important'. However, in further examination of this factor, $78.6 \%$ of the responses stated that the level of significance in regards to their decision was 'moderately important', which included the responses expressing this factor as 'important' or 'very important'. Therefore, it was interesting to find that $14.3 \%$ of the Chinese respondents believed the safety of the destination was 'unimportant' or 'of little importance'.

In terms of whether the country was English-speaking seemed to be 'of little importance' to the Chinese respondents (28.6\%) (table 4.9). It was identified that 34.3\% of respondents who believed that it was either 'important' or 'very important' that the country they were to visit was English-speaking, with $12.9 \%$ expressing it was a 'very important' factor. However, $41.5 \%$ of the sample population illustrated that this factor was below 'moderately important'. This finding was interesting due to the fact that the respondent's mother tongue not being English, but Chinese; yet, this visit to New Zealand could have been an opportunity for the respondents to 'develop' their English skills.

Interestingly, half of the respondents demonstrated the importance of a high level of environmental protection in their decision to visit New Zealand (table 4.9), with 60\% of the responses stating that this factor was 'important' or 'very important'. From the 70 
responses given, $35.7 \%$ expressed that a high level of environmental protection was 'very important' in their decision; nonetheless, $14.3 \%$ of the respondents considered that this factor was completely 'unimportant'.

Conversely, when studying the overall importance of the five factors in the decision for the Chinese visitors travelling to New Zealand, the means of each factor was examined (figure 4.4). It was acknowledged that in regards to the factors that the respondents perceived as 'very important', the safety within the destination sustained the largest mean of 3.97 ( $S D=1.154)$, which was followed by responses indicating that the destination having a high level of environmental protection played a very important impact on the visitors decision to visit New Zealand, with the mean of 3.63 ( $S D=1.385)$. The overall cost of the visit to New Zealand was also an important factor with a mean of $3.10(\mathrm{SD}=1.287)$.

However, it was interesting to find that the destination being an English-speaking country having such a low mean, at 2.93 ( $\mathrm{SD}=1.243)$, based on the findings of other studies expressing Chinese visitors rarely speaking English, which would therefore impact on the visitors' level of experience and satisfaction. It was also identified that the duration of flight from China had the lowest mean at 2.27 ( $S D=1.273)$, expressing this factor as the least important impact on the visitor's decision to travel to New Zealand.

Figure 4-4: Examination of Factors that Impacted on the Respondents Decision to Visit New Zealand $\mathbf{n}=70$

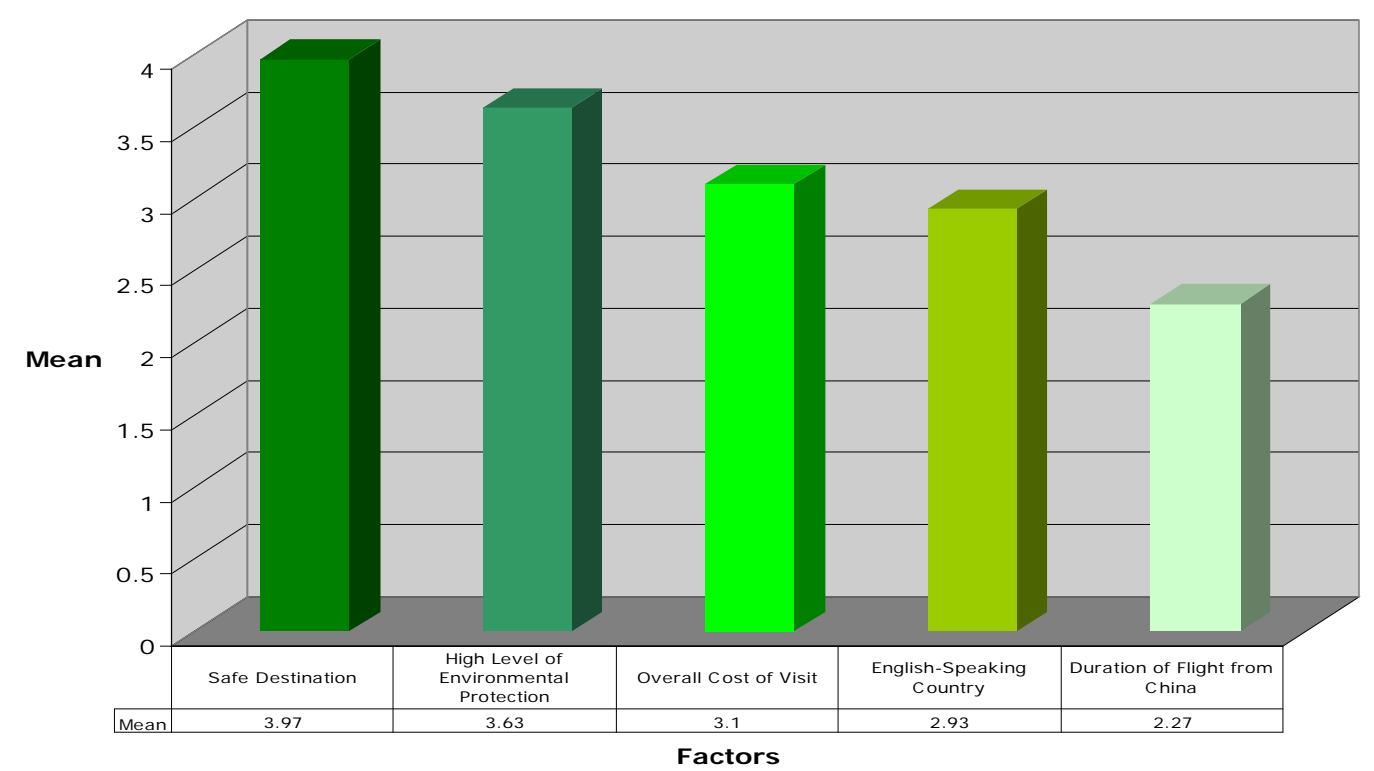




\subsubsection{Sustainability}

As one of the key areas being investigated in this study, a section to examine 'sustainability' was derived to tackle the aims of this research. This section essentially observes a number of components, such as if the respondents have heard of the term 'sustainability', the respondents' level of understanding of the term, the respondents' perception of 'sustainability', whether the respondents believe it is important for tourists to understand the term, and if the respondents think New Zealand is a sustainable tourist destination.

When asked if the respondents have heard of the term 'sustainability', 74.3\% expressed that they have heard of the term; whereas, 25.7\% acknowledged that they have not. There was one question within the questionnaire that asked the Chinese visitors what they interpret 'sustainability' to mean. This question was ultimately not analysed because the interpretations expressed became too complex to tackle and analyze. Conversely, from the 52 respondents that stated they have heard of the term 'sustainability', 73.1\% of the respondents believe they have a 'moderate' and/or above 'moderate' understanding of the term 'sustainability', with $23.1 \%$ expressing they believe they have a 'very good' understanding of 'sustainability' (table 4.10). Hence 26.9\% of the respondents stated they consider they have a below 'moderate' understanding of the term, with $19.2 \%$ reporting they have a 'very limited' understanding of the term 'sustainability'. With regards to the level of understanding respondents have of the term 'sustainability', the mean was 3.06. However, it should be identified that not too much can be interpreted from the findings relating to the understanding of the term 'sustainability' because these responses are self-declared.

Table 4-10: Level of Understanding Respondents have of the term 'Sustainability' (5-point scale) (\%) n=52

\begin{tabular}{|c|c|c|c|c|c|}
\hline $\begin{array}{l}\text { I have a very } \\
\text { limited } \\
\text { understanding } \\
\text { of the term } \\
\text { 'sustainability' } \\
1\end{array}$ & 2 & $\begin{array}{c}\text { I have a } \\
\text { moderate } \\
\text { understanding } \\
\text { of the term } \\
\text { 'sustainability' } \\
3\end{array}$ & 4 & $\begin{array}{l}\text { I have a very } \\
\text { good } \\
\text { understanding of } \\
\text { the term } \\
\text { 'sustainability' } \\
5\end{array}$ & Total \\
\hline $19.2 \%$ & $7.7 \%$ & $44.2 \%$ & $5.8 \%$ & $23.1 \%$ & $100 \%$ \\
\hline
\end{tabular}


From the 52 responses that demonstrated the respondents have heard of the term 'sustainability', it was acknowledged that $75 \%$ of the responses believed that it is important for tourists to understand the term 'sustainability' because of a number of reasons; namely 'to respect future tourists’ (30.4\%), 'protect present resources’ (22.8\%), 'ensure resources can be utilized by the next generations' (19\%), and 'to give tourists a sense of responsibility' (3.8\%). The 'other' category consisted of $22.8 \%$ of the responses, and entailed statements that involved 'developing a deeper understanding of New Zealand', 'the development of tourism' (50\%), 'to improve tourism issues' (37.5\%), and the 'other' category (12.5\%). However, the remaining 25\% of the 52 responses expressed that they do not believe it is important for tourists to understand 'sustainability' and demonstrated several reasons; a general response was that respondents believed 'tourists come to a destination to enjoy themselves, and only stay for a short period of time, therefore shouldn't worry about sustainability', others expressed that they thought it was not their concern because 'they don't belong to that country, but should be the concern of a tourist board or local government'. In regards to this statement it is established that it echoes responses expressed by the Chinese visitors on who the respondents believed was most responsible for the impacts of tourism on the destination, which was evidently governments, this will be examined further in the discussion section of this study.

As another primary section in the examination of 'sustainability', the sustainability of New Zealand as a tourist destination was investigated in terms of the Chinese visitors' view. Investigating whether respondents believed New Zealand is a sustainable tourism destination or not was beneficial to this study by demonstrating firstly the Chinese respondents' perception of New Zealand's tourism industry, but secondly to identify if there is a need for New Zealand's tourism industry to do more to illustrate the significance of sustainable tourism to the visitor market.

Table 4-11: Do Respondents think New Zealand is a Sustainable Tourism Destination (5-point scale) (\%) $n=52$

\begin{tabular}{|c|c|c|c|c|c|}
\hline $\begin{array}{l}\text { I do not think NZ } \\
\text { is a very } \\
\text { sustainable } \\
\text { tourist destination } \\
1\end{array}$ & 2 & $\begin{array}{l}\text { I think NZ is a } \\
\text { reasonably sustainable } \\
\text { tourist destination } \\
3\end{array}$ & 4 & $\begin{array}{l}\text { I think NZ is a } \\
\text { very sustainable } \\
\text { tourist } \\
\text { destination } \\
5\end{array}$ & Total \\
\hline $7.7 \%$ & $5.8 \%$ & $34.6 \%$ & $11.5 \%$ & $40.4 \%$ & $100 \%$ \\
\hline
\end{tabular}


From the study of the responses regarding whether or not the respondents' thought New Zealand was a sustainable tourism destination (table 4.11), 51.9\% of the responses reported that New Zealand was more than just a reasonably sustainable tourism destination. The majority of the responses expressed that the Chinese visitors believed New Zealand was a very sustainable tourism destination (40.4\%), this response was closely followed by the responses expressing that respondents thought New Zealand was only a reasonably sustainable tourist destination (34.6\%). Nonetheless, 13.5\% of the responses was ranked below New Zealand being a reasonably sustainable tourism destination, with $7.7 \%$ of the responses expressing they thought New Zealand was not a very sustainable tourism destination; with the mean at $3.71(\mathrm{SD}=1.273)$.

\subsubsection{New Zealand's Marketing Image}

In terms of whether the Chinese visitors have seen New Zealand's '100\% PURE NZ' tourism campaign, $42.9 \%$ of the respondents demonstrated they have seen tourism campaign, with 57.1\% stating they have not. In further examination of New Zealand's '100\% PURE NZ' tourism campaign, respondents were asked whether they believed that the tourism campaign impacted on their decision to visit New Zealand. Out of the 30 respondents that stated they have seen the ' $100 \%$ PURE NZ' tourism campaign, $10 \%$ of the responses thought the campaign was 'very important' on their decision to visit New Zealand, with 6.7\% expressing the campaign was 'important' (table 4.12). However, the majority of the responses conveyed that the ' $100 \%$ PURE NZ' tourism campaign was only 'moderately important' in their decision to visit New Zealand. Nonetheless, 36.7\% stated that the campaign was less than 'moderately important', with $16.7 \%$ reporting that the campaign was 'unimportant' in their decision to visit New Zealand, with the mean of $2.73(\mathrm{SD}=1.143)$.

Table 4-12: Did the '100\% PURE NZ' tourism campaign impact on the Respondents Decision to Visit New Zealand (5-point scale) (\%) n=30

\begin{tabular}{|r|r|c|c|c|c|}
\hline Unimportant & $\begin{array}{c}\text { Of Little } \\
\text { Importance }\end{array}$ & $\begin{array}{c}\text { Moderately } \\
\text { Important }\end{array}$ & Important & $\begin{array}{c}\text { Very } \\
\text { Important }\end{array}$ & Total \\
\hline 1 & 2 & 3 & 4 & 5 & \\
\hline $16.7 \%$ & $20 \%$ & $46.7 \%$ & $6.7 \%$ & $10 \%$ & $\mathbf{1 0 0} \%$ \\
\hline
\end{tabular}

In addition to the responses that have seen the ' $100 \%$ PURE NZ' tourism campaign there was an even number of responses expressing that the images depicted by the 
tourism campaign related to their New Zealand experience at a level of ' 3 ' on a 5-point scale (30\%) or at a level of ' 5 ' demonstrating what the respondent saw in the ' $100 \%$ PURE NZ' tourism campaign matched exactly what they saw on their trip in New Zealand (30\%), as expressed in table 4.13. Additionally, $26.7 \%$ of the responses illustrated that on a 5-point scale they express that the '100\% PURE NZ' tourism campaign related to their New Zealand experience at level '4' (important). However, it was interesting to identify that only $13.4 \%$ of the responses were below level ' 3 ' (moderately important), with 6.7\% expressing the campaign gave a completely wrong impression of their experience in New Zealand. Nonetheless, the mean for whether the respondents thought the ' $100 \%$ PURE NZ' tourism campaign related to the visitors' experience was $3.67(\mathrm{SD}=1.184)$.

Table 4-13: How the Respondents think the '100\% PURE NZ' tourism campaign relates to New Zealand as experienced on the Respondents trip (5-point scale) (\%) $=30$

\begin{tabular}{|c|c|c|c|c|c|}
\hline $\begin{array}{l}\text { Gives the } \\
\text { completely } \\
\text { wrong } \\
\text { impression } \\
1\end{array}$ & 2 & 3 & 4 & $\begin{array}{c}\text { Matches } \\
\text { exactly what } \\
\text { I saw on this } \\
\text { trip } \\
5\end{array}$ & Total \\
\hline $6.7 \%$ & $6.7 \%$ & $30 \%$ & $26.7 \%$ & $30 \%$ & $100 \%$ \\
\hline
\end{tabular}

When taking into account the various messages portrayed in New Zealand's ' $100 \%$ PURE NZ' tourism campaign an array of key statements were chosen to be examined in the questionnaire, these messages involved: New Zealand as a young country, New Zealand as being untouched by modern development, New Zealand having outstanding scenery, New Zealand having a unique culture, New Zealand having many adventure activities, and New Zealand being unpolluted. Each of these variables were studied individually on a 4-point scale in regards to the level of association with the ' $100 \%$ PURE NZ' tourism campaign, and in comparison of the means for each variable to establish which message respondents expressed as most closely aligned with the tourism campaign.

As an overview of the array of messages portrayed in New Zealand's '100\% PURE NZ' tourism campaign (table 4.14), it was identified that the message of New Zealand being 'unpolluted' (40\%) was the most strongly associated with the '100\% PURE NZ' tourism campaign. The association of New Zealand being 'unpolluted' was very 
different in comparison to the other messages that were suggested as being strongly associated with the ' $100 \%$ PURE NZ' tourism campaign, for example New Zealand having 'outstanding scenery' (26.7\%), New Zealand being 'untouched by modern development' (20\%), and New Zealand having 'many adventure activities' (20\%). Interestingly, two key messages that Tourism New Zealand is trying to depict involve: New Zealand having a 'unique culture' (16.7\%), and New Zealand as a 'young country' (10\%); however, were not seen as being as strongly associated with the ' $100 \%$ PURE NZ' tourism campaign in this study.

Table 4-14: Messages that Respondents Associated Most closely with the '100\% PURE NZ' tourism campaign (4-point scale) $(\%) \mathrm{n}=30$

\begin{tabular}{|c|c|c|c|c|c|}
\hline Message & $\begin{array}{c}\text { Not at all } \\
1\end{array}$ & $\begin{array}{l}\text { Somewhat } \\
2\end{array}$ & $\begin{array}{c}\text { Strongly } \\
3\end{array}$ & $\begin{array}{c}\text { Very } \\
\text { Strongly } \\
4\end{array}$ & Total \\
\hline NZ is a Young Country & $23.3 \%$ & $36.7 \%$ & $30 \%$ & $10 \%$ & $100 \%$ \\
\hline $\begin{array}{l}\text { NZ is untouched by } \\
\text { modern development }\end{array}$ & $23.3 \%$ & $46.7 \%$ & $10 \%$ & $20 \%$ & $100 \%$ \\
\hline $\begin{array}{l}\text { NZ has outstanding } \\
\text { scenery }\end{array}$ & $3.3 \%$ & $23.3 \%$ & $46.7 \%$ & $26.7 \%$ & $100 \%$ \\
\hline NZ has a unique culture & $3.3 \%$ & $30 \%$ & $50 \%$ & $16.7 \%$ & $100 \%$ \\
\hline $\begin{array}{l}\text { NZ has many } \\
\text { adventurous activities }\end{array}$ & $26.7 \%$ & $20 \%$ & $33.3 \%$ & $20 \%$ & $100 \%$ \\
\hline NZ is unpolluted & $3.3 \%$ & $13.3 \%$ & $43.3 \%$ & $40 \%$ & $100 \%$ \\
\hline
\end{tabular}

In terms of whether respondents associated the message of New Zealand being a young country the majority of the responses demonstrated that the statement was only 'somewhat' associated with the '100\% PURE NZ’ tourism campaign (36.7\%); however, this was directly followed by responses expressing the message was 'strongly' associated with New Zealand's tourism campaign (30\%).

When examining whether respondents associated the message of New Zealand being untouched by modern development, 70\% of the responses expressed that the statement was 'somewhat' or less associated with New Zealand's '100\% PURE NZ' tourism campaign, with $23.3 \%$ of the responses stating that New Zealand being untouched by modern development was 'not at all' associated, and $46.7 \%$ of the responses demonstrating that New Zealand being untouched by modern development was 'somewhat' associated with the '100\% PURE NZ' tourism campaign. 
Out of the 30 responses demonstrating the Chinese respondents that have seen New Zealand's '100\% PURE NZ' tourism campaign, 46.7\% of the responses expressed that they believe the message that New Zealand has outstanding scenery is 'strongly' associated with the ' $100 \%$ PURE NZ' tourism campaign. This was also a similar finding in relation to the message articulating New Zealand having a unique culture, with $50 \%$ of the responses exhibiting the statement being 'strongly' related to the ‘100\% PURE NZ’ tourism campaign.

In regards to responses expressing the association of New Zealand having many adventure activities in New Zealand's '100\% PURE NZ' tourism campaign, there was a clear divergence in responses, with $26.7 \%$ depicting there was hardly any correlation; whereas, $33.3 \%$ of the responses stating there 'strongly' being an association with the '100\% PURE NZ’ tourism campaign.

Additionally, it is interesting to identify that $83.3 \%$ of the responses recognized the message of New Zealand as unpolluted being above 'strongly' associated with New Zealand's '100\% PURE NZ' tourism campaign. There were almost an even percentage of responses that expressed that the message of New Zealand as unpolluted being 'strongly' or 'very strongly' related to the tourism campaign; 43.3\% of the responses conveyed that the message 'strongly' linked with the tourism campaign. Whereas, $40 \%$ of the responses believed that the message, demonstrating New Zealand as unpolluted as ‘very strongly’ associated with New Zealand’s ‘100\% PURE NZ' tourism campaign.

In the assessment of the means of the various messages associated with New Zealand's '100\% PURE NZ' tourism campaign the message expressing New Zealand as unpolluted having the highest mean of 3.20 ( $\mathrm{SD}=0.805$ ), followed by New Zealand having outstanding scenery of 2.97 ( $\mathrm{SD}=0.809$ ), New Zealand having a unique culture of 2.80 ( $\mathrm{SD}=0.761$ ), New Zealand having many adventure activities of $2.47(\mathrm{SD}=1.106)$, New Zealand being a young country of 2.27 ( $\mathrm{SD}=0.944)$, and New Zealand being untouched by modern development of 2.27 ( $\mathrm{SD}=1.048)$. A possible reason for the messages of New Zealand being unpolluted, having outstanding scenery, and having a unique culture acquiring the largest means can perhaps be due to a larger degree of imagery regarding these specific features in the ' $100 \%$ PURE NZ' tourism campaign within China. 


\subsection{Part 2}

\section{In-Depth Analysis}

After the identification of the key frequencies regarding the descriptive data from the questionnaire responses, cross-tabs were employed to examine the primary variable in relation to the various other components of the questionnaire to further the analysis of data, and investigate more in-depth information about the Chinese visitor market and 'sustainability'. The variable used was travel structure, the reason why this variable was employed as an analytical variable was due to the Chinese outbound market being under-researched, but also as a means of identifying whether the Chinese visitor market to New Zealand is as homogeneous as established. By examining the travel structure of the Chinese visitors the researcher is able to establish whether there are factors such as life and travel experiences that impact on the travel motivations and expectations of the visitors that may or may not occur for visitors either travelling with a tour group or independently.

There are also a number of explanations why it is advantageous to examine Chinese visitors via their travel structure; distinctively because research on travel structure is still scarce in numerous aspects, specifically in regards to the tendency for prior research to concentrate on demographics and trip characteristics, and the considerable focus on the demand side (Chen, 2002). However, with travel structure as a variable, linkages are able to be acknowledged to assist in establishing the emerging motivators and travel behaviours of Chinese visitors, and whether there is still a large proportion of visitors who prefer "mass" travel, or if the Chinese visitor market has begun to mature as FITs to enjoy more adventurous, personal experiences (Basala \& Klenosky, 2001).

To further the understanding of the quantitative data travel structure variables were employed chi-square and t-tests were employed to examine the extent to which there were significant statistical differences between Chinese tour group visitors and independent travellers.

\subsubsection{Visitor Characteristics \& Trip Characteristics}

Examining the travel structure of the visitors' trip in New Zealand showed that there is no significant difference that occurs between the age groups of tour group and 
independent visitors ( $p=0.541$ ), table 4.15 . However, there seems to be almost a 50:50 division between the number of visitors who travelled with a tour group or travelled independently in the age group of 30-49 years and in the age group of 50-69 years. However, there was an identifiable difference in the travel structure of the respondents in the age group of $18-29$ years. In this age group $63.6 \%$ of the respondents travelled with a tour group; whilst $36.4 \%$ travelled independently.

An assumed reason this distinction could either involve: the language barrier that may exist if these respondents were to travel independently, the companionship that they may receive when travelling around New Zealand with a tour group, or the sense of safety when travelling in numbers; however, for the Chinese respondents that stated that they were 18 years, 3 out of the 4 respondents travelled around New Zealand independently.

Table 4-15: Cross tabulation of Travel Structure \& Age Group n=70

\section{Travel Structure}

\begin{tabular}{|l|r|r|r|}
\hline \multicolumn{1}{|c|}{ Age Group } & With a Tour Group & Independently & \multicolumn{1}{c|}{ Total } \\
\hline $18-29$ years & $36.8 \%$ & $25 \%$ & $\mathbf{3 1 . 4 \%}$ \\
\hline $30-49$ years & $44.7 \%$ & $50 \%$ & $\mathbf{4 7 . 1 \%}$ \\
\hline $50-69$ years & $18.4 \%$ & $25 \%$ & $\mathbf{2 1 . 4 \%}$ \\
\hline Total & $\mathbf{1 0 0 \%}$ & $\mathbf{1 0 0 \%}$ & $\mathbf{1 0 0 \%}$ \\
\hline
\end{tabular}

* Due to the fact that chi-square criteria not being met, the Likelihood ratio was employed rather than the Pearson chi-square (Cavana, Delahaye, \& Sekaran, 2001).

In the evaluation of the length of stay with regards to the differing travel structures, it was identified that there was a statistically significant difference between the visitors' length of stay and whether they travelled around New Zealand with a tour group or independently (table 4.16). With regards to the length of stay of tour groups, it was established that over half of the tour group respondents stayed between 4-7 nights in New Zealand (63.2\%) (table 4.17). Conversely, over $65.6 \%$ of the independent travellers articulated that they stayed in New Zealand longer than 2 weeks in New Zealand. 
Table 4-16: Cross tabulation of Travel Structure \& Length of Stay $n=70$

\begin{tabular}{|r|r|r|r|}
\hline & \multicolumn{3}{|c|}{ Travel Structure } \\
\hline Length of Stay & With a Tour Group & Independently & Total \\
\hline $1-3$ nights & $21.1 \%$ & $6.2 \%$ & $\mathbf{1 4 . 3 \%}$ \\
\hline $4-7$ nights & $63.2 \%$ & $28.1 \%$ & $\mathbf{4 7 . 1 \%}$ \\
\hline $8-14$ nights & $13.2 \%$ & $18.8 \%$ & $\mathbf{1 5 . 7 \%}$ \\
\hline $15-22$ nights & $0 \%$ & $6.2 \%$ & $\mathbf{2 . 9 \%}$ \\
\hline $23-29$ nights & $0 \%$ & $9.4 \%$ & $\mathbf{4 . 3 \%}$ \\
\hline 30 nights or more & $2.6 \%$ & $31.2 \%$ & $\mathbf{1 5 . 7 \%}$ \\
\hline Total & $\mathbf{1 0 0} \%$ & $\mathbf{1 0 0} \%$ & $\mathbf{1 0 0} \%$ \\
\hline
\end{tabular}

Table 4-17: T-test of Travel Structure \& Length of Stay n=70

\section{Travel Structure}

\begin{tabular}{|r|r|r|}
\hline $\begin{array}{c}\text { With a Tour Group } \\
\text { Mean }\end{array}$ & $\begin{array}{c}\text { Independently } \\
\text { Mean }\end{array}$ & \multicolumn{2}{c|}{ Total Mean } \\
\hline 6.47 & 19.94 & $\mathbf{1 2 . 6 3}$ \\
\hline & $t=-5.281, d f=68, p=0.000$ & \\
\hline
\end{tabular}

In the examination of the New Zealand Islands visited by the Chinese respondents, 42.9\% demonstrated that they had travelled to both the North and South Islands during their travels in New Zealand (table 4.18). However, there were no statistically significant difference $(p=0.165)$ between the New Zealand Islands visited and the travel structure employed by the Chinese respondents.

It was illustrated in the findings that there were more tour group visitors that visited both the North and South Islands (50\%), than there were independent travellers that visited both islands (34.4\%). In regards to tour group visitors, $47.4 \%$ conveyed that they only visited the North Island, in comparison to the 53.1\% of independent travellers that only visited the North Island. It was also identified that there were more independent travellers that visited only the South Island (12.5\%). 
Table 4-18: Cross tabulation of Travel Structure \& New Zealand Islands Visited n=70

\section{Travel Structure}

\begin{tabular}{|l|r|r|r|}
\hline \multicolumn{1}{|c|}{ NZ Island Visited } & With a Tour Group & Independently & Total \\
\hline North Island Only & $47.4 \%$ & $53.1 \%$ & $\mathbf{5 0 \%}$ \\
\hline South Island Only & $2.6 \%$ & $12.5 \%$ & $\mathbf{7 . 1 \%}$ \\
\hline Both North \& South Islands & $50 \%$ & $34.4 \%$ & $\mathbf{4 2 . 9 \%}$ \\
\hline Total & $\mathbf{1 0 0} \%$ & $\mathbf{1 0 0} \%$ & $\mathbf{1 0 0 \%}$ \\
\hline
\end{tabular}

$L R=3.600, d f=2, p=0.165$

* Due to the fact that chi-square criteria not being met, the Likelihood ratio was employed rather than the Pearson chi-square (Cavana, Delahaye, \& Sekaran, 2001).

In the examination of the main purpose of visitation to New Zealand findings illustrated that independent travellers visited friends and family significantly more than tour group visitors; however, it was also demonstrated that there was a significant difference in the tour groups and independent visitors that come to New Zealand for a holiday/vacation (table 4.19). With regard to the Chinese visitors that travelled around New Zealand with a tour group, $73.7 \%$ stated that their main purpose of visit was for holiday/vacation.

It was evident that there were no respondents that came for the purpose of visiting friends and family, or education due to the fact that the visitors were travelling with a tour group, therefore coming to New Zealand for these purposes was not feasible. However, groups that came for business (15.8\%) or conference/convention (7.9\%) were still apparent, and were quite similar to the results of independently travelling Chinese visitors, business (12.5\%) and conference/convention (9.4\%). In regards to the main purpose of visit of independent travellers was to visit friends and family (50\%). Nevertheless, the independent Chinese travellers have a wider variety of people coming to New Zealand for a larger array of purposes, which includes those coming for a holiday/vacation (18.8\%), and education (6.2\%). 
Table 4-19: Cross tabulation of Travel Structure \& Main Purpose of Visit to New Zealand n=70

\section{Travel Structure}

\begin{tabular}{|l|r|r|r|}
\hline \multicolumn{1}{|c|}{ Main Purpose of Visit } & With a Tour Group & Independently & \multicolumn{1}{c|}{ Total } \\
\hline $\begin{array}{l}\text { Visiting Friends \& } \\
\text { Family }\end{array}$ & $0 \%$ & $50 \%$ & $\mathbf{2 2 . 9 \%}$ \\
\hline Holiday/Vacation & $73.7 \%$ & $18.8 \%$ & $\mathbf{4 8 . 6 \%}$ \\
\hline Education & $0 \%$ & $6.2 \%$ & $\mathbf{2 . 9 \%}$ \\
\hline Business & $15.8 \%$ & $12.5 \%$ & $\mathbf{1 4 . 3 \%}$ \\
\hline Conference/Convention & $7.9 \%$ & $9.4 \%$ & $\mathbf{8 . 6 \%}$ \\
\hline Other & $2.6 \%$ & $3.1 \%$ & $\mathbf{2 . 9 \%}$ \\
\hline Total & $\mathbf{1 0 0} \%$ & $\mathbf{1 0 0} \%$ & $\mathbf{1 0 0 \%}$ \\
\hline
\end{tabular}

* Due to the fact that chi-square criteria not being met, the Likelihood ratio was employed rather than the Pearson chi-square.

In relation to the travel structure of the Chinese respondents and the major activities the respondents participated in there are a number of similarities in regards to respondents' involvement in activities involving: sightseeing, shopping, and visiting a historical site (table 4.20). However, it was clear that attending a Maori cultural performance (86.8\%) and visiting a casino (60.5\%) were participated in by more tour groups than independent travellers; a probable explanation of this could be the fact that tour groups are only in a destination for a limited amount of time, and it would be quite typical for visitors to attend or participate in a local/traditional activity. With regards to tour groups visiting casinos it would most likely be a strategy to straightforwardly increase local revenue; yet, when specifically examining the Chinese market gambling or visiting a casino can be identified as a characteristic leisure activity. When studying the major activities that independent travellers participated in, there were a large number of respondents demonstrating they involved themselves in visiting friends and family (53.1\%), visiting a botanical garden (56.3\%), and visiting a museum/gallery (50\%). The primary reason why a majority of independent visitors stated they participated in the activity of visiting friends and family was because this was their primary purpose of their visit to New Zealand. In spite of this, a possible rationale for the independent travellers visiting a botanical garden, and/or visiting a museum/gallery could have essentially been because their friends and family believed that these activities were worthwhile for them to participate in to learn more about the local environment in New Zealand, but could also be related to these activities being more value for money due to the fact that these activities are generally free. 
Table 4-20: Cross tabulation of Travel Structure \& Major Activities Participated in During Visit to New Zealand $n=70$ (1)

\section{Travel Structure (Percentage Cases \%)}

\begin{tabular}{|l|r|r|r|}
\hline Major Activities & With a Tour Group & Independently & Total \\
\hline Visited Friends \& Family & $5.3 \%$ & $53.1 \%$ & $\mathbf{2 7 . 1 \%}$ \\
\hline Visited a Historical Site & $68.4 \%$ & $53.1 \%$ & $\mathbf{6 1 . 4 \%}$ \\
\hline Visited a Botanical Garden & $52.6 \%$ & $56.2 \%$ & $\mathbf{5 4 . 3 \%}$ \\
\hline Visited a Beach & $50 \%$ & $34.4 \%$ & $\mathbf{4 2 . 9 \%}$ \\
\hline Visited a Museum/Gallery & $47.4 \%$ & $50 \%$ & $\mathbf{4 8 . 6 \%}$ \\
\hline Visited a Farm & $42.1 \%$ & $34.4 \%$ & $\mathbf{3 8 . 6 \%}$ \\
\hline Visited a Vineyard & $5.3 \%$ & $6.2 \%$ & $\mathbf{5 . 7 \%}$ \\
\hline Visited a Casino & $60.5 \%$ & $28.1 \%$ & $\mathbf{4 5 . 7 \%}$ \\
\hline Visited Hot Pools/ Geothermal & $36.8 \%$ & $34.4 \%$ & \\
\hline Sites & & & $\mathbf{3 5 . 7} \%$ \\
\hline Whale/Dolphin Watching & $0 \%$ & $9.4 \%$ & $\mathbf{4 . 3 \%}$ \\
\hline Zoo/Wildlife/Marine Park & $18.4 \%$ & $15.6 \%$ & $\mathbf{1 7 . 1 \%}$ \\
\hline Rafting/Kayaking/Jet Boating & $5.3 \%$ & $6.2 \%$ & $\mathbf{5 . 7 \%}$ \\
\hline Mountain/Rock Climbing/Caving & $0 \%$ & $9.4 \%$ & $\mathbf{4 . 3 \%}$ \\
\hline Snow Boarding/Skiing & $0 \%$ & $9.4 \%$ & $\mathbf{4 . 3 \%}$ \\
\hline Maori Cultural Performance & $86.8 \%$ & $21.9 \%$ & $\mathbf{5 7 . 1 \%}$ \\
\hline Fishing & $0 \%$ & $9.4 \%$ & $\mathbf{4 . 3 \%}$ \\
\hline Tramping & $0 \%$ & $12.5 \%$ & $\mathbf{5 . 7 \%}$ \\
\hline Bungy Jumping & $10.5 \%$ & $0 \%$ & $\mathbf{5 . 7 \%}$ \\
\hline Sightseeing & $81.6 \%$ & $71.9 \%$ & $\mathbf{7 7 . 1 \%}$ \\
\hline Shopping & $76.3 \%$ & $68.8 \%$ & $\mathbf{7 2 . 9 \%}$ \\
\hline Golf & $2.6 \%$ & $0 \%$ & $\mathbf{1 . 4 \%}$ \\
\hline Other & $0 \%$ & $3.1 \%$ & $\mathbf{1 . 4 \%}$ \\
\hline Multiple Response Question & & & \\
\hline
\end{tabular}

In the investigation of the main source of information utilized by the respondents, it was established that respondents that travelled around New Zealand with a tour group expressed that their primary source of information was from the organization they work for and/or work colleagues (44.7\%), followed by the use of travel agents (42.1\%) (table 4.21). However, in comparison to the other sources of information utilized by tour groups, there was a large difference in the number of respondents that employed the sources of information, for example those that employed the use of friends and family (18.4\%), guidebooks (15.8\%), and Internet website/s in Chinese (13.2\%). Yet, in contrast over $50 \%$ of the Chinese independent visitors expressed the respondents used friends and family as their main source of information. Independent visitors also employed other sources of information; conversely, was quite divergent in comparison to the number of respondents that employed friends and family, for example only $21.9 \%$ 
used the organization they work for and/or work colleagues, and 18.8\% used Internet website/s in Chinese. It was also identified that the number of independent travellers that employed Internet website/s in English and guidebooks were equal at $12.5 \%$. Nonetheless, it was interesting to find that no independent visitors used travel agents as a source of information; however, 3.1\% of independent visitors utilized the TV/radio, whereas TV/radio was not employed at all by tour group travellers.

Table 4-21: Cross tabulation of Travel Structure \& Sources of Information n=70 (1)

\begin{tabular}{|l|r|r|r|}
\hline & \multicolumn{3}{|c|}{ Travel Structure } \\
\hline Sources of Information & With a Tour Group & Independently & \multicolumn{1}{c|}{ Total } \\
\hline Friends \& Family & $0 \%$ & $65.6 \%$ & $\mathbf{4 0 \%}$ \\
\hline Internet website/s in English & $7.9 \%$ & $12.5 \%$ & $\mathbf{1 0 \%}$ \\
\hline Internet website/s in Chinese & $13.2 \%$ & $18.8 \%$ & $\mathbf{1 5 . 7 \%}$ \\
\hline Newspaper/Magazine & $5.3 \%$ & $6.3 \%$ & $\mathbf{5 . 7 \%}$ \\
\hline $\begin{array}{l}\text { Organization you work for or work } \\
\text { colleagues }\end{array}$ & $44.7 \%$ & $21.9 \%$ & $\mathbf{3 4 . 3 \%}$ \\
\hline TV/Radio & & & \\
\hline Travel Agent & $42.1 \%$ & $3.1 \%$ & $\mathbf{1 . 4 \%}$ \\
\hline Guidebooks & $15.8 \%$ & $0 \%$ & $\mathbf{2 2 . 9 \%}$ \\
\hline $\begin{array}{l}\text { Other } \\
\text { (1) Multiple Response Question }\end{array}$ & $2.6 \%$ & $12.5 \%$ & $\mathbf{1 4 . 3 \%}$ \\
\hline
\end{tabular}

\subsubsection{Satisfaction}

With regards to the level of satisfaction displayed by the Chinese visitors, it is identified that there was no statistically significant difference between the different travel structures (table 4.23). However, it was clearly identified that in both forms of travel structure the majority of the responses demonstrated respondents were 'moderately satisfied' with their visit to New Zealand, as illustrated in table 4.22. In regards to the respondent's level of satisfaction, $47.2 \%$ of the respondents that travelled with a tour group, and $50 \%$ of the respondents that travelled independently around New Zealand were 'moderately satisfied' with their visit to New Zealand. The respondents that travelled around New Zealand independently were the only group in regards to travel structure that had responses that expressed their experience in New Zealand was less that 'moderately satisfied'. However, $21.9 \%$ of the 32 independent respondents were 'very satisfied' with their visit to New Zealand, with $25 \%$ of the 36 tour group 
respondents stating they were also 'very satisfied'. Chen (2002) established the fact that with tour group travel the tour leader's service will impact on the engagement the visitors will have with the 'company's image, customer loyalty and word-of-mouth communications' (p.23); this was therefore possibly a factor that impacted on the level of satisfaction the tour group visitors experience within the destination. Additionally, word-of-mouth communications are essentially as a primary form of information source for Chinese visitors as seen in this study; hence, tour guide performance is a very important element in the visitors' level of knowledge and satisfaction. In contrast, tour group visitors have a higher mean in regards to their level of satisfaction (mean=3.78, $\mathrm{SD}=0.832$ ), than that of independent travellers (mean=3.66, $\mathrm{SD}=0.865$ ).

Table 4-22: Cross tabulation of Travel Structure \& Level of Satisfaction (5-point scale) n=68

\begin{tabular}{|c|c|c|c|c|c|c|}
\hline & \multicolumn{6}{|c|}{ Level of Satisfaction } \\
\hline $\begin{array}{c}\text { Travel } \\
\text { Structure }\end{array}$ & $\begin{array}{c}\text { Very } \\
\text { Dissatisfied }\end{array}$ & 2 & $\begin{array}{l}\text { Moderately } \\
\text { Satisfied }\end{array}$ & 4 & $\begin{array}{c}\text { Very } \\
\text { Satisfied }\end{array}$ & Total \\
\hline $\begin{array}{l}\text { With a Tour } \\
\text { Group }\end{array}$ & $0 \%$ & $0 \%$ & $47.2 \%$ & $27.8 \%$ & $25 \%$ & $52.9 \%$ \\
\hline Independently & $0 \%$ & $3.1 \%$ & $50 \%$ & $25 \%$ & $21.9 \%$ & $47.1 \%$ \\
\hline Total & $0 \%$ & $1.5 \%$ & $48.5 \%$ & $26.5 \%$ & $23.5 \%$ & $100 \%$ \\
\hline
\end{tabular}

Table 4-23: T-test of Travel Structure \& Level of Satisfaction n=68

\section{Travel Structure}

\begin{tabular}{|c|c|c|}
\hline $\begin{array}{c}\text { With a Tour Group } \\
\text { Mean }\end{array}$ & $\begin{array}{c}\text { Independently } \\
\text { Mean }\end{array}$ & Total Mean \\
\hline 3.78 & 3.66 & 3.72 \\
\hline & $t=0.590, d f=66$, sig 2-tailed $=0.872$ & \\
\hline
\end{tabular}

\subsubsection{Sustainable Tourism in New Zealand}

Whilst assessing of the travel structure the Chinese visitors and if the visitors have heard of the term 'sustainability', results indicate that there was no significant difference ( $p=0.128$ ) between the two groups. It was established that $81.6 \%$ of tour group respondents have heard of the term 'sustainability', which comprises of $61.5 \%$ of all respondents that expressed they have heard of 'sustainability' (table 4.24). While, out of the 32 independent travellers $65.6 \%$ demonstrated that they have heard of 'sustainability'. 
Table 4-24: Cross tabulation of Travel Structure \& If the Respondent has heard of the term 'Sustainability' n=70

Travel structure

\begin{tabular}{l|r|r|r|}
\hline $\begin{array}{l}\text { If the Respondent have } \\
\text { Heard of the Term } \\
\text { 'Sustainability' }\end{array}$ & With a Tour Group & Independently & \multicolumn{1}{c|}{ Total } \\
\hline Yes & & & \\
\hline No & $59.6 \%$ & $40.4 \%$ & $\mathbf{7 4 . 3 \%}$ \\
\hline Total & $38.9 \%$ & $61.1 \%$ & $\mathbf{2 5 . 7 \%}$ \\
\hline
\end{tabular}

Of the 52 respondents that have heard of the term 'sustainability', their level of understanding was examined in relation to their travel structure, from the t-test results it was identified that there was no statistically significant difference between tour group and independent traveller responses (table 4.26). Findings indicated $21.4 \%$ of tour group respondents believed that they have an above 'moderate' understanding of 'sustainability', with $19.3 \%$ of the 31 respondents that were with a tour group reporting they have a 'very good' understanding of ‘sustainability' (table 4.25). In comparison, $28.6 \%$ of the 21 independent travellers articulated that they believed they have a 'very good' understanding of 'sustainability'.

However, 48.4\% of tour group respondents expressed they only have a 'moderate' understanding of the term; whereas, $38.1 \%$ of the independent travellers stated that they also had a 'moderate' understanding of 'sustainability'. From the results, it was also identified that $25.8 \%$ of all tour group respondents, and $28.6 \%$ of the independent travellers have a below 'moderate' understanding of 'sustainability'. Nonetheless, $16.1 \%$ of tour group responses conveyed respondents had a 'very limited' understanding of the term 'sustainability'. In regards to the comparison of the means, independent travellers have a slightly higher mean $(3.10, \mathrm{SD}=1.513)$ than tour group visitors (3.03, $\mathrm{SD}=1.278)$. 
Table 4-25: Cross tabulation of Travel Structure \& Level of Understanding Respondents have of the term 'Sustainability' $n=52$

\begin{tabular}{|c|c|c|c|c|c|c|}
\hline \multirow[b]{2}{*}{$\begin{array}{l}\text { Travel } \\
\text { Structure }\end{array}$} & \multicolumn{6}{|c|}{$\begin{array}{l}\text { Level of Understanding Respondents have of the term 'Sustainability' (5 point } \\
\text { scale) }\end{array}$} \\
\hline & $\begin{array}{l}\text { I have a very } \\
\text { limited } \\
\text { understanding of } \\
\text { the term } \\
\text { 'sustainability' } \\
1\end{array}$ & 2 & $\begin{array}{l}\text { I have a moderate } \\
\text { understanding of } \\
\text { the term } \\
\text { 'sustainability' } \\
3\end{array}$ & 4 & $\begin{array}{l}\text { I have a very } \\
\text { good } \\
\text { understanding of } \\
\text { the term } \\
\text { 'sustainability' } \\
5\end{array}$ & Total \\
\hline $\begin{array}{l}\text { With a Tour } \\
\text { Group }\end{array}$ & $16.1 \%$ & $9.7 \%$ & $48.4 \%$ & $6.5 \%$ & $19.4 \%$ & $59.6 \%$ \\
\hline Independently & $23.8 \%$ & $4.8 \%$ & $38.1 \%$ & $4.8 \%$ & $28.6 \%$ & $40.4 \%$ \\
\hline Total & $100 \%$ & $100 \%$ & $100 \%$ & $100 \%$ & $100 \%$ & $100 \%$ \\
\hline
\end{tabular}

Table 4-26: T-test of Travel Structure \& Level of Understanding Respondents have of the term 'Sustainability' n=52

Travel Structure

\begin{tabular}{|c|c|c|}
\hline $\begin{array}{c}\text { With a Tour Group } \\
\text { Mean }\end{array}$ & $\begin{array}{c}\text { Independently } \\
\text { Mean }\end{array}$ & Total Mean \\
\hline 3.03 & 3.10 & 3.06 \\
\hline
\end{tabular}

With regards to the respondents travel structure and whether the Chinese respondents believed it is important for tourists to understand the term 'sustainability', almost an even number of tour group and independent travelling respondents expressed that it is important for tourists to understand the term. In addition, it can be stated that there is no significant relationship between the visitors' travel structure and if the respondents believe it is important for tourists to understand the term 'sustainability', this was demonstrated in the almost equal number of tour group and independent travellers that believe it is important for tourists to understand the term 'sustainability' (table 4.27). It was recognized that in the findings over $70 \%$ of both travel structure groups believed comprehending the term 'sustainability' was significant, with $77.4 \%$ of tour group responses, and $71.4 \%$ of independent traveller responses demonstrating the terms importance. Nonetheless, $22.6 \%$ of tour group responses, and $28.6 \%$ of independent traveller responses illustrated that it is unimportant for tourists to understand the term ‘sustainability'. 
Table 4-27: Cross tabulation of Travel Structure \& Is it Important for Tourists to Understand the term 'Sustainability' $n=52$

\begin{tabular}{|l|r|r|r|}
\hline & \multicolumn{3}{|c|}{ Travel Structure } \\
\hline $\begin{array}{l}\text { Is it Important for } \\
\text { Tourists to Understand } \\
\text { the Term 'Sustainability' }\end{array}$ & $\begin{array}{c}\text { With a Tour } \\
\text { Group }\end{array}$ & Independently & \multicolumn{1}{c|}{ Total } \\
\hline Yes & $77.4 \%$ & $71.4 \%$ & $\mathbf{7 5 \%}$ \\
\hline No & $22.6 \%$ & $28.6 \%$ & $\mathbf{2 5 \%}$ \\
\hline Total & $\mathbf{5 9 . 6 \%}$ & $\mathbf{4 0 . 4 \%}$ & $\mathbf{1 0 0 \%}$ \\
\hline
\end{tabular}

In the examination of the respondents travel structure and the responses regarding who the respondents believed was the most responsible for dealing with the impacts of tourism on the destination, no statistically significant differences in responses were observed between the two variables (table 4.28). Over 50\% of tour group respondents (55.6\%) and independent traveller respondents (59.4\%) believed governments were the most responsible for such impacts of tourism. It was also interesting to find that both tour group respondents and independent traveller respondents believed that the tourists themselves were the most responsible for the impacts of tourism on the destination, with $13.9 \%$ of the tour group responses, and $21.9 \%$ of the independent traveller responses stating so. However, out of the responses given, only those that visited New Zealand with a tour group articulated that local tourism organizations are the most responsible for dealing with the impacts of tourism on the destination (5.6\%).

Table 4-28: Cross tabulation of Travel Structure \& Who Respondents believe is the most responsible for dealing with the impacts caused by tourism on the destination $n=68$

\begin{tabular}{|c|c|c|c|}
\hline \multirow[b]{2}{*}{$\begin{array}{l}\text { Most responsible for } \\
\text { dealing with impacts }\end{array}$} & \multicolumn{3}{|c|}{ Travel Structure } \\
\hline & With a Tour Group & Independently & Total \\
\hline The Tourist & $13.9 \%$ & $21.9 \%$ & $17.6 \%$ \\
\hline Tourism Businesses & $11.1 \%$ & $6.3 \%$ & $8.8 \%$ \\
\hline Tour Operators & $13.9 \%$ & $12.5 \%$ & $13.2 \%$ \\
\hline $\begin{array}{l}\text { Local Tourism } \\
\text { Organizations }\end{array}$ & $5.6 \%$ & $0 \%$ & $2.9 \%$ \\
\hline Governments & $55.6 \%$ & $59.4 \%$ & $57.4 \%$ \\
\hline Total & $52.9 \%$ & $47.1 \%$ & $100 \%$ \\
\hline \multicolumn{4}{|c|}{$L R=3.689, d f=4, p=0.450$} \\
\hline
\end{tabular}




\subsubsection{New Zealand's Marketing Image}

According to the responses expressing the respondents have seen New Zealand's ' $100 \%$ PURE NZ' tourism campaign, the results revealed that there was no statistically significant difference between the travel structure and whether the respondents have seen the tourism campaign. It was identified that more tour group visitors have seen the campaign, in comparison to independent travellers; however, there was no significant difference ( $p=0.127$ ), as demonstrated in table 4.29. Whilst investigating the responses regarding the Chinese respondents who have seen New Zealand's '100\% PURE NZ' tourism campaign, $63.6 \%$ of tour group responses, and $36.7 \%$ of the independent traveller responses conveyed the respondents have seen the tourism campaign. In spite of this, when examining the responses stating the respondents haven't seen New Zealand's '100\% PURE NZ' tourism campaign, the respondents that travelled independently had a higher percentage of responses that articulated the respondents haven’t seen the '100\% PURE NZ’ tourism campaign (55.3\%).

Table 4-29: Cross tabulation of Travel Structure \& Have the Respondents seen the '100\% PURE NZ' tourism campaign $n=68$

\begin{tabular}{|l|r|r|r|}
\hline $\begin{array}{l}\text { Have Respondents seen } \\
\text { the '100\% PURE NZ' } \\
\text { tourism campaign }\end{array}$ & With a Tour Group & $\begin{array}{r}\text { Travel Structure } \\
\text { Independently }\end{array}$ & \multicolumn{1}{c|}{ Total } \\
\hline Yes & & & \\
\hline No & $63.6 \%$ & $36.7 \%$ & $\mathbf{4 4 . 1 \%}$ \\
\hline Total & $44.7 \%$ & $55.3 \%$ & $\mathbf{5 5 . 9 \%}$ \\
\hline
\end{tabular}

In the investigation of whether New Zealand's '100\% PURE NZ' tourism campaign impacted on the respondents' decision to visit New Zealand, it was identified that the chi-square test did not detect any significant difference between the travel structure of the Chinese visitors, and whether the New Zealand tourism campaign influenced their decision to take a trip to New Zealand, as displayed in table 4.31. However, there was obviously a difference in the distribution between the tour group and independent travellers who have seen the ' $100 \%$ PURE NZ' tourism campaign (table 4.30). Furthermore, for both tour group visitors and independent travellers the majority of the responses illustrated that the campaign was only 'moderately important' as an influencer in their decision to visit New Zealand. However, there were no independent 
travellers that stated the campaign was either 'important' or 'very important'; yet, $15.8 \%$ of tour group visitors expressed that the ' $100 \%$ PURE NZ' tourism campaign was 'very important'. It was also demonstrated in the findings that there was almost an even number of tour group responses (36.9\%) and independent traveller responses (36.4\%) that expressed the campaign was less than 'moderately important' on their decision to visit New Zealand. Nonetheless, from the tour group responses illustrated that there was more responses that expressed that the campaign was 'unimportant' (15.8\%) on the respondents' decision to visit New Zealand. Yet, for the independent travellers there were an even number of responses that stated the ' $100 \%$ PURE NZ' tourism campaign was 'of little importance' (18.2\%) and 'unimportant' (18.2\%). Alternatively, when examining the means of the differing travel structures, tour group visitors had a higher mean at $2.89(\mathrm{SD}=1.286)$ than independent travellers with a mean at $2.45(\mathrm{SD}=0.820)$.

Table 4-30: Cross tabulation of Travel Structure \& Did the '100\% PURE NZ' tourism campaign impact on the Respondents decision to visit New Zealand (5-point scale) $\mathbf{n = 6 8}$

\begin{tabular}{|c|c|c|c|c|c|c|}
\hline \multirow[b]{2}{*}{$\begin{array}{l}\text { Travel } \\
\text { Structure }\end{array}$} & \multicolumn{6}{|c|}{$\begin{array}{c}\text { Did the ' } 100 \% \text { PURE NZ' tourism campaign impact on the respondents } \\
\text { decision to visit }\end{array}$} \\
\hline & $\begin{array}{c}\text { Unimportant } \\
1\end{array}$ & $\begin{array}{c}\text { Of Little } \\
\text { Importance } \\
2\end{array}$ & $\begin{array}{c}\text { Moderately } \\
\text { Important } \\
3\end{array}$ & $\begin{array}{c}\text { Important } \\
4\end{array}$ & $\begin{array}{c}\text { Very } \\
\text { Important } \\
5\end{array}$ & Total \\
\hline $\begin{array}{l}\text { With a Tour } \\
\text { Group }\end{array}$ & $15.8 \%$ & $21.1 \%$ & $36.8 \%$ & $10.5 \%$ & $15.8 \%$ & $100 \%$ \\
\hline Independently & $18.2 \%$ & $18.2 \%$ & $63.6 \%$ & $0 \%$ & $0 \%$ & $100 \%$ \\
\hline Total & $16.7 \%$ & $20 \%$ & $46.7 \%$ & $6.7 \%$ & $10 \%$ & $100 \%$ \\
\hline
\end{tabular}

Table 4-31: T-test of Travel Structure \& Did the '100\% PURE NZ' tourism campaign impact on the Respondents decision to visit New Zealand $n=68$

Travel Structure

\begin{tabular}{ccc|}
$\begin{array}{c}\text { With a Tour Group } \\
\text { Mean }\end{array}$ & $\begin{array}{c}\text { Independently } \\
\text { Mean }\end{array}$ & Total Mean \\
\hline 2.89 & 2.45 & $\mathbf{2 . 7 3}$ \\
\hline & $t=1.017, d f=28$, sig 2-tailed=0.318 & \\
\hline
\end{tabular}




\section{CHAPTER 5 Qualitative Analysis - ADS Tour Operators' Perspective}

\subsection{Introduction}

This chapter is set out to examine the qualitative data collected in the face-to-face interviews with the ADS registered inbound tour operators that cater to and target the Chinese visitor market. The suppliers' perspective was implemented in this study to enhance the data collected from the questionnaires, but to also develop an alternative view of the themes being examined in this study. At present there has been very limited research that has incorporated the suppliers' view, specifically regarding sustainability and sustainable tourism in the context of a particular market. To produce a more comprehensive examination of the interview data, a content analysis was employed with regards to the same variables investigated in the quantitative analysis chapter: visitor characteristics, trip characteristics, satisfaction, factors that impact on the visitors' decision to visit a destination, sustainable tourism in New Zealand, and New Zealand's marketing campaign. With regards to the aspect of 'sustainability', the term was broadly employed in the interviews, therefore tour operators were able to comment and give their opinions according to their own observations, unless a particular component of sustainability was examined, such as the environmental aspect.

With the content analysis of the tour operator interviews, it should be clarified that the tour operators only cater to the Chinese visitors that employ the use of the intermediary; therefore, the comments that they have made regarding FITs are not representative of the 'true FIT'. 'True FIT' visitors to New Zealand are those who travel around independently, in contrast to those who participate in coach or packaged tours (TNZ, 2008). Due to the fact that the qualitative data was only collected to enhance the quantitative data; the data retrieved was not employed as a generalization of the entire tour operator population. Although the key variables as displayed in the analytical framework were investigated in the interviews, the inbound tour operators also introduced two other subjects: the ADS system, and shopping tours. These two subjects were not planned to be examined by this research; however, developed a number of interesting opinions and suggestions that added to the interpretation of the 
environmental sustainability of tourism in New Zealand, and the importance of understanding the Chinese visitor market to New Zealand. The findings of this study will therefore be investigated further in the discussion chapter of this thesis in correspondence with the quantitative results.

\subsection{Part 1}

\subsubsection{ADS Registered Tour Operator Profile}

- Why do Tour Operators target the Chinese Visitor Market?

In this section of data analysis, interview data will specifically study the general profile of the tour operators (see Appendix G), and identify the primary characteristics of their Chinese visitors. With reference to the tour operator profile matrix, a large number of the tour operators specifically target the Chinese visitor market because they believed that their experience with the market and the cultural background make the Chinese visitor market less problematic to target.

However, Operator B and Operator D demonstrated that their organizations offer tours in other destinations. These two operators were also the only operators interviewed that stated that they do not specifically target the Chinese international visitor market. Operator B stated that their organization does not target the Chinese market in particular because they have previously attempted to; however, the market became problematic to target as the Chinese market tended to focus on shopping tours, therefore making the visitor market very price competitive.

"We wanted to target China, but it's very difficult because of the shopping group and we don't do any shopping group, so it's not competitive compared with the other shopping group agents...” (Operator B)

Whereas, Operator D described their organizations encounter with the Chinese visitor market and the difficulty the tour operator faced when attempting to target the market. Operator D conveyed that their organization prided themselves in the quality of their tour products, and the level of experience the visitors gained from the participation of their tours. However, with budget Chinese visitor tours and the escalating intensity of 
undercutting shopping tours, the organization turns down the exclusive focus on targeting Chinese visitors.

"We are very experienced in the rest of South East Asia, and China is a growing market... we targeted them, but because of so much competition, and everybody's undercutting then there's no profit in it... Because we pride ourselves as a company that gives quality service and we like that everyone that comes to book with us has a good experience. So we stay out of all those budget tours and undercutting shopping tours... we're trying to go back to see how the market is, and to test it... we find that I think there's some room for us to go in and target the high end incentive group and the leisure group.” (Operator D)

Out of the seven tour operators there were three tour operators (Operator C, Operator E, and Operator $G$ ) that articulated the Chinese visitor market as their main visitor market targeted. However, Operator B was one particular interviewee that expressed that their company's primary visitor market was not China, reporting that the Japanese visitor market comprises of $99 \%$ of their customer base.

Demonstrated in the interviews was the fact that the majority of the tour operators offered tours to Australia and New Zealand. From the tour operators that expressed they offer their Chinese visitors Australian and New Zealand tours, the greater part of the tour operators state that approximately $90 \%$ of their Chinese visitors travel to Australia, with just $10 \%$ visiting New Zealand. Operator F expands on this discussion by stating tours that combine a visit to both Australia and New Zealand will take about 10 days; however, they will spend almost a week in Australia, leaving only 3 days in New Zealand. Operator $G$ continues the assertion by stating possible reasons for New Zealand having only a limited number of tour groups from China; there are very few tour groups from China that solely visit New Zealand. Operator G specifically illustrated that their organization only received 2-3 tours every month that come explicitly to New Zealand, and was not an 'add-on' to an Australian tour.

"...the first reason is because if 100 tours go overseas, like come to the South Pacific and only 10 tours will be Australia and New Zealand, and probably 1 or 2 tours will be pure New Zealand tour. The reason is the air fare because the... if you fly from China to Australia, there are quite a few airlines and it's really, really low fares and New Zealand can't take the competition. There's no competing price. The second one is Australia is more attractive than New Zealand for the Chinese. They've got a big country... and also for their tour fees it's a little bit lower than New Zealand.” (Operator G) 
In addition, all tour operators undertake ADS tours due to New Zealand Government requirements regarding Chinese visitors needing an ADS visa, and because ADS visas are processed within 10 days, rather than a month for a regular visitor visa (Cropp, 2008).

- What types of Chinese Visitors do the Tour Operators receive?

The majority of tour operators conveyed that their Chinese visitor customer base was largely leisure travellers. Alternatively, Operator E and Operator F articulated that most of their Chinese visitors were government employees. With Operator B and Operator D pointing out that they also undertake a number of business/incentive based tours. However, the other interviewed operators said their business visitors in comparison to holiday visitors are quite low, with Operator C expressing that holiday visitors comprise of $90 \%$ of their Chinese market.

Conversely, Operator F and Operator $G$ were the only operators that expressed their organizations having an FIT customer base; yet, this market is still a small group. With regards to a statement made by Operator F concerning FIT visitors, it is clear that the operator believes that the number of Chinese FIT has not as yet increased or matured as fast, or as steadily as other visitor markets to New Zealand, conveying that a possible reason for this could be related to the overall cost of independent travel, and other issues such as culture and language.

Tourism New Zealand has now signed an agreement with seven travel agents in Beijing and Shanghai to promote packages to New Zealand for FIT, and as part of this arrangement Immigration New Zealand has committed to turnover the processing of individual independent travel visas more rapidly (Cropp, 2008). However, Operator G portrayed the difficulty in gaining an independent visa to New Zealand, and the various criteria involved in the process. Operator $\mathrm{G}$ also illustrated the length of time it takes for the Chinese visitors to acquire a visa, with and without ADS approval, demonstrating that with an ADS visa it takes less time to process and gain approval. On the other hand, this exhibits the complexity in maturing the Chinese visitor market from tour groups to FITs. 
"Not many FIT because it's very hard for them to get a visa in China. Might take about 10-15 days to process but you have to prepare everything like your bank statement and your police certificate, everything and you submit into the embassy and it takes about 10-15 days and for ADS only 3 days." (Operator G)

\subsubsection{Chinese Visitor Demographics \& Trip Characteristics}

- Chinese Visitor Demographics

In the examination of the general demographics of the operators' Chinese visitors the majority of the operators stated that their visitors were between 30-60 years, with four of the seven interviewed tour operators conveying that the Chinese visitors to New Zealand demonstrated no difference in the gender of the visitors, with the other three tour operators articulating that the majority of their visitor were male. Operator $G$ expressed several facets concerning the general demographics of their Chinese visitors, portraying that they are between 30-60 years old, mostly male, middle-class or higher; therefore having a higher degree of disposable time and money. Operator $G$ also conveyed that their visitors are possibly less experienced in the travel industry, which illustrates differing motivations and expectations from other visitor markets to New Zealand.

“Age about 30-60 cause they've got more budget and it's common... mostly male... travelling overseas is a middle class in China or maybe even higher level can afford to travel overseas and maybe at the age of $30-35 . .$. you can see they have like 10 years of working experience and they earn about 10 years of money and they can afford to travel overseas.” (Operator G)

In a study undertaken by Hemström et al. (2006) the authors examine a report by Price Waterhouse Coopers in 2001, and identified that a sizeable number of Chinese tourists travelling internationally were married male between 24-44 years old with high incomes. Moreover, the investigation by Price Waterhouse Coopers (2001) acknowledged that there are largely three groups of Chinese travellers, seniors who retire comparatively earlier than Western societies, therefore having more discretionary time to travel. Young people between 25-35 years old who search for adventure, and lastly families who are possibly more price sensitive in comparison to the seniors and younger travellers, but travel to more neighbouring countries to get the most of their visit (Hemström et al., 2006). Although from the interviews it was identified that there were 
a number of tour operators that target the more experienced, higher-class consumers. Operator D was the only operator that articulated their organization targeted or offered tours to student, which are focused on the cultural exchange and OE (overseas experience), rather than for educational or language purposes. This could be a result of increasing demand from the student market.

“...we do a lot of leisure tours and incentive...we also do student groups as well, not so much as the language team but more of the cultural exchange kind.” (Operator D)

\section{- Chinese Visitor Trip Characteristics}

Tour operators also demonstrated a similarity in the types of tours their Chinese visitors took part in. The majority of the operators stated that their visitors only visit the North Island, staying in New Zealand for 3-4 nights, which may also be a factor relating to where the Chinese visitor came from in China, as articulated by Operator A.

“...4 days, 3 nights... and from a different part of China. ...like the South of China they may stay 6-7 days, from South to North Island.” (Operator A)

The interviewed tour operators had also indicated a resemblance in the percent of visitors from China that visit both the North and South Islands. Operators demonstrated that approximately $75-80 \%$ of their Chinese visitors only visit the North Island when travelling to New Zealand; hence, revealing that only 18-20\% of Chinese visitors visit the North and South Islands. It was also expressed by Operator F that of the Chinese visitors that travel around the North Island the visitors only travel to Auckland and Rotorua. In an article by Cropp (2008), the author concurs with this view, expressing that a considerable number of the Chinese visitor groups that spend 3 days in New Zealand are on a tour attached to an Australian tour. The author also adds to this statement by indicating that when the Chinese visitors come to New Zealand they are taken from Auckland to Rotorua and back, occasionally in substandard transportation, resulting in the visitors not being able to see much of New Zealand's iconic scenery because many are directed from one souvenir shop to the next (Cropp, 2008).

With regard to whether the tour operators' Chinese visitors generally stayed longer in New Zealand after the completion of their tour, all tour operators stated that their 
visitors depart New Zealand straight after their tours. The answers to this question sparked interesting findings, in regards to the strict requirements of gaining an ADS visa, but also because of certain cultural barriers as expressed by Operator $\mathrm{C}$ and Operator D.

“They leave New Zealand because it's under certain visa they have a restriction they won't allow to do any extension. They have to go back." (Operator C)

"So far we haven't come across anyone extending their stay after their tour. The reason being they're inability to speak English confidently around without a guide and secondly also because of visa requirements, so most of them doesn't... They have to return.” (Operator D)

Parker (2008) also sums up the criteria relating to gaining access to an ADS visa to New Zealand: Chinese visitors must apply for these visas with a Chinese travel agency, which is licensed under the Approved Destination Status, in addition these visitors must present the travel agencies with a bank statement demonstrating their funds before they are even considered. On top of that, visitors must also display a letter to the agents from a person not travelling with them to New Zealand to ensure that the visitor will return to China, with a supplementary letter from the visitors employer communicating they approve the trip and will retain the visitors job until they return (NZ Herald, 2008). Therefore, as expressed in the New Zealand Herald article, regulations in regards to the ability to gain a visa to New Zealand is quite difficult, and with an ADS visa, visitors are only able to stay in New Zealand for a certain period of time, which is generally between 3-4 nights, or 5-6 nights depending on the length of the tour in New Zealand. This also illustrates the complexity in the maturation of the Chinese visitor market from tour groups to FIT. Ryan \& Mo (2001) suggests a possible reason for the market having more tour group visitors than FIT, which may be because of the market still being in the ‘explorer' or 'innovative’ phase (p.25).

- How do the Tour Operators cater specifically to their Chinese Visitors?

With reference to whether the tour operators do anything to specifically cater to their Chinese market, a number of the tour operators expressed they are merely inbound tour operators, and do not produce the tour itineraries for the visitors themselves. However, they do attempt to make the tours as comfortable and convenient as possible for their 
visitors by providing Chinese-speaking tour guides and drivers. Operator A specifically reported that their organization goes so far as to organise food and beverages that are particularly targeted to their Chinese visitors.

“...we mainly follow the Chinese style of restaurant. If the people want to have the European restaurant we will book it, but usually we will take them to the Chinese restaurant." (Operator A)

This statement expressed by Operator A is interesting due to the fact that in Becken's (2003) study, the author portrayed that Chinese visitors generally enjoyed sticking to food and beverages that they are use to and instead of experiencing something they are unfamiliar with. This fundamentally contradicts the fact that many Chinese visitors travel to extend their experiences of the outside world, and broaden their knowledge of other cultures (Becken, 2003). Fundamentally, indicating that there are signs that some groups within the Chinese visitor market are still not maturing very quickly.

Although the majority of the tour operators conveyed that they provide a Chinesespeaking tour guide for their Chinese visitors, Operator D was the only tour operator to state their tour guides were bilingual and was separate from the actual tour bus driver.

\footnotetext{
"We normally give them an English-speaking driver and they'll come with a tour guide that is normally bilingual, able to do the translation. If they are unable to include a local Chinese-speaking guide to assist them all the way through, we provide one at point of arrival to the point of departure." (Operator D)
}

The results to this question particularly overlap with the sub-section examining whether tour operators receive many FITs, and the key comparable finding is that cultural normalities play a large impact on whether Chinese visitors travel around New Zealand with a tour group or independently. A key component that impacts on the travel structure of the Chinese visitors is definitely the type of visa the visitor is on, and secondly the language barrier between the visitors, the locals, and the tour operators.

\subsubsection{Sustainability}

As indicated in the introduction of this chapter, the term 'sustainability' was broadly employed in the interviews to allow tour operators to give their opinions regarding all 
elements of 'sustainability': the environmental, the socio-cultural, and the economic. However, if a particular component of sustainability was examined, such as the environmental aspect, it was expressed to the tour operator in the interview. This section will be divided into four subject matters, specifically examining: the tour operators' perspectives of 'sustainability', the importance of understanding 'sustainability', who tour operators believe is responsible for creating and dealing with the impacts of tourism, and lastly how the tour operators educate their Chinese visitors about sustainable tourism in New Zealand.

\section{- Tour Operators' Perspectives of 'Sustainability'}

In the review of the interviews, it was identified that out of the seven tour operators, two of the operators have not heard of the term 'sustainability', and therefore have no current understanding of the concept. Whereas, from the five remaining tour operators that demonstrated they have an understanding of the term, a number of them related their explanations to the travel industry and the Chinese visitor market. The tour operators also continue by expressing differences in the interpretation of 'sustainability' with regards to the Western and Eastern views.

With regards to the interpretations of 'sustainability' that incorporate aspects of the travel industry and the Chinese visitor market, Operator D expressed they believe that being able to retain a market that is still undeveloped is difficult. China in comparison to other Asian visitor markets is identified as being 'young', therefore becoming complex to manage sustainably at this point in time.

"I find that the market is still very new. The agents are not mature enough to maintain a role with you yet, unlike other Asian countries that are mature enough and they understand how the market works once they have dealing with you. The trust is there and they just leave it.” (Operator D)

Operator $\mathrm{F}$ expands on the above statement by Operator $\mathrm{D}$, by expressing that the limited amount of time Chinese visitors have in New Zealand fundamentally influences where and what the visitors see and partake in. This is therefore likely to affect the experience the visitors have during their trip in New Zealand. From the report made by Operator F it is identified that the 'sustainability' of the Chinese visitor market in New Zealand is essentially associated with their level of satisfaction and the experiences they 
take away. However, if New Zealand was to become more sustainable the tourism industry should look at delivering experiences that are more satisfying to generate a repeat visitor market from China. In addition, from the statement below made by Operator $\mathrm{G}$, it can be established that a number of tour operators believe that sustainability involves the travel industry, the Chinese market, and how the company operates with regards to the growth of the market.

“...They don't care. Even some comment from other tour operators they said... we only need every person from China to come to New Zealand once and we'd earn enough. They don't expect the customer will travel again. Lots of tour operators don't care. They only care about this time.” (Operator G)

Operator $\mathrm{G}$ also indicated in their opinion that they believe the Chinese visitor market is not yet sustainable, because many tour operators believe that it is not necessary to look at developing return visitors from China to New Zealand, due to the fact that the population in China is so large that if one person from China visited New Zealand once it would generate enough revenue to maintain the New Zealand travel industry. As a member of Tourism New Zealand, Tim Hunter also reiterates a similar point by stating: “A lot of the trouble we're having is that many Chinese travel agents don't care what kind of experience visitors are getting in New Zealand. They don't think about getting repeat custom. There are so many consumers; if people don't come back they wouldn't really notice” (Cropp, 2008). Nonetheless, it can be recognized that this argument may be impractical or in more of a direct manner, impossible. Therefore, tour operators need to understand that for the Chinese market to be sustainable in the travel industry they need to consider the necessity of repeat visitors.

Alternatively, in the examination of Operator A's explanation of 'sustainability' the tour operator looks specifically at the sustainability of the Chinese market in the travel industry, and the difference in terminology between the Western and Eastern understanding of the term.

"Yeah, because I think the difference is the different market have a different way of doing business... because some markets are very mature, like 10 or 20 years age they started in the travel industry, so you can see the market, the people and the way they are enjoying is different. But for China, for my market, for the China market, and even the Indian market it's quite new... so 
this way you can find they are different and they enjoy thing different... they come for the cheap, they see things and also their feelings is quite different." (Operator A)

Operator C demonstrates a similar opinion towards 'sustainability' and the difference in terminology between the Western and Eastern understanding of the term. Operator $\mathrm{C}$ articulated that a potential explanation of why the understanding of 'sustainability' may be different because the Western comprehension of the term has developed for a longer period of time, and therefore could have given the travel and tourism industry more time for stakeholders to acknowledge and be aware of 'sustainability'. Conversely, this differs in terms of the Chinese terminology because this market has just begun to develop further in their experience in the travel and tourism industry; and consequently have yet to become more mainstream in their opinions and understanding of 'sustainability', due to the strong relationship that Chinese visitors have with their customs and traditions.

"Maybe it is a bit different because it's a very new market for them and they just open up and every new market, especially the country has been enclosed for so many years... they just started going out of the country they saying a lot of things quite different for them from what the tourism is expected here like the Chinese custom, they come here to purchase some of the souvenirs for the relative that is the reason why they come here, the shopping become an important part of the tour that's a lot of tourism industry... don't like to sat that but actually it's part of the Chinese culture." (Operator C)

From the two statements made by Operator $\mathrm{A}$ and Operator $\mathrm{C}$ it can be established that the tour operators articulate the fact that there is a difference in the understanding of the term 'sustainability', which can be due to the difference in culture and customs. Particularly in regards to the Chinese custom of shopping on tours, and the purchasing of cheap products, this facet of the typical Chinese visitor tour has essentially impacted on the physical financial benefits that the tour operators gain from the increasing number of Chinese visitors (Parker, 2008). Due to this, the newly administered ADS regulations attempt to reduce or cut-out high-commission shopping tours to encourage or refocus the experience in New Zealand rather than on price, which as expressed by some tour operators will affect their overall number of visitors, and the Chinese visitors' level of satisfaction. 
- Do Tour Operators believe it is important for Chinese Visitors \& their Organisation to understand 'Sustainability'?

In the investigation of whether the tour operators thought it was important for tourists to understand the meaning of 'sustainability', only three tour operators (Operator A, Operator D, and Operator $\mathrm{G}$ ) reported the importance, with two operators (Operator B and Operator F) articulating they do not believe it's necessary for tourists to understand the meaning of 'sustainability', whilst the last two tour operators expressing they either were not too sure, or had no idea.

Operator $G$ was one of the tour operators that conveyed the importance of tourists understanding the meaning of 'sustainability'.

"It is important but it's hard. No one do the promotion and even if you do the promotion no one cares because it's Chinese and I know what they're thinking about their concept is cheaper is best. They only choose the cheap products and they don't care what's... this product they buy will cause some affect to this industry... but they don't care.” (Operator G)

From what was identified in the statement made by Operator $\mathrm{G}$ it can be recognized that in addition to the significance of tourists understanding the meaning of 'sustainability', Operator $G$ believes the Chinese market will not really care about the concept of 'sustainability' even if marketing endeavours were made to promote its importance. This could be linked to the fact that the visitors seek cheap products, thus not fully comprehending the significance of 'sustainability'.

Conversely, Operator D takes a different view in regards to whether they believed it to be important for tourists to understand the meaning of 'sustainability', the tour operator communicated that over time, and with more travel experience tourists will begin to acknowledge and comprehend the value of 'sustainability'. Yet, Operator B states that they do not consider it to be important for tourists to understand the meaning of 'sustainability' because they are just clients. In addition to the point made by Operator $\mathrm{B}$, Operator $\mathrm{C}$ maintains a similar view by expressing that tourism sustainability is still in the development stages, and to attempt to teach or extend the understanding of 'sustainability' to an undeveloped market such as China may be too premature. 
"I still think sustainability is in very, very early stage and the part of the consumer is very hard to understand.” (Operator C)

However tour operators were asked if they thought it was important for the organization to understand the meaning of 'sustainability', three out of the seven tour operators (Operator A, Operator D, and Operator G) considered it to be important for the tour operator to understand 'sustainability'; however, only one tour operator (Operator B), expressed it was to be inconsequential, and the other three tour operators stating they were unsure of whether it is significant to understand the term or not (Operator C, Operator E, and Operator F).

Operator $\mathrm{D}$ reported that it is important for the tour operators to comprehend the meaning of 'sustainability' because the tour operator believes that with the organization understanding the term, and delivering quality products will make the organization more sustainable, but also develop the Chinese visitor market to be sustainable as well. With particular reference to the following statement made by Operator $\mathrm{D}$, the tour operator expresses their understanding of 'sustainability' with reference to the attempt to preserve the quality and standard of their products; which results in the sustainability of their organization.

“... try to maintain the quality and the standard and we keep telling the people... Whatever you buy from us, we deliver it and you get quality services.” (Operator D)

Operator $G$ takes a similar approach in deliberating the significance of their organization to understand the meaning of 'sustainability'. However, Operator G expresses that 'sustainability' is also interrelated to the operation of their organization and profits.

"Yes, we're doing business of course... we want to do better and better, we want to go further and further. So sustainability will help us, not just in this market, for other markets and for our profit.” (Operator G)

- Who do Tour Operators believe are Responsible for Creating \& Dealing with the impacts caused by Tourism on a Destination? 
In the investigation of who the tour operators believe are responsible for the impacts created by tourism on the destination, the results from the interviews were divided, with Operator A as the only tour operator that believes it to be the responsibility of tourists and Operator E stating it to be the government's responsibility. Four out of the seven interviewed tour operators expressed that they believe more than one stakeholder as responsible for creating the impacts of tourism on the destination. Out of the four tour operators Operator B was the only interviewee that thought every stakeholder was responsible, whereas Operator $G$ believed both the tourists and tour operators to be responsible, and Operator $\mathrm{D}$ and Operator $\mathrm{F}$ believed both the tour operator and government to be responsible for creating the impacts of tourism on the destination. Operator $\mathrm{C}$ was the only tour operator that was not sure about who they thought was responsible for the impacts created by tourism.

The reason why Operator E conveyed governments to be responsible for creating the impacts of tourism on the destination is due to the part they play in regards to promoting the country, and developing the destination's marketing image, therefore creating various perceptions and impacts.

“The governments always... do the job promoting New Zealand as a tourism destination, just letting the Chinese people know how New Zealand is clean, pure and safe.” (Operator E)

Although it is clear that a number of the interviewees believe that governments are responsible for creating the impacts of tourism; there are several reasons why other stakeholders are also responsible. Operator B expressed that they thought every tourism stakeholder was responsible because each party involved in the tourism industry has a different impact. Operator $\mathrm{C}$ gives an example of how both the tourist and tour operator can be identified as being jointly responsible.

“... I think it's very natural for the people to come into the country and then people will become quite aware when environment... I don't think they would do it intentionally because you know people are trying to minimise it (negative impacts) and as a travel agent, as a tour guide you know you try to educate them as well because you know when they come here try to brief them and educate them and then they can see such an environment is not like their country and everyone will try behave in that way as well." (Operator C) 
In Operator C's statement it is expressed that when tourists arrive in a destination they are unaware of the impacts they may cause; however, their knowledge and consciousness of the impacts they create develops as their tour guide or tour operator educates them. Therefore, it can also be identified that it is the responsibility of the tour guides and tour operators for creating the impacts of tourism if tourists aren't educated appropriately.

When the interviewees were asked who they thought was responsible for dealing with the impacts caused by tourism. Four interviewees expressed that they thought it was the responsibility of more than one stakeholder to deal with such impacts, whereas Operator $\mathrm{C}$ and Operator $\mathrm{F}$ believed it was just the responsibility of the government. Operator $\mathrm{E}$ was however the only tour operator that thought attraction management as responsible for dealing with the impacts.

With regard to a statement made by Operator A, the tour operator demonstrates why all stakeholders are responsible for dealing with the impacts caused by tourism, the operator illustrates how each stakeholder, such as governments can only do so much to deal with tourism and its impacts, therefore joint efforts need to be made to ensure the best for the tourists, locals, destination, and other tourism-related parties.

"I think the government are doing very good, like promotion, advertisement to promote New Zealand in the overseas market, either China or in anywhere. And for land operators, we are the operators, and we can just retell them how to do this. I think that the government can't do everything. They won't see the agent everyday, so they can just send the concept to the operator, to the overseas agent, or deliver all the concepts to the customers in the first line. And after that we can do the after services... So I think the government and the land operators need to work together, yeah I think that is the way." (Operator A)

Additionally, Operator A expresses that once an idea or 'concept' comes about to assist in the managing the impacts of tourism, it needs to be passed down to the other stakeholders to ensure mutual efforts. However, in regards to Operator B's statement the tour operator conveyed that both the tour guides and government are responsible due to their relationship within the tourism industry, and the position they play in the delivery of the tourism product. 
"I think the guide has to educate them and the government has to set the rule to give them a fine to protect our environment, it is most effective to ask for money as penalty.” (Operator B)

Operator G also expressed that they thought it to be the responsibility of the tour guide to deal with the impacts of visitors based on the fact that they have direct contact with the visitors, and that they are there to educate the visitors about the destination, it's cultures, traditions, and environment. However, the tour operator conveyed that the tourists are the primary factor that impacts on the destination, therefore should play a part in dealing with the impacts caused by tourism on the destination.

"First of all tourists, second of all local guide. Tour operators, we are sitting in the office, we don't know what happening. I always educate my local guide when they get the tour, so they can tell the visitor... but I think the responsibility part of it will be the local guide.” (Operator $G$ )

- Do Tour Operators do anything to educate their Chinese Visitors about Sustainable Tourism in New Zealand?

When the tour operators were asked if their organization was doing anything to educate their Chinese visitors about 'sustainability' in New Zealand, the larger proportion demonstrated the fact they were only the tour operator, therefore they do not do anything directly to educate their Chinese visitors. Since the interviewees did not have direct contact with visitors, the tour operators expressed they educate their visitors via their tour guides. Operator B was the only tour operator that does not do anything at all to educate their visitors. With Operator $\mathrm{D}$ being the only tour operator to illustrate they are members of Green Globe, and they use their membership to educate their visitors.

Operator E conveys the fact that it is difficult to educate their visitors prior to arrival; however, when they arrive the tour guides generally follow with verbal instructions.

"We can't do them a pre-education. Just after their arrival the tour guide will tell them they should follow these rules... Just a verbal rule.” (Operator E)

Operator F and Operator G also display indications that the tour operators' tour guides are utilized as their means of educating their Chinese visitors about 'sustainability'. 
"As the local guide if I meet the Chinese people I tell them something about the culture, about the New Zealand. How to do something right because you know Chinese people have a lot bad habits... So I told them to be aware of it and how to keep the face for Chinese." (Operator F)

"We not really educate them but we will tell them how to meet the requirement of the code of conduct. And you know... we can only suggest them, we can't educate them.” (Operator G)

In the examination of the above statement made by Operator F, the tour operator also articulates that their organization educates their Chinese visitors about 'sustainability' to ideally protect the New Zealand culture and environment, but to also save 'face' for the Chinese visitors. In the Asian culture 'face' is an important factor, specifically in China, because of the impact that 'face' influences on business communication (Hwang, 1987). Although there are a number of straightforward definitions of 'face', Ho (1976) describes the intricacy of the concept as the respectability and/or deference that an individual can retain for him/herself from others, by the desirable qualities of the comparative position that the individual engages in through the social network and the degree to which that individual is judged to have adequate positioning in their social conduct (Hwang, 1987). With Operator F attempting to educate their Chinese visitors about how they can save one's own 'face' it allows effective approaches to improve the communication and cooperation between the visitors and the sustainability of the destination.

In regards to Operator A's account, the tour operator conveys that their organization attempts to educate all members through a 'trickle-down' affect regarding 'sustainability' in New Zealand, which will eventually reach their Chinese visitors from the organization's operating staff, with regards to the tour operator assisting in modifying the visitors itineraries to become more sustainable in relation to a New Zealand visit.

“... In our company the first thing is... our first line operating staff will tell the overseas agent operating staff how to get, create itineraries, and how to make itineraries more sustainable, and how to make itineraries more reasonable, because you know that sometimes China is so big. Is not all the operating staff can tell about New Zealand the travelling... sometimes they mistake.” (Operator A) 
At present, Operator D is a part of Green Globe, and with Green Globe several criteria need to be satisfied, which Operator D employs as their main structure of education about 'sustainability' in New Zealand to their visitors.

"At the moment we are members of the Green Globe. So everything... we have to... we talk about recycling and everything and a lot of our agents besides China are aware of it and they like to work with us... They prefer to work with someone that is conscious about the environment so that the next generation can enjoy it as well” (Operator D)

Operator D also articulates that Green Globe acts as a form of competitive advantage in regards to some agents preferring to employ the tour operator because of their membership and awareness regarding destination culture and environment. Operator D adds to their statement by portraying Chinese tour group members appreciate their membership in Green Globe one way or another, and will ultimately increase in the future.

"Yes, Chinese tour groups appreciate it, but I think eventually with understanding and everything and with a lot of publicity now, everywhere in the world will appreciate it.” (Operator D)

\subsubsection{Sustainable Tourism Destination}

- Tour Operators Perception of Sustainable Tourism in New Zealand

After establishing the understanding that tour operators have of 'sustainability', interviewees were asked if the organization they work for believes 'sustainability' is an important concept in New Zealand's tourism industry, and six of the seven tour operators believed so, with only one tour operator expressing they have no idea of what 'sustainability' means or what it stands for. Below is a depiction of why Operator F believed 'sustainability' was an important concept in New Zealand's tourism industry.

"Yes, very important. If we do everything right we've got a future..." (Operator F)

In Operator F's statement, it is clear that the tour operator believes 'sustainability' is an important concept in New Zealand's tourism industry because the term will lead to the industry or tour operators themselves to continue in the future. However, Operator A 
takes an alternative opinion by articulating the significance of the term 'sustainability' is not just necessary for the New Zealand tourism industry, but also the global tourism industry.

"I think it's not only for the New Zealand industry, all the industries have to think about sustainability... but I think the important thing is we can't put the experience for the American market or the European market and use the same way to put it in out Chinese market. Because the cultural background, everything is different.” (Operator A)

In Operator A's statement above the tour operator also asserted that for the Chinese visitor market to become 'sustainable' in the New Zealand's tourism industry, stakeholders such as tour operators, need to develop management and operational techniques that cater specifically to the Chinese visitor market.

Conversely, Operator D expresses the significance of 'sustainability', but the operator also conveys how their organization attempts to maintain the Chinese market sustainably in the New Zealand tourism industry.

"We try to but then at the same time we do not want to tell them what to do... We try to help them to understand that and... try to groom them to understand how the market works instead of letting them ruin the whole market." (Operator D)

In addition to Operator D's report, it can be identified that by endeavouring to coach the Chinese visitors' comprehension of the New Zealand environment and culture it will in essence reduce the ability for the visitors tarnishing the development of the entire market.

- Do Tour Operators believe New Zealand is a Sustainable Tourism Destination? In correlation with the analysis on 'sustainability', tour operators were asked if they believed New Zealand is a sustainable tourism destination in regards to the environmental component of 'sustainability', four out of the seven tour operators thought New Zealand to be a sustainable tourism destination. Whereas, Operator B and Operator G stated that they did not believe New Zealand to be a sustainable tourism destination; Operator E was the only tour operator that did not express any opinion. 
A number of explanations were made by the four tour operators about why they believe New Zealand to be an environmentally sustainable tourism destination. A majority of the statements made expressed that the operators believed so because New Zealand's environment is still untouched thus attracting visitors.

"I think it still have a lot of unspoilt area you know attractive and to introduce to the customers overseas.” (Operator C)

In addition to the statement made by Operator $\mathrm{C}$, Operator $\mathrm{A}$ adds that stakeholders have participated in the sustainable development of the tourism industry in New Zealand.

“... at the moment... yes, I think so. I think that in New Zealand, Tourism New Zealand is doing a lot job on this concept. And I think this is the right way, for the long term, and to continue the New Zealand environment." (Operator A)

However, with regards to Operator D and Operator F's interpretation of the situation, they believe New Zealand to be a sustainable tourism destination; yet they believe that work is still required to maintain the industry's environmental 'sustainability'. Operator F brings particular attention to the need for the government to develop policies that are specifically focused on 'sustainability' of the New Zealand tourism industry, with regard to the supply of products but also policies that will assist in the 'sustainability' of the tour operators.

"Yes, New Zealand is a premier destination, however, we can develop more to become more sustainable and also I think the quality of service from the hospitality industry has to improve to become more sustainable.” (Operator D)

"I think so but need to do lots of work especially the government have to do the right policy and not wrong. So now a lot of policies are not correct... and how to protect companies like us.” (Operator F)

Operator B and Operator G take a different perspective expressing they don't think New Zealand as a completely sustainable tourist destination, with Operator B articulating the fact that they believe New Zealand not to be sustainable because visitors travel in a cycle, and New Zealand is only a destination within this travel cycle. 
Operator $G$ on the other hand communicated that visitors do not really 'care' about the environment, and therefore are not concerned about the destination they visit because the visitors are able to gain that experience in a variety of destinations, therefore reducing the sustainability of New Zealand as a tourism destination.

“... they just come to New Zealand to learn about the culture, they not really care about the environment. I always promote New Zealand as a beautiful place in the world. The cleanest place in the world... So what?? They just want to have a holiday or relax. They can go to Australia to relax, they can go to Thailand to relax... why New Zealand??” (Operator G)

- Has the Tour Operator heard of the New Zealand Tourism Strategy 2015?

Whilst studying the section concerning sustainable tourism destination, tour operators were asked whether they or their organization have heard of the New Zealand Tourism Strategy 2015. It was clearly illustrated in the results that all but one tour operator (Operator A) have not heard of the New Zealand Tourism Strategy 2015. Nonetheless, Operator A articulated that they have seen the strategy; but have not seen or read it in detail, the tour operator believes that there are many pieces of information and suggestions that are applicable and appropriate for tourism businesses and the New Zealand tourism industry. However, not all recommendations made in the New Zealand Tourism Strategy 2015 were identified as feasible or practical in the actual operation of tourism businesses.

“... I saw some of them, I not see very clearly... some things is right, but I have to say that some things is not workable, and that some things are not fair to everyone who work in the tourism industry." (Operator A)

\subsubsection{New Zealand's Marketing Image}

- Do Tour Operators believe New Zealand's '100\% PURE NZ' tourism campaign influence Chinese Visitors decisions to visit New Zealand?

In terms of examining New Zealand's marketing image, the interviews also investigated whether tour operators believe New Zealand's '100\% PURE NZ' tourism campaign influences on the Chinese visitors decision to take a trip to New Zealand. From the results of the interviews, all interviewees apart from two (Operator A and Operator G) expressed that 'yes' the ' $100 \%$ PURE NZ' tourism campaign impacts on the decision 
for Chinese visitors to take a trip to New Zealand; yet, this is only a partial impact, and more promotion is required to enhance the influence on the visitors decision.

For Operator A and Operator G, they believe that New Zealand's '100\% PURE NZ' tourism campaign is ineffective in affecting the decisions of Chinese visitors to travel to New Zealand based on the fact that many of these visitors identify New Zealand as part of Australia, and New Zealand tours are an addition to the overall Australian tour product. Operator $\mathrm{G}$ expresses that marketing is needed in more provinces in China not just the main cities, such as Shanghai, as seen in studies undertaken by Tourism New Zealand both Beijing and Guangzhou are also cities that bring in a large proportion of Chinese visitors to New Zealand.

"No, not at all, most the people in China, around the $10 \%$ of people still think that New Zealand is part of Australia... They still think like that... I think the 'PURE NZ' is a individual image... 'PURE NZ' does not very attract people to come to New Zealand.” (Operator A)

"I doubt it. From my experience to promote New Zealand I just feel a little but upset. It's a really nice country but they really not care. It's like an additional product they purchase with Australia product and the tour operator will be like "why don't you purchase Australia and New Zealand?" We're not an independent product. We just like... coming with the Australia, always we can't be independent.” (Operator G)

As portrayed in the interview with Operator $A$ and Operator G New Zealand is identified as an additional product to the Australian tour, conveying the New Zealand tourism industry is seen not to spend enough time, money, and resources on the Chinese market, as expressed below by Operator G.

"I know that they have some kind of budget to promote New Zealand in Shanghai but no other province in China. They don't spend enough money, they don't spend time and resource into Chinese market.” (Operator G)

Although many operators have expressed that there has been little promotions in China to maintain the Chinese market and retain the sustainability of tourism in New Zealand, in October 2008 Tourism New Zealand pushed the promotional and trade activity of New Zealand as a 'must see' tourist destination (Tourism News, 2008). Some of the marketing activities employed by Tourism New Zealand entailed celebrity blogs, high- 
profile 'influencers' event, promotions in some of the industrious spots in Shanghai, and the Kiwi Link trade event in October (Tourism News, 2008). As a key promotional activity celebrity blogger, Hung Huang, who carries a number of notable media, cultural and historical acknowledgments, was invited to tour around New Zealand (Tourism News, 2008). Tourism New Zealand General Manager International PR, Jane Dent, expressed that "Getting Hung Huang to New Zealand was a massive coup", and that "Her audience matches the group we target - they are well-educated, well-travelled, 2040 years old, with expendable income and looking for new experiences” (Tourism News, 2008). By inviting such an influential person to New Zealand that caters to the explicit market that New Zealand is targeting, Tourism New Zealand potentially reaches their target market that is the 'interactive travellers', and possibly prospective tour groups.

With regard to the interviewees that articulated they believed the ' $100 \%$ PURE NZ' tourism campaign to some extent impacts on the Chinese visitors decision to visit New Zealand, Operator $\mathrm{C}$ adds to the discussion by expressing there are other factors that also impact on their decision. Whilst, Operator D conveys that the ' $100 \%$ PURE NZ' tourism campaign only illustrates images of tourist attractions, rather than depictions of 'sustainable', environmental images.

"Partially yes... Because some of them when they travel to a destination there are some factors, prices is very important factor and visa application is another factor whether 'PURE' or not 'PURE'... I don't think that it's a concern to them is maybe for some of them maybe for the younger generations they want to see the real natural appeal of New Zealand but for some other just "Oh we are going to Western country"... so that is not the main reason of destination because of the 'PURE' and 'Green' image." (Operator C)

Central North Island tourism manager for Ngai Tahu Tourism, Rob Finlayson expressed: "If you look at the history of the Chinese going back thousands of years - it is a very strong and set culture that I won't change as an operator and New Zealand won't change as a destination. They will do what they do until they die so I can't see the price sensitivity changing in any great hurry" (Cropp, 2008). In further examination of Finlayson's statement, he specifically points out that culture runs so deep in the veins of the Chinese, that is becomes very difficult to change their train of thought, therefore 
Finlayson conveys that it is very challenging to adjust the visitors idea of price and its impact on their travel decisions (Cropp, 2008).

In further observation of the interview with Operator D it was also identified that the tour operator thought there was more need for the '100\% PURE NZ' tourism campaigns to demonstrate how visitors can maintain the destination they are visiting.

“The ' $100 \%$ PURE' promotion does impact on a lot of Chinese tourists companies in New Zealand, but the things that we have to educate them that if you are to come here, you should enjoy it, maintain it, not destroy it... there's a lot of publicity in China on New Zealand... but on tourist attraction point but not on this environment thing." (Operator D)

However, the overall opinion of the interviewees expressed that New Zealand's ' $100 \%$ PURE NZ' tourism campaign was not sufficient to attract or influence Chinese visitors to come specifically to New Zealand, when Australian tours are more frequent and recognized.

"I think that is one way you will attract them to come to New Zealand... More, need more, because some people told me in China they only see very little to promote New Zealand, they only put sheep and tree... Everywhere has sheep... "Why do I have to go to your country?” (Operator B)

"Actually most of Chinese have no idea about New Zealand, so somebody has to give them the idea that New Zealand would be wonderful tourism destination that role would be played by the government. Like advertisement, through radio, newspaper or internet.” (Operator C)

- Do Tour Operators promote New Zealand as a Sustainable Tourism Destination?

With regard to the final question in the interviews concerning New Zealand as a sustainable tourism destination, tour operators were questioned about whether they promote New Zealand as a sustainable tourism destination. Essentially, two out of the seven tour operators stated that they do promote New Zealand as a sustainable tourism destination; however, these two tour operators demonstrated no evidence of how they apparently do so. Furthermore, from the tour operators that expressed that they do not promote New Zealand as a sustainable tourism destination stated that it is not up to the tour operator but up to those officially positioned to promote New Zealand, or those who have direct contact with clients, such as the sales agents in the visitors' origin. As 
inbound tour operators, Operator G expresses the need to try and promote New Zealand as a sustainable tourism destination; however, this is not as straightforward of a process as one may think because the tour operators do not have direct contact with the Chinese visitors, yet educating visitors is a key to preserving and sustaining New Zealand as a tourist destination.

"We're trying to... we're really trying to because we are all inbound tour operators and we need to keep number of Chinese come here high... and we are trying to protect it (New Zealand tourism industry).” (Operator G)

\subsubsection{Further Comments made by Tour Operators}

The last section of this chapter will now examine the two operator introduced subjects: the ADS system, and shopping tours. Although these two subjects were not introduced as key variables in this research; the comments made by the tour operators have generated a number of opinions and suggestions worth noting to assist in the interpretation of environmental sustainability of tourism in New Zealand, and the importance of understanding the Chinese visitor market to New Zealand.

- Comments Regarding ADS System

As a brief background to the New Zealand China Group Tour Approved Destination Status (ADS) system, the program began operation on the $1^{\text {st }}$ November 2007. The ADS system essentially entails the approval of New Zealand based inbound tour operators to operate within the ADS system, as well as monitoring their conduct, performance and quality standards (TNZ, 2008). Tourism New Zealand established the China Monitoring Unit in September 2007, as the division that administers ADS approval to the inbound tour operators (TNZ, 2008). The China Monitoring Unit is responsible for administering the following activities:

1. Assessing new applicants

2. Frequently implementing compliance evaluation on the inbound tour operators approved by the ADS.

3. Monitoring ADS approved operators to ensure compliance with Code of Conduct for ADS Tours requirements 
4. Managing complaints and feedback from Chinese tour group visitors to New Zealand

To start the discussion regarding the ADS system, Operator A begins by stating how tour operators become ADS registered, it was identified that there are numerous criteria in place for New Zealand tour operators to become a member of the ADS; however, the actual system brings about controversial reactions.

"First one you have to at least 2 years company and you have to been feeding into the China business and of course your financial statement and everything you have to show them, and after you have to do the report to code ADS groups for arrival and then you need a licence and so one... I think ADS is correct but I think you have to target our market; you have to know our market... I think the ADS is right, but what they want is they want to keep this market longer... but they need to do in a way they can maintain the tourism business too...” (Operator A)

With regard to the controversial reactions to the ADS system, it was demonstrated in several of the interviews that the tour operators believed that the implementation of the ADS system has strategic advantages; yet, barriers also arise in terms of operationalization for the tour operators, as expressed by Operator A, Operator C, and Operator F.

"I think the way they are is right, but I think the way is also wrong because we follow the rules on the ADS we are taking a lot of time and the people to prepare for the paperwork is too many." (Operator A)

"ADS is good it is especially for Chinese people. It's a special visa for Chinese people. I think that it is good for New Zealand, but how to manage the ADS group is very important.” (Operator F)

To further the discussion on the ADS system, a number of tour operators give examples of the positive and negative impacts of having the ADS system. In general, tour operators identified that with the ADS system it encourages operators that target a larger array of markets to pursue the Chinese visitor market to New Zealand, by reducing the competitive advantage budget tour operators have when they sell cheap tours through increasing quality regulations with the ADS system. 
"Yes, I believe the ADS system is a good thing, because we... our company is too big. It's not flexible. Everything you need is through the system. So the small operators organise wholesalers... Our price will be a bit over than usual. So we don't have that many group... After ADS they said that they have ADS to monitor group so we start to increase the number of Chinese...” (Operator B)

However, with regards to the following statement made by Operator G, the ADS system allows the pressure of quality to be assigned to the tourism suppliers to essentially retain the business for the tour operators. Nonetheless, Operator $G$ states that although the ADS system brings forth certain criteria, not all tour operators abide by these rules, which therefore decrease the ADS registered tour operators' competitive advantage.

"The good thing with ADS is that we can transfer the pressure to the suppliers, like the hotels, like the cultural providers. We can say if you want to run our business like the ADS tour, you must have to have your card to pass the 3 star, otherwise I can't use you. Same with hotel you have to get Qualmark rated. The bad thing is there still a lot of tour operators out there that don't care; they don't care about Tourism New Zealand. They don't mind about quality. The thing is we lost our competitive advantage.” (Operator G)

Operator D and Operator E express a few of the barriers that occur with the implementation of the ADS system, with Operator D specifically recognizing that there are numerous ambiguities in the ADS system which suggests that there are still improvements necessary for the increase of benefits of the system for all stakeholders involved in the Chinese market.

“The Chinese tourism market is a complicated problem. We can't solve all the problems. ADS does improve the quality but gives us a lot of barriers in operating... Some of the regulations sound funny. From the first of December we had to use Qualmark rated hotels, otherwise like some of the small towns, if there are no Qualmark hotels, we can't take tourists there, that's quite ridiculous." (Operator E)

"It's a system that will take time to work. It will work if everybody works together but then I find that there's a lot of loopholes, even though its ADS member, any Tom, Dick and Harry can still get away with, they either have to have very strict rule explaining it's only for ADS members. If your not ADS member, forget it, because at the moment non ADS members are still able to get visa, applications and everything. It's just with extra money, and extra time... The ADS also to some extent restrict independent travel itineraries and travellers.” (Operator D) 
With regard to the last statement made by Operator D, it was identified that the ADS system can in one way or another impact on the number of Chinese visitors that choose to visit New Zealand independently; this could be a result of a number of reasons. Firstly, a possible reason could be because the ADS visas take less time to process in comparison to the independent holiday visa. However, secondly it could also be a result of there not being enough visitor information for independent travellers in Chinese for the visitors to feel confident to travel around New Zealand independently.

\section{- Comments Regarding Shopping Tours}

In addition to the discussion concerning the reactions that tour operators had towards the ADS system, the tour operators also gave a few comments regarding the tendency for Chinese visitors to participate in shopping tours. From the interviews it was acknowledged that there were split opinions with regard to the significance of shopping tours. Operator B expresses in the discussion that with shopping tours the quality of the tours is lower, and is therefore not important to tour operators such as themselves. Operator $\mathrm{C}$ also demonstrates a similar opinion by conveying the importance of other factors whilst visiting New Zealand, such as the environment, adventure, and culture; hence, placing the importance of shopping as a less important feature. Although Operator C states that shopping should be treated as a less central component of tours, the operator understands and expresses their concerns about the amount of time it will take to mature the Chinese market in believing so.

"There are many complaints in China on the shopping group and many agents in China... retail agents, they realize that the shopping group got many complaints and if they are proper travel agents they will say no shopping groups. That's why they will find us because we don't do shopping groups since we open.” (Operator B)

In relation to the statement made by Operator B, Cropp (2008) stated that the competitiveness in the price of package tours for Chinese visitors was so low $(10,000$ RMB or NZ\$2,500) for an 11-day tour to both Australia and New Zealand, that operators were forced to demand commissions to make a profit (Cropp, 2008). It is estimated that up to $60 \%$ of the operators' profits were made from commissions from selected souvenir shops, with some operators insisting on their Chinese visitors visit these souvenir shops for 3-4 hours a day (Cropp, 2008). Tourism New Zealand's Tim 
Hunter extends this argument by stating "In some cases, especially in Northern China, there is no payment being made at all to the intermediaries for the price of the tour and they're trying to make up the cost of operating the tour through shopping commissions alone. This so-called 'zero priced' touring has become endemic in New Zealand which is unfortunate because 18 months ago it didn’t really occur” (Cropp, 2008). This therefore demonstrates the complexity in identifying whether Tourism New Zealand should be focusing their quality standards on the tour operators or perhaps other members of the tourism industry such as travel agents.

"For me and being an inbound operator for a long time in the tourism industry, we like to see normal visitors from other country that enjoy scenery and put shopping as secondary, as a supplement, it is not a main thing but at the moment we can't do it, it's a shame you know, they don't see that you know, but it's not like we are the ones that can change the market. I think the market will change gradually when the people are more matured and had the chance to get out to more countries shopping will become less important.” (Operator C)

"I take some tour from Shanghai and that group is more of the young population and they come here and they mainly like sightseeing... I happy to see that, and as tour operator we're happy to see that because mostly that's what we are trying to do and people coming here more active like bungy jumping that's what we want to see... so it won't be a big number of that but we can see some of the changes as well but that will take time, it's a huge country and it takes time.” (Operator C)

With regards to the above statement made by Operator $\mathrm{C}$, it is established that there is a growing number of Chinese visitors that seek adventure activities. However, as conveyed by China Contact (an organization specializing in the Chinese market), the adventure activities should encompass a sense of prestige, with the promotion of uncommonness of the experience; and essentially correlates the experience with status representations (Coventry, 2008). This specific aspect could potentially lead to the increased sustainability within the tourism industry in New Zealand by: firstly generating more awareness and demand for tourism products that New Zealand is recognized for, but secondly increase the financial viability of tourism businesses by discouraging these so-called shopping tours to tours that encompass a variety of elements of New Zealand culture and natural environment. 
However, in contrast to the operators that expressed that they believed that shopping tours played a negative impact on the sustainability of the New Zealand tourism industry and the Chinese visitor market, there were tour operators that suggested that shopping tours were important to reach and maintain the Chinese outbound market to New Zealand.

“I don’t want to see shopping becoming more and more important. I want the price going back to normal. What they pay, what they get... I really want to have this... I want to see this happening some day... but Chinese are more interested in shopping and sightseeing, not activities. They're not really attracted by the outdoor activities...” (Operator G)

With regard to the statement made by Operator G, China Contact, a tourism business focusing specifically on the Chinese market, expressed that many within this visitor market are now in search of varying activities (Coventry, 2008). China Contact proposes that the Chinese market are now seeking activities, which are family-oriented, encompasses an array of shopping experiences, the activities should also be sophisticated, and 'deep impact' sightseeing which highlights the cultural components of New Zealand (Coventry, 2008). It is also expressed in the article that although the Chinese visitor market is focused on shopping tours, Chinese tourists overtime will become more attracted to adventure tourism because of the importance of prestige and status in the Chinese culture (Coventry, 2008).

From the discussions with the tour operators it is difficult to fully establish whether shopping tours are significant or not to the economic sustainability or ongoing financial viability of the Chinese visitor market to New Zealand. What is identified though is the importance of further reducing or countering shopping tours to develop a more sustainable tourism destination. Shopping tours undertaken by the Chinese market to New Zealand has generated much controversy, and with tour operators conveying inconsistent opinions it is problematical for Tourism New Zealand and other tourism stakeholders to address the situation. However, it is recognized that more promotions is necessary to generate more awareness of environmental, cultural, and adventure products; rather than certain hot spots or iconic symbols of New Zealand, such as farms and sheep. In addition, possibly with more promotion in a larger array of provinces in China, Chinese visitors to New Zealand may become more conscious of what is available, which could potentially reduce their predisposition to partake in shopping 
tours. The interviews with the tour operators also demonstrated the need not only to educate them, but also those further down the line, such as the travel agents in China, to actually learn about the products available in New Zealand, and to gain knowledge of the importance of 'sustainability' in New Zealand. On the other hand, it can be acknowledged that it is vital to develop new markets such as China, and attempting to broaden their experiences from shopping tours to more interactive engagement. It is also identified that there has been a change in the attitudes and behaviours of Chinese visitors to New Zealand, due to an increase in travel experiences. This has led to a shift from the previously established homogeneous tour group visitors to more independent interactive Chinese travellers.

To conclude this chapter, as indicated in the introduction the primary results of the qualitative analysis will be examined in the discussion chapter, in association with the findings from the quantitative analysis. The amalgamation of the findings from both sources of information will then allow for a comprehensive interpretation of the visitors' and suppliers' perspectives of environmentally sustainable tourism in New Zealand. 


\section{CHAPTER 6 Discussion}

\subsection{Introduction}

This chapter will entail the incorporation of both the quantitative and qualitative analysis results to address various themes as an attempt to generalize the findings to investigate the factors that influence the environmental sustainability of the tourism industry in New Zealand. As a means of structuring this chapter the same themes employed to analyze the quantitative and qualitative data were implemented to allow for further interpretation of the data, but also to establish the interrelationships that occur between the visitors' and suppliers' perspectives.

Whilst examining the findings of this study, it was established that there has been a shift from the traditional travel structure of Chinese visitors, with package tours, to an increase in independent travel. However, by employing the use of statistical tests, such as chi-square and t-tests, it was identified that there were more statistically significant differences between tour group and independent travellers concerning their travel preferences, behaviours and attitudes then there were with regards to various trip characteristics.

The overall summary for the discussion chapter and this thesis will therefore be expressed in the conclusion chapter which will also bring forth various recommendations for the private and public sectors to attempt to capitalise on New Zealand's unique environmentally sustainable reputation.

\subsection{Visitor Characteristics}

In a review of the visitor characteristics of the Chinese visitors who had participated in this study, there was almost a 50:50 split between the two genders, with slightly more female (51.4\%) than male (48.6\%) visitors. It was also identified that the larger proportion of Chinese visitors that visited New Zealand were between the ages of 3049 years (47.1\%), this showed close resemblance to the median age of Chinese visitors to New Zealand as expressed by the International Visitor Survey (IVS) at 44.5 years old (Ministry of Tourism, 2008). With regards to the occupation of the 
Chinese visitors, it was illustrated in this study that the majority of the visitors worked in skilled professions involving managerial, administrative or qualified employment positions. Becken (2003) brings forth a similar finding that Chinese outbound travellers are generally from high- to middle-income groups, who are normally entrepreneurs, white-collar professionals, and/or are representatives from media, sports and entertainment.

This study also established that over half of the Chinese visitors who participated in this research were from the Eastern region of China (67.1\%), with $48.6 \%$ of the Chinese visitors coming from Shanghai. A reason for this finding could be the direct flights that operate between Shanghai and Auckland, or as indicated by several tour operators the impact of the large proportion of New Zealand tourism campaigning conducted in Shanghai. Therefore, this could perceivably impact on the number of Chinese visitors coming from this region. Some respondents also came from the South Central China (22.9\%) and the North of China (9.9\%). Although the number of visitors from these other regions within China was not as large as the proportion that came from the East of China, it should be acknowledged that Chinese outbound visitors appear to come from a variety of areas within China.

\subsection{Trip Characteristics}

With regards to the aim to extend existing knowledge of the Chinese visitor market to New Zealand, it was established that the median length of stay of Chinese visitors to New Zealand as expressed by Tourism New Zealand was 3 days (YE March 2008). However, this research identified that the median length of stay of respondents was 6 nights. Furthermore it was found that $63.2 \%$ of tour group visitors stayed in New Zealand between 4-7 nights; whereas the majority of independent travellers stayed in New Zealand for 30 nights or more. Also illustrated in the findings of this study was the large number of Chinese visitors that visited both the North and South Islands (47.1\%). In the examination of the relationship between the length of stay and the New Zealand Islands visited, a possible reason for the longer length of stay of tour group visitors in comparison to the findings presented by Tourism New Zealand can be seen as a result of more tour group visitors wanting to experience both the North and South Islands during their trip in New Zealand. A potential motive for more tour groups to begin to visit both the North and South Islands can be related to an increase in Chinese visitors wanting to gain more 'bang for their buck', implying tour group 
visitors from China are now willing to experience the entirety of New Zealand because the visitors may not have any intentions of returning to New Zealand or to the Pacific. Operator G conveyed many visitors come to New Zealand for their first and final trip; therefore, many tour operators believe it is not necessary to look at developing a return visitor customer base from China. Whereas, more independent travellers may have visited only the North Island (53.1\%), because of their main purpose of visit, which was generally to visit friends and family, in essence this may have affected their length of stay. An additional reason why the independent travellers may have stayed longer in New Zealand can be related to visa allowances. Although it is identified that there is a difference in the lengths of stay between tour group and independent travellers; Operator A expressed that depending on the different areas of China the visitor is from it could potentially impact on the visitors length of stay. This factor could specifically be linked to the differing levels of income within China, therefore, the higher the visitors' disposable income the longer they may stay in New Zealand. For example Beijing (39684yuan) and Shanghai (37585yuan) have the highest average income within China, illustrating that the people within these regions have a higher disposable income (National Bureau of Statistics of China, 2008), and as indicated by Zhao (2006) cities such as Guangzhou, Beijing and Shanghai have the highest percentages of outbound travel from China.

Whilst determining that there are a number of disparities between tour group and independent travellers with regards to their length of stay and the New Zealand Islands visited, it is also recognized that there were differences regarding their sources of information employed. Overall, the majority of Chinese visitors in this study employed the use of information gathered from friends and family (26.9\%), followed by the organization the visitor worked for or work colleagues (23.1\%). A key finding was that the Chinese independent travellers sought information about New Zealand from a larger array of resources, such as newspapers, magazines, TV, radio, and guidebooks. This characteristic falls in line with the attitudes associated with New Zealand's target market, the 'interactive traveller', and their aspirations to research the destination they are to visit, but it also illustrates the importance of word-of-mouth information from friends and family. Interestingly, no independent travellers employed the use of travel agents to gain information about New Zealand prior to their arrival. Yet, tour group visitors still demonstrate similar characteristics 
to that expressed by Tourism New Zealand, conveying that the majority of Chinese visitors use travel agents as a primary source of information.

However, it can be acknowledged that tour group visitors have begun to modify the sources of information they generally employ (Ryan \& Mo, 2001). For example in the case of this study, a large number of Chinese tour group visitors still use travel agents (42.1\%), but a sizeable proportion of these visitors are now utilizing the organisation they work for or work colleagues for information (44.7\%). With the utilization of the organisation the visitors work for or their work colleagues, it is demonstrated that word-of-mouth recommendations are very important to Chinese visitors; nevertheless, this also illustrates that there has been an increase in incentive or business travel that essentially involves the use of the company travel agent. Additionally this study established that tour group visitors are now implementing the use of a variety of information resources, such as Internet websites in English and Chinese (21.1\%), newspapers/magazines (5.3\%), and guidebooks (15.8\%); demonstrating the start of the maturation of the Chinese tour group market.

67.1\% of the Chinese visitors studied had travelled internationally in the last 5 years. In a study undertaken by Ryan \& Mo (2001) it was identified that from their sample population a quarter of the population had made four or more overseas trips prior to the respondents' visit to New Zealand, with 6\% of the responses making eight or more international excursions outside of China, conveying that in their study the mean number of international trips made by the Chinese visitors was 2.8; however, this study indicated the mean number of trips for this sample population at 2.51. Possible reasons for this difference could be due to this study asking if the visitors had travelled internationally within the last 5 years, or potentially the difference in sample size between the two studies. However, this study also examined whether the Chinese visitors had taken a trip to any other countries before arriving in New Zealand, and if they were going to visit any other destinations after departing New Zealand. Demonstrated in the findings was that almost half of the Chinese visitors visited another country prior to arriving in New Zealand (44.3\%), with the majority stating that they had visited Australia (84.4\%). Although fewer Chinese visitors in this study expressed they were going to visit another country after departing New Zealand, 55.5\% stated that they were going to visit Australia. In the interviews with the tour operators it was established that a large proportion of them supply tours to 
both Australia and New Zealand, some of the tour operators expand on this by stating that approximately $90 \%$ of their Chinese visitors travel to Australia, with just $10 \%$ visiting New Zealand. Operator F discusses this further by expressing the tours that combine a visit to both Australia and New Zealand takes approximately 10 days; however, the visitors spend up to a week in Australia, leaving only 3 days in New Zealand. Operator $\mathrm{G}$ adds by conveying that very few tour groups from China come solely to visit New Zealand because in many circumstances New Zealand is seen as an 'add-on' to an Australian tour. With regards to this situation the New Zealand tourism industry needs to be able to generate more appeal to the Chinese visitor market to indicate to them that New Zealand has more on offer than can be completed in a 3-day period. By doing so it could increase the number of Chinese visitors that come to New Zealand through positive word-of-mouth, which in turn would impact on the sustainability of the tourism industry.

Results from this study indicate that the majority of the Chinese visitors participated in a large variety of activities, but more specifically: sightseeing (77.1\%), shopping (72.9\%), visiting a historical site (61.4\%), attending a Maori cultural performance (57.1\%), and visiting a botanical garden (54.3\%). More independent travellers tended to participate in outdoor activities, such as mountain/rock climbing/caving, and snow boarding/skiing. However, tour groups participated in more commercialized adventure activities, which are well known to New Zealand, such as jet boating and bungy jumping. New Zealand's adventure tourism industry supplies an extensive selection of commercially operated outdoor adventure activities entailing an amalgamation of adventure and excitement; which include: aviation-related, landbased, or water-based activities (Bentley et al., 2001). The adventure tourism industry in New Zealand has developed rapidly over the past decade resulting in discussions regarding the management of risk (Bentley et al., 2001). Even though the Chinese visitors that participated in this study demonstrated some interest in New Zealand's adventure tourism industry, China Contact (an organization specializing in the Chinese market), expressed that Chinese visitors are “...frequently motivated by the perceived status of a particular destination and activity” (Coventry, 2008). Therefore, if New Zealand was to sustain its adventure tourism industry the marketing of various products is vital, as a means of demonstrating to the Chinese visitors that high-prestige adventure activities and experiences are available in New Zealand. On the other hand, Chinese visitors still appreciate the safety of the 
destination and the activity they are participating in, as demonstrated in this study as a primary factor impacting on the visitors' decision to visit New Zealand. Potentially, a reason why only a limited number of Chinese visitors partook in adventure activities can be associated to the recently publicized accidents with tourism products such as the jet boating accident that involved a Chinese tourist in early 2008.

In this study it was acknowledged that shopping tours have generated much controversy within the New Zealand tourism industry. The results of this study also indicate that a large proportion of Chinese visitors, both tour group (76.3\%) and independent travellers (68.8\%) partake in shopping activities while in New Zealand. It was identified that shopping was the second most participated in activity following sightseeing. In a study undertaken by Swanson \& Horridge (2006) regarding travel motivations as souvenir purchase indicators, souvenirs are known as being commonly connected with tourism. Purchasing commercially produced souvenirs act as a reminder of the visitor's tourism experience, but also as a means of bringing a piece of their experience back for friends and family (Swanson \& Horridge, 2006). With regards to the findings from the 'China Outbound Travel Handbook' (2008), shopping for the Chinese visitor market is a highlight of travelling internationally for a number of reasons. Firstly, Chinese consumers are normally price conscious, and purchase items that are generally luxury goods; prices of luxury products can be at least $20-30 \%$ higher in the Mainland China, in comparison to Hong Kong or Europe, due to high import tariffs and consumption taxes (China Contact, 2008). Secondly, gift giving is a key characteristic of the Chinese culture, and when travelling Chinese are inclined to bring back gifts that represent the countries they have travelled to (China Contact, 2008). Lastly, the array of luxury products available in Mainland China is still quite restricted in comparison to overseas destinations, and in some circumstances brands do not offer their full range of products; therefore impacting as a further incentive for the Chinese tourists to desire to shop whilst on holiday (China Contact, 2008).

Although souvenir shopping is demonstrated to be essential to many destinations and visitor markets; New Zealand shopping tours have generated a number of issues regarding quality, satisfaction, and repeat visitation by Chinese visitors. Due to new regulations put in place by Tourism New Zealand regarding ADS registered tour operators, souvenir shopping on tours can/should only be undertaken for a certain 
length of time. In the study of the tour operators' opinion concerning shopping tours, it was illustrated that the operators understand the importance of shopping tours due to price competitiveness and commissions for profit. However, other operators expressed that shopping should not be a key component of tours to New Zealand, but should act as a secondary element. Operator C conveyed that shopping should be a tourism activity that is of lesser importance than environmental, adventure, and cultural features. As a result, it can be established that shopping is a part of the travelling and touring tradition for Chinese visitors. This specific factor potentially makes it difficult for New Zealand's tourism industry to steer Chinese visitors away from low quality, low satisfaction shopping tours. Nonetheless, understanding and acknowledging that not all tour operators aim to attract their visitors through this method, implying that there is potential for some Chinese visitors or markets to modify their travel structure. Therefore, the new ADS regulations, regarding the limitations of shopping will act as a way for the Chinese visitor market to mature.

\subsection{Satisfaction}

With regards to the level of satisfaction gained from the Chinese visitors' trip to New Zealand, it was identified that only $23.5 \%$ of the Chinese visitors were 'very satisfied' with their travel experiences in New Zealand. Nonetheless, $50 \%$ of the Chinese visitors expressed they were above 'moderately satisfied' with their visit to New Zealand; with no visitors reporting they were 'very dissatisfied'. However, there was a slight difference between the two travel structures; tour group visitors interestingly portraying a higher mean (3.78) than independent travellers (3.66). Yet, the independent travellers had a slightly higher standard deviation $(\mathrm{SD}=0.865)$ than the tour group visitors ( $\mathrm{SD}=0.832$ ), stipulating that independent travellers provided a wider range of answers. Potentially, a reason for tour group visitors expressing a higher level of satisfaction than independent travellers can be related to the impact that tour guides have on their experience, and the added engagement that tour group visitors have with a destination when having a third party to break-down certain barriers, such as language. Although having a tour guide is seen to be more convenient for differing visitors, due to the fact that the visitor's entire trip in the destination is mapped out, a number of visitors prefer to travel independently because of the freedom and flexibility whilst planning and travelling in the destination (Chen, 2002). However, the freedom and flexibility that independent 
travellers obtain may not always be satisfactory, because many Chinese visitors to New Zealand struggle with cultural disparities as acknowledged in this study.

This study examined a number of areas regarding the Chinese visitors' level of satisfaction during their experience in New Zealand; identified in this study was the most and least enjoyed aspects of the visitors' experience. It was interesting to find that the results of this study correlated to the findings of a number of other studies such as Chen (2002), and Zhao (2006). It was established from the findings that a large proportion of the Chinese visitors to New Zealand believed that New Zealand's 'clean, green' reputation impacted positively on their level of enjoyment whilst on their trip in New Zealand; 19.4\% expressed that they enjoyed the 'good environment' that was presented to them whilst holidaying in New Zealand. Expressed by Tourism New Zealand (2008) was that Chinese visitors believed that New Zealand does well at delivering with regards to natural landscapes and presenting a clean environment averaging a score of 8.6 points on a scale of 10 for satisfaction. Furthermore, Tourism New Zealand (2008) illustrated that $45 \%$ of Chinese visitors considered New Zealand's environment to exceed their initial expectation, this high impact of the environment was also observed in this study.

Nevertheless, there were also a number of other components involving the enjoyment of New Zealand's environment that was portrayed by the Chinese visitors, such as the New Zealand's beautiful scenery, clean/fresh air, and the clean 'green' image. Components such as the friendly locals (12.5\%), and unique culture (3.8\%) were also aspects that were identified as impacting on the visitors' level of satisfaction. As a results of these factors impacting positively on the Chinese visitors' travel experience, it is acknowledged that opportunities arise for New Zealand to employ this cultural aspect as a potential feature to strengthen New Zealand's cultural sustainability within tourism.

In spite of that, several aspects were acknowledged as impacting negatively on the Chinese visitors' trip in New Zealand; these involved the high prices (17.3\%), deficient public transportation (13.3\%), issues with language and communication (9.2\%), and a number of other dissimilarities between the visitors' lifestyle at home and what was presented to them in New Zealand. With regards to the least enjoyed aspects it was established that culture played a large impact on the satisfaction for the 
Chinese visitors. As recognized by Zhao (2006), visitors tend to travel as a means of escaping everyday life, whilst attempting to maintain their traditions and culture. Therefore, finding familiarity within the destination will create a feeling of security for the visitors in a foreign location (Zhao, 2006). Authors have also demonstrated the difficulty for Chinese visitors to travel around New Zealand independently; particularly regarding 'long travelling time between places' (Chen, 2002), and the need for information to be written in Chinese (Zhao, 2006). Identified in the findings of this study was that a number of Chinese visitors believed they didn't stay long enough at visitor site, taking into consideration that respondents also found that they least enjoyed certain aspects of the activities and attractions available in New Zealand during their stay. This becomes a problem for the tourism industry based on the fact that New Zealand prides itself on its environment and culture, and if there are respondents expressing New Zealand has bad sightseeing, and that they aren't spending much time at certain visitor sites, Chinese visitors are prevented from encountering a comprehensive and meaningful tourism experience in New Zealand. Additionally, if Tourism New Zealand endeavours to mature the Chinese visitor market to New Zealand, and develop the potential for FITs. However, this may also mean that there is more need for New Zealand's tourism industry to develop the understanding of what operators are presenting to visitors, and what the visitors are essentially encountering and observing.

Even though previous literature state that Chinese outbound visitors are intrigued by and take pleasure in learning about the 'outside world', comprising of their interest in other cultures, particularly Western cultures (Becken, 2003); it was identified that in this study even though there was interest in the New Zealand culture it also acted as a barrier to the level of satisfaction taken from the visit by the Chinese travellers, due to factors such as communication issues, and/or because the Chinese visitors were not accustomed to the New Zealand lifestyle. This finding was also recognized by Wen Pan \& Laws (2001) as the authors established the fact that Chinese visitors are fascinated by foreign cultures; however, seldom spoke English, and favoured eating their own cultural dishes rather than experiencing Western food offered in the destination being visited (Becken, 2003). An interesting finding that was established in Chen's (2002) study on tour group and independent Chinese travellers to New Zealand was that more independent visitors believed New Zealand was a 'small country, has a low population, and was safe' (p.90); all these aspects were in fact 
also recognized in this study as the most enjoyed and least enjoyed components of the Chinese visitors experience in New Zealand.

\subsection{Factors that impact on the Visitors' decision to visit a destination}

In this study there was an examination on various factors that Chinese visitor's may have considered in their decision to visit New Zealand. The factors that were being investigated involved: the duration of flight from China, the overall cost of the visit, if the destination was safe, if the destination was an English-speaking country, and whether a high level of environmental protection impacts on the respondents' decision to visit New Zealand. The aim of this question was to establish which factors were more important in the travel decisions of the Chinese visitors, but also if a destination's level of environmental protection is a significant influence when Chinese visitors choose their holiday destinations. From the findings of this study it was depicted that the 'safety of the destination' was the leading factor that impacted on the visitors' decision to visit New Zealand, with a mean of 3.97. Most visitors, no matter what market they are from, will commonly express their concern for safety; however, this factor may be of particular concern for the Chinese visitor market because they are still a young market, hence, these visitors may still have insecurities regarding travelling to foreign countries. This is potentially the reason why many Chinese visitors partake in tour group travel, because tour groups offer the visitors familiarity with culture between other participants, and the tour guide.

Interestingly, the second factor that was reported as having the highest mean in this study was the destination having a 'high level of environmental protection' (3.63). With the steady growth of the Chinese economy, and as the most heavily populated nation in the world, the country confronts a number of issues involving resources and the environment (Goffman, 2007). It has also been demonstrated that China has a heavy dependence on one of the most polluting energy sources, coal, which increases the environmental stress on the nation. While there are a variety of causes that have led to the degradation of the environment within China, circumstances have begun to change as the government and policymakers develop the awareness of environmental issues (Goffman, 2007). The growing level of environmental awareness within China could have essentially acted as a 'push' factor away from the visitors' origin to the destination that is more environmentally inclined. Whereas, New Zealand's own 
natural beauty could have functioned as a 'pull' factor for Chinese visitors, which may have come from a less environmentally aware country. From the interviews with the inbound tour operators, it was identified that several operators believe Chinese visitors understand the importance of environmental protection and conservation; however, the operators acknowledge the fact that there are also other factors that will essentially affect the visitors' decision to travel to a destination, such as the overall cost of their visit. Nonetheless, this would fundamentally impact on the marketing of New Zealand because this indicates a certain level of demand for environmentally focused tourism products by the Chinese market, and that the current images being portrayed to these visitors through the ' $100 \%$ PURE NZ' tourism campaign essentially affects the development of sustainable tourism.

Results from this study indicated that in general Chinese visitors might not be as concerned with the 'overall cost of their visit' as may be predicted, with a mean of 3.1, due to the fact that there has been much apprehension regarding the competitive pricing of tours to New Zealand as indicated by tour operators. Potentially, Chinese visitors on tours to New Zealand may not be as worried about the overall cost of their visit because in some circumstances the visitors make no payments towards the tours themselves. In these situations it is recorded that tour operators essentially receive their profits from commission earned from sales at souvenir shops while travelling in New Zealand. However, as the economy within China develops even further, Chinese visitors may be more forthcoming with spending more to ensure that their overall experience while on holiday is worthwhile. On the other hand, Chinese visitors may appreciate the fact that they only have a limited amount of time to travel on their holiday; therefore may not be concerned about the cost of their travel experience.

As a less significant factor, visiting an 'English-speaking country' did not discourage Chinese visitors from visiting a destination, presenting a mean of 2.93. Ryan \& Mo (2001) also identify that language is generally not a drawback for Chinese visitors travelling with a tour group, because a tour guide that can speak both English and Chinese escorts them around the destination. However, this study suggested that although this factor was not as important as the other factors on the visitors destination choice, it was indicated that language or being able to communicate independently without a third party is vital to keep satisfaction levels high, but also 
to make independent travel more convenient. It is recognized that language is more important to independent travellers than tour groups because communication between the visitor and the other party becomes the sole responsibility of the traveller, and if communication issues arise, it will eventually impact on the ability for the independent traveller to receive what is demanded or requested; therefore, reducing the level of satisfaction of the visitor. This becomes problematic in the development of repeat Chinese visitors that have travelled previously to New Zealand with a tour group, but also potential FITs from China (Ryan \& Mo, 2001).

As the least important factor that Chinese visitors reported to impact on their decision to visit New Zealand was the 'duration of flight from China', with the lowest mean of 2.27. The likely reason for this factor being of little significance can be related to the desire for the visitors to escape from their daily lives, but possibly to encounter a foreign destination no matter how far or how long it may take to get to the destination. Nonetheless, there were some visitors that believed the duration of flight from China to New Zealand was a negative aspect of their travel experience, and as the least enjoyed component of their trip to New Zealand. At present, there is very little that the New Zealand tourism industry can do specifically to resolve this situation, apart from attempting to make the visitors' experience in New Zealand worthwhile. However, this particular issue regarding the duration of flight from China to New Zealand may have been tackled by a number of tour operators by offering their clients tours that incorporated the visitation of other destinations, such as Australia, during the same tour to New Zealand.

\subsection{Sustainable Tourism in New Zealand}

In further investigation of 'sustainability' and sustainable tourism in New Zealand, it was demonstrated in the results that a large proportion of Chinese visitors have heard of the term 'sustainability' (74.3\%). Interestingly more tour group visitors (59.6\%) have heard of the term in contrast to independent travellers (40.4\%). In general, it would be assumed that FITs would be more aware of the term, due to them choosing such a travel style. However, it is possible that more tour group visitors have heard of 'sustainability' from their tour guides. From the interviews with the tour operators it was identified that a number of the operators that have not heard of the term, therefore impacting on their ability to educate their visitors about its importance to New Zealand. Furthermore, this indicated that the level of recognition of the term 
'sustainability' between Chinese visitors and operators were quite diverse. With regard to why there may have been a difference in the recognition of the term can be related to the continued difficulty in the generation of a comprehensive consensus (Cabezas et al., 2003). However, the differing interpretations of the term by the various stakeholders can be associated with what they were taught to understand from the term, for example tour operators may consider sustainability to relate to the financial profitability of their organisation. In general, the Chinese visitors considered 'sustainability' as entailing the conservation of resources for future generations, with specific consideration for environmental aspects. However, some visitors corresponded their understanding with the consideration of future tourists to the destination, and the continued preservation of natural attractions.

When tour operators were asked about the differences in the comprehension of the term between Western and Eastern societies, several tour operators stated that there will generally be a variance in the understanding of the term because in Western society the comprehension of 'sustainability' has had longer to develop; hence, allowing the tourism industry more time for stakeholders to acknowledge and become aware of the significance of the concept. On the contrary, with regards to the Eastern or Chinese terminology of 'sustainability', the Chinese outbound visitor market is still in its development stages, and has yet to fully mature in experience within the travel and tourism industry. Consequently, the idea and consciousness of 'sustainability' has yet to become mainstream, as a result of the strong relationship Chinese visitors have with their customs and traditions. Croall (1995) had also demonstrated similar findings indicating that in various countries different aspects of 'sustainability' and 'sustainable tourism' is emphasized according to their economic, environmental, and social standpoint. This also means that the tourism industry must allow the Chinese visitor market to develop further before the idea of 'sustainability' can be entirely recognized.

Results demonstrated that both tour group and independent travellers believe it is important for tourists to understand 'sustainability'. Nonetheless, there were mixed opinions from tour operators regarding whether they thought it was vital for visitors to understand the term. A tour operator made an assertion regarding visitors as 'clients', and that therefore they should not necessarily need to comprehend the meaning of 'sustainability'; correlating closely to particular statements made by a 
number of Chinese visitors regarding why they believed it to be unnecessary for tourists to understand the term 'sustainability'. These Chinese visitors essentially reported that as visitors to the destination they are only in the destination for a limited amount of time, and are in the destination to enjoy themselves; therefore there is no real reason why they need to understand the term. To further this discussion another tour operator states that the Chinese visitor market is still young, and even if promotions were extended to market sustainability in New Zealand to Chinese visitors it will continue to be difficult to change the opinions of the visitors. In spite of that, the operators interviewed acknowledge the fact that sustainable tourism in New Zealand is still in the developmental stages; hence, attempting to teach or extend the understanding of the term to Chinese visitors may be too premature for the tourism industry. Although educating tourists about 'sustainability' may be considered as premature, it is indicated in this study that many tour operators acknowledge that Chinese visitors have much to learn about the industry and the significance of 'sustainability', but overtime with more travel experience visitors may become more aware of the term and its principles, and the fact that without a sustainable tourism industry the natural environment that the Chinese visitors come to see may be degraded.

Conversely, when the tour operators were asked if they deemed it to be important for their organisation to understand 'sustainability'; three out of the seven tour operators believed it to be significant for them to understand the term in comparison to the number of operators thought it important for Chinese visitors to understand the term. From the few tour operators that regard it to be vital for their organisation to understand 'sustainability' the majority deliberated that the significance of the term interrelates with the operation of their organisation and the generation of profits. Additionally, one operator stated that understanding 'sustainability' will assist in the retention and development of their organisation through the delivery of quality products. Surprisingly, only one tour operator stated that he/she has heard of the New Zealand Tourism Strategy 2015. This finding was of particular interest because the New Zealand Tourism Strategy 2015 is set out to assist tourism businesses to operate more sustainably. Nonetheless, Croall (1995) conveys that there are a number of obstacles hindering stakeholders from contributing to sustainable tourism. Some of the primary barriers correlate directly to the traditional associations with mass tourism, and the strictly business focused tour operators with short-term visions 
(Croall, 1995). Therefore, attempting to shift the complexity of environmental practicability and profitability at a simultaneous rate has led to many tour operators overlooking 'sustainability', because of the lack of productive support for sustainable tourism development activities through education and funding.

As a result of tourism, many destinations have recognized the extent to which tourism can bring about positive economic advantages, but also negative social and environmental consequences (Kavallinis \& Pizam, 1994). Therefore, to extend the comprehension of this situation further, this study examined the stakeholders responsible for creating and dealing with the impacts of tourism. Findings of this study illustrated that Chinese visitors believe that the stakeholder most responsible for creating the impacts of tourism was the government. This was interesting, firstly because the tourists are the consumers of the tourism products; and secondly because tour operators and tourism businesses are the suppliers of the tourism products and essentially have direct contact with the consumers. The results of this study was closely related to that of a study undertaken by Kavallinis \& Pizam (1994) on the various perceptions of residents, entrepreneurs, and tourists concerning the negative environmental impacts of tourism on the Greek island of Mykonos. Chinese visitors in this research acknowledged that a number of stakeholders are responsible for the generation of tourism impacts, with one of these specific stakeholders being themselves.

In contrast, when assessing who the Chinese visitors thought was responsible for dealing with the impacts of tourism over half of the visitors believed governments to be the most responsible; presenting the other stakeholders as less responsible. Conversely, the tour operators expressed mixed reactions to this subject, with the majority conveying that they believed that more than one stakeholder was responsible for dealing with the impacts of tourism. This suggestion was accompanied by statements portraying each stakeholder as a key party in the creation of the impacts of tourism, due to the position they play in the development and delivery, management, and promotion of the tourism product or service. Furthermore, tour operators stated each stakeholder can only do so much to assist in the reduction of the negative impacts of tourism; however, education at each level of the tourism industry is vital to become upfront with how to deal with the affects that tourism generates, but also to advance the 'sustainability' of the tourism environment. 
The findings of this study demonstrated that only a small proportion of the Chinese visitors examined believed that tourists are responsible for creating and dealing with the impacts of tourism. Yet, over half of both tour group and independent travellers thought it to be important for tourists to understand the term 'sustainability'. This was interesting because it illustrated the fact that very few Chinese visitors acknowledge their contributions to the creation of tourism impacts; however, the visitors appreciate the need for them to comprehend sustainable tourism. Nevertheless, understanding and acknowledging the position visitors perform in the tourism industry complements the development in the awareness of 'sustainability'.

\subsection{New Zealand's Marketing Image}

In the examination of New Zealand's marketing campaign and image, it was illustrated in this study that $42.9 \%$ of Chinese visitors have seen the ' $100 \%$ PURE NZ' tourism campaign; $63.6 \%$ of the tour group visitors and $36.7 \%$ of independent travellers. Although quite a few Chinese visitors have stated that they have seen the ' $100 \%$ PURE NZ' tourism campaign, it can be established that this could be enhanced if the exposure of the campaign was more widespread within China. Potentially a large number of Chinese visitors examined in this study have seen the tourism campaign because the majority have come from Shanghai, where the bulk of New Zealand's campaigning is undertaken. From the independent travellers that reported they have seen the ' $100 \%$ PURE NZ' tourism campaign none of these visitors believed that the campaign was either 'important' or 'very important' as an influencer on their decision to visit New Zealand. Yet, it was noteworthy that $15.8 \%$ of the tour group visitors thought the New Zealand tourism campaign was 'very important' in their decision to visit the destination. To add to these findings, five of the tour operators interviewed suggested that the '100\% PURE NZ' tourism campaign to some extent affects the Chinese visitors' decision to come to New Zealand. However, the operators add to this statement by expressing there are other factors that will also influence the holidaymakers travel decision, such as political stability, and potentially the cost of the experience.

A key finding in this section was that only $30 \%$ of the Chinese visitors believed that the ' $100 \%$ PURE NZ' tourism campaign 'matched exactly what they saw on their trip to New Zealand'. This finding was of particular importance because in the examination of the messages that the Chinese visitors most closely associated with 
the '100\% PURE NZ' tourism campaign, it was visible that New Zealand's long standing themes, such as: New Zealand's outstanding scenery, New Zealand's unique culture, New Zealand having many adventurous activities, and New Zealand being unpolluted; were the most widely connected messages that the Chinese visitors linked to New Zealand's tourism campaign. With regards to this finding, it is established that many stakeholders believe that the ' $100 \%$ PURE NZ' tourism campaign has done a good job in drawing in international visitors to New Zealand; however, it needs to be sustained to continue to be advantageous for tourism in New Zealand, as expressed by Christian Schwalbach, group publisher of American Express' Centurion and Platinum magazines, Asia Pacific, conveys that "New Zealand has been extremely smart with its 100\% Pure New Zealand branding, which resonates internationally and is universally recognized, understood and valued. As long as New Zealand can maintain the integrity of this brand image it will enjoy a strong and enduring foundation to build its tourism activities on.” (The New Zealand Herald, 2008). Although a number of Chinese visitors have identified that New Zealand's outstanding scenery and New Zealand being unpolluted as most widely associated messages relating to New Zealand's tourism campaign, in recent studies by Tourism New Zealand, the country's international status as a 'clean, green holiday destination' is becoming an issue to maintain. In a 2008 Tourism New Zealand survey it was revealed that most visitors to New Zealand were satisfied with the destination's natural landscapes and clean environment (TNZ, 2008). However, there were several environmental problems identified by visitors who partook in this survey, which included a decline in natural resources (31\%), the increase in litter (36\%), and lack of recycling opportunities (37\%) (TNZ, 2008). Tourism New Zealand's chief executive George Hickton conveys: "we know that our international visitors are becoming more environmentally aware and that the ' $100 \%$ PURE' (marketing) brand means they come here with a set of expectations about the way we are managing our environment” (Burgess, 2008). Hence, if international visitors are to become more aware of environmental issues the tourism industry in New Zealand needs to maintain its clean and green image to retain its primary visitor market. However, in the interviews undertaken in this study it was indicated by the tour operators that the image of New Zealand as 'PURE' does not appeal to all Chinese visitors, due to the fact that many see their visitation to New Zealand as a typical visit to a Western destination. Therefore, images of 'purity' or being 'green' will not necessarily draw Chinese visitors to New Zealand. Conversely, this contradicts the 
fact that a large proportion of Chinese visitors stated that a primary influencer on their decision to visit New Zealand was the country's high level of environmental protection. Additionally, this demonstrates that there is a difference of opinion between the Chinese visitors and the tour operators, and that there might be a possibility that the tour operators are only expressing that they believe Chinese visitors are not drawn by New Zealand's ‘clean, green' image because they are not willing to alter their current products and services to become more sustainable. This therefore affects one of the primary aims of the New Zealand Tourism Strategy 2015, which is to achieve a balance between the operations of financially viable businesses, satisfy the needs of customers, protect the natural environment, and support the host community (NZTS 2015, 2008). Nonetheless, some of the more recent messages portrayed by Tourism New Zealand; i.e. New Zealand being a young country, were not believed by visitors to be as closely associated with the ' $100 \%$ PURE NZ' tourism campaign. Potentially, this message may not be as attractive to the Chinese visitor market due to the fact that the messages may not be as tangible as the other messages portrayed by Tourism New Zealand, but also because being such a 'young country' Chinese visitors may not feel as assured about their experience in New Zealand as they may in a 'developed' destination.

In spite of this, it is established in the overall assessment of the tour operators statements that New Zealand's '100\% PURE NZ' tourism campaign is not sufficient to attract or influence the Chinese visitors to come specifically to New Zealand and to stimulate the visitors to become more 'sustainable' if the significance of 'sustainability' is not promoted appropriately. Consequently, with the insufficient promotion and marketing of New Zealand as an independent destination it becomes difficult for the tour operators and the tourism industry to compete with Australian tours that are more frequently promoted and recognized in the Chinese outbound visitor market. Conversely, the current Prime Minister and Tourism Minister of New Zealand, John Key, states that he would be partial to "liven up” New Zealand's '100\% PURE NZ' brand, by essentially “refreshing” the campaign (Gower, 2008). By “refreshing” the '100\% PURE NZ' brand, New Zealand's tourism industry may be able to attract more potential Chinese visitors to New Zealand by marketing and promoting the destination in more cities and provinces in China, but also incorporating images in promotions that will surpass barriers and draw visitors to 
experience New Zealand as a independent destination; rather than an addition to an Australian tour. 


\section{CHAPTER 7 Conclusion}

\subsection{Introduction}

This chapter sets out by summarizing the rationale on why this study was undertaken, a brief review on how this study was implemented, and the key findings that will be discussed in the context of the five aims. This is then followed by a discussion of the formulation of recommendations for the private and public sectors based on the findings of this study. Following the recommendations is a section that covers suggestions for further research.

Essentially, the primary reasoning behind the development of this research was to generate a broader understanding of sustainable tourism in New Zealand. 'Sustainability' was identified as being an important concept in the New Zealand tourism industry because of the direct association that many tourism products have with the natural environment and as a priority of the New Zealand Tourism Strategy 2015. This research was conducted on the context of the Chinese inbound market to New Zealand because this visitor market has consistently shown evidence of potential for growth and development. In addition, little is known about the preferences and travel behaviours of the Chinese visitor market; therefore, by examining the visitors' attitudes towards sustainable tourism in New Zealand it will effectively assist in managing the continuous growth of visitor arrivals, a greater understanding of the visitors, and a broader comprehension of sustainability in New Zealand. Consequently, guiding the ability for the tourism industry in New Zealand to enhance the promotions and the management of tourism products for the Chinese visitor market.

To achieve the aims of this study a mixed method research approach was employed to gain both the visitors' and suppliers' perspective of the research subjects. The research variables that were examined in this study were: visitor characteristics, trip characteristics, satisfaction, factors impacting on the visitors' decision to visit New Zealand, sustainable tourism in New Zealand, and New Zealand's marketing image. These subjects were also expressed in the analytical framework to demonstrate how this research was structured, and how the data collected from the quantitative and qualitative research was employed to satisfy the aims. With regards to the 
quantitative research approach a questionnaire was developed to survey Chinese visitors; whereas, the qualitative research approach entailed the interviewing of ADS registered tour operators. The mixed method approach essentially strengthened the findings of this study by presenting a comprehensive interpretation of sustainable tourism in New Zealand from the Chinese visitors’ perspective.

Therefore, the following research aims were generated to assist in the thorough examination of the Chinese visitors' view of sustainable tourism in New Zealand:

1. Enhance existing knowledge of the Chinese visitor market to New Zealand.

2. Establish whether the sustainable development of a destination influences the travel decisions of Chinese visitors and how this impacts on New Zealand's tourism industry.

3. Achieve a better understanding of the Chinese visitor's view and the tour operator's view of sustainable tourism in New Zealand.

4. Identify whether New Zealand's '100\% PURE' tourism campaign is effectively and efficiently attracting Chinese visitors to New Zealand.

5. Establish how the tour operators promote sustainable tourism to their customers.

\subsection{Research Aim One:}

Enhance existing knowledge of the Chinese visitor market to New Zealand.

The literature review highlighted the growing significance of the Chinese outbound market to the global tourism industry; however, very little was known about the visitor market to New Zealand. Due to the fact that a number of studies undertaken on the Chinese visitor market in New Zealand are now outdated, this study updated some of the key demographics and trip characteristics of this visitor market. From the quantitative analysis it was identified that there was almost a 50:50 split between the male and female Chinese visitors, with the majority between the age of 30-49 years. It was interesting to find that over $50 \%$ of the Chinese visitors to New Zealand came from the East of China; this could be linked to the wider promotions of New Zealand in that area, for example the Tourism New Zealand office that is located in Shanghai. However, from the findings of this study it can be asserted that the 
Chinese visitor market to New Zealand does not only come from one specific region within China, but from a variety of cities and provinces.

This study specifically identified that there were slightly more Chinese tour groups visiting New Zealand than independent travellers. This particular finding indicates the change in travel styles by the Chinese outbound market, in past literature authors have generally emphasized the importance of tour group travel for the Chinese outbound market; yet, this study recognizes the altering travel preferences of the Chinese market. Although there were only two operators out of the seven interviewed that conveyed that their organization had an FIT customer base. The operators identified their FIT customer base as still being relatively small, one particular operator stated that he/she believed that the number of Chinese FIT is still very limited because the market has yet to develop to its full potential, and due to issues such as culture and language the Chinese FIT market has not evolved at the same rate as other markets with regards to travel experience.

With regards to the Chinese visitor trip characteristics, it was indicated that the median number of nights stayed in New Zealand by Chinese visitors was 6 nights, however, according to statistics presented by Tourism New Zealand, it is demonstrated that the median length of stay for Chinese holiday visitors to New Zealand of 3 days (TNZ, 2008). Furthermore, when examining the length of stay with regards to Chinese tour group and independent travellers, it was identified that there was a statistically significant difference between the visitors' length of stay. It was established that over half of the tour group visitors stayed between 4-7 nights; whereas, the majority of the independent travellers stayed in New Zealand in New Zealand for more than 2 weeks. With regards to the New Zealand Islands that the Chinese visitors stated that they visited, it was identified that more tour group visitors toured through both the North and South Islands in comparison to independent traveller. More specifically, half of the tour group visitors visited both the North and South Islands; whereas, the majority of the independent travellers expressed they only visited the North Island. These findings suggest that the Chinese visitor market has begun to mature with regards to their travel experiences, and many tour groups now appear to appreciate the fact that they are not in New Zealand for a long period of time, therefore may be willing to spend slightly more to see and experience the entirety of New Zealand. 
In the examination of whether the Chinese visitors have travelled internationally in the last 5 years, it was established that a large proportion of the visitors have, with the majority travelling between 1-3 times within those 5 years. Although very few Chinese visitors specified that they had visited New Zealand previously, out of those that did just over half stated they have taken 1-2 trips to New Zealand in the past. While investigating the Chinese visitors' trip characteristics, it was identified that almost half of the Chinese visitors had visited another country before arriving into New Zealand, and from those visitors the majority had visited Australia. On the other hand when the Chinese visitors were asked if they were going to visit another country after departing New Zealand a significant proportion stated that they were not going to visit another country; yet, out of those that conveyed that they were, going to visit another country after they depart over half stated that they were going to visit Australia.

It was established from the findings that the three primary purposes for visiting New Zealand were to: holiday/vacation, visit friends and family, or for business. Identified in this study was the large proportion of Chinese visitors coming to New Zealand for holiday/vacation purposes; this in itself was interesting because of the shift from business travel being the primary purpose over the last decade to many Chinese visitors travelling to New Zealand for alternative reasons. Although a number of Chinese visitors still travel to New Zealand for business reasons, or to attend conferences/conventions, a large degree of Chinese visitors now come to visit friends and family, and as demonstrated in this study with half of the independent travellers stating that they have come to New Zealand to visit friends and family.

With regards to the activities the visitors participated in the majority of both tour group and independent travellers partook in: sightseeing, shopping, and visiting a historical site. This study specifically identified that independent travellers were more willing to participate in activities or view attractions that may be recognized as environmentally-aware, or activities that showcased New Zealand's tourism industry, such as mountain/rock climbing/caving, snow boarding/skiing, or tramping. Whereas, tour group visitors generally participated in more commercialised activities or attractions, such as Maori cultural performances and/or visiting casinos. A potential reason for tour groups participating in a variety of commercialised activities and/or 
attractions can directly relate to the itineraries set out for them by their travel agents. In many of these situations the travel agents have only a very limited knowledge of what is available in New Zealand; therefore, they tend to sell the cheaper versions of what they believe to be iconic to New Zealand.

Alternatively, the findings have demonstrated that Chinese visitors have begun to employ the use of a larger array of information sources. Although, a larger portion of tour group visitors are still utilizing travel agents as a main source of information, a large degree of them now choose to investigate the tourism products and services they intend to purchase themselves, may it be via the Internet, from the organization they work for or work colleagues. Independent travellers on the other hand have begun to research the tourism products and services they are to purchase more widely, employing the use of a variety of sources, such as newspapers/magazines, TV/radio, and guidebooks; indicating the increased engagement and interactivity of Chinese independent travellers.

In the examination of the satisfaction level of the Chinese visitors, there was a 50:50 split between visitors that articulated they were above moderately satisfied with their trip in New Zealand, and those that conveyed they were only moderately satisfied or lower. Interestingly, tour group visitors had a higher level of satisfaction than independent travellers, with no tour group visitors stating that they believed their experience in New Zealand was lower than moderately satisfying. With regards to the findings, it was demonstrated that a key aspect of the visitors' trip in New Zealand that they enjoyed the most was the destination having a 'good environment'. The findings also indicated that there were a number of other examples expressed by the Chinese visitors reflecting the trend towards the importance of the environment, for example the beautiful scenery, the clean/fresh air, the clean 'Green' image, and New Zealand's good conservation/keeping of the environment. Conversely, the areas that were identified as being the least enjoyed generally concerned the impact of the high cost of several components of the visitors' trip, safety and security, and essentially culture and language barriers. When examining the aspects of the visitors trip in New Zealand that they least liked, it was detected that some tour group visitors believed that they weren't given enough time at the visitor sites; whereas, the independent travellers had issues with the difficulty to locate various places, such as attractions because of bad road signage. This becomes a concern due to the fact that 
there are obvious problems in the way that the Chinese visitor market is being catered to, with regards to both the tour group and independent traveller groups.

This thus demonstrated that existing literature regarding the Chinese visitor market to New Zealand concerning the visitors' demographics and trip characteristics is slightly outdated; and that the Chinese visitor market is maturing with regards to travel experience leading to a shift in travel choices, such as travel style, trip attributes, and activity/attraction choice.

\subsection{Research Aim Two:}

Establish whether the sustainable development of a destination influences the travel decisions of Chinese visitors and how this impacts on New Zealand's tourism industry.

In terms of whether the sustainable development of a destination influences the travel decision of Chinese visitors; this study established that with regards to environmental conservation and preservation, Chinese visitors do believe this to be a key factor that may influence their decisions to visit a destination. This study identified that safety was the primary factor impacting on the visitors' travel decisions; however, this was followed by the destination displaying a high level of environmental protection, which for example was more important than price. This essentially impacts on New Zealand's tourism industry because it can be acknowledged that the sustainable development of a destination acts as a potential pull factor for visitors to come to a destination. Therefore, if the tourism industry in New Zealand continues to develop and deliver sustainable products the industry may prospectively draw in and retain the country's Chinese visitor market. With these results it can be ascertained that environmentally sustainable tourism is a draw card for many Chinese visitors, either as a 'push' away from their origin, or as a motivation for visiting a destination. However, as indicated by the tour operators, the environmental aspect of a destination is only one factor that may motivate the Chinese visitors' holidaymaking decisions and will not act as the key influencer of their destination choice. 


\subsection{Research Aim Three:}

Achieve a better understanding of the Chinese visitors' view and tour operators' view of sustainable tourism in New Zealand.

This study highlighted the fact that just over half of the Chinese visitors perceived New Zealand to be more than just a reasonably sustainable tourism destination, with a large portion of the Chinese visitors stating that New Zealand was a very sustainable tourism destination. In addition, the majority of the Chinese visitors believed it to be important for tourists to understand 'sustainability', indicating that Chinese visitors are willing to be educated about issues that may be associated with 'sustainability', or 'sustainable tourism in New Zealand'. Whereas, four out of seven tour operators interviewed believed New Zealand to be a sustainable tourism destination, the majority conveyed such an insight due to the fact that they believed the New Zealand environment to still be untouched, thus being able to continue attracting visitors. However, two tour operators believe that New Zealand is a sustainable tourism destination; yet, they believe that work is still needed to retain the tourism industry's environmental 'sustainability'. One operator drew particular attention to the need for the government to generate policies that are specifically focused on sustainable tourism in New Zealand, with regards to the supply of products, and also the policies involving tour operators. Conversely, another operator conveys that sustainable tourism in New Zealand is still in the development stages. From the findings it is illustrated that a large number of Chinese visitors identify New Zealand's tourism industry as being reasonably sustainable, in spite of that the majority of tour operators did not think so. This was interesting because the tour operators that work within the tourism industry believe that more is needed to structure a sustainable tourism sector in New Zealand. However, the visitors that come to experience New Zealand portray the country's environmental sustainability as an enticing characteristic. 


\subsection{Research Aim Four:}

Identify whether New Zealand's '100\% PURE' tourism campaign is effectively and efficiently attracting Chinese visitors to New Zealand.

In the findings of this study it was demonstrated that a number of Chinese visitors have seen the New Zealand '100\% PURE' tourism campaign; however, this could be due to the large proportion of Chinese visitors in this study coming from Shanghai, where the majority of New Zealand campaigning is done within China. Furthermore, only a few of the Chinese visitors indicated that the ' $100 \%$ PURE' tourism campaign played a very important factor on their decision to visit New Zealand. In fact, nearly half of the Chinese visitors who had seen the campaign expressed that it was only moderately important as a factor that impacted on their decision to visit New Zealand. Yet, when the tour operators were asked whether they believed the New Zealand ' $100 \%$ PURE' tourism campaign would influence the Chinese visitors decision to visit New Zealand, two operators stated that the campaign is ineffective in influencing the decisions of Chinese visitors based on the fact that many visitors still identify New Zealand as part of Australia, and New Zealand tours are seen as an addition to the overall Australian tour product, one operator adds by articulating the need for more marketing in China to draw attention to New Zealand as a independent destination.

Also identified in this study was that only a small number of the Chinese visitors who have seen New Zealand's '100\% PURE' tourism campaign thought it matched exactly what they saw and experienced during their trip in New Zealand. However, hardly any of the responses conveyed that the '100\% PURE' campaign gave the completely wrong impression of what they experienced in New Zealand. Nevertheless, the majority of the Chinese visitors conveyed that the '100\% PURE NZ' tourism campaign closely matched exactly what they saw and experienced during their trip in New Zealand. In the review of the messages illustrated in New Zealand's '100\% PURE' tourism campaign, Chinese visitors identified that the message of New Zealand being 'unpolluted' as the most strongly associated with the New Zealand tourism campaign. This was then followed by New Zealand having 'outstanding scenery', New Zealand being 'untouched by modern development', and New Zealand having 'many adventure activities'. However, the messages of New 
Zealand having a 'unique culture', and New Zealand being a ‘young country' was not closely associated with the ' $100 \%$ PURE NZ' tourism campaign. This finding may cause some concern for the New Zealand tourism industry due to the fact that the Maori culture is one of the country's primary selling points, and as the New Zealand Tourism Strategy 2015 states the Maori culture adds a unique dimension to the overall tourism product in New Zealand, therefore if not utilized appropriately the destination essentially losses out on a competitive advantage. However, with regards to the message about New Zealand being a 'young country', this message has just been recently implemented, therefore may not be as effective in drawing appeal to audiences.

\subsection{Research Aim Five:}

Establish how the tour operators promote sustainable tourism to their customers.

This study emphasized the fact that very few of the tour operators promote sustainable tourism to their customers. The majority of the tour operators demonstrated that they were merely tour operators, and therefore do not have direct contact with their Chinese visitors to educate them. However, they do attempt to employ the use of their tour guides to inform their visitors about certain pieces of information regarding 'sustainability' and 'sustainable tourism in New Zealand'. Several of the tour operators interviewed also expressed that the ADS regulations that they follow places a certain degree of pressure on the quality of their products and services; therefore, impacting on the tourism organizations ability to retain the visitors and fundamentally the tourism product they are attempting to supply. Another way that some tour operators promote sustainable tourism to their customers is through the disapproval of shopping tours. A number of tour operators disapproved shopping tours because they saw that they were closely linked to low quality and unsustainable practices, but the operators also indicated that their organization believes there are other factors that are more important than shopping during their customers visit to New Zealand, such as the environment and culture. This study also identified that only one operator acknowledged the significance of being a Green Globe member in distributing information regarding the importance of sustainable tourism and environmental protection. 


\subsection{Recommendations}

In integrating the findings of this research, recommendations transpired for a variety of tourism stakeholders, such as those within the private sector, and public sector. In other words, as the Chinese inbound visitor market to New Zealand continues to develop, there is potential for change with regards to New Zealand's marketing campaign to attract and retain these visitors. At present, not a huge number of Chinese visitors acknowledge that they have heard of the term 'sustainability'; yet many do recognize the significance of a destination having a high level of environmental protection. This particular factor as seen in this study plays a highly significant role in the Chinese visitors' decision to visit New Zealand, just following the concern for safety. The recommendations from the findings of this study will therefore be summarized in the context of the private sector and the public sector. Although recommendations were made from the emergence of various themes in this study, it must be noted that the primary limitation of this research was the restricted sample size; consequently a mixed method approach was employed to attempt to overcome the shortcomings of the small sample.

\subsubsection{Recommendations for the Private Sector}

This research has identified an array of recommendations for the private sector to take into consideration, whilst they bear in mind the need for sustainable tourism in New Zealand as they target and cater for the Chinese visitor market. With the large amount of tour operators that now target the Chinese visitor market, having the ADS approval system for these tour operators is essential. It was established in this study that the ADS system was acknowledged as a key accreditation to have as a tour operator targeting the Chinese market; yet was identified by tour operators as a system that brought a number of challenges and issues, namely issues regarding tourist itineraries. As these ADS approved tour operators now need to abide by certain criteria and regulations this section aims to recommend various educational procedures, and activities that the tour operators can put in place to reduce their reliance on commissioned shopping tours, to potentially develop revenues by promoting various aspects of New Zealand that could lead to the industry becoming more environmentally sustainable.

Due to the fact that tour operators are the main suppliers of tourism to New Zealand, they are identified as the individuals that have first hand contact with visitors. As a 
key recommendation tour operators should expand their knowledge of their products and services to the various parties that sell their tours to inform and educate others about the importance of sustainable tourism in New Zealand. This form of education could potentially extend further by attempting to inform the Chinese visitors upon arrival into New Zealand about environmental sustainability. This would best be done in written and verbal form, as many Chinese recognize the significance of various pieces of information more if written down and given to them in Chinese (Zhao, 2006). Although it is understandable that the tour operators do not have direct contact with their visitors, it is vital that they educate their tour guides about the importance of their conduct and how they are able to inform their visitors about environmental preservation and conservation in New Zealand. By doing so, it may eliminate the potential conflict that may occur between the visitors and host community, but also as a 'face-giving' gesture to the visitor by the tour guide. However, with regards to educating those, such as travel agents, that sell the tour operators' products and services, this becomes an important influence on the types of tours that the visitors will essentially purchase. Hence, if a travel agent was to present a more sustainable tourism product to visitors, stressing the status and potentially better travel experience that comes with this product, visitors may be more inclined to purchase it even if it comes at a slightly higher price than the badly publicized 'shopping tours'.

As established in this study and a number of others, status for Chinese visitors is a highly important factor that influences their preferences and behaviours whilst travelling. Yet, many tourism activities and attractions that are associated with the idea of status are more costly, and due to the fact that the Chinese visitors are more price sensitive in comparison to other visitor markets to New Zealand a number of tour operators have rejected to insert activities that may include a charge, such as wine tasting or whale watching. Instead many tour operators who target the Chinese visitor market take their visitors to attractions that are free of charge, such as national parks, or to scenic spots that are on the same route to commission-based souvenir stores. These occurrences potentially impact on the visitors' level of satisfaction, and their willingness to repeat visit or give positive word-of-mouth recommendations about New Zealand. In general, this will impact negatively on the overall sustainability of the tourism industry in New Zealand, the image of New Zealand's environmental conservation and preservation, but also the retention of the Chinese 
visitor market due to the fact that there is a high level of dependence on word-ofmouth recommendations.

To promote the status associated with the visitation to New Zealand tour operators should essentially offer visitors itineraries that showcase New Zealand's well-known adventure tourism activities, and wine tourism. The geography of New Zealand offers an admirable opportunity for visitors to enjoy sightseeing activities, but it also supplies a chance for tourists to engage in various recreational and adventure activities, such as hiking, skiing, bungy jumping, and jet boating (Collier, 2006). Adventure activities are seen as being closely associated with status because these activities are generally dependent on natural or environmental attractions; which will vary from destination to destination, thus conveying the 'once-in-a-lifetime' impact of such activities. In addition, as the Chinese visitor market becomes more developed and experienced with travel they may seek differing tourism products and services; hence, shifting from the confined and strict regulations of commission-based shopping tours, to more liberated, all-embracing tours that incorporate a larger array of activities and attractions that support environmental awareness. By doing so, it promotes the importance of the environmental sustainability in New Zealand's tourism industry, but also the significance of the retention of the evolving Chinese visitor market.

A potential recommendation that can be made for both the New Zealand tourism industry and inbound tour operators that target the Chinese visitor market is the incorporation of wine tourism during the visitors' tours around New Zealand. Specific aspects of wine tourism may be a potentially beneficial addition to Chinese visitor tours to New Zealand because it has been established that as the middle class in China increased the appearance of wine as a key status symbol begun to develop. Patricio de la Fuente Saez, director of Links Concept, a Hong Kong-based wine distributor stated that "wine is the latest must-have item in urban China” (Baker et al., 2005, p.3). For that reason, this could essentially assist in the generation of both direct and indirect tourism revenues as the Chinese visitors purchase local wines during their tour to bring back as souvenirs for friends and family. The wine industry in New Zealand is increasingly delivering and trading on the country's 'clean, green' image. By offering tours that integrate the sustainable goals of the New Zealand Tourism Strategy 2015, regarding the need to retain New Zealand's '100\% PURE' 
image, that incorporation of tourism products that are associated with environmentally sustainable objectives will essentially educate visitors, but also increase the sustainability of the tourism industry in New Zealand.

\subsubsection{Recommendations for the Public Sector}

This research has developed a number of recommendations for the public sector; these recommendations focus specifically on either sustainability or New Zealand's marketing image and campaign. Firstly, it is recommended that Tourism New Zealand continue with the management and monitoring of inbound tour operators that target and cater for the Chinese visitor market. It would essentially be more beneficial if all operators that cater to the Chinese visitor market be monitored and regulated, and not just those registered with the ADS because it would create more stability within the tourism industry as a means of attempting to maintain quality and satisfaction. Additionally, it may be advantageous if there were seminars available for the private sector to reinforce to tour operators and other tourism suppliers the key points of the New Zealand Tourism Strategy 2015. The findings of this study demonstrate that very few of the tour operators interviewed have heard of or comprehend the New Zealand Tourism Strategy 2015, which conveys that the key message of the strategy is not being acknowledged or understood. The purpose of the Tourism Strategy is to attain equilibrium between the operations of financially viable businesses, satisfying visitors, preserving the natural environment, and maintaining the host community (NZTS 2015, 2008).

As illustrated by Tourism New Zealand and a number of other authors the impact of independent travel is seen as the positive alternative to mass tourism. In this study it is demonstrated that the Chinese visitor market is showing signs of maturity and development with regards to the increasing number of independent travellers; yet, it was identified that the tourism industry in New Zealand was not entirely prepared for this change. In general, research has specifically focused on either how the New Zealand tourism industry is able to improve tour group travel from China, or the specific similarities or differences between Chinese tour groups and independent travellers. However, this study indicated the need for the tourism industry in New Zealand to be more prepared for Chinese independent travellers and the potential difficulties they may have with communication and language; therefore providing 
more information in Chinese at certain tourist points would be advantageous to generate positive tourist experiences.

Thirdly, with regards to New Zealand's marketing image and campaign it was identified in this study that very few Chinese visitors have seen the ' $100 \%$ PURE' tourism campaign, the reason for this could be directly related to the limited budget that Tourism New Zealand has for campaigning efforts within China. Many Chinese visitors portray their visit to New Zealand as an 'add-on' to an existing tour they are taking to Australia. This issue unquestionably needs to be addressed by Tourism New Zealand, due to the fact that it becomes a problem in the retention of the Chinese visitor market to New Zealand. If New Zealand is unable to reach the Chinese visitor market through traditional promotions of the country due to budget constraints it may be advised that with the increasing array of information sources that the Chinese market is now utilizing, Tourism New Zealand may want to consider refocusing their promotions to specifically target the Chinese visitor market.

Identified in this study was the growth in the use of Internet websites both in English and Chinese, but also the organization that the visitor works for. The increased use of the Internet as a source of travel information by the Chinese will potentially be beneficial for tourism promotions because New Zealand will be able to develop marketing approaches that specifically appeal to the Chinese visitor market, for example short video clips in Chinese with Chinese presenters promoting New Zealand. This is essentially a more cost effective marketing technique that would reach a larger population in comparison to having large billboards in one or two cities within China; additionally these clips can also be uploaded onto other electronic media through blogs and podcasts, which will specifically attract the interactive traveller market within China. With regards to the target promotions of New Zealand to potential Chinese consumers, new and improved messages can be employed to push the focus onto sustainable tourism in New Zealand. The reason for employing new messages to be associated with New Zealand's '100\% PURE' tourism campaign is that it will assist in the education of the Chinese visitors prior to arrival, but it would also act as a screening process to eliminate unwanted visitors that may not value New Zealand's sustainable goals. Moreover, the alteration of New Zealand's promotional messages may also appeal to the increasing Chinese independent traveller market. 
As a means of modifying the New Zealand '100\% PURE' tourism campaign to specifically target the Chinese visitor market, a tagline can be employed as a way to draw attention to what New Zealand has on offer for these visitors. A potential tagline that can be implemented is: 'Luxury or Uniqueness that lies within'. This tagline can essentially be implemented in the same way as the 'What's On' tagline for Australia; by placing specific emphasis on what can be inserted at the end of the phrase, for example in the case of Australia: 'What's On: Summer 2009'. Hence, depending on what Tourism New Zealand may want to promote, it will dictate the message during that season, for example 'Luxury that lies within: Nature'. The primary reason why 'luxury' and 'uniqueness' were utilized as the key draw cards can be related to the increasing demand for status interrelated products and services by Chinese visitors, but also because of the uniqueness that is associated with luxury products.

On the other hand, a method at which the public sector is able to tap into the business/incentive-based tourist market from China is potentially through having events to showcase New Zealand to organizations in China as a means of promoting the country as a good destination to send their staff as a reward, but also as a country that has potential to assist in the development of their employees understanding of the New Zealand business environment, and the management of the natural environment.

\subsection{Further Research}

This research has sought to fill the research gaps identified by studying sustainable tourism in New Zealand, through the examination of the Chinese inbound market. Although this study has demonstrated a broad understanding of sustainable tourism in New Zealand, the augmentation of existing knowledge of the Chinese outbound market, the various factors that impact on the Chinese visitors decision to visit a destination, and New Zealand's marketing image; the research has generated opportunities that merits further examination. In particular, to obtain a more comprehensive representation of New Zealand's '100\% PURE' tourism campaign and how a more effective and efficient marketing strategy can be developed to promote sustainable tourism in New Zealand to visitors. Consumer-based research needs to be carried out to examine further the factors that impact on the Chinese visitors' decision to visit a destination. This consumer-based research should also 
entail an investigation on various motivations that are associated with sustainable connotations. Establishing the various motivations that visitors may have that are associated with sustainable connotations can result in the tourism industry identifying whether or not sustainable tourism is important to visitors; and if the visitor market(s) have matured with regards to the tourism products and services demanded. In addition, it may be beneficial for researchers to consider studying the impact of the ' $100 \%$ PURE NZ' tourism campaign on Chinese tour group and independent travellers, to essentially identify whether the differing images appeal to differing visitors. This could also lead to research that is undertaken in China to develop an understanding of why some Chinese visitors do not choose to visit New Zealand.

With regards to extending existing knowledge of the Chinese outbound market, it may be interesting to investigate the growing independent traveller market. Due to the fact that a large array of studies have been undertaken to distinguish the similarities and differences between the two travel styles, it would be beneficial to identify what motivates the visitors to travel independently, and what do they expect to experience travelling independently. On the other hand, further research could be undertaken on the similarities and differences between tour group and independent travellers regarding sustainable tourist behaviours; investigating specifically: what they believe sustainable tourist behaviour is, how they believe they act whilst travelling, and if they believe they should act sustainability whilst they are on holiday.

As the final component that calls for future research the potential comparison of the Asian and European markets, and their perspective of 'sustainability', or more specifically sustainable tourism in New Zealand should be examined. This specific research area may be of interest to both the public and private sectors of the tourism industry because it can firstly establish whether there is a difference in the understanding of 'sustainability' or sustainable tourism in New Zealand by these two visitor groups. But lastly, this type of research would allow the researcher to identify if differing groups may require more assistance when it comes to understanding 'sustainability' and sustainable tourism in New Zealand, and by doing so it may alter how suppliers target and cater to their visitors. 


\section{APPENDICES}

\section{Appendix A - Visitor Information Sheet}

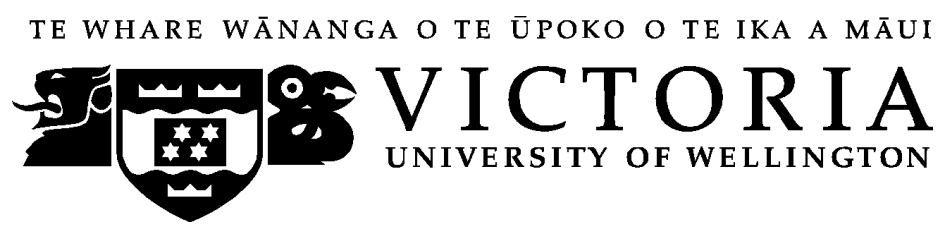

'Research on Chinese Visitors to New Zealand'

Hi, my name is Diana Chan and I am a Masters student in Tourism Management at Victoria University of Wellington (New Zealand). I am conducting research on the under-explored but rapidly growing Chinese visitor market to New Zealand. This questionnaire research aims to improve our understanding of Chinese visitors' views of sustainability and the New Zealand tourism industry. The New Zealand Ministry of Tourism supports this research project and your participation will contribute to the improved management of New Zealand's tourism industry.

Victoria University requires ethical approval to be obtained for research, therefore, by completing this questionnaire you are giving consent for the information you provide to be used in my Master's thesis, published in an academic journal and to be shared with the New Zealand Ministry of Tourism as well as Auckland and Christchurch airports. All information collected will be anonymous; data received from the questionnaires will be treated as confidential, stored in a safe place, and destroyed a year after the completion of the project.

The completion of the questionnaire will take 7-8 minutes. If you wish to receive a copy of the results, please contact me via email. If you have any further questions please contact me or my supervisor.

Thank you for your assistance.

Researcher: Diana Chan, Masters of Tourism Management student, Victoria Management School, Victoria University of Wellington, PO Box 600, Wellington, New Zealand

Email: chandian@student.vuw.ac.nz

Supervisor: Dr. Christian Schott, Senior Lecturer in Tourism Management, Victoria Management School, Victoria University of Wellington, PO Box 600, Wellington, New Zealand

Email: christian.schott@vuw.ac.nz 


\section{Appendix B - Visitor Survey}

TE WHARE WĀNANGA O TE ŪPOKO O TE IKA A MĀUI

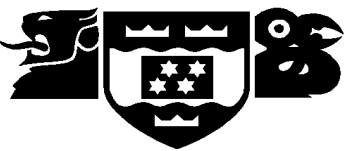

\section{Questionnaire}

\section{'Research on Chinese Visitors to New Zealand'}

\section{Instructions}

- Only answer this questionnaire if you are a resident of Mainland China visiting New Zealand.

- Please answer all questions in this questionnaire that are applicable to you.

1. What is your place of residence in Mainland China ( $\underline{\text { City/Town }})$ ?

2. How long is your visit to New Zealand? Night(s)

3. On this trip, did you visit any other countries before arriving in New Zealand?

$\square \quad$ Yes Please state the countries you visited No

4. On this trip, are you going to visit any other countries after you depart New Zealand and before you return to China?

$\square \quad$ Yes $\quad$ Please state the countries you are going to visit No

5. Before this trip have you traveled internationally (excluding Macau \& Hong Kong) in the last 5 years?

$\square \quad$ Yes Please state how many international trips you have taken in the last 5 years?

$$
\text { No }
$$

6. Have you previously visited New Zealand?

$\square \quad$ Yes Please state how many times you have visited New Zealand (before this trip) No

The following questions relate to your present visit to New Zealand

7. During your visit to New Zealand which island did you visit? (Please tick as many as apply)

$\square \quad$ North Island South Island

8. What is the main purpose of your visit to New Zealand? (Please tick one box only)
Visiting friends \& relatives
Holiday/Vacation
Education
Other (please specify)

$\square \quad$ Business

Conference/Convention 
9. How are you currently traveling around New Zealand? (Please tick one box only)

Independent travel

$\underline{\text { Tour group }}$

10. Which major activities did you participate in during this visit to New Zealand?

(Please tick as many as apply)

$\begin{array}{ll}\square & \text { Visited friends \& family } \\ \square & \text { Visited a historical site } \\ \square & \text { Visited a botanical garden } \\ \square & \text { Visited a beach } \\ \square & \text { Visited a Museum/Gallery } \\ \square & \text { Visited a farm } \\ \square & \text { Visited a vineyard } \\ \square & \text { Visited a casino } \\ \square & \text { Visited hot pools/geothermal sites } \\ \square & \text { Whale/Dolphin watching } \\ \square & \text { Zoo/wildlife/marine park } \\ \square & \text { Rafting/kayaking/jet boating }\end{array}$

$\begin{array}{ll}\square & \text { Cycling/mountain biking } \\ \square & \text { Mountain/rock climbing/caving } \\ \square & \text { Snow boarding/skiing } \\ \square & \text { Sky diving or parachuting } \\ \square & \text { Maori cultural performance } \\ \square & \text { Fishing } \\ \square & \text { Tramping } \\ \square & \text { Bungy jumping } \\ \square & \text { Sightseeing } \\ \square & \text { Shopping } \\ \square & \text { Golf } \\ \square & \text { Other (Please specify) }\end{array}$

11. Which sources of information did you use for this trip to New Zealand? (Please tick as many as apply)

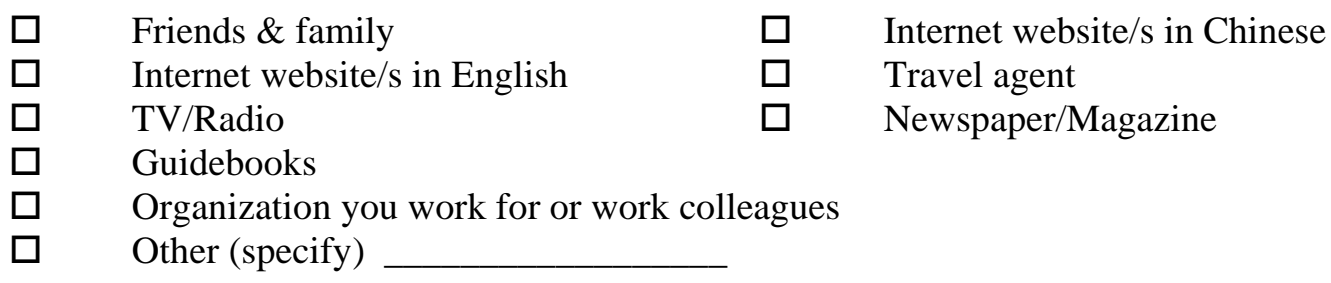

12. Have you heard of the term 'sustainability'?

$\square \quad$ Yes

No (Proceed to Q 17)

13. How do you rate your level of understanding of the term 'sustainability' on a scale of $1-5$ ?

\begin{tabular}{|c|c|c|c|c|}
\hline $\begin{array}{c}\text { I have a very } \\
\text { limited } \\
\text { understanding } \\
\text { of the term } \\
\text { 'sustainability' }\end{array}$ & $\begin{array}{c}\text { I have a moderate } \\
\text { understanding of the } \\
\text { term 'sustainability' }\end{array}$ & & $\begin{array}{c}\text { I have a very good } \\
\text { understanding of } \\
\text { the term } \\
\text { 'sustainability' }\end{array}$ \\
\hline 1 & 2 & 3 & 4 & 5 \\
\hline
\end{tabular}

14. Please explain briefly in one or two sentences what 'sustainability' means?

15. Do you think that it is important for tourists to understand the meaning of 'sustainability'?

$\square \quad$ Yes Why?

No Why Not? 
16. Do you think that New Zealand is a sustainable tourist destination?

\begin{tabular}{|c|c|c|c|c|}
\hline $\begin{array}{c}\text { I do not think } \\
\text { New Zealand is } \\
\text { a very } \\
\text { sustainable } \\
\text { tourist } \\
\text { destination }\end{array}$ & $\begin{array}{c}\text { I think New Zealand } \\
\text { is a reasonably } \\
\text { sustainable tourist } \\
\text { destination }\end{array}$ & $\begin{array}{c}\text { I think New } \\
\text { Zealand is an } \\
\text { very sustainable } \\
\text { tourist } \\
\text { destination }\end{array}$ \\
\hline 1 & 2 & 3 & 4 & 5 \\
\hline
\end{tabular}

17. What were your main considerations when making your decision to visit New Zealand?

\begin{tabular}{|l|c|c|c|c|c|}
\hline Considerations & Unimportant & $\begin{array}{c}\text { Of Little } \\
\text { Importance }\end{array}$ & $\begin{array}{c}\text { Moderately } \\
\text { Important }\end{array}$ & $\begin{array}{c}\text { Very } \\
\text { Important }\end{array}$ & $\begin{array}{c}\text { Very } \\
\text { Important }\end{array}$ \\
\hline $\begin{array}{l}\text { Duration of flight } \\
\text { from China }\end{array}$ & 1 & 2 & 3 & 4 & 5 \\
\hline $\begin{array}{l}\text { Overall cost of the } \\
\text { visit }\end{array}$ & 1 & 2 & 3 & 4 & 5 \\
\hline Safe destination & 1 & 2 & 3 & 4 & 5 \\
\hline $\begin{array}{l}\text { English-speaking } \\
\text { country }\end{array}$ & 1 & 2 & 3 & 4 & 5 \\
\hline $\begin{array}{l}\text { High level of } \\
\text { environmental } \\
\text { protection }\end{array}$ & 1 & 2 & 3 & 4 & 5 \\
\hline
\end{tabular}

18. How satisfied are you with your visit to New Zealand on a scale of 1-5?

\begin{tabular}{|c|c|c|c|c|}
\hline $\begin{array}{c}\text { Very } \\
\text { Dissatisfied }\end{array}$ & $\begin{array}{c}\text { Moderately } \\
\text { Satisfied }\end{array}$ & & Very Satisfied \\
\hline 1 & 2 & 3 & 4 & 5 \\
\hline
\end{tabular}

19. What 3 aspects of your visit to New Zealand did you enjoy the most?

1.

2.

3.

20. What 3 aspects of your visit to New Zealand did you enjoy the least?

1.

2 .

3.

21. Who do you believe is responsible for the impacts created by tourism on the destination?

(Please tick as many as apply)

$\square \quad$ The tourist

$\square \quad$ Tourism Businesses

$\square \quad$ Tour operators (for package tours) $\square \quad$ Local Tourism Organizations

$\square \quad$ Governments

$\square \quad$ Other (Please specify)

22. Who do you believe is most responsible for dealing with the impacts of tourism on the destination? (Please tick one box only)

$\square \quad$ The tourist

Local Tourism Organizations 
$\square \quad$ Tourism Businesses

Tour operators (for package tours)

$\square \quad$ Governments

$\square \quad$ Other (Please specify)

23. Have you seen the '100\% PURE New Zealand' tourism campaign?

Yes

No (Proceed to Q 27)

24. Did the '100\% PURE New Zealand' campaign impact on your decision to visit New Zealand on this trip?

\begin{tabular}{|c|c|c|c|c|}
\hline Unimportant & $\begin{array}{c}\text { Of little } \\
\text { Importance }\end{array}$ & $\begin{array}{c}\text { Moderately } \\
\text { Important }\end{array}$ & Important & $\begin{array}{c}\text { Very } \\
\text { Important }\end{array}$ \\
\hline 1 & 2 & 3 & 4 & 5 \\
\hline
\end{tabular}

25. Which of these messages do you associate most closely with the '⿳㇒00\% Pure New Zealand' tourism campaign?

\begin{tabular}{|l|c|c|c|c|}
\hline \multirow{2}{*}{ New Zealand... } & \multicolumn{4}{|c|}{ Level of association } \\
\cline { 2 - 5 } & Not at all & Somewhat & Strongly & $\begin{array}{c}\text { Very } \\
\text { strongly }\end{array}$ \\
\hline ...is a young country & 1 & 2 & 3 & 4 \\
\hline $\begin{array}{l}\text {..is mostly unspoiled by modern } \\
\text { development }\end{array}$ & 1 & 2 & 3 & 4 \\
\hline ...has outstanding scenery & 1 & 2 & 3 & 4 \\
\hline ...has a unique culture & 1 & 2 & 3 & 4 \\
\hline ...has many adventure activities & 1 & 2 & 3 & 4 \\
\hline ...is unpolluted & 1 & 2 & 3 & 4 \\
\hline
\end{tabular}

26. Now that you have completed your visit to New Zealand, how you think the ' $\mathbf{1 0 0 \%}$ PURE New Zealand' campaign relates to New Zealand as you have experienced it on this trip?

\begin{tabular}{|c|c|c|c|c|}
\hline $\begin{array}{c}\text { Gives the } \\
\text { completely } \\
\text { wrong } \\
\text { impression }\end{array}$ & & & & $\begin{array}{c}\text { Matches exactly } \\
\text { what I saw on } \\
\text { this trip }\end{array}$ \\
\hline 1 & 2 & 3 & 4 & 5 \\
\hline
\end{tabular}

27. What is your occupation in China?

28. Age?

$\begin{array}{llll}\square & \text { Under } 19 \text { years } & \square & 20-29 \text { years } \\ \square & 30-39 \text { years } & \square & 40-49 \text { years } \\ \square & 50-59 \text { years } & \square & 60-69 \text { years } \\ \square & 70 \text { years and over } & & \end{array}$

29. Gender

$\square \quad$ Male $\quad \square \quad$ Female

THANK YOU for your participation

Please drop your completed questionnaire into one of the designated box 


\section{Appendix C - Visitor Survey - Chinese Version}

TE WHARE WĀNANGA O TE ŪPOKO O TE IKA A MĀUI

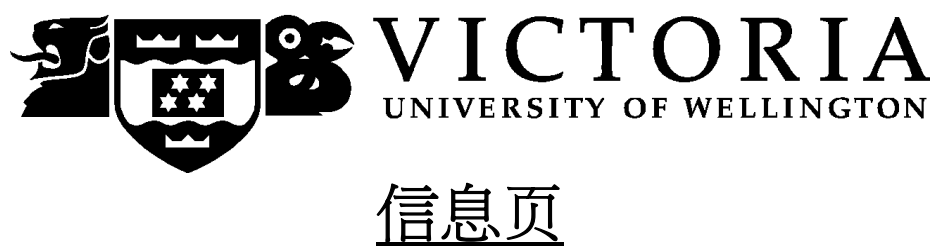

'Research on Chinese Visitors to New Zealand' “对于访新西兰的中国游客调查”

您好, 我叫陈詠詩, 是惠灵顿维多利亚大学旅游管理系的硕士研究生, 我正在做一项 关于中国游客的市场问卷调查。此项调查的目的是了解中国游客对于旅游业可持续发 展的看法, 以及对新西兰旅游业的意见。在您的参与和新西兰旅游局的大力支持下， 此项研究将大大的帮助新西兰旅游业的发展。

根据维多利亚大学的规定, 资料收集必须在您的许可下才能进行, 填写此问卷调查表 明, 您已同意并授权将该信息在我的论文, 相关学术刊物及新西兰旅游局中使用。全 部收集到的信息均匿名存档且安全存放，并将于此计划结束一年后销毁。

完成此问卷调查需要 7 至 8 分钟。如果您希望收到此次调查的结果, 欢迎给我发电子 邮件。如有任何问题, 请与我或我的导师联系。

谢谢您的合作

调查人：陈詠詩

电子邮箱：chandian@student.vuw.ac.nz

导师 : 克里斯蒂安博士 维多利亚大学管理学院, 旅游管理高级讲师

电子邮箱： christian.schott@vuw.ac.nz

- 请保留此页

・ 填写完请将问卷调查放入收集箱内。 


\section{Appendix D - Visitor Survey - Chinese Version}

TE WHARE WĀNANGA O TE ÜPOKO O TE IKA A MĀUI

\section{问卷}

中国游客来新西兰旅游的相关研究

- 此问卷调查的对象只包含中国游客

- 请回答此问卷中所有适用的问题

1. 您在中国的居住地 (城市/乡镇)

2. 您在新西兰逗留的时间? 晚

3. 在这次的旅程中, 您到达新西兰之前是否去过其他国家?

口 是, 请注明您这次行程中到访过的其他国家:

ㅁ是

4. 在这次行程中, 您是否会在离开新西兰后直接返回中国?

口 不是, 请注明您接下来将要前往的国家

ㅁ 是

5. 在过去的 5 年中, 您有否到过国外旅游 (澳门, 香港除外)?

口 有, 请注明您过去 5 年到国外旅游的次数

口 没有

6. 您以前有来过新西兰吗?

口来过, 请注明您之前来过的次数 (不包括本次旅程)

口 从没来过

下面是与您本次新西兰旅程相关的问题

7. 在这次的旅程中, 您到访过哪个岛屿? (请选取所有适用项)

口北岛

口南岛

8. 下列哪项是您这次来新西兰的最主要目的? (请只选取一项)

口探亲访友

公干

口旅游/度假

口参加会议

口 升学

$\square$ 就医

口 其他 (请注明) 
9. 您这次是用什么形式来新西兰旅游的?

口 参加旅游团

口自由行

10. 这次的行程中, 您所参加过的主要活动有哪些? (请选取所有适用项)

$\begin{array}{ll}\square & \text { 探亲访友 } \\ \square & \text { 名胜古迹 } \\ \square & \text { 参观动植物公园 } \\ \square & \text { 到海滩游玩 } \\ \square & \text { 参观博物馆/艺术馆 } \\ \square & \text { 参观农场 } \\ \square & \text { 参观酒庄 } \\ \square & \text { 参观奢场 } \\ \square & \text { 浸温泉 } \\ \square & \text { 观鲸鱼/海豚表演 } \\ \square & \text { 参观野生动物园/海洋馆 } \\ \square & \text { 漂筏/漂流/喷射飞船 }\end{array}$

口越野自行车

口爬山/攀岩

口 滑雪

口 跳降落伞

口毛利人文化表演

$\square$ 钓鱼

口 远足

$\square$ 蹦极

$\square$ 观光

口购物

口高尔夫球

口 其他 (请注明)

11. 下列哪些资料来源促成您这次的新西兰之旅? (请选取所有适用项)
口亲朋好友
口 英文互联网
口 中文互联网
口报纸/杂志
口 其他 (请注明)

口电视/收音机

$\square \quad$ 旅行社

$\square$ 工作单位或同事

$\square$ 旅行指南

12. 您有听过”可持续发展”这个词汇吗?

$\square$ 有听过 $\square$ 没听过 (请接问题 17)

13. 从 1 到 5 的级别中, 您如何评价您对”可持续发展”这个词汇的理解?

\begin{tabular}{|c|c|c|c|c|}
\hline $\begin{array}{c}\text { 我对这个词汇的 } \\
\text { 理解非常有限 }\end{array}$ & $\begin{array}{c}\text { 我对这个词汇基 } \\
\text { 本理解 }\end{array}$ & & $\begin{array}{c}\text { 我对这个词汇非常 } \\
\text { 理解 }\end{array}$ \\
\hline 1 & 2 & 3 & 4 & 5 \\
\hline
\end{tabular}

14. 请您用一两句话解释何谓”可持续发展”?

15. 您认为游客对”可持续发展”一词的理解是否重要?

口 重要 为什么?

口 不重要 为什么?

16. 您同意新西兰是个可持续发展的旅游胜地吗? 


\begin{tabular}{|l|l|l|l|l|}
\hline 1 & 2 & 3 & 4 & 5 \\
\hline
\end{tabular}

17. 下列因素对您决定来新西兰旅游起着多重要的作用?

\begin{tabular}{|l|c|c|c|c|c|}
\hline 考虑的因素 & 不重要 & 有一点重要 & 基本重要 & 重要 & 非常重要 \\
\hline 从中国出发的飞行距离 & 1 & 2 & 3 & 4 & 5 \\
\hline 旅游总开销 & 1 & 2 & 3 & 4 & 5 \\
\hline 目的地的安全考虑 & 1 & 2 & 3 & 4 & 5 \\
\hline 英文语系的国家 & 1 & 2 & 3 & 4 & 5 \\
\hline 高水平的环保措施 & 1 & 2 & 3 & 4 & 5 \\
\hline
\end{tabular}

18. 从 1 到 5 的级别中, 您如何评价您对这次新西兰之旅的满意度?

\begin{tabular}{|c|c|c|c|c|}
\hline 非常不满意 & & 基本满意 & & 非常满意 \\
\hline 1 & 2 & 3 & 4 & 5 \\
\hline
\end{tabular}

19. 您这次旅程最满意的三个方面?

1.

2.

3.

20. 您这次旅程最不满意的三个方面

1.

2.

3.

21. 您认为谁最该为旅游业发展带来的后果负责? (请选取所有适用项)

$\square \quad$ 游客

$\square \quad$ 旅游业本身

$\square$ 旅游业从业员
口本地旅游团体

$\square$ 政府

口 其他 (请注明)

22. 您认为谁该为旅游业发展带来的后果负最大责任? (请只选取一项)

$\square \quad$ 游客

$\square \quad$ 旅游业本身

$\square \quad$ 旅游业从业员
口本地旅游团体

$\square$ 政府

口 其他 (请注明)

23. 您有看过”百分百纯新西兰” 这个广告宣传吗?

$\square$ 有看过 $\square$ 没看过 (请接问题 27)

24. “百分百纯新西兰” 这个广告宣传对您来新西兰花旅游的决定起有重要的作用 吗?

\begin{tabular}{|c|c|c|c|c|}
\hline 不重要 & 有一点重要 & 一般重要 & 重要 & 非常重要 \\
\hline 1 & 2 & 3 & 4 & 5 \\
\hline
\end{tabular}


25. 以下哪些宣传口号最能够使您联想到”百分百纯新西兰”这个广告宣传?

\begin{tabular}{|l|c|c|c|c|}
\hline \multirow{2}{*}{ 新西兰就是 } & \multicolumn{4}{|c|}{ 相关联的程度 } \\
\cline { 2 - 5 } & 毫不相关 & 有一点关联 & 有关联 & 非常关联 \\
\hline$\ldots$ 一个年轻的国家 & 1 & 2 & 3 & 4 \\
\hline$\ldots$ 现代文明发展的处女地 & 1 & 2 & 3 & 4 \\
\hline$\ldots$ 世外桃园 & 1 & 2 & 3 & 4 \\
\hline$\ldots$ 独特的文化 & 1 & 2 & 3 & 4 \\
\hline$\ldots$ 刺激冒险的活动 & 1 & 2 & 3 & 4 \\
\hline$\ldots$ 人间净土 & 1 & 2 & 3 & 4 \\
\hline
\end{tabular}

26. 现在您即将结束新西兰的旅程, 您如何评价”百分百纯新西兰” 这个广告宣传和 您的亲身体验?

\begin{tabular}{|c|c|c|c|c|}
\hline $\begin{array}{c}\text { 完全错误的第一 } \\
\text { 印象 }\end{array}$ & & & & $\begin{array}{c}\text { 完全符合我的亲 } \\
\text { 身体验 }\end{array}$ \\
\hline 1 & 2 & 3 & 4 & 5 \\
\hline
\end{tabular}

27. 您在中国从事的职业?

28. 年龄?
口 19 岁以下
口 30-39 岁之间
口 20-29 岁之间
口50-59 岁之间
口40-49 岁之间
口70 岁以上
60-69 岁之间

29. 性别

口男性只性 


\title{
Appendix E - ADS Tour Operator Information Letter
}

TE WHARE WĀNANGA O TE ŪPOKO O TE IKA A MĀUI

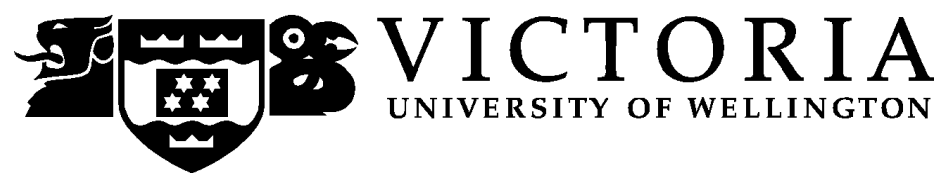

August, 2008

\author{
Diana Chan \\ 158 Akaroa Drive, \\ Maupuia, \\ Wellington, NZ \\ 6022 \\ (021) 2147138 \\ chandian@student.vuw.ac. \\ $\mathrm{nz}$
}

\author{
Recipient Name \\ Address line 1 \\ Address line 2 \\ City, State/Province Postal Code
}

Dear,

My name is Diana Chan and I am a Masters student in Tourism Management at Victoria University of Wellington. With the support of the Ministry of Tourism I am conducting research on the under-explored but rapidly growing Chinese visitor market to New Zealand. My research examines this market not only because of its increasing economic significance to the New Zealand tourism industry but also due to the need to develop a better understanding of the environmental attitudes of visitors, including specific markets such as China.

Because your company is registered as an ADS approved tour operator on a list published by Tourism New Zealand I am very interested in hearing your views and experiences of working with the Chinese visitor market and I would thus like to ask you to participate in an interview that seeks to examine this visitor market further.

Due to the fact that I am based in Wellington, I will only be able to conduct these interviews between the $27^{\text {th }}$ October $2008-31^{\text {st }}$ October 2008. Each interview will take between 30-45 minutes to complete. At the conclusion of this study a copy of the findings will be made available to you and your organization.

Thank you for your time and I do hope that you will be able to participate in this important research.

Kind Regards,

Diana Chan 


\section{Appendix F - ADS Tour Operator Interview Questions}

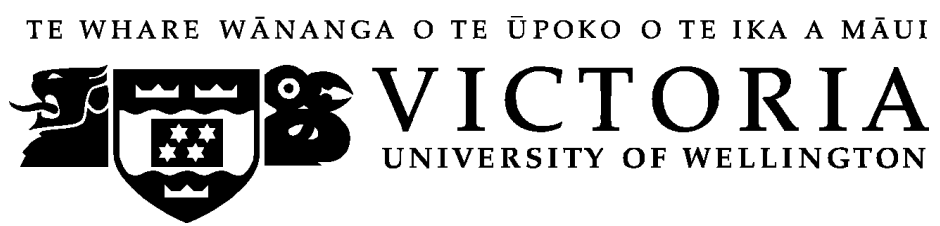

Researcher: Diana Chan

Purpose of Research: Masters Thesis

Fieldwork Support: Ministry of Tourism \& Victoria University of Wellington

\section{Research Problem:}

'Sustainable Tourism in New Zealand: The Chinese Visitors View'

\section{General Questions about the tour operator}

1. Name of New Zealand tour operator...

2. What types of tours does your organisation offer?

\section{Chinese International Visitor Questions}

3. Does your organisation specifically target the Chinese international visitor market? If yes, why?

If no, why not?

4. What are the general demographics of these Chinese visitors?

i.e. age, gender, occupation?

5. How long do the Chinese visitors generally stay on these tours?

6. Do the Chinese visitors on your tours generally stay longer in New Zealand after the completion of their tour or do they depart New Zealand straight after?

7. How does your organisation specifically cater to the Chinese market?

i.e. bilingual tour guides, going to specific activities or attractions in New Zealand?

Are the tours that the Chinese visitors attend constructed specifically for their requirements?

\section{Sustainability Questions}

8. What is your current understanding of the concept of 'sustainability'?

Sub-question for Chinese tour operators - Do you believe there is a difference in the terminology of 'sustainability' between the western and eastern understanding of the term?

9. Does your organisation believe 'sustainability' is an important concept in New Zealand's tourism industry?

10. Do you think that it is important for tourists to understand what 'sustainability' means?

If yes, why?

If no, why not?

11. Do you think it is important for yourself and your organisation to understand what 'sustainability' means?

If yes, why?

If no, why not?

12. In regards to the environmental component of 'sustainability', do you think that New Zealand is a sustainable tourist destination?

If yes, why?

If no, why not?

13. Who do you believe is responsible for the impacts created by tourism on the destination? 
i.e. the tourist, tourism businesses, tour operators (for package tours), local tourism organizations, governments?

Why do you believe they are responsible for such impacts?

14. Who do you believe is most responsible for dealing with the impacts caused by tourism?

i.e. the tourist, tourism businesses, tour operators (for package tours), local tourism organizations, governments?

Why do you believe they are most responsible for such impacts?

15. Does your organisation do anything specific to educate your Chinese visitors about 'sustainability' in New Zealand, for example a code of conduct while in New Zealand?

If the organisation has a code of conduct as if I am able to get a copy.

16. Does your organisation have any level of environmental accreditation or awards?

For example Qualmark Green, New Zealand Tourism Awards (Environmental NZ Tourism Award), or/and Green Globe?

\section{Sustainable Tourism and Sustainable Promotional Efforts}

17. Has your organisation heard of the New Zealand Tourism Strategy 2015?

If yes, what does the New Zealand Tourism Strategy 2015 mean to your organisation?

If yes, does your organisation operationalize some of the 'sustainable suggestions?

If yes, what suggestions do you operationalize?

If no, does your organisation have any specific environmental strategies in place?

i.e. code of conduct, best environmental practices, eco-labels, environmental management systems (EMSs) such as an environmental manager, recycling schemes, tree planting as a means of reversing carbon emissions.

18. Do you believe that the ' $100 \%$ PURE New Zealand' campaign impacts on the decision for Chinese visitors to take a trip to New Zealand?

19. Does your organisation promote New Zealand as a sustainable tourism destination?

Ask interviewee if they would like to add any other comments. 


\section{Appendix G - ADS Tour Operator Matrix}

\begin{tabular}{|c|c|c|c|c|c|}
\hline \multicolumn{6}{|c|}{ ADS Registered Tour Operator Profile n=7 } \\
\hline & $\begin{array}{l}\text { Types of tours } \\
\text { operator offers }\end{array}$ & $\begin{array}{l}\text { Main visitor } \\
\text { markets targeted }\end{array}$ & $\begin{array}{c}\text { Does the operator } \\
\text { specifically target the } \\
\text { Chinese international } \\
\text { visitor market? }\end{array}$ & $\begin{array}{l}\text { General demographics of the } \\
\text { operator's Chinese visitors }\end{array}$ & $\begin{array}{l}\text { Chinese visitor trip } \\
\text { characteristics }\end{array}$ \\
\hline $\begin{array}{l}\text { Operator A } \\
\text { (Large) }\end{array}$ & $\begin{array}{ll}\text { - } & \text { NZ \& } \\
& \text { Australia tours }\end{array}$ & $\begin{array}{l}\text { - } \text { China } \\
\text { - Taiwan } \\
\text { - } \text { Malaysia } \\
\text { - Singapore } \\
\text { - Australian Chinese }\end{array}$ & - $\quad$ Yes & $\begin{array}{ll}\text { - } & \text { Between 25-60 years } \\
\text { - } & \text { Both male \& female } \\
\text { - } & \text { Hardly any business visitors. } \\
\text { - } & \text { Mainly ADS tour groups. }\end{array}$ & $\begin{array}{l}\text { - } 3-4 \text { nights for those just } \\
\text { visiting the North Island. } \\
\text { 6-7 nights for those visiting } \\
\text { both the North \& South Island. }\end{array}$ \\
\hline $\begin{array}{l}\text { Operator B } \\
\text { (Large) }\end{array}$ & $\begin{array}{ll}\text { - } & \text { Europe tours } \\
\text { - } & \text { NZ \& } \\
& \text { Australia tours }\end{array}$ & $\begin{array}{l}\text { No specific visitor } \\
\text { markets targeted. }\end{array}$ & - $\quad$ No & $\begin{array}{ll}\text { - } & \text { Between } 30-50 \text { years } \\
\text { - } & \text { Both male \& female } \\
\text { - } & \text { Upper class visitors } \\
\text { - } & \text { Mainly ADS or } \\
& \text { business/reward tour groups. }\end{array}$ & $\begin{array}{l}\text { - 3-4 days for those just visiting } \\
\text { the North Island. } \\
\text { One or two people a month will } \\
\text { do a tour that includes the } \\
\text { North \& South Island. }\end{array}$ \\
\hline $\begin{array}{c}\text { Operator C } \\
\text { (Small-medium) }\end{array}$ & $\begin{array}{ll}\text { - } & \text { NZ \& } \\
& \text { Australia tours }\end{array}$ & - China & - $\quad$ Yes & $\begin{array}{ll}\text { - } & \text { Between } 40-50 \text { years } \\
\text { - } & \text { Mainly male } \\
\text { - } & 10 \% \text { business groups } \\
\text { - } & 90 \% \text { holiday makers }\end{array}$ & $\begin{array}{l}\text { - 3-4 days for those just visiting } \\
\text { the North Island. } \\
\text { Approximately } 8 \text { days for those } \\
\text { visiting both the North \& South } \\
\text { Island. }\end{array}$ \\
\hline $\begin{array}{l}\text { Operator D } \\
\text { (Large) }\end{array}$ & 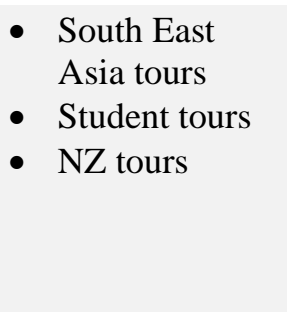 & $\begin{array}{l}\text { - Most of South East } \\
\text { Asia }\end{array}$ & - $\quad$ No & $\begin{array}{ll}\text { - } & \text { Middle aged-elderly } \\
\text { - } & \text { Some are senior citizen } \\
\text { - } & \text { groups } \\
\text { - } & \text { Moth mainle \& female } \\
\text { - } & \text { Incentive tours are also } \\
& \text { popular. }\end{array}$ & $\begin{array}{l}\text { - } 3 \text { nights for those just visiting } \\
\text { the North Island. } \\
\text { - } 5-6 \text { nights for those visiting } \\
\text { both the North \& South Island. }\end{array}$ \\
\hline
\end{tabular}




\begin{tabular}{|c|c|c|c|c|c|}
\hline $\begin{array}{c}\text { Operator E } \\
\text { (Small-medium) }\end{array}$ & $\begin{array}{l}\text { - } \\
\text { NZ \& } \\
\text { Australia tours }\end{array}$ & - China & - Yes & $\begin{array}{ll}\text { - } & \text { Between 30-55 years } \\
\text { - } & \text { Both male \& female } \\
\text { - } & \text { Most are government } \\
& \text { employees or business tours. }\end{array}$ & $\begin{array}{l}\text { - } 3 \text { nights for those just visiting } \\
\text { the North Island. } \\
\text { 4-5 nights for those visiting } \\
\text { both the North \& South Island. }\end{array}$ \\
\hline $\begin{array}{c}\text { Operator F } \\
\text { (Small-medium) }\end{array}$ & $\begin{array}{ll}\text { - } & \text { NZ \& } \\
& \text { Australia tours }\end{array}$ & $\begin{array}{l}\text { - Taiwan } \\
\text { - China }\end{array}$ & - Yes & 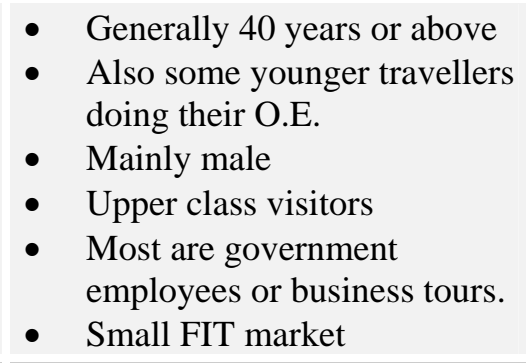 & - 2-3 days in New Zealand. \\
\hline $\begin{array}{c}\text { Operator G } \\
\text { (Small-medium) }\end{array}$ & $\begin{array}{l}\text { - } \\
\text { NZ \& } \\
\text { Australia tours }\end{array}$ & - China & - $\quad$ Yes & $\begin{array}{ll}\text { - } & \text { Between } 30-60 \text { years } \\
\text { - } & \text { Mainly male } \\
\text { - } & \text { Mainly ADS tour groups. }\end{array}$ & $\begin{array}{l}\text { - 3-4 nights for those just } \\
\text { visiting the North Island. } \\
\text { - Approximately } 8 \text { days for those } \\
\text { visiting both the North \& South } \\
\text { Island. }\end{array}$ \\
\hline
\end{tabular}




\section{REFERENCES}

Abacus International. (2007). New generation Chinese travellers. Retrieved July 7, 2008, from http://www.4hoteliers.com.

Asia Pacific Foundation of Canada. (2002). Canada Asia Review 2002. Retrieved August 20, 2008, from http://www.asiapacific.ca/analysis/pubs/pdfs/car2002/car2002.pdf.

Anonymous. (2005). Defining Sustainable Development. "Not as Easy as it Sounds.” Engineering and Mining Journal, 206(6), 4-6.

Anonymous. (2008). Green Globe Gives Green Light. NZ Business, 22(3), 31. Retrieved January 4, 2009, from http://www.nzbusiness.co.nz/.

Aronsson, L. (2000). The Development of Sustainable Tourism. New York: Continuum.

Basala, S. L., \& Klenosky. (2001). Travel-Style Preferences for visiting a Noel Destination: A Conjoint Investigation across the Novelty-Familiarity Continuum. Journal of Travel Research, 40, 172-182.

Becken, S. (2003). Chinese Tourism to New Zealand: Discussion Paper. Landcare Research, 1-15.

Becken, S. (2005). The role of tourism icons for sustainable tourism. Journal of Vacation Marketing, 11(1), 21-29.

Berry, S., \& Ladkin, A. (1997). Sustainable tourism: a regional perspective. Tourism Management, 18(7), 433-440.

Beeton, S., \& Benfield, R. (2002). Demand Control: The case for Demarketing as a Visitor and Environmental Management Tool. Journal of Sustainable Tourism, 10(6), 497-513.

Bentley, T., Page, S., Denny, M., Chalmers, D., \& Laird, I. (2001). How safe is adventure tourism in New Zealand? An Exploratory Analysis. Applied Ergonomics, 32, 327-338.

Bouma, G. D. (1995). The Research Process. Australia: Oxford University Press Australia.

Broun, B. (2008, September 26). Trapped tourist dies after jet boat flips on Shotover River. The Dominion Post, p. A1.

Budeanu, A. (2002). Impacts and responsibilities for sustainable tourism: a tour operator's perspective. Journal of Cleaner Production, 13, 89-97.

Butcher, J. (2006). Natural Capital and the Advocacy of Ecotourism as Sustainable Development. Journal of Sustainable Tourism, 14(6), 529-544.

Butler, R. W. (1999). Sustainable tourism: a state-of-the-art review. UK: Routledge. 
Byrd. Erick. (2006). Stakeholders in Sustainable Tourism Development and their Roles: Applying Stakeholder Theory to Sustainable Tourism Development. Tourism Review, 62(2), 6-13.

Cabezas, H., Pawlowski, C. W., Mayer, A. L., \& Hoagland, N. T. (2003). Sustainability: ecological, social, economic, technological, and systems perspectives. Clean Techn Environ Policy, 5, 167-180.

Cavana, R. Y., Delahaye, B. L., \& Sekaran, U. (2001). Applied Business Research: Qualitative and Quantitative Methods. Australia: John Wiley \& Sons Australia, Ltd.

Carey. S., \& Gountas, Y. (1997). Tour operators and destination sustainability. Tourism Management, 18(7), 425-431.

Chen, J. (2002). Tour Group and Independent Travel: An Analysis of Asian Chinese Visitors to New Zealand. A Thesis submitted to Victoria University of Wellington.

Chen, J. I. (2008). Where the Bloody Hell Are We? Ecotourism Experience in Chinese Visitors. CAUTHE 2008 Conference. University of Queensland.

China Contact. (2008). China Outbound Travel Handbook. Retrieved December 16, 2008, from http://www.ccontact.com/.

China Daily. (2008). China's tourism market set to be No. 2 globally. Retrieved July 20, 2008, from http://www.chinadaily.com.cn/.

China Daily. (2008). China sees ecotourism on the rise. Retrieved July 20, 2008, from http://www.chinadaily.com.cn/.

China Knowledge Press. (2008). Branding in China. Retrieved September 13, 2008, from http://www.chinaknowledge.com/MediaCenter/media-articledetail.aspx?type=MA\&ID=16.

Churchouse, N. (2008, October 18). Chinese tourists bypass city. The Dominion Post, p. C4.

Clark, H. (2007) Helen Clark Berlin Speech: Sustainable Development. Retrieved July 9, 2008, from http://www.scoop.co.nz.

Clark, H. (2007). Launch of NZ Tourism Strategy. Retrieved July 23, 2008, from http://www.beehive.govt.nz.

Clark, J. (1997). A Framework of Approaches to Sustainable Tourism. Journal of Sustainable Tourism, 5(3), 224-233.

Clifton, J., \& Benson, A. (2006). Planning for Sustainable Ecotourism: The Case for Research Ecotourism in Developing Country Destinations. Journal of Sustainable Tourism, 14(3), 238-254. 
Collier, A., $7^{\text {th }}$ ed. (2006). Principles of Tourism: A NZ Perspective. Auckland: Pearson Education NZ.

Coventry, N. (2008). Tips on maturing China market, which now wants different options...Inside Tourism. Retrieved July 14, 2008, from www.insidetourism.com.

Croall, J. (1995). Preserve or Destroy: Tourism and the Environment. London: Calousle Gulbenkian Foundation.

Cropp, A. (2008, November 15). 100\% Ripped Off. Your Weekend, p. 10.

Curtin, S., \& Dusby ,G. (1999). Sustainable Destination Development: the Tour Operator Perspective. International Journal of Tourism Research, 1(2), 135147.

D’Amore, L. J. (1992). Promoting sustainable tourism- the Canadian approach. Tourism Management, 258-262.

Daily Travel News. (2008). Daily Travel \& Tourism Newsletter: The prospects for China as a source market. Retrieved July 7, 2008, from http://www.traveldailynews.com.

Dearden, P., \& Harron, S. (1994). Alternative Tourism and Adaptive Change. Annals of Tourism Research, 21, 81-102.

Department of Economic and Social Affairs. (1999). Commission on Sustainable Development: The Global Importance of Tourism. Retrieved July 12, 2008, from http://www.undesa.it/.

Dinan, C. (2000). Social Marketing and Sustainable Tourism- is there a Match? International Journal of Tourism Research, 2(1), 1-14.

Dingding, X. (2008). Outbound tourism sector to open wider. China Daily. Retrieved December 13, 2008, from http://www.chinadaily.com.cn/.

Dolnicar, S., Crouch, G. I., \& Long, P. (2008). Environment- friendly Tourists: What Do We Really Know About Them? Journal of Sustainable Tourism, 16(2), 197-242.

Denscombe, M., $3^{\text {rd }}$ ed. (2007). The Good Research Guide: For Small-scale Social Research Projects. Oxford: McGraw-Hill International.

Eccles, G. (1995). Marketing, Sustainable development and international tourism. International Journal of Contemporary Hospitality Management, 7(7), 20-26.

Espinosa, A., Harnden, R., \& Walker, J. (2007). A complexity approach to sustainability- Stafford Beer revisited. European Journal of Operational Research, 187, 636-651. 
European Tour Operators Association. (2007). The Chinese Outbound Tourism Market: New ETC/UNWTO study to be launched in March 2007. Retrieved December 4, 2008, from http://www.etoa.org/.

Font, X., \& Harris, C. (2004). Rethinking Standards from Green to Sustainable. Annals of Tourism Research, 31(4), 986-1007.

Fortuny, M., Solar, R., C’anovas, C., \& Antoni, S’anchez. (2007). Technical approach for a sustainable tourism development: Case study in the Belearic Islands. Journal of Cleaner Production, 1-10.

Garrod, B., \& Fyall, A. (1998). Beyond the rhetoric of sustainable tourism. Tourism Management, 19(3), 199-212.

Georg Arlt, W. (2006). China's Outbound Tourism. Oxford: Routledge.

Goffman, E. (2007). China \& the Path to Environmental Sustainability. Proquest

Halme, M. (2001). Learning for Sustainable Development in Tourism Networks. Business Strategy and the Environment, 10(2), 100-114.

Hardy, A., Beeton, R. J. S., \& Pearson, L. (2002). Sustainable Tourism: An Overview of the Concept and its Position in Relation to Conceptualisations of Tourism. Journal of Sustainable Tourism, 10(6).

Harris, R., Griffin, T., \& Williams, P. (2002). Sustainable Tourism: A global perspective. Oxford: Butterworth-Heinemann.

Harris, R., \& Leiper, N. (1995). Sustainable Tourism: An Australian Perspective. Chatswood: Butterworth- Heinemann.

Hemstrom, O., Luu, J., Unenge, U., \& Anderson, H. (2006). Attracting Chinese tourism: How Sweden can gain a larger share of the Chinese outbound tourism. Internationella Handelshogskolan.

Horobin, H., \& Long, J. (1996). Sustainable tourism: the role of the small firm. International Journal of Contemporary Hospitality Management, 8(5), 15-19.

Hudman, L. (1991). Tourism's Role \& Response to Environmental Issues \& Potential Future Effects. The Tourists Review. (4).

Hui, T., Wan, D., \& Chi, M. F. (2008). Chinese Tourists visiting Singapore: Pull and Push Factors. Advances in Hospitality and Leisure, 4, 229-244.

Hwang, K. (1987). Face \& Favor: The Chinese Power Game. American Journal of Sociology, 92(4).

Jayawardena, C. (2003). Sustainable tourism development in Canada practical challenges. International Journal of Contemporary Hospitality Management, 15(7), 408-413. 
Kavallinis, L., \& Abraham, P. (1994). The Environmental Impacts of TourismWhose Responsibility Is It Anyway? The Case study of Mykonos. Journal of Travel Research, 33(2), 26-32.

Katser, J., Cook, K. H., \& Crouch, W. W. (1998). Evaluating Information: A Guide for Users of Social Science Research. USA: McGraw-Hill.

Ko, J. T. G. (2001). Assessing Progress of Tourism Sustainability. Annals of Tourism Research, 28(3), 817-820.

Krysiak, F. C., \& Krysiak, D. (2006). Sustainability with Uncertain Future Preferences. Environmental \& Resource Economics, 33, 511-531.

Lansing, P., \& Vries, P. D. (2006). Sustainable Tourism: Ethical Alternative or Marketing Ploy? Journal of Business Ethics, 72, 77-85.

Lau, M. A., \& Tol, R. S. J. (2006). The Chinese are coming- An Analysis of the Preferences of Chinese Holiday Makers at Home and Abroad: Working Paper.

Lee, K. F. (2001). Sustainable tourism destinations: the importance of cleaner production. Journal of Cleaner Production, 9, 313-323.

Lew, A. A. (2007). China’s Growing Wanderlust. Far Eastern Economic Review, 170(8), 60-63.

Liu, Z. (2003). Sustainable Tourism Development: A Critique. Journal of Sustainable Tourism, 11(6), 459-475.

McManus, G. (2005). Travel Biz: Sustainable travel. NZ Business, 19(10), 60.

Midgley, N. (2007, June 1). 'It’s all about sustainability,' says NZ. Travel Weekly, p.14.

Miller, G., \& Twining- Ward, L. (2005). Monitoring for a Sustainable Tourism Transition: The Challenge of Developing \& Using Indicators. Oxfordshire: CABI Publishing.

Miller, G., Rathouse, K., Scarles, C., Holmes, K. and Tribe, J. (2007). Public understanding of sustainable leisure and tourism: A report to the Department for Environment, Food and Rural Affairs. University of Surrey. Defra, London.

Ministry of Economic Development. (2008). Ecolabels and Sustainability Claims. Retrieved October 14, 2008, from http://www.med.govt.nz.

Ministry of Economic Development. (2008). Improving the Chinese Visitor Experience- Media Statement. Retrieved December 11, 2008, from http://www.med.govt.nz.

Ministry of Tourism. (2008). Discover The Future of Tourism: Tourism Flows Model. Retrieved January 4, 2009, from http://www.tourism.govt.nz/. 
Ministry of Tourism. (2006). Understanding The Dynamics of NZ Tourism, August 2006, New Zealand. Retrieved January 12, 2008, from http://www.tourism.govt.nz/.

Ministry of Tourism. (2007). NZ Tourism Forecasts 2007-2013: Summary Document. Retrieved January 14, 2009, from http://www.tourism.govt.nz/.

Ministry of Tourism. (2008). Tourism Leading Indicators Monitor: Series 3/2008, April 2008, New Zealand. Retrieved January 12, 2009, from http://www.tourism.govt.nz/.

Ministry of Tourism. (2008). Tourism Leading Indicators Monitor: Series 2008/7, August 2008, New Zealand. Retrieved January 12, 2009, from http://www.tourism.govt.nz/.

Ministry of Tourism. (2008). New Zealand Tourism Forecasts 2008-2014: Summary Document. Retrieved January 12, 2009, from http://www.tourism.govt.nz/.

Mowforth, M., \& Munt, I. (2003). Tourism \& Sustainability: Development \& New Tourism in the Third World. London: Routledge.

National Bureau of Statistics in China. (2008). Retrieved January 4, 2008, from http://www.stats.gov.cn/enGliSH/.

New Zealand. (2008). Olympics Takes a Toll on Visitor Arrivals. Retrieved January 4, 2009, from http://www.newzealand.com.

New Zealand Tourism Strategy 2015. (2008). Retrieved July 20, 2008, from http://www.nztourismstrategy.com/.

Northcote, J. (2005). Conceptualizing Yield: Sustainable Tourism Management. Annals of Tourism Research, 33(1), 199-220.

Nyberg, L. (2001). Destination 21- A discussion contribution on a scheme for sustainable tourism development. Tourism Review, 56(1), 54-56.

O’Conner, D. (2007). New tourism sustainability website. Retrieved June 12, 2008, from http://www.tourism.govt.nz/.

O’Conner, D. (2008). Government commits funding to sustainable tourism. Retrieved July 21, 2008, from http://www.beehive.govt.nz.

O’Connor, D. (2008). Government funding for sustainable tourism in regions. Retrieved July 9, 2008, from http://www.beehive.govt.nz.

O’Conner, D. (2008). Tourism Minister Encourages Tourism Business to 'Go for Gold’. Retrieved January 12, 2009, from http://www.beehive.govt.nz.

Ooi, C. (2007). Creativity at Work: Chinese Tourists in Denmark. Creative Encounters Working Papers, 5, 1-19. 
Oppermann, M. (1995). A Model of Travel Itineraries. Journal of Travel Research, 33, 57-61.

Oppermann, M. (1997). First-time and repeat visitors to New Zealand. Tourism Management, 18(3), 177-181.

Page, S. J., \& Thorn, K. (2002). Towards Sustainable Tourism Development and Planning in New Zealand: The Public Sector Response Revisited. Journal of Sustainable Tourism, 10(3), 222-238.

Parker, T. (2008). Horror tales from Chinese Tourists'. Retrieved November 15, 2008, from http://www.nzherald.co.nz/.

Pawson, R., \& Tilley, N. (1998). Realistic Evaluation. Great Britain: The Cromwell Press.

Pearce, D. G., \& Butler, R. W. (2000). Contemporary issues in Tourism development. Great Britain: TJ International Ltd.

Pearce, D. G., \& Butler, R. W. (2002). Contemporary issues in Tourism development. London: Routledge.

Rea, L. M. (2005) Designing \& Conducting Survey Research: A Comprehensive Guide. San Francisco: Jossey-Bass.

Richards, L., \& Morse, J. M. (2007). User's Guide to Qualitative Methods. USA: Sage Publications Inc.

Roberto, J., \& Salom, P. (2001). Sustainable Tourism: Emerging Global and Regional Regulation. Georgetown International Environmental Law Review, 13(4), 801-835.

Ryan, C., \& Mo, Xiaoyan. (2001). Chinese visitor to New Zealand- Demographics and Perceptions. Journal of Vacation Marketing, 8(13), 13-26.

Saarinen, J. (2006). Traditions of sustainability in tourism studies. Annals of Tourism Research, 33(4), 1121-1140.

Scandinavian Tourist Board. (2002). China Outbound Travel Market Research Report June 2002. Retrieved January 8, 2009, from http://www.robtex.com/dns/swetourism.se.html.

Sharpley, R. (2000). Tourism and Sustainable Development: Exploring the theoretical Divide. Journal of Sustainable Tourism, 8(1), 1-19.

Statistics New Zealand. (2007). Tourism Satellite Account: 2007. Wellington, NZ: Statistics New Zealand.

Swabrooke, J. (1999). Sustainable Tourism Management. Oxon: CABI Publishing.

Swanson K. K., \& Horridge, P. E. (2006). Travel motivations as souvenir purchase indicators. Tourism Management, 27, 671-683. 
Taylor, I. (2006, July 14). Green ‘will rule travel’. Travel Weekly, p. 5.

Tsaur, S. H., Lin, Y. C., \& Lin, J. H. (2005). Evaluating ecotourism sustainability from the integrated perspective of resource, community and tourism. Tourism Management, 27, 640-653.

Tourism Business. (2007). Lessons from Hong Kong: What do tourist from mainland China really want? Retrieved December 16, 2008, from http://www.tourismbusinessmag.co.nz/.

Tourism News. (2008). Half a Century in Tourism. Retrieved January 2, 2009, from http://wwwtourismnewzealand.com.

Tourism News. (2008). Market Highlights. Retrieved January 4, 2009, from http://wwwtourismnewzealand.com.

Tourism New Zealand. (2005). Improving The Chinese Visitor Experience. Retrieved January 4, 2008, from http://www.tourismnewzealand.com.

Tourism New Zealand. (2008). ADS Register. Retrieved May 29, 2008, from http://www.tourismnewzealand.com.

Tourism New Zealand. (2008). Financial Crisis Impacts Visitor Arrivals. Retrieved January 4, 2009, from http://www.tourismnewzealand.com.

Tourism New Zealand. (2008). Sustainable Tourism. Retrieved January 12, 2009, from http://www.newzealand.com/.

Tourism New Zealand. (2008). Visitor Satisfaction: Environment. Retrieved December 12, 2008, from http://www.tourismnewzealand.com.

Tourism Queensland. (2008). The Chinese Ecotourism Market. Retrieved December 2, 2008, from http://www.undesa.it/.

Touum, C. (2000). Challenges of sustainable tourism development in the developing world: the case of Turkey. Tourism Management, 22, 289-303.

United Nations Department of Economic \& Social Affairs Division for Sustainable Developments (DSD). (2004). Agenda 21. Retrieved June 12, 2008, from http://www.un.org/.

University of Surrey. (2007). Public understanding of sustainable leisure and tourism. A research report completed for the Department for Environment, Food and Rural Affairs by the University of Surrey.

Veal, A. J. (1997). Research Methods for Leisure and Tourism: A Practical Guide. England: Person Education Limited.

Velikova, M. P. (2001). How Sustainable is Sustainable Tourism? Annals of Tourism Research, 28(2), 196-199.

Visit Norwich. (2008). Retrieved July 3, 2008, from http://www.visitnorwich.co.uk/. 
Wall, G., \& Mathieson, A. (2006). Tourism: Change, impacts \& opportunities.

Wang, Y., \& Sheldon, P. (1995). The Sleeping Dragon Awakes: The Outbound Chinese Travel Market. Journal of Travel \& Tourism Marketing, 4(4), 41-54.

Weaver, D. (2006). Sustainable Tourism: Theory \& Practice. Oxford: Elsevier Butterworth-Heinemann.

Welford, R., Utterhus, B., \& Eligh, J. (1999). Tourism and sustainable development: An analysis of policy and guidelines for managing provision and consumption. Sustainable Development, 7(4), 165-177.

Wen Pan, G., \& Laws, E. (2001). Tourism marketing opportunities for Australia in China. Journal of Vacation Marketing, 8(1), 39-48.

Williams, M. (2003). Making Sense of Social Research. London: Sage Publications Ltd.

Winson, A. (2006). Ecotourism and Sustainability in Cuba: Does Socialism Make a Difference? Journal of Sustainable Tourism, 14(1), 6-23.

Witt, S. F., \& Gammon, S. (1991). Sustainable Tourism Development in Wales. The Tourist Review, 4.

Xola Consulting, Inc. (2008). Chinese Travelers: Trends for Adventure Companies and Destinations. Retrieved January 4, 2009, from http://www.xolaconsulting.com/index.php.

Zhang, H. Q., \& Heung, V. C. S. (2001). The emergence of the mainland Chinese outbound travel market and its implications for tourism marketing. Journal of Vacation Marketing, 8(1), 7-11.

Zhao, C. (2006). New Zealand's Destination Image and the Chinese Outbound market: A Comparative study between the Beijing (north) and the Guangdong (south) Markets. Auckland University of Technology: Master of Business. 